Copyright

by

Janghwan Kim

2010 
The Dissertation Committee for Janghwan Kim Certifies that this is the approved version of the following dissertation:

\section{FINITE ELEMENT MODELING OF TWIN STEEL BOX-GIRDER BRIDGES FOR REDUNDANCY EVALUATION}

Committee:

Karl H. Frank, Co-Supervisor

Eric B. Williamson, Co-supervisor

John L. Tassoulas

Sharon L. Wood

Todd Helwig

Mark E. Mear 


\title{
FINITE ELEMENT MODELING OF TWIN STEEL BOX-GIRDER BRIDGES FOR REDUNDANCY EVALUATION
}

\author{
by \\ Janghwan Kim, B.E., M.E.
}

\author{
Dissertation \\ Presented to the Faculty of the Graduate School of \\ The University of Texas at Austin \\ in Partial Fulfillment \\ of the Requirements \\ for the Degree of \\ Doctor of Philosophy
}

The University of Texas at Austin

May 2010 
Dedicated to my family 


\section{ACKNOWLEDGMENTS}

To begin with, I would like to express my deep gratitude to my supervising professors, Dr. Frank and Dr. Williamson, for their generous support, guidance, and sincere advices. Their kind encouragement has been my driving force to keep focusing on my research without giving up whenever I faced a tough challenge. I also appreciate to all my committee members, Dr. Tausullas, Dr. Wood, Dr. Mear, and Dr. Helwig for their precious comments and suggestions.

I am grateful to have a unique chance to join the full-scale bridge fracture test program due to the financial and the material supports by the Texas Department of Transportation (TxDOT) and the University of Texas Civil Engineering Department.

I should not forget to mention the immense contributions of my research colleagues, Bryce J. Neuman and Vasilis Samaras to this project. Due to their endeavors, the full-scale bridge tests could be conducted successfully. I would also like to thank Joshua M. Mouras for his contributions providing important solutions required for my research, and all staffs at Ferguson Structural Engineering Laboratory.

It would be an understatement that I am lucky to have so many friends who I hope to say thanks for their emotional and physical help for the last six years in the United States. Because of them, the life here has been truly enjoyable

Lastly, I would like to thank to my family members and hope to say that I love them. All works that I had done could not be completed without them. They have always supported and encouraged me regardless wherever I am. 


\title{
Finite Element Modeling of Twin Steel Box-Girder Bridges for Redundancy Evaluation
}

\author{
Publication No.
}

Janghwan Kim, Ph.D.

The University of Texas at Austin, 2010

Supervisors: Karl H. Frank and Eric B. Williamson

Bridge redundancy can be described as the capacity that a bridge has to continue carrying loads after suffering the failure of one or more main structural components without undergoing significant deformations. In the current AASHTO LRFD Bridge Design Specification, two-girder bridges are classified as fracture critical, which implies that these bridges are not inherently redundant. Therefore, two-girder bridges require more frequent and detailed inspections than other types of bridges, resulting in greater costs for their operation. Despite the fracture-critical classification of two-girder bridges, several historical events involving the failure of main load-carrying members in twogirder bridges constructed of steel plate girders have demonstrated their ability to have significant reserve load carrying capacity. Relative to the steel plate girder bridges, steel box-girder bridges have higher torsional stiffness and more structural elements that might contribute to load redistribution in the event of a fracture of one or more bridge main members. These observations initiated questions on the inherent redundancy that twin box-girder bridges might possess. Given the high costs associated with the maintenance 
and the inspection of these bridges, there is interest in accurately characterizing the redundancy of bridge systems.

In this study, twin steel box-girder bridges, which have become popular in recent years due to their aesthetics and high torsional resistance, were investigated to characterize and to define redundancy sources that could exist in this type of bridge. For this purpose, detailed finite element bridge models were developed with various modeling techniques to capture critical aspects of response of bridges suffering severe levels of damage. The finite element models included inelastic material behavior and nonlinear geometry, and they also accounted for the complex interaction of the shear studs with the concrete deck under progressing levels of damage. In conjunction with the computational analysis approach, three full-scale bridge fracture tests were carried out during this research project, and data collected from these tests were utilized to validate the results obtained from the finite element models. 


\section{TABLE OF CONTENTS}

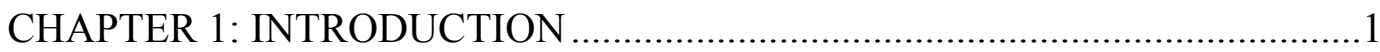

$1.1 \quad$ Historical background ......................................................................

1.2 Redundancy of two girder bridge ..........................................................

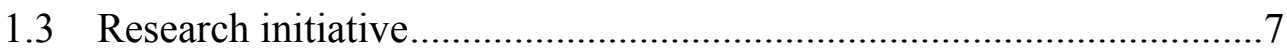

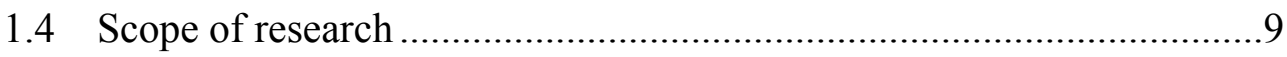

CHAPTER 2: REDUNDANCY EVALUATION METHODOLOGY ..................11

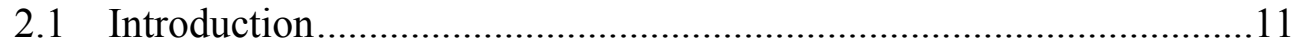

2.2 Damage scenario (damage types and levels) .......................................11

2.3 Live load and loading method..............................................................15

2.3.1 Truck live load .....................................................................15

2.3.2 Loading method .........................................................................16

CHAPTER 3: NUMERICAL MODELING OF TWIN STEEL BOX-GIRDER

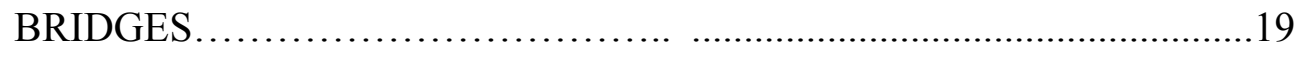

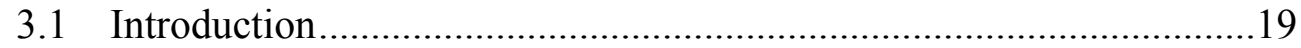

3.2 Finite Element Model of the Bridge .................................................19

3.3 Material Nonlinearities and Degradation.............................................22

3.3.1 Steel 22

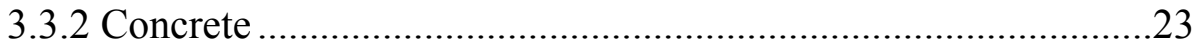

3.3.3 Shear stud and haunch ...............................................................39

3.3.4 Railing interaction.....................................................................51

CHAPTER 4: BRIDGE FRACTURE TEST AND SIMULATION ………..........54

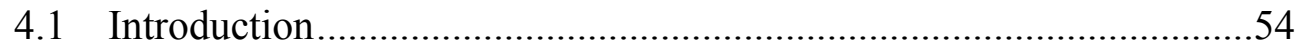

4.2 First bridge test (bottom flange removal) …………............................56

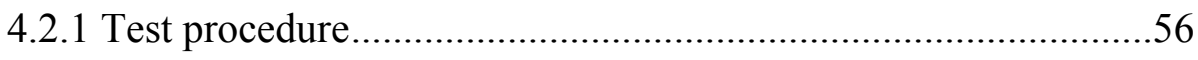

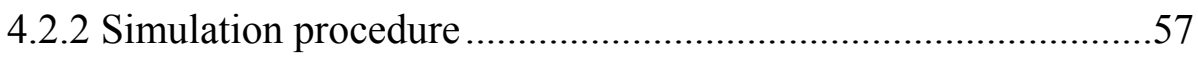

4.2.3 Bridge test and simulation results ............................................59

4.3 Second bridge test (bottom flange and web removal) .........................63

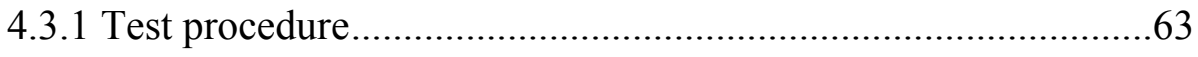

viii 
4.3.2 Simulation procedure ........................................................66

4.3.3 Bridge test and simulation results ..........................................68

4.4 Third bridge test (remaining capacity evaluation) ............................77

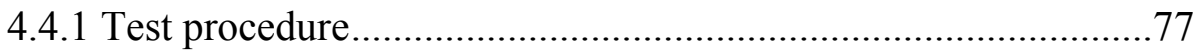

4.4.2 Simulation procedure ........................................................ 80

4.4.3 Bridge test and simulation results ......................................83

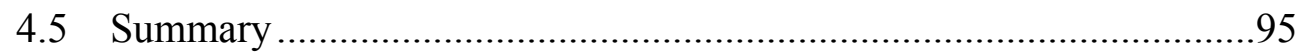

CHAPTER 5: PARAMETERS AFFECTING BRIDGE LOAD-CARRYING

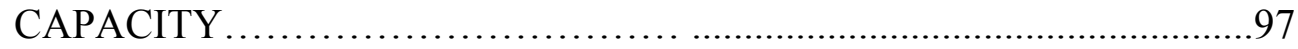

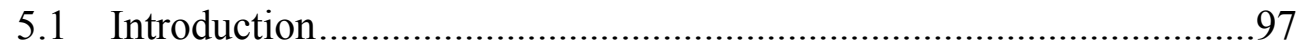

5.2 Concrete strength and truck live load ..........................................97

5.3 Background information on bridges investigated during parameter studies 100

5.4 Bridge component contributions on bridge capacity .......................101

5.4.1 Stud length and deck haunch ............................................... 101

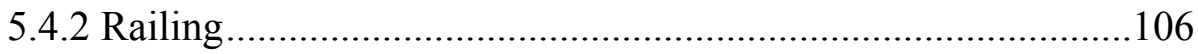

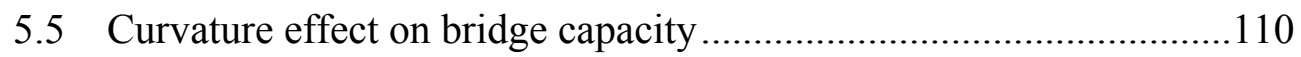

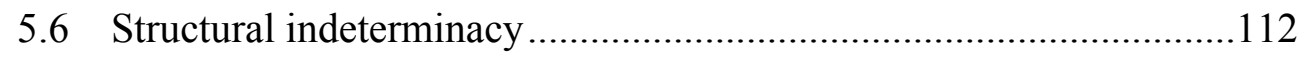

5.7 Bridge span length and dynamic amplification factor .....................117

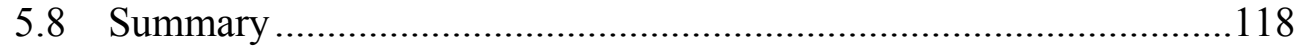

CHAPTER 6: REDUNDANCY EVALUATION (APPLICATION) .................120

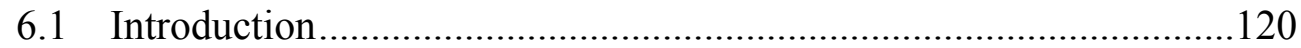

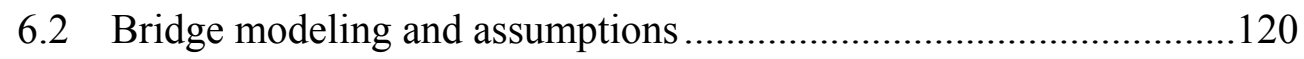

6.3 Determination of fracture location and analysis procedure ...............122

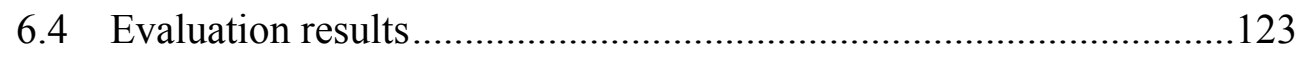

6.4.1 Dynamic displacement response..........................................123

6.4.2 Dynamic amplification factor .......................................... 126

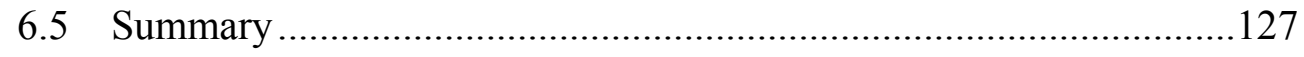

CHAPTER 7: CONCLUSIONS AND RECOMMENDATIONS ......................128

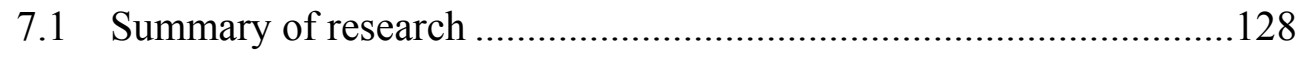




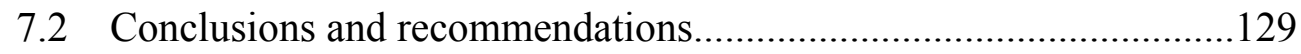

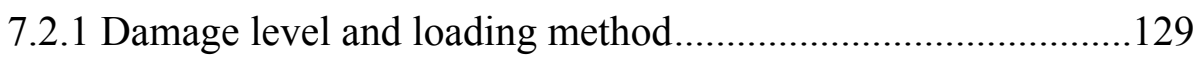

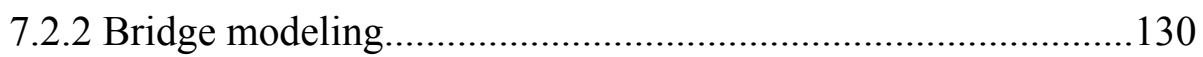

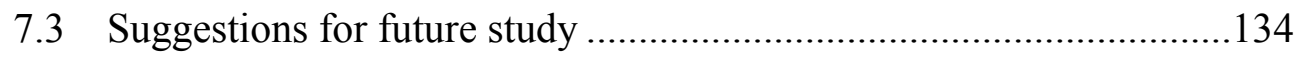

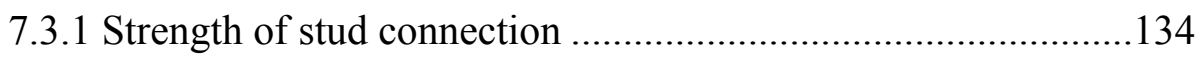

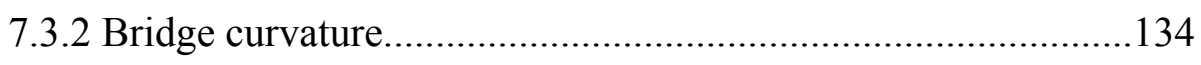

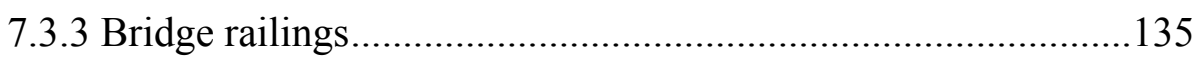

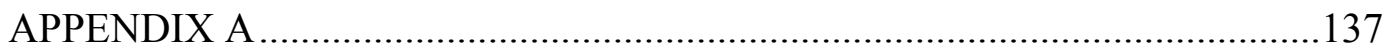

A.1 Anchor strength in concrete under tension force ...........................137

A.2 Modified anchor strength equation for haunch configuration ...........139

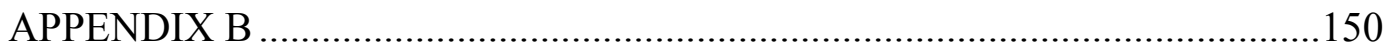

B.1 ACI anchor strength equation ................................................. 150

B.2 Method 1 (modified equation proposed by Mouras) ........................151

B.3 Method 2 (modified equation using a haunch modification factor) ..153

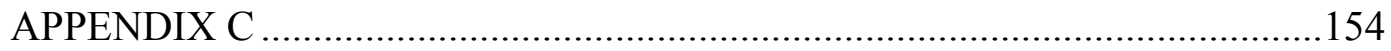

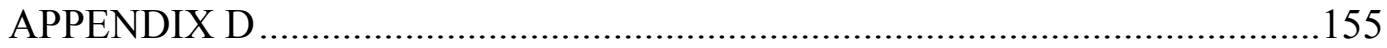

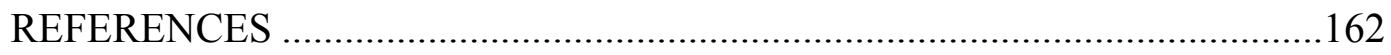

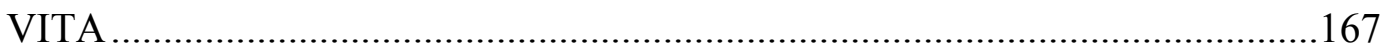




\section{LIST OF TABLES}

Table 4.1 Simulation procedures for first bridge fracture test ..................................... 58

Table 4.2 Simulation procedures for second bridge fracture test .................................. 66

Table 4.3 Simulation procedures for third bridge fracture test ................................... 81

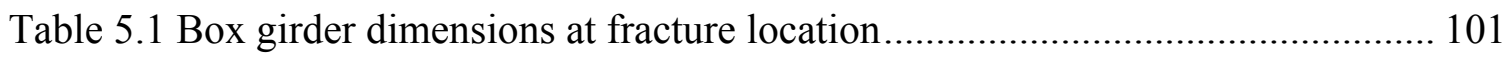

Table 6.1 Primary dimensions and strength of stud connection ................................ 121

Table 6.2 Maximum dynamic displacement of intact (IG) and fractured girder (FG) ... 124

Table A.1 Comparison of test results and estimations using modified equations.........149 


\section{LIST OF FIGURES}

Figure 1.1 Silver bridge before and after fracture (Wikipedia, 2009) ............................. 1

Figure 1.2 Neville Island Bridge girder fracture (Dexter et al., 2005) ........................... 2

Figure 1.3 Typical twin steel box-girder bridge in Austin, TX .................................... 6

Figure 1.4 Typical cross-section views of two-girder bridges...................................... 8

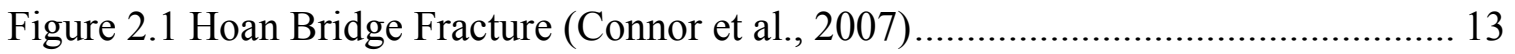

Figure 2.2 AASHTO HS-20 standard design truck ............................................... 15

Figure 2.3 simplified moving load model on simply supported beam .......................... 16

Figure 3.1 Finite element bridge model ................................................................... 20

Figure 3.2 Shear studs and haunches of twin box-girder bridge................................. 21

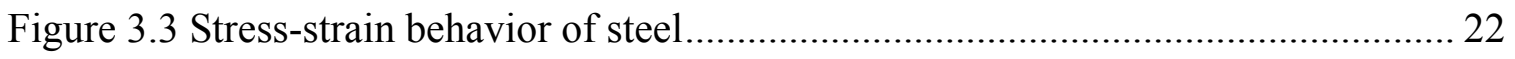

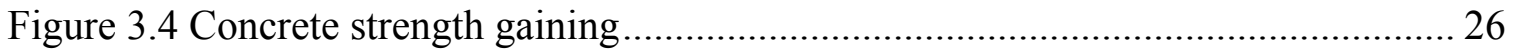

Figure 3.5 Material behavior in concrete smeared cracking model .............................. 27

Figure 3.6 Small deck model to calibrate bridge concrete slab .................................. 29

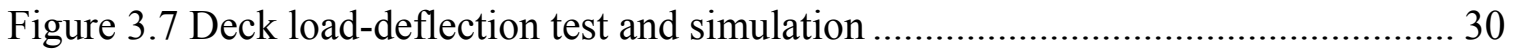

Figure 3.8 Deflection behavior of small deck (concrete smeared cracking) ................... 30

Figure 3.9 Material behavior in cast iron plasticity model ........................................ 33

Figure 3.10 Deflection behavior of small deck (cast iron plasticity) ............................. 34

Figure 3.11 Tensile strength effect on deck deflection response .................................. 35

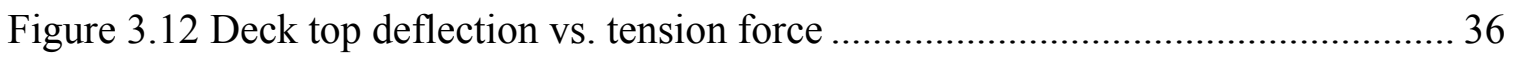

Figure 3.13 Normalized energy difference between tests and FE analysis .................... 38

Figure 3.14 Deflection behavior of calibrated cast iron plasticity deck model ............... 38

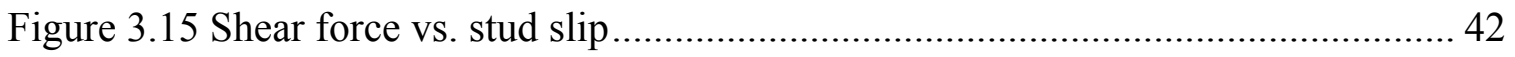

Figure 3.16 Tensile load-displacement behavior of stud connection ........................... 46

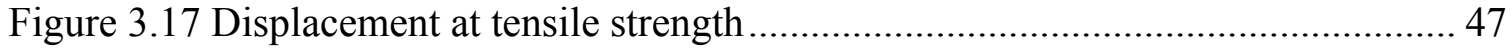

Figure 3.18 Damage initiation and evolution mechanism (Dassault Systemes, 2007a) ... 50

Figure 3.19 Single connector element behavior under tension and shear forces............. 50

Figure 3.20 Spring element behavior between rails................................................ 52 


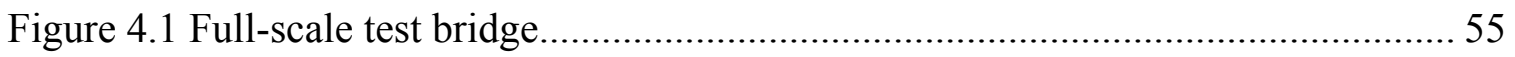

Figure 4.2 First bridge fracture test (bottom flange removal by explosion) ..................... 56

Figure 4.3 Predefined bottom flange fracture path ......................................................... 59

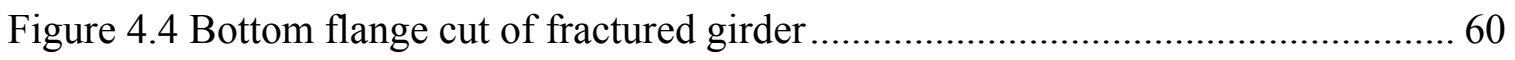

Figure 4.5 Girder deflection of intact and fractured girder............................................. 61

Figure 4.6 Fractured girder deflection after bottom flange removal ................................ 62

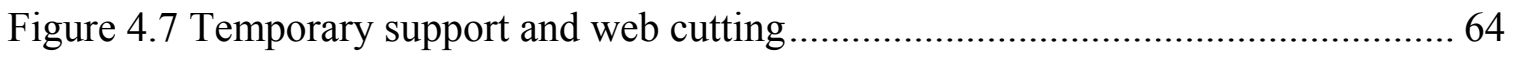

Figure 4.8 Simulated truck live load configuration (AASHTO HS-20) ........................... 64

Figure 4.9 Temporary truss support and explosive setup ................................................. 65

Figure 4.10 Second bridge fracture test (bottom flange and 83\% web removal) ............ 65

Figure 4.11 predefined fracture path in east girder........................................................ 67

Figure 4.12 Haunch separation of fractured girder............................................................ 68

Figure 4.13 Haunch separation along bridge span....................................................... 69

Figure 4.14 Haunch slope in cross-sectional plane....................................................... 70

Figure 4.15 Dynamic and static stud pullout test (Mouras, 2008) .................................. 71

Figure 4.16 Dynamic girder deflection ................................................................... 72

Figure 4.17 Static displacements of test and simulation............................................... 72

Figure 4.18 Deck displacement at midspan .............................................................. 74

Figure 4.19 deck deflection shape change caused by haunch separation ........................ 75

Figure 4.20 Longitudinal strain response by dynamic loading........................................ 76

Figure 4.21 Concrete block configuration on bridge deck .......................................... 78

Figure 4.22 Crack propagation in fractured girder outside web .................................... 79

Figure 4.23 Loading process and bridge collapse in third bridge fracture test................. 79

Figure 4.24 Applying concrete block and road base load............................................... 82

Figure 4.25 Bridge component failure sequence …………………………………...... 87

Figure 4.26 Girder deflection response ( $18 \mathrm{ft}$. away from midspan) ............................... 88

Figure 4.27 Haunch separation in FG-Out.................................................................. 89

Figure 4.28 Slip between the deck and girder top flange along FG-Out .......................... 89

Figure 4.29 Girder displacement response with reduced shear strength .......................... 92 


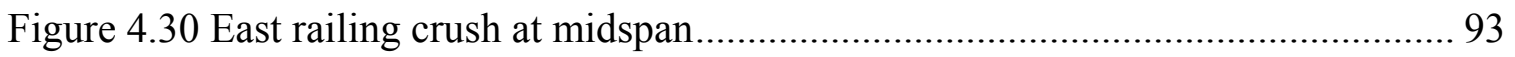

Figure 4.31 Longitudinal strain response along railing height ................................... 95

Figure 5.1 Fractured girder deflection at midspan (loading type and concrete strength

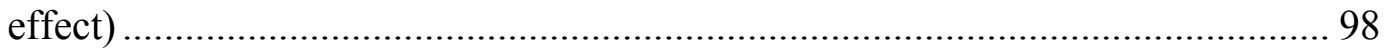

Figure 5.2 Cross-section view of twin steel box-girder bridge................................. 101

Figure 5.3 Tensile strength variation along stud length........................................... 103

Figure 5.4 Girder deflection at midspan (stud length effect) .................................... 103

Figure 5.5 Haunch separation in FG-In (5in. stud model) ......................................... 105

Figure 5.6 Separated haunch length variation along applied load .............................. 106

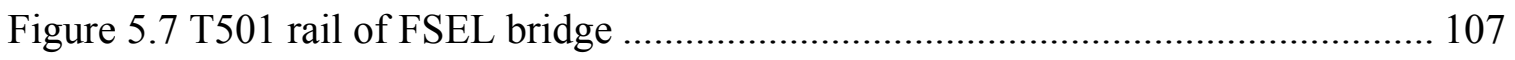

Figure 5.8 Deck deflection of fractured girder centerline at midspan ......................... 107

Figure 5.9 Separated haunch length difference depending on railing presence ............. 108

Figure 5.10 Shear stress of bottom flange at midspan .............................................. 111

Figure 5.11 Fractured girder deflection at midspan (curvature effect) ......................... 112

Figure 5.12 Normal stress envelop curve along bridge span .................................... 113

Figure 5.13 Girder deflection at midspan (continuous span) ..................................... 114

Figure 5.14 Girder deflection at midspan (continuous span with T501 rail)................ 116

Figure 5.15 Girder deflection at midspan (span length effect) ................................. 118

Figure 6.1 Schematic of stud connection with haunch ......................................... 121

Figure 6.2 Dynamic displacement behavior of fractured girder (FG) ........................ 125

Figure 6.3 Normalized maximum displacement of fractured girder along span to depth ratio

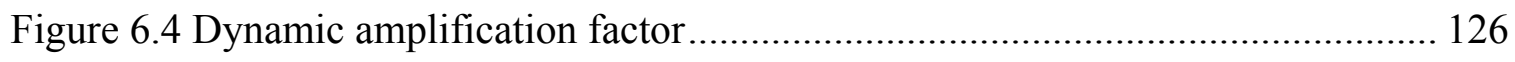

Figure A.1 Concrete breakout shape under tension force (CCD method) ..................... 138

Figure A.2 CCD (dashed) and observed (solid) failure cone shapes (Mouras, 2008) ... 140

Figure A.3 Dimensions for stud connection with haunch...................................... 143

Figure A.4 Normalized tensile strength variation along haunch edge distance............. 144

Figure A.5 Normalized tensile strength variation along effective stud length excluding haunch height 
Figure A.6 Tensile strength estimation for three studs in a row ................................. 148

Figure A.7 Tensile strength estimation for two studs in a row ................................... 148

Figure A.8 Tensile strength estimation for one stud............................................. 149

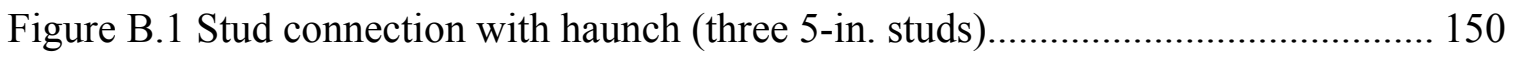

Figure B.2 Dimensions of stud connection with haunch and projected failure cone area in ACI anchor strength equation ............................................................... 151

Figure B.3 Dimensions of stud connection with haunch and projected failure cone area in modified ACI anchor strength equation by Mouras (2008) ............................ 152

Figure B.4 Dimensions of stud connection with haunch and projected failure cone area in ACI anchor strength equation modified by haunch modification factor ............ 153

Figure D.1 Displacement at tensile strength of stud connection ............................... 155

Figure D.2 Schematic of assumed tension region and dimensions for computing haunch

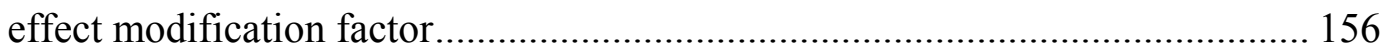

Figure D.3 Schematic of tensile load-displacement behavior of stud connection depending on haunch effect modification factor

Figure D.4 Separated haunch length of fractured girder inside along applied live load .160

Figure D.5 Vertical deflection behavior of fractured girder. 161 


\section{CHAPTER 1: INTRODUCTION}

\subsection{HISTORICAL BACKGROUND}

On December 15, 1967, the Silver Bridge (Figure 1.1) over the Ohio River collapsed during rush hour, leading to 46 casualties. The investigation of the failure determined that the fracture of a single eye-bar connecting the bridge's suspension chain released the primary load path, which resulted in the total collapse of the structure (Scheffey, 1971). This tragic accident initiated new legislation mandating regular inspections and maintenance of bridges.

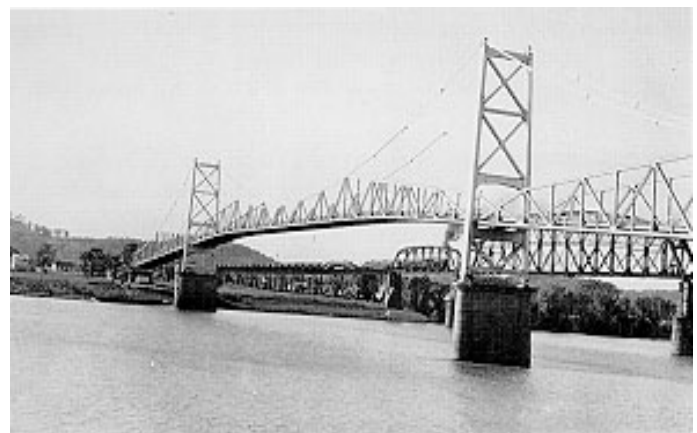

(a) In service

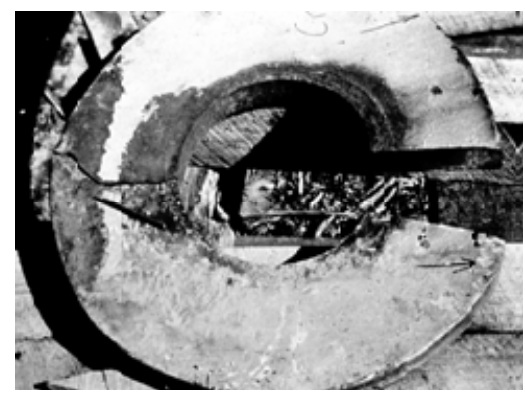

(b) Fractured eye-bar

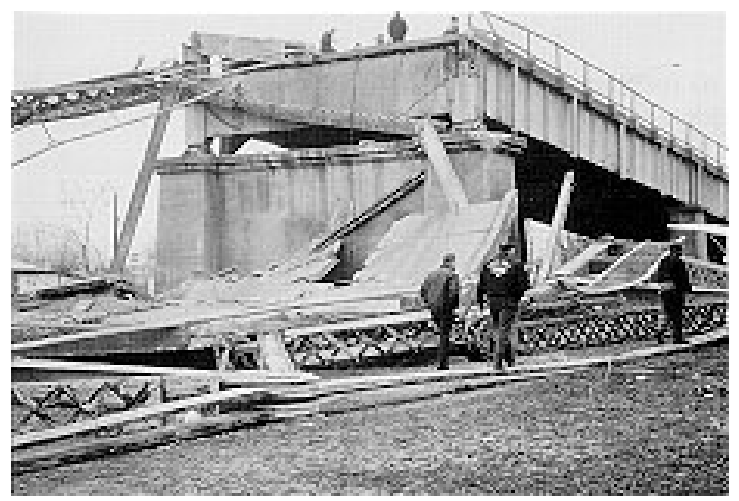

(b) After fracture

Figure 1.1 Silver bridge before and after fracture (Wikipedia, 2009) 
In 1969, Bryte Bend Bridge near Sacramento, CA was severely damaged due to a brittle fracture that initiated in a connecting joint where lateral braces were welded into the top flange. This bridge utilized a single trapezoidal box-girder that was constructed using A517 steel, which has low notch toughness; thus, it was vulnerable to brittle fracture (Barsom, 1999). The Lafayette Street Bridge in St. Paul, MN was shut down in 1975 because of a large crack in one of its main girders, which led to a large (7-inch) vertical deflection at the location of the crack. The crack was initiated by the lack of fusion areas in the weld of the lateral bracing and transverse stiffener, which resulted in a brittle fracture of the girder web (Fisher et al., 1977). In 1977, the I-79 Bridge at Neville Island, PA was closed due to a 10-ft-long crack found in one of two girders (Figure 1.2). It turned out that the fracture was initiated from a large weld defect developed during the girder fabrication (Fisher et al., 1985).

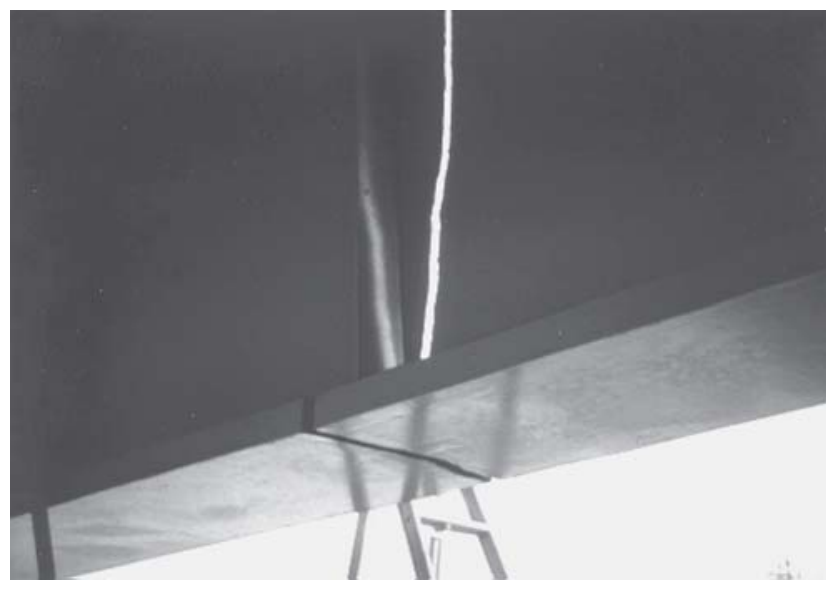

Figure 1.2 Neville Island Bridge girder fracture (Dexter et al., 2005) 
In response to the occurrence of brittle fractures that took place during the 1960s and 1970s, even though these fractures did not result in total bridge collapse in many cases, provisions for fracture-toughness of steel used in highway bridges were established in the 12th edition of the AASHTO (American Association of State Highway Transportation Officials) Standard Specification for Highway Bridges (1977). In the current edition of AASHTO LRFD Bridge Design Specifications (AASHTO, 2007), the fracture toughness provision requires higher toughness for fracture critical members (FCMs) than other tension members. The FCMs are defined as a "component in tension whose failure is expected to result in the collapse of the bridge or the inability of the bride to perform its function". Furthermore, strict fabrication procedures such as radiographic and ultrasonic testing for FCM groove welding are also mandated by the AASHTO AWS D1.5 Bridge Welding Code (2002). In addition to the material and the fabrication controls for the FCMs, the National Bridge Inspection Standards (NBIS), which were revised in 1988, requires "hands-on inspection" for bridges having FCMs. These restrictions lead to increased costs for bridge construction and bridge maintenance, which encourages bridge designers to avoid bridges containing FCMs despite other positive attributes that these bridges may have including structural efficiency and aesthetic appeal.

\subsection{REDUNDANCY OF TWO GIRDER BRIDGE}

Bridge redundancy can be described as the capacity that a bridge has to continue carrying loads after suffering the failure of one or more main structural components without undergoing excessive deformations. If a bridge is expected to collapse as the result of the failure of a primary structural component in tension, Section 1.3.4 of the AASHTO LRFD Bridge Design Specifications (2007) defines such a bridge as fracture 
critical (i.e., non-redundant), and such a component is considered to be a fracture critical member. Dexter et al. (2005) introduced similar terminology: "A fracture critical element (FCE) is an element in tension that if fractured would probably cause a portion of or the entire bridge to collapse. A fracture critical member (FCM) is a member containing such a FCE". According to these definitions, the existence of a fracture critical member in a bridge should be investigated to determine whether or not a bridge is fracture critical; however, it is not a simple procedure to assess whether or not a member is fracture critical because bridge components act together as part of a structural system that may allow for alternate load-transferring paths (i.e., redundancy sources) in the event that one or more main load-carrying members fractures. Therefore, possible redundancy sources in a bridge should be considered in the procedure indentifying a fracture critical member.

There are three different sources of redundancy that are described in the literature: internal redundancy, load-path redundancy, and structural redundancy (Hartle et al., 1991). Internal redundancy refers to the ability of an individual component to sustain damage without failing such as when individual bolts or rivets fail without causing a member to fail. Load-path redundancy refers to the ability of a structure to transfer loads from a failed component to other structural components so that the dead and live loads acting on a structure can eventually be carried to the foundation without structural collapse. Such load paths may be achieved through direct investigation during the design of a structure, or they may require some structural components to carry loads that they were not initially intended to carry. For example, in a multi-girder bridge, it is possible for the loads that may have been initially carried by a girder that fractures to be transferred to other girders through load paths achieved through the reinforced concrete deck or through external bracing. Lastly, structural redundancy is achieved through 
designs that utilize structural systems that are statically indeterminate such as when continuous girders over multiple spans are utilized.

The AASHTO LRFD specification (2007), as well as most other design specifications, utilizes an approach to design that is based on the behavior of individual components with little or no consideration given to the interaction of members or the system-wide behavior of a structure. Based on this design philosophy, the AASHTO LRFD Specification (2007) currently classifies two-girder bridges as fracture critical because system-wide behavior is not considered. Accordingly, such bridges must be constructed using more stringent fabrication and material provisions than bridges that are not fracture critical. Furthermore, they must be inspected more frequently (biennial inspection) than other bridges that are not classified as fracture critical. In addition, the National Bridge Inspection Standards mandate a "hands-on inspection" for these types of structures, which increases inspection costs $200 \%$ to $500 \%$ compared with non-fracturecritical bridges (Connor et al., 2005)

Despite the guidelines from AASHTO (2007) that all two-girder bridges be classified as fracture critical, some bridges with twin steel plate girders have sustained the full fracture of the bottom flange and the partial fracture of the web or even the fracture of the full depth of the web without collapsing or undergoing severe deformations (Dexter et al., 2005) including, for example, the US-52 Lafayette Street Bridge in St. Paul, MN (1975) and the I-79 Glenfield bridge at Neville Island, PA (1977). Based on the results of an experimental research study, Idriss et al. (1995) also raised concerns about the fracture critical classification of two-girder bridges. They conducted a fracture test of a two-girder bridge on interstate I-40 in New Mexico. The test bridge consisted of two plate girders and three continuous spans. They cut the bottom flange and $60 \%$ of the web of one of the girders at the midspan. After damaging the girder, they placed a truck load 
on the bridge and found that the applied load was resisted by the fractured girder though cantilever action longitudinally and by the intact girder through transverse load redistribution across secondary components such as the concrete deck, the floor beams, and the lateral bracing members near the fracture location. These observations suggest that two-girder bridge systems currently classified as fracture critical may have redundancy and capacity to redistribute loads in the event that a fracture takes place in one of the girders. In the example cited above, however, the bridge included in the test program had structural redundancy because it comprised three continuous spans and damage was induced in the interior span. In the case of a single-span bridge or for the end span of a continuous bridge, such structural redundancy is not available. Thus, under such conditions, it is still not clear if sufficient redundancy exists to prevent collapse.

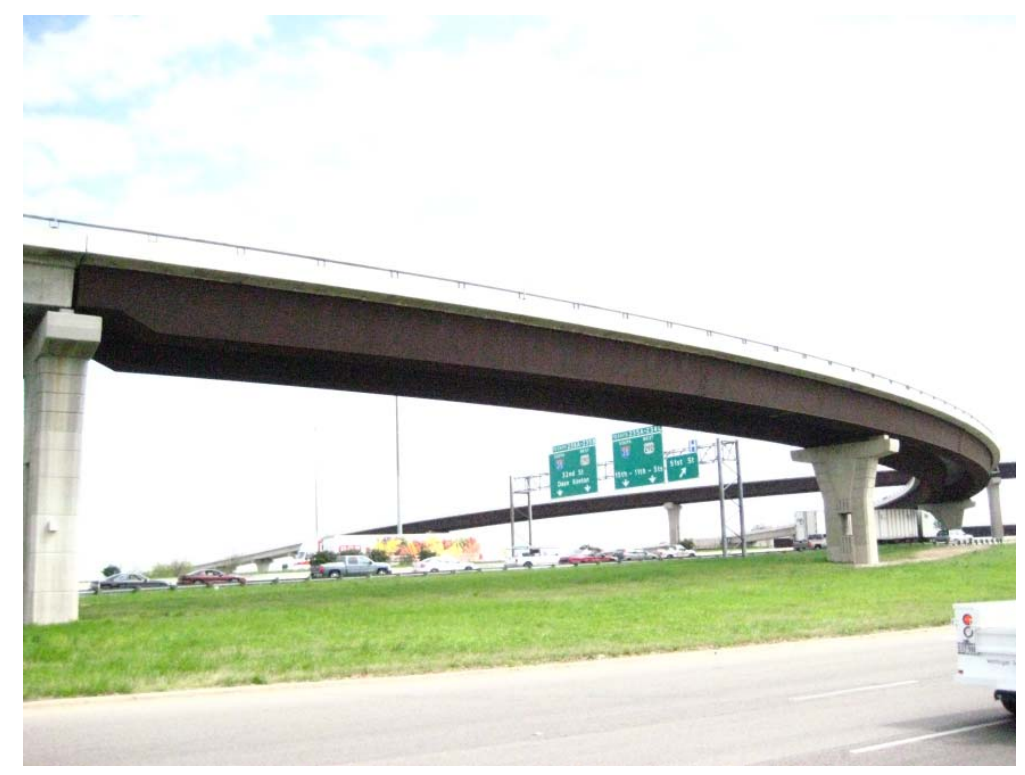

Figure 1.3 Typical twin steel box-girder bridge in Austin, TX 


\subsection{RESEARCH INITIATIVE}

In recent years, twin steel box-girder bridges (Figure 1.3) have become popular, especially in highway interchanges, because of their aesthetically pleasing external appearance and their high torsional resistance. Nonetheless, they are classified as fracture critical even if they possess structural redundancy as a result of having continuous spans. Relative to steel plate girder bridges, trapezoidal box-girder bridges have very high torsional stiffness. The high torsional resistance can contribute to load redistribution in the event of a fracture of one of the girders because the load acting on the fractured girder would cause torsion about the longitudinal axis of the bridge. Furthermore, as pointed out by Hovell (2007), design details of a twin steel box-girder bridge are similar to a four plate-girder bridge considering the fact that the twin steel box-girder bridge has four webs as shown in Figure 1.4. This implies the possibility of additional load paths relative to two-girder bridges constructed of I-shaped plate girders.

Based on the performance of several bridges that have experienced severe damage and full-depth girder fractures without failing, the results of past research reported in the literature, and the results of many years of inspection, the classification of twin boxgirder bridges as fracture critical has come under question. Given the high costs associated with the construction, maintenance, and inspection of these bridges classified as fracture critical under the current AASHTO guidelines, there is interest in characterizing the redundancy of these types of bridge systems. If these bridges can be shown to possess sufficient redundancy enabling them to be classified as non-fracture critical (i.e., redundant), Texas and other states could save the funds spent for frequent inspections of these bridges. To address this concern, the Texas Department of Transportation (TxDOT) initiated a study on the performance of fracture critical twin box-girder bridges. The purpose of this research program was to investigate the inherent 
redundancy that this type of bridge may possess and to provide bridge engineers with quantitative methods for evaluating the redundancy of these bridges. To meet the goals of the research, extensive experimental, analytical, and computational work was conducted by a team of researchers at the University of Texas at Austin. The research included fullscale bridge fracture tests, laboratory tests, development of a simplified modeling method, and development of a detailed finite element modeling method.

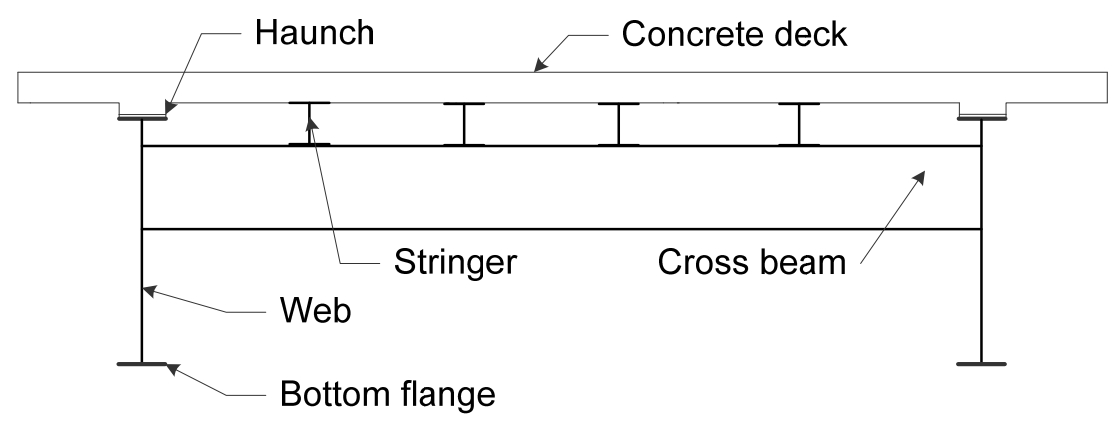

(a) Cross-section of plate girder bridge

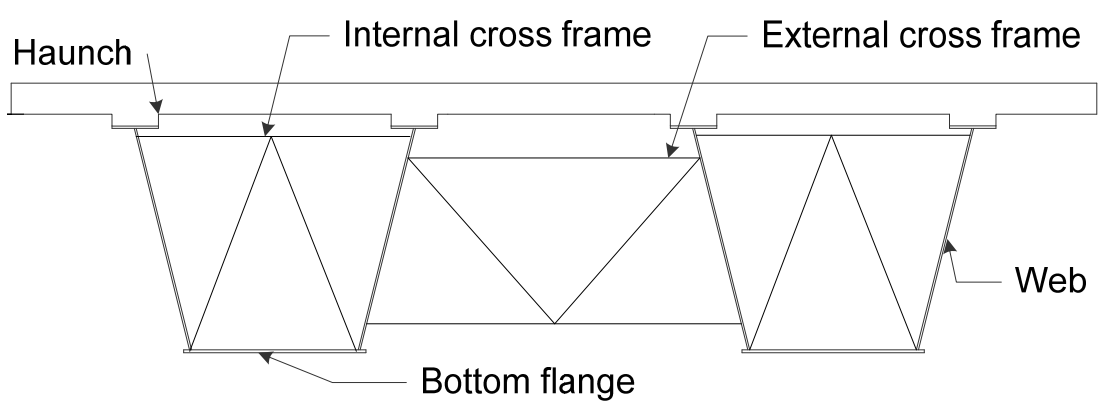

(b) Cross-section of twin steel box-girder bridge

Figure 1.4 Typical cross-section views of two-girder bridges 


\subsection{SCOPE OF RESEARCH}

In this study, twin steel box-girder bridges were investigated using the commercial finite element analysis (FEA) software package ABAQUS/Standard (v6.7). The purpose of this research was to develop a suitably accurate finite element model for simulating the response of a severely damaged bridge, such as when the fracture of one girder in a two-girder bridge occurs. Significant effort was placed on the development of models that were both computationally efficient and accurate. This study mainly focused on load-path redundancy that can be achieved through bridge components such as the bridge deck, stud connections, and railings to determine load-carrying capabilities of damaged twin box-girder bridges. Thus, contributions of those bridge components to overall bridge response were investigated using finite element models that were validated using data from laboratory tests and full-scale bridge tests.

The detailed finite element models were constructed through several levels of refinement to capture critical aspects of response that occur in damaged twin box-girder bridges. The response to be captured includes large deflections, yielding of steel plates, concrete cracking or crushing, stud connection failures, and railing contact over expansion joints. In conjunction with the FEA, full-scale bridge fracture tests were carried out at the Ferguson Structural Engineering Laboratory (FSEL) at the University of Texas at Austin. The test bridge, was originally in service on interstate I-10 in Houston. The bridge was disassembled and then reconstructed at FSEL. These full-scale bridge tests provided very useful insight on how the bridge performed when subjected to localized damage initiated by the loss of a fracture critical component. In the following chapter, a damage level and a loading method for evaluating the redundancy of a twin box-girder bridge is discussed. Inelastic material properties and mechanical behavior used for detailed finite element bridge models are described in Chapter 3. Analysis 
procedures to evaluate bridge redundancy and remaining load-carrying capacity are included in Chapter 4 with relevant full-scale bridge fracture tests. Contributions and sensitivities of various bridge components to the overall bridge load-carrying capacity are provided in Chapter 5. The implementation of the suggested redundancy evaluation method is present in Chapter 6. In the last chapter, a summary of the research and recommendations for computationally evaluating redundancy is presented. 


\section{CHAPTER 2: REDUNDANCY EVALUATION METHODOLOGY}

\subsection{INTRODUCTION}

There are three main conditions that should be specified to systematically evaluate the redundancy of a bridge system (Ghosn et al., 1998): damage scenario, load case, and target limit state. In this study, a considered damage scenario was the sudden fracture (intended to simulate brittle fracture) of one girder in a twin steel box-girder bridge. To simulate the worst-case loading condition, it was assumed that the girder fracture occurred at the time when a moving vehicle was positioned to induce the maximum positive bending moment on the fracture location. As a possible damage scenario, two different damage levels were considered: fracture of the bottom flange and the full-depth fracture of one girder. An HS-20 standard design truck load specified in the AASHTO LRFD (2007) was used as a base live load. These damage levels and loading scenario were applied to full-scale bridge fracture tests and to finite element simulations. Detailed application procedures of the suggested damage and loading scenario for the bridge fracture tests and the finite element simulations are described in Chapter 4.

\subsection{DAMAGE SCENARIO (DAMAGE TYPES AND LEVELS)}

There are various possibilities which might cause damage to - or fracture of bridge members such as corrosion, fatigue cracking, brittle fracture or traffic collisions. If these damage sources could cause the failure of one or more fracture critical members (FCMs), it would be expected to result in bridge collapse according to the fracture critical definition of the AASHTO LRFD Bridge Design Specifications (AASHTO, 2007). It should be noted that FCMs are not confined only to steel members; members constructed from concrete or other materials could also be classified as FCMs. Traditionally, 
however, only steel members in tension are considered as FCMs (Dexter et al., 2005). In this study, emphasis is placed on brittle fracture as an initiating failure mechanism, and damage resulting from other sources such as vehicle collision are not considered. In many highway bridges, fatigue crack growth precedes brittle fracture until the crack size becomes critical (Fisher, 1984); therefore, bridges can be maintained by replacing or repairing members with fatigue cracks through regular inspections. However, it is not always possible to detect fatigue cracks before they become critical because for some bridge details, inspection of fatigue cracks can be problematic. Furthermore, brittle fractures are not necessarily induced only by fatigue crack growth.

The girder fracture of the I-79 Glenfield bridge at Neville Island, PA in 1977 suggests that a brittle fracture propagating through the full-depth of a steel plate girder is a distinct possibility. This bridge was constructed using two steel plate girders with three continuous spans. When the fracture was observed, the bottom flange and lower portion of the web of one girder was already separated at the midspan, and within an hour, the crack propagated upward and finally penetrated through the entire web height. Fisher et al. (1985) found that the crack was initiated from a weld defect in the vicinity of the welded splice in the bottom flange of the fractured girder. This finding came from their fractographic analysis of the steel. They also observed the evidence of a brittle fracture in the bottom flange caused by low toughness welding material. The I-794 Hoan bridge in Milwaukee, WI (2000), which is shown in Figure 2.1, suffered full-depth girder fractures initiated by sudden crack propagation in two of three girders. One of two girders of the US-422 bridge in Pottstown, PA (2003) also fractured in a brittle manner, although the crack did not propagate over the full-depth of the girder. In these bridges, brittle fractures occurred without any significant fabrication default or fatigue crack growth. Connor et al. (2007) investigated these bridges and found that the lack of web gap constrained the 
through-thickness deformation of the web and consequently resulted in a high tri-axial stress condition. Under such high tri-axial stresses, the web steel fractured suddenly prior to material yielding, which is called a constraint-induced fracture (CIF).

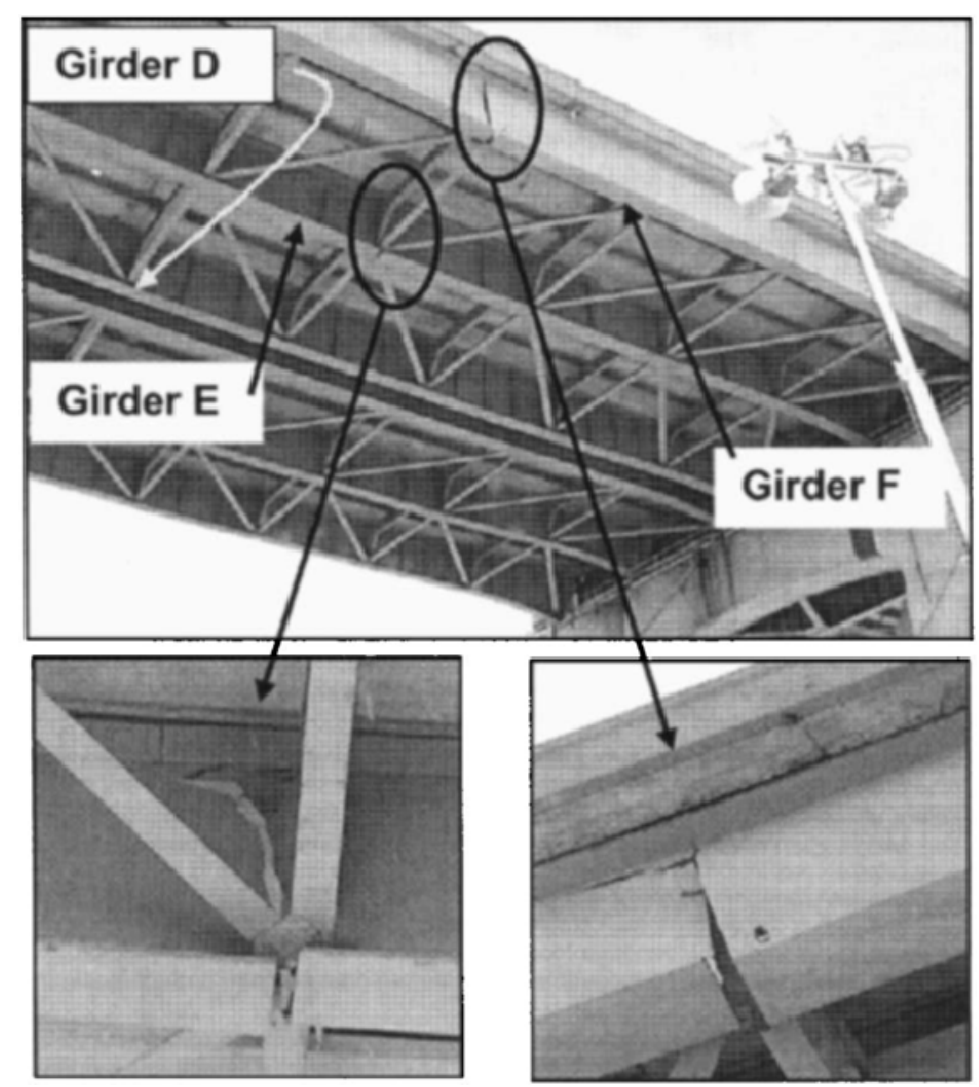

Figure 2.1 Hoan Bridge Fracture (Connor et al., 2007)

When it comes to twin steel box-girder bridges, it is not certain as to whether or not such brittle fractures could occur like those that were experienced by the steel plate girder bridges described previously. To date, no brittle fracture events have been reported for these types of bridges. Because AASHTO (2007) currently has provisions for the 
minimum fracture toughness for the steel used on fracture critical bridges (FCBs), and because the current AASHTO specification requires that the transverse bracing members be attached to girder flanges or longitudinal stiffness members, it is expected that the chances that a brittle fracture will occur in twin box-girder bridges is very low. Nonetheless, given the experience of brittle fractures that have occurred in plate girder bridges, the economical loss caused by bridge closing and repairs could be significant. Furthermore, a brittle fracture of a bridge could cause the potential loss of life because of unnoticed and dynamic natures. Therefore, evaluation of redundancy considering the possibility of brittle fracture in twin box-girder bridges is an important research need. For this reason, sudden girder fracture was assumed as a damage type to evaluate the redundancy of a twin steel box-girder bridge. As indicated above, the considered damage levels in this study included loss of the bottom flange (because the bottom flange is currently classified as a fracture critical member in the AASHTO LRFD specification) and the full-depth fracture of one girder (based on the fracture experiences of steel plate girder bridge as described previously), with a truck positioned so as to cause the maximum bending moment at the fracture location.

As described previously, this research program included three full-scale bridge tests and detailed finite element simulations. The full-scale bridge fracture test program and the finite element simulations were designed according to the damage scenarios indicated above. The first test in the experimental program was designed to simulate the bottom flange fracture of one girder, and the second test was designed to simulate the full-depth fracture of one girder (the girder was not fully fractured in this test because of safety issues). Lastly, the test bridge was utilized to investigate the remaining loadcarrying capacity following the full-depth fracture of one of the two girders. Detailed descriptions for the tests and the simulations are presented in Chapter 4. 


\subsection{LIVE LOAD AND LOADING METHOD}

\subsubsection{Truck live load}

In the current AASHTO LRFD Bridge Design Specifications (AASHTO, 2007), a notional live load is described, which allows for the combination of lane loads and design truck loads for a variety of cases. Different load factors are used for the notional live load depending upon the target limit state or load combinations under consideration. According to the specification, a notional live load is defined as "a group of vehicles routinely permitted on highways of various states". It is not intended to represent any particular truck or illegal overloads, nor does it represent a specific short duration or special load. Instead of requiring consideration of these individual load cases, the notional load is scaled by load factors to address a variety of cases in the LRFD bridge specification.
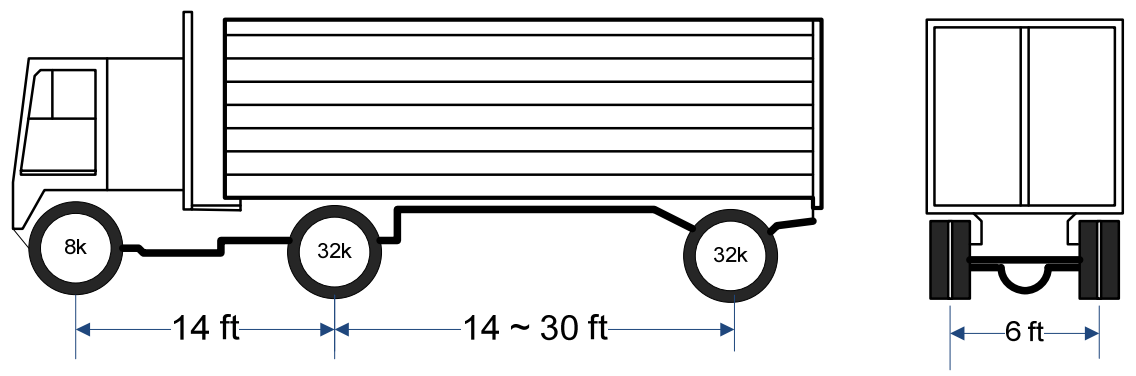

Figure 2.2 AASHTO HS-20 standard design truck

In this study, the standard truck load (HS-20) specified in the Bridge Design Specifications (AASHTO, 2007) was selected as the primary live load for evaluating bridge redundancy. The HS-20 truck live load, as shown in Figure 2.2, consists of 3 axles: one 8-kip front axle and two 32-kip middle and rear axles. The distance between the front and middle axles is fixed at $14 \mathrm{ft}$., and the distance between the middle and rear 
axles can vary from $14 \mathrm{ft}$. to $30 \mathrm{ft}$. In this study, the distance between the middle and rear axles is fixed at $14 \mathrm{ft}$. to maximize the positive bending moment response of a bridge.

\subsubsection{Loading method}

\subsubsection{Dynamic impact of moving vehicle}

A vehicle travelling on a bridge is usually modeled as a series of moving concentrated loads. Figure 2.3 shows a single-axle moving load model. The moving vehicle produces a higher loading effect than it would if it were applied statically. For design, the increased loading effect of the moving vehicle is accounted for by amplifying the load by a wheel impact factor, which is also called a dynamic amplification factor (DAF). The DAF is defined as a loading effect ratio on the bridge by dividing the dynamic loading effect by the static loading effect. There are various factors which affect the DAF, including the dynamic properties of a bridge (natural frequency and damping), road surface conditions, vehicle velocity, support conditions.

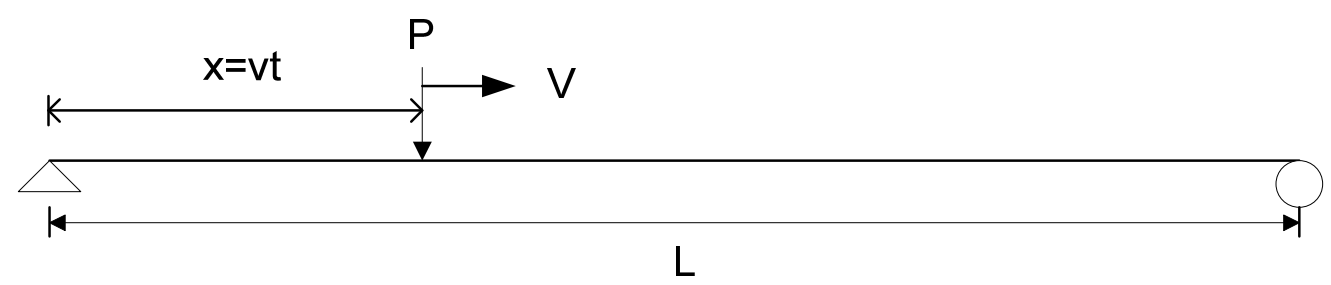

Figure 2.3 simplified moving load model on simply supported beam

To account for the effects of the wheel impact associated with a moving vehicle on a bridge, the AASHTO LRFD specification requires the design truck load to be 
increased by 33 percent. The wheel impact factor is based on measurements obtained from field studies that showed a 25 percent increase (which was the maximum measured wheel impact) over static vehicle response on typical highway bridges. The specified value of 33 percent was determined by multiplying the factor $4 / 3$ with the 25 percent value to incorporate the effect of illegal overloads (AASHTO, 2007).

\subsubsection{Loading method for redundancy evaluation (loading scenario A)}

The considered loading for redundancy evaluation in this study was a moving HS20 truck on a bridge. Although a moving vehicle causes a higher loading effect than one caused by statically applied loads, and such higher loading effect could be accounted for using a wheel impact factor as described above, the impact factor was not considered for the truck live load in this study because the dynamic response of the bridge resulting from the assumed damage scenario (i.e., the sudden bottom flange fracture or the sudden full-depth fracture of one girder) was directly measured or computed. For the current research, the truck live load was statically positioned on a bridge before applying the specified girder fracture in such a manner as to induce the maximum possible bending moment at the location where the fracture would occur. Although the truck live load was statically applied without accounting for a wheel impact factor, it was believed that a much higher dynamic load effect for the truck live load than the wheel impact factor would occur because the truck load would be released suddenly according to the assumed damage scenario. In a real fracture event, however, it is not expected that a truck will be stopped precisely in the position as to cause the maximum stresses at the fracture location, and the fracture itself will dissipate energy as it propagates through the steel section. Thus, while the damage and loading scenario used in this research is not entirely consistent with the design assumptions included in the AASHTO LRFD (2007), it is 
believed to represent a worst-case scenario. This loading method was utilized in the first and the second full-scale bridge fracture tests and the finite element simulations. The detailed analysis procedure to simulate this loading scenario is described in Chapter 4.

\subsubsection{Loading method for remaining load-carrying capacity evaluation (loading scenario B)}

In addition to the loading scheme associated with the assumed damage scenario for redundancy evaluations described in the previous section, another loading scheme was considered in this study to investigate the remaining load-carrying capacity of a twin box-girder bridge following the fracture of one girder. This loading scenario was used to determine the contributions of various bridge components that can provide alternate load transfer paths following girder fracture. In this loading scheme, dynamic loading effects were not considered. Thus, fracture of one girder was induced statically on a bridge, and then a truck live load was applied at the same location used for the redundancy evaluation. The HS-20 truck load was also used as a primary truck live load, but the load was increased proportionally to each axle load beyond one truck loading. Therefore, its loading configuration corresponds to placing one truck on top of other truck loads. The third full-scale bridge test and the corresponding finite element simulation (described in Chapter 4) followed this loading scenario (loading scenario B). Loading scenario B was also utilized in finite element simulations to evaluate the contribution of bridge components on overall bridge load-carrying capacity after fracture of one girder took place (described in Chapter 5).

In the next chapter, the main features of a finite element bridge model for redundancy evaluation, including element properties, material inelasticity, and mechanical properties, are discussed. 


\section{CHAPTER 3: NUMERICAL MODELING OF TWIN STEEL BOX- GIRDER BRIDGES}

\subsection{INTRODUCTION}

Finite element models used to simulate the response of twin steel box-girder bridges considered for this research were developed using ABAQUS/Standard (v6.7), which is a commercially available general purpose finite element analysis software package. To incorporate nonlinear material behavior, traditional metal plasticity was used to represent steel components, and cast iron plasticity was used to represent concrete components. The choice of a metal-based plasticity formulation to represent concrete material is described in detail below. In addition to material nonlinearities, railing contact and stud connection failures were also considered in the simulation models using nonlinear spring elements and connector elements, respectively. For the railing contact,

nonlinear spring elements were installed in gaps between bridge rails instead of conducting a direct contact analysis. The deck haunch placed between a steel girder top flange and the concrete deck was not modeled explicitly, but it was accounted for in the prescribed load-deformation response of the connector elements. Connector element performance was validated against small-scale laboratory tests on specimens that included a haunch and a wide array of shear stud arrangements (Mouras, 2008). Details of the computational model are described in the sections below.

\subsection{Finite Element MOdel OF THE BRIDGE}

A trapezoidal steel box-girder bridge consists of several components, such as steel plate girders, brace members, shear studs, a concrete deck, bridge rails. As shown in Figure 3.1, finite element models for bridges were constructed with various types of 
elements to provide a realistic representation of the box-girder bridge under investigation. The steel plates were modeled using 8-node shell elements (S8R), and the internal and external brace members were modeled using 2-node truss (T3D2) and beam elements (B31). For the concrete deck, 8-node solid elements (C3D8R) were used. The reinforcement in the concrete deck was represented using 2-node truss elements (T3D2) that were embedded into the concrete elements.

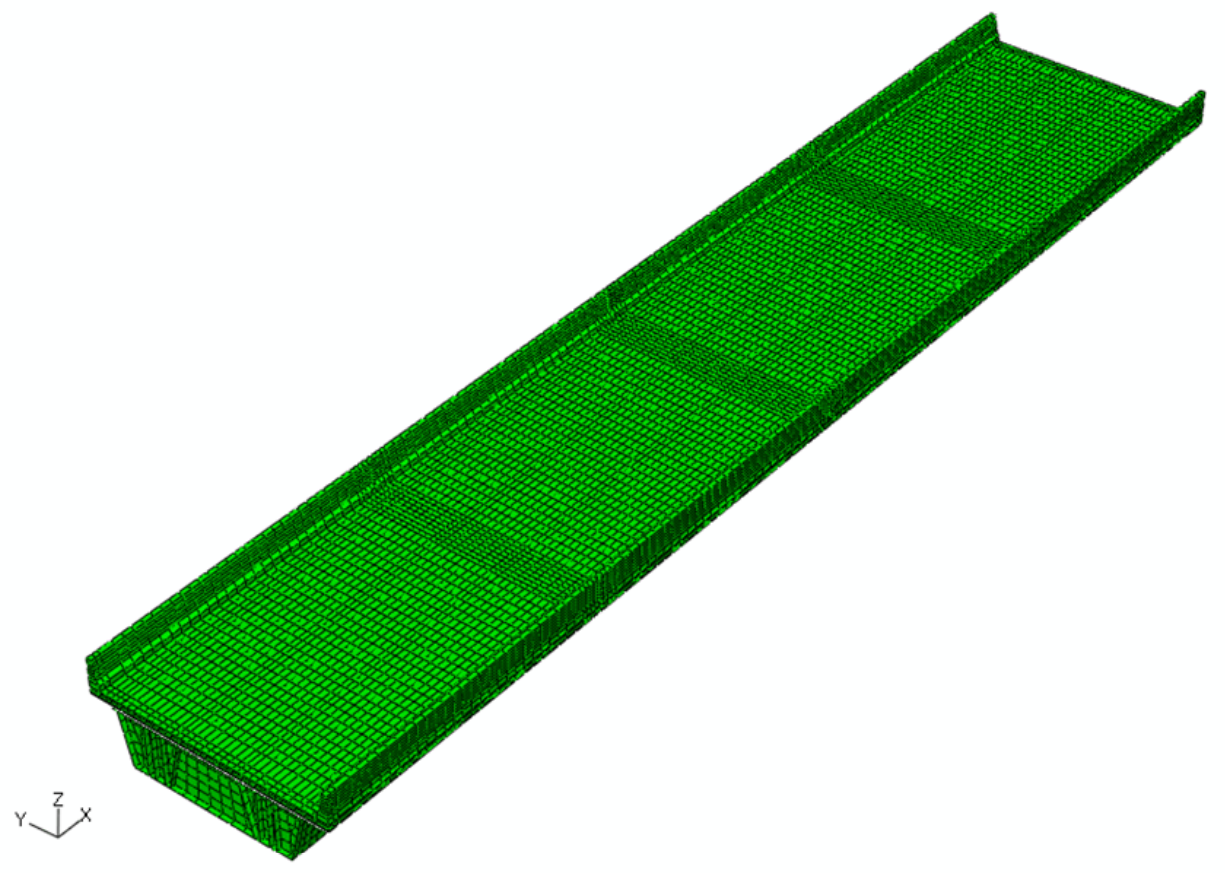

Figure 3.1 Finite element bridge model

In the construction of a steel box-girder bridge, shear studs are used to develop composite action between the concrete deck and the box girders. These shear studs, as shown in Figure 3.2(a), are installed on the top flanges of the box girders prior to casting of the concrete deck. Haunches above the girder top flanges, as indicated in Figure 3.2(b), 
allow for a uniform deck thickness along the bridge span. In the simulation model, such haunches were not modeled explicitly; instead, their effects on the tensile strength of shear stud connections were incorporated into the vertical response of connector elements (CONN3D2). The shear resistance of shear studs between the deck and the steel box girders were simulated by the horizontal response of the connector elements. Equations used to define the load-deformation response of stud connections were obtained from available literatures that will be described in Section 3.3.3. Bridge rails and railing interactions were modeled by 8-node solid elements and nonlinear spring elements (SPRING2) to account for railing contact. These nonlinear springs were assumed to be effective only in compression after a deflection of $3 / 4$ in. was reached, which was the initial gap distance between rails in the finite element model based on field measurements of the bridge tested at FSEL and the prescribed geometry called for in the TxDOT T501 traffic railing (TxDOT, 2003).

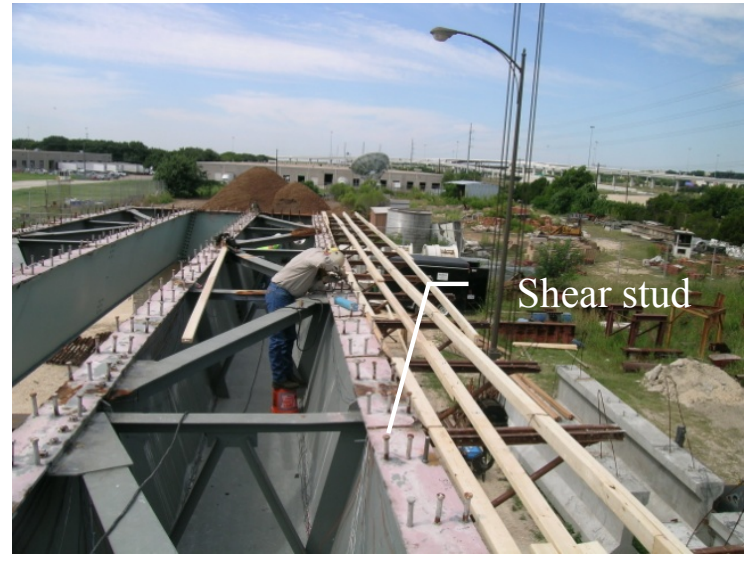

(a) Shear studs installed on top flange

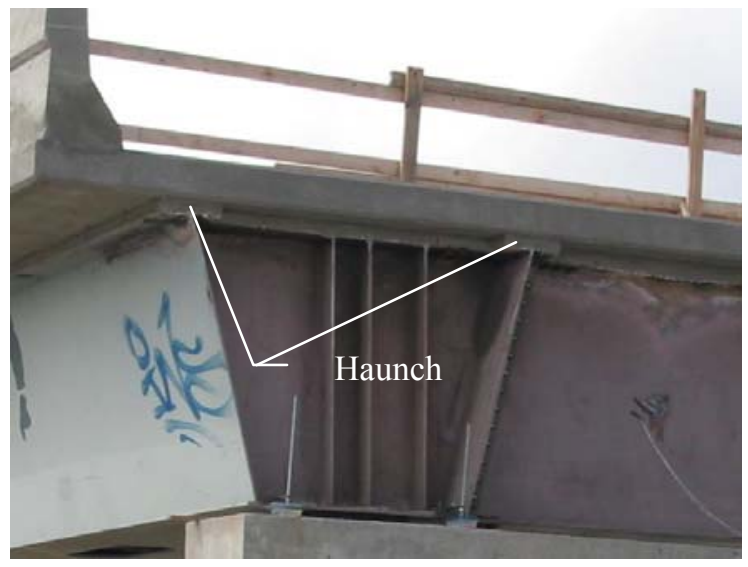

(b) Deck haunch

Figure 3.2 Shear studs and haunches of twin box-girder bridge 


\subsection{MATERIAL NonlineARITIES AND DEGRADATION}

\subsubsection{Steel}

The inelastic behavior of steel plates, brace members, and reinforcing steel were modeled using a multi-linear inelastic material model with isotropic hardening rule (Dassault Systemes, 2007a) in both tension and compression. Based on classical metal plasticity, it was assumed that the material yielded when the equivalent stress exceeded the von Mises yield criterion; multi-linear hardening behavior was assumed when the stress exceeded the yield strength. In this study, $50 \mathrm{ksi}$ for the plates and $60 \mathrm{ksi}$ for the reinforcing steel, respectively, were used as the yield strengths in the finite element model of the full-scale test bridge. Figure 3.3 shows the stress-strain behavior of the steel plate and rebar under uniaxial tensile forces.

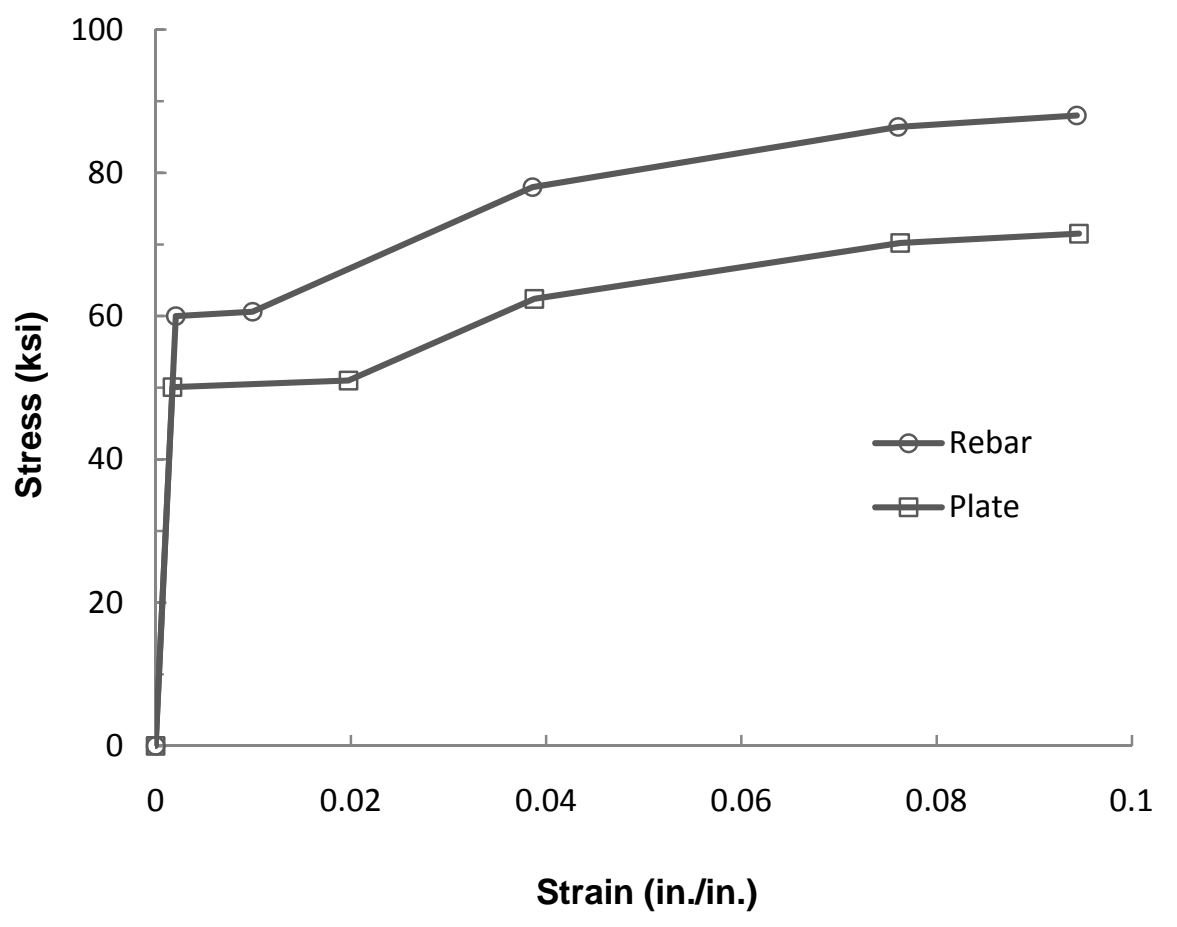

Figure 3.3 Stress-strain behavior of steel 


\subsubsection{Concrete}

\subsubsection{Compressive strength}

The concrete deck of the full-scale test bridge was constructed using TxDOT class-S-type concrete, which has a specified 28-day strength of 4,000 psi. To determine concrete strength as a function of time for the full-scale bridge tested at FSEL, concrete cylinder specimens from the deck and railings were tested at various intervals. The average compressive strength obtained from the concrete cylinder test is plotted in Figure 3.4. Totally 63 specimens ( 42 specimens for the deck concrete and 21 specimens for the railing concrete) were used for the concrete cylinder test. Among these specimens, 26 specimens (18 specimens of the deck concrete and 8 specimens of the railing concrete) were utilized to investigate the 28-day concrete strength, and 25 specimens (17 specimens of the deck concrete and 8 specimens of the railing concrete) were utilized to evaluate the concrete strength at the time of the first bridge fracture test, and 12 specimens ( 7 specimens of the deck concrete and 5 specimens of the railing concrete) were utilized for the concrete strength evaluation of the second bridge fracture test. The deck concrete was cast on 17 August 2006, and the railing was cast on 24 August 2006. Sixty-six days after the deck was cast, the first full-scale bridge fracture test was done, and the second bridge fracture test was conducted 293 days after placing the concrete for the deck. As shown in Figure 3.4, the railing concrete strength was slightly higher than the deck concrete strength. For simplicity, however, a single concrete strength value was used to model both the deck and the railing in the bridge fracture test simulations: 5,370 psi in the first test simulation and 6,230 psi in the second test simulation. The third bridge fracture test was performed in March 2009. Although the concrete strength at that time would most probably be slightly higher than the strength at the time of the second test due to concrete aging effects, the same concrete strength of 6,230 psi was utilized for this 
test simulation because specific test data on concrete strength were not available. Concrete strength gain is typically very small after the first year; therefore the additional strength gain achieved following the second test was not expected to be significant.

In general, the concrete strength specified in the construction of bridge elements is typically based on the 28-day value-though some states specify the concrete strength corresponding to an age of 56 days (Russell et al., 2003). In practice, the specified concrete strength of bridge components typically ranges between 4,000 psi and 8,000 psi (Russell et al., 2003). To accurately account for the aging effect of concrete components in a bridge simulation model, detailed strength data as a function of time would be needed. Collecting such data, however, would not be practical. Instead, the equation (for concrete comprised of Type I cement and moist-cured at $70 \mathrm{~F}^{\circ}$ ) proposed by $\mathrm{ACI}$ Committee 209 (1982) can be used to estimate the strength gain of concrete as a function of time:

$$
\begin{gathered}
f_{c}^{\prime}(t)=f_{c}^{\prime}(28)\left[\frac{t}{4+0.85 t}\right] \\
\text { where } f_{c}^{\prime}(t)=\text { concrete compressive strength at age } t(\mathrm{ksi}) \\
t \quad=\text { curing time (day) }
\end{gathered}
$$

In the current study, when simulating the response of the bridge tested at FSEL, the most accurate material properties available were used in the simulation model. In most cases, these values were directly measured in laboratory tests; in some cases, however, they were estimated based on available data. Conversely, when evaluating the redundancy of other bridges, it was conservatively assumed that concrete components 
had a strength of 4,000 psi, which was the lowest specified strength of concrete reported by Russell et al. (2003). In addition, expected strength increases with time were not included. These assumptions were made to ensure conservative estimates of the overall load carrying capacity of twin steel box-girder bridges that suffer a full-depth fracture of one of its girders.

Concrete compressive strengths were also used to specify hardening rules in tension and compression. A hardening curve in compression was constructed using Equation 3.2 as suggested by Hognestad (1951), and the initial stiffness of the stressstrain curve in compression was used to define the tensile behavior.

$$
f_{c}=f_{c}^{\prime}\left[\frac{2 \varepsilon}{\varepsilon_{o}}-\left(\frac{\varepsilon}{\varepsilon_{o}}\right)^{2}\right]
$$

$$
\begin{aligned}
\text { where } f_{c} & =\text { concrete compressive stress at given strain }(\mathrm{ksi}) \\
f_{c}, & =\text { concrete compressive strength }(\mathrm{ksi}) \\
\varepsilon & =\text { strain } \\
\varepsilon_{0} & =\text { strain at maximum stress }
\end{aligned}
$$




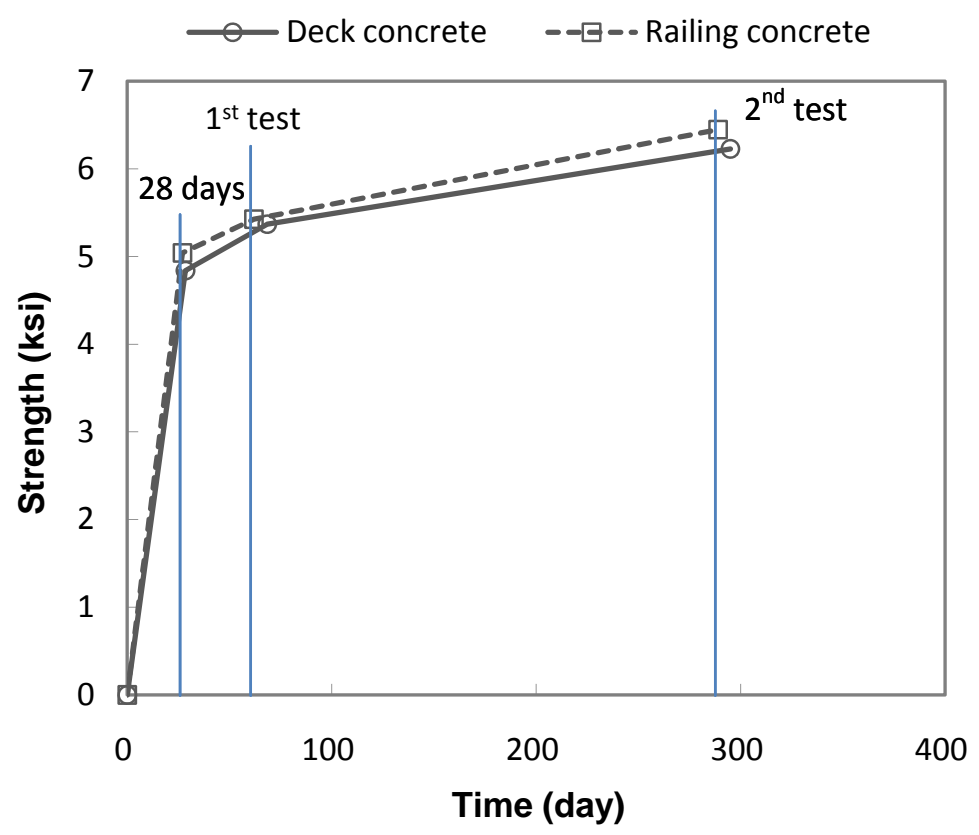

Figure 3.4 Concrete strength gaining

\subsubsection{Concrete smeared cracking}

The concrete deck and rails were modeled using 8-node solid elements. To account for the inelastic behavior of concrete, such as tensile cracking and compressive crushing, ABAQUS/Standard (v6.7) provides a concrete smeared cracking model and a concrete damaged plasticity model. The latter model is appropriate for cases in which high confining pressures exist, while the former model is appropriate for problems with low confining pressures (Dassault Systemes, 2007a). For the concrete deck of a twin steel box-girder bridge, high confining pressures are not expected due to the fact that the thickness of the deck is much smaller than the width and the length and because the axial restraint in the plane of the deck is limited. For this reason, the concrete smeared cracking model was initially adopted to simulate the response of the full-scale bridge tested during this research. 


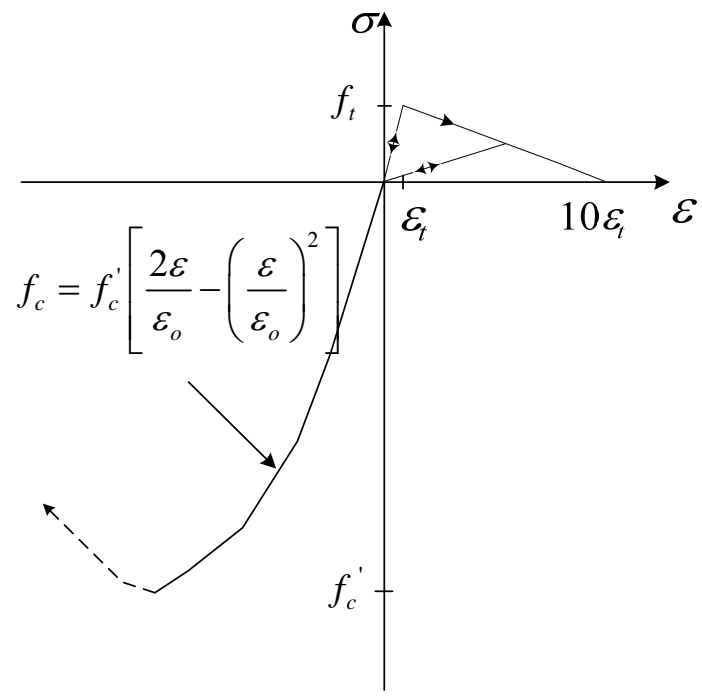

(a) Stress-strain behavior (under uniaxial force)

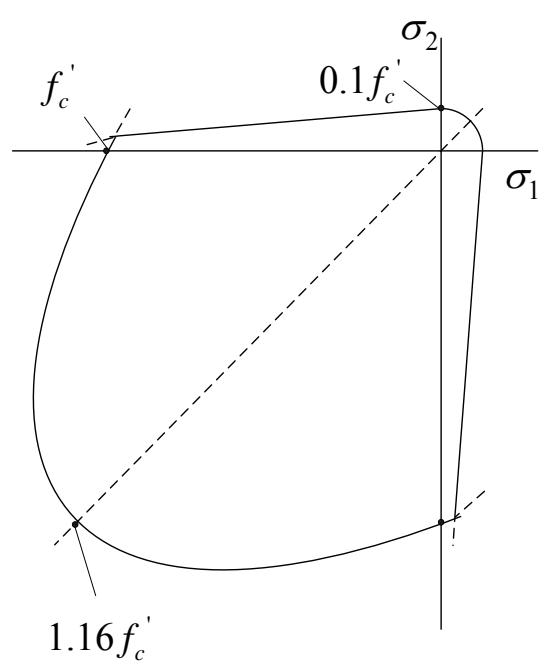

(b) Yield surface

Figure 3.5 Material behavior in concrete smeared cracking model

Various aspects of material response must be defined when utilizing the concrete smeared cracking model, including the compressive behavior, the post-tension failure behavior, the failure ratios needed to define a yield surface, as well as several other parameters. Figure 3.5 shows the uniaxial stress-strain curve and the yield surface associated with the concrete smeared cracking model.

Finite element models that utilize the concrete smeared cracking model are known to produce results that are sensitive to mesh density (Dassault Systemes, 2007a). Therefore, concrete element size in the plane of the concrete deck was determined such that each element contained reinforcing steel because mesh sensitivity tends to be reduced by the interaction between reinforcing steel and concrete (Dassault Systemes, 2007a). Other parameters affecting the accuracy of the computed results, including material properties and element size though thickness of the deck, were calibrated using 
finite element simulations of lab tests on a small deck model that represented a portion of the full-scale bridge deck.

The small deck model, as shown in Figure 3.6(a), was developed based on the expected deck deflection behavior in a damaged bridge. With one girder fractured, as assumed for the redundancy evaluation, the bridge deck would initially bend transversely in double curvature to transfer loads from the fractured girder to the intact girder, as shown in Figure 3.6(b). When the deck deflects in double curvature, an inflection point results approximately at the mid-section of the deck between the two girders, and tension forces act on the shear studs of the fractured girder due to the bending of the deck. Figure 3.7 shows a small deck test specimen and a finite element simulation model used to represent the assumed bending response of the deck following the fracture of one girder. The small deck tests, also referred to as stud pull-out tests herein, were conducted by Sutton (2007) and Mouras (2008) as part of the research program. From their tests, the load-displacement response of small deck specimens and the tensile strengths of shear stud connections were obtained, and the measured data were used to calibrate the small deck finite element models. 

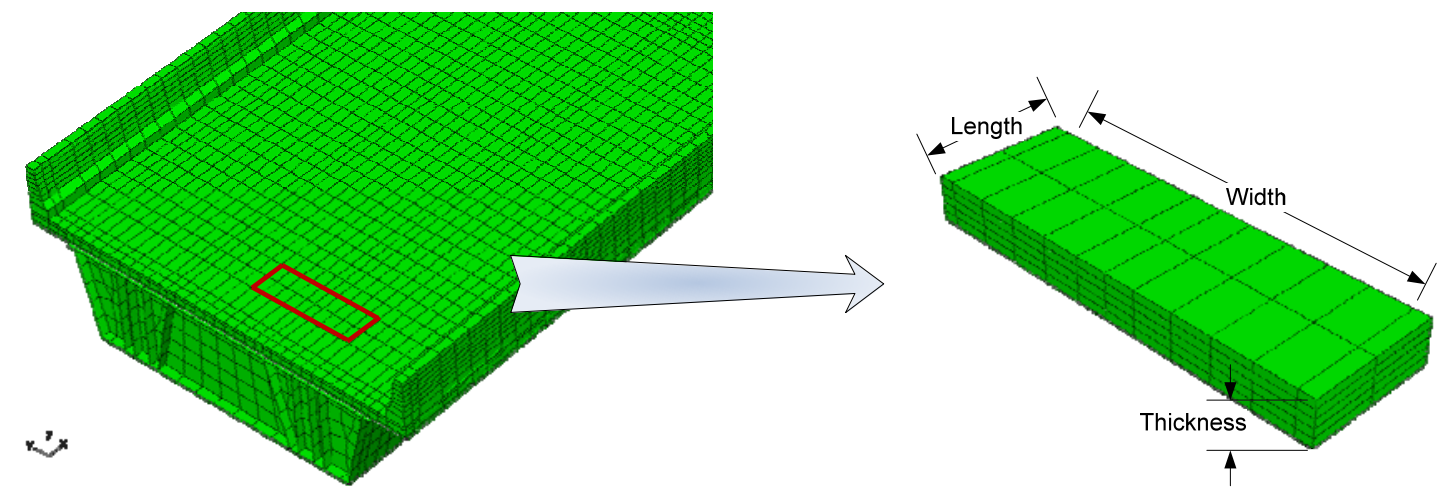

(a) Small deck portion in full-scale bridge for small deck model

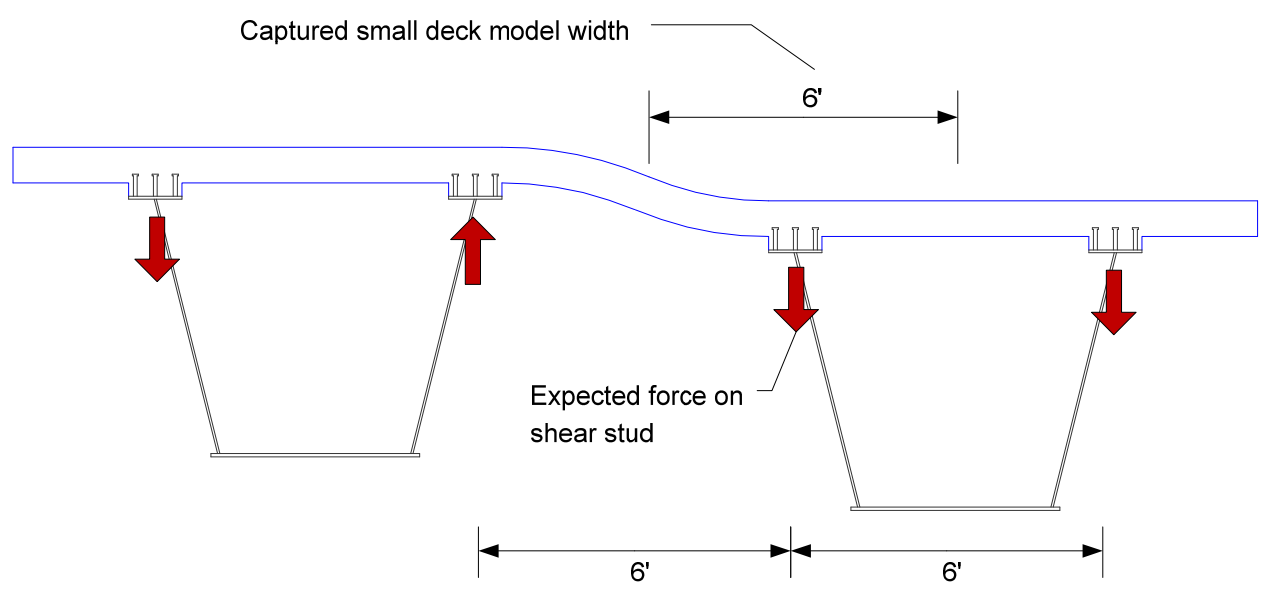

(b) Expected deformed shape in bridge cross-section

Figure 3.6 Small deck model to calibrate bridge concrete slab 


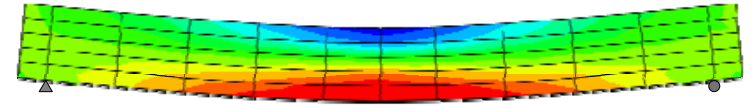

Downward displacement loading

(a) Finite element model

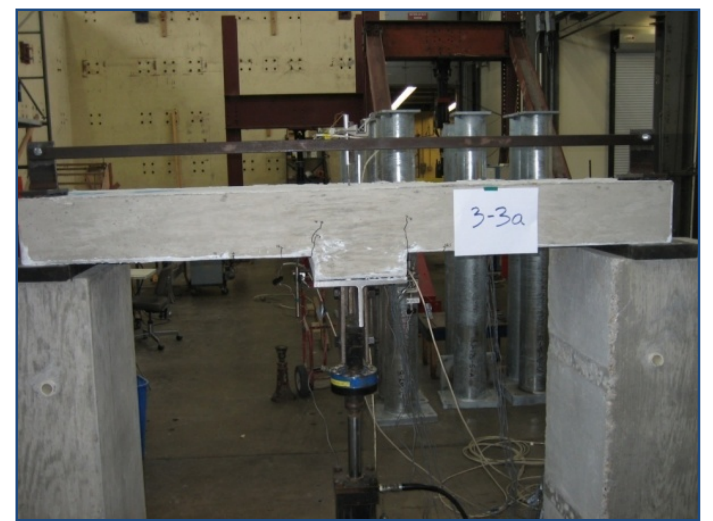

(b) Test setup (Sutton, 2007)

Figure 3.7 Deck load-deflection test and simulation

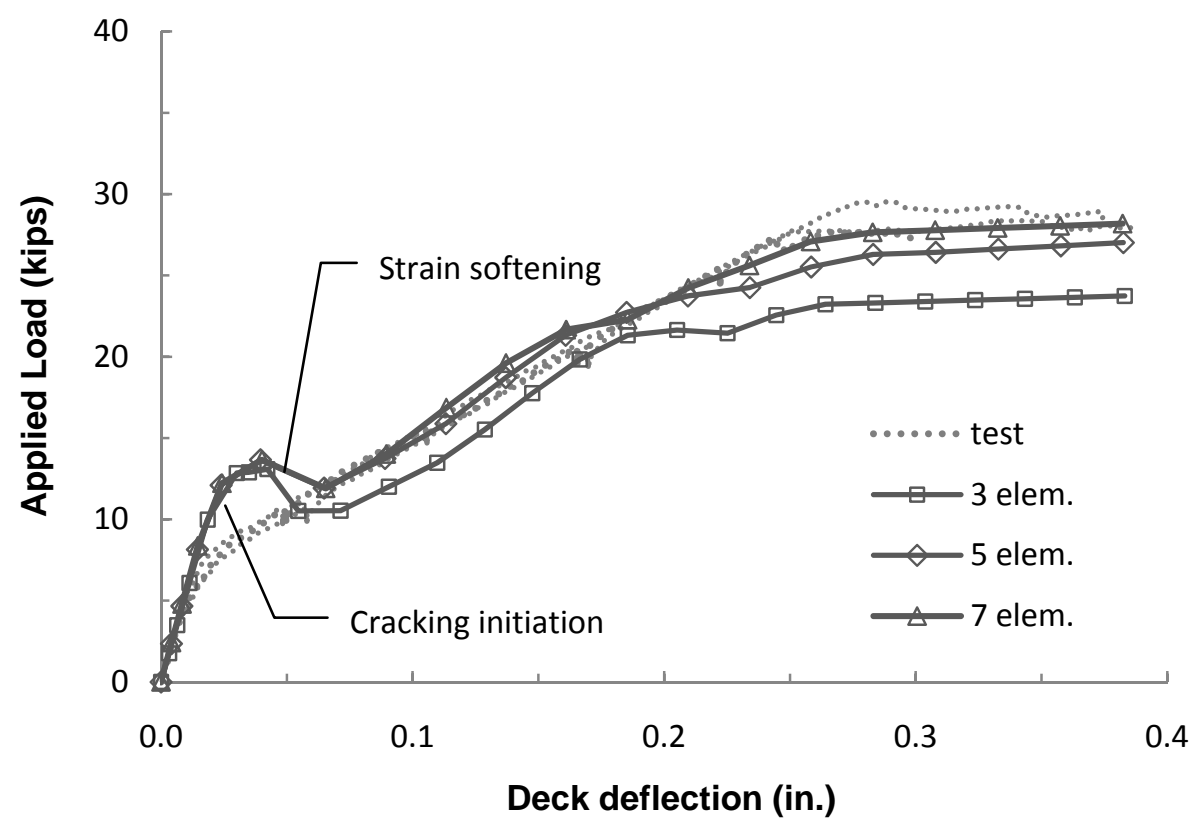

Figure 3.8 Deflection behavior of small deck (concrete smeared cracking) 
Figure 3.8 compares measured load-displacement data from a laboratory test on a small deck specimen with results obtained from finite element simulations. The assumed tensile strength of the concrete for the simulations was $10 \%$ of the average concrete compressive strength, which was 5,100 psi for the small deck test specimen. To define the stress-strain behavior beyond the cracking strain, it was assumed that the stress reduces linearly to zero, where the total strain at zero stress was 10 times the cracking strain, as shown in Figure 3.5(a). This post-cracking stress-strain relationship is also referred to as strain-softening behavior (Dassault Systèmes, 2007a). The number of elements in the finite element model was 10 along the width and two along the length, in Figure 3.6(a). The prominent behavior demonstrated by the small deck simulation models, as shown in the Figure 3.8, was a reduction in bending stiffness near 15 kips loading, which was initiated by concrete element cracking at the bottom of the deck near the midspan. The reduced bending stiffness of the deck models eventually became negative because of the assumed post-failure stress-strain relationship (i.e., strain softening).

In addition to the strain softening, the number of elements through the thickness of the deck also affected the stiffness of the simulation models. In Figure 3.8, the deck model with three elements through the thickness shows a higher rate of stiffness reduction after the bottom of the deck cracked than did the other cases with five or seven elements. This tendency could be a result of the different rates of bending stiffness loss depending on the element size of the small deck models. Once the stress in one translational direction of an element exceeds the cracking strength, the element loses its resistance entirely in that stress direction. Therefore, a more gradual reduction in bending stiffness can be achieved as the number of elements through the thickness of a deck model is increased. According to the small deck simulation results, 10 elements along the 
deck width and five elements through the deck thickness resulted in good agreement between the measured and the predicted load-displacement response of the specimens.

The same mesh density and material parameters obtained from the small deck simulations were utilized to construct the concrete deck of the full-scale bridge finite element model. The finite element simulation of the full-scale bridge with the assumed damage and loading conditions for the redundancy evaluation, however, was unable to run to completion due to a numerical instability associated with the concrete deck response. Such instability was initiated by local cracking failures in the deck, which eventually caused convergence problems in the very early stages of the analysis as the cracks on the top of the deck extended longitudinally from the midspan of the bridge. In the smeared concrete cracking model, a cracking failure of concrete initiates strainsoftening behavior. Usually, conducting a finite element analysis allowing for softening behavior with a force-controlled loading procedure is numerically challenging, which sometimes requires excessive computation time and frequently terminates prior to completion due to numerical convergence problems (Dassault Systemes, 2007a).

\subsubsection{Cast iron plasticity}

As a result of the convergence problems encountered with the initial finite element simulations of the full-scale bridge, the cast iron plasticity model was investigated to determine if it could provide suitably accurate predictions of response without encountering the numerical difficulties that resulted when using the concrete smeared cracking model. While it would seem that a constitutive model based on a metal plasticity formulation would be an inappropriate choice for modeling concrete material, the cast iron plasticity formulation includes several features that make it well suited for the current application. Most importantly, the cast iron plasticity model is able to 
represent different strengths for tension and compression. To do so, the cast iron plasticity model utilizes a composite yield surface, and it is assumed that tension yielding is governed by a maximum principal stress and that compression yielding is governed by deviatoric stresses (Dassault Systemes, 2007b).

Figure 3.9 shows the uniaxial behavior and the yield surface of the cast iron plasticity model, which was used to model concrete material behavior in this study. Basically, the model has a von Mises-type yield surface, but it is truncated by a Rankine fracture criterion to incorporate a reduced yield strength in tension. Under a plane stress state, the von Mises yield surface has an elliptical shape, and the Rankine yield surface is a square (Ugural, 1995). Figure 3.9(b) depicts the resultant yield surface under a biaxial stress state. This yield surface has a shape similar to that of the concrete smeared cracking model under the biaxial stress state, as shown in Figure 3.5(b).

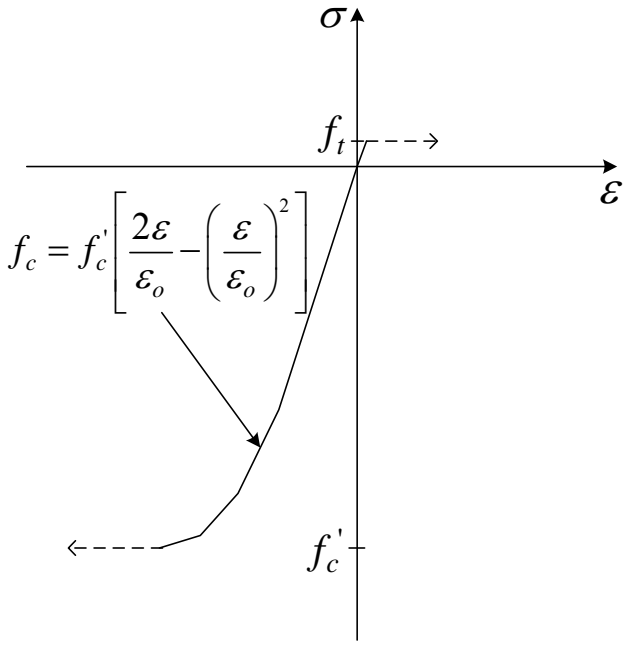

(a) Stress-strain behavior

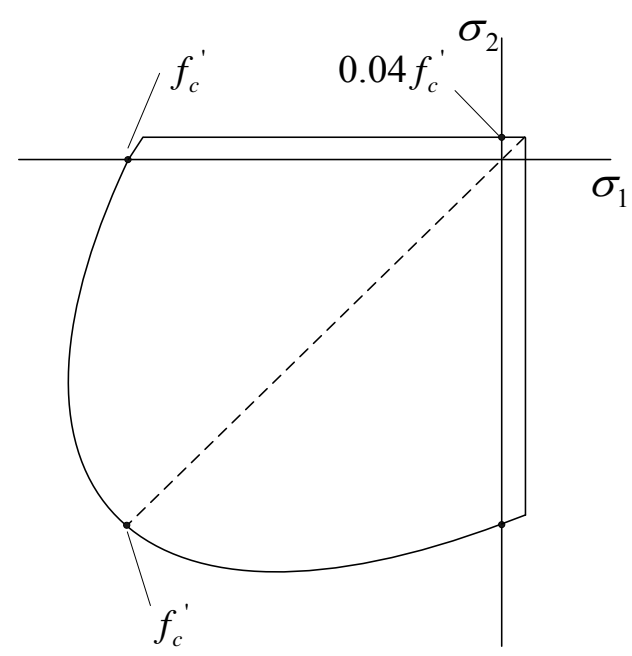

(b) Yield surface

(under uniaxial force)

Figure 3.9 Material behavior in cast iron plasticity model 


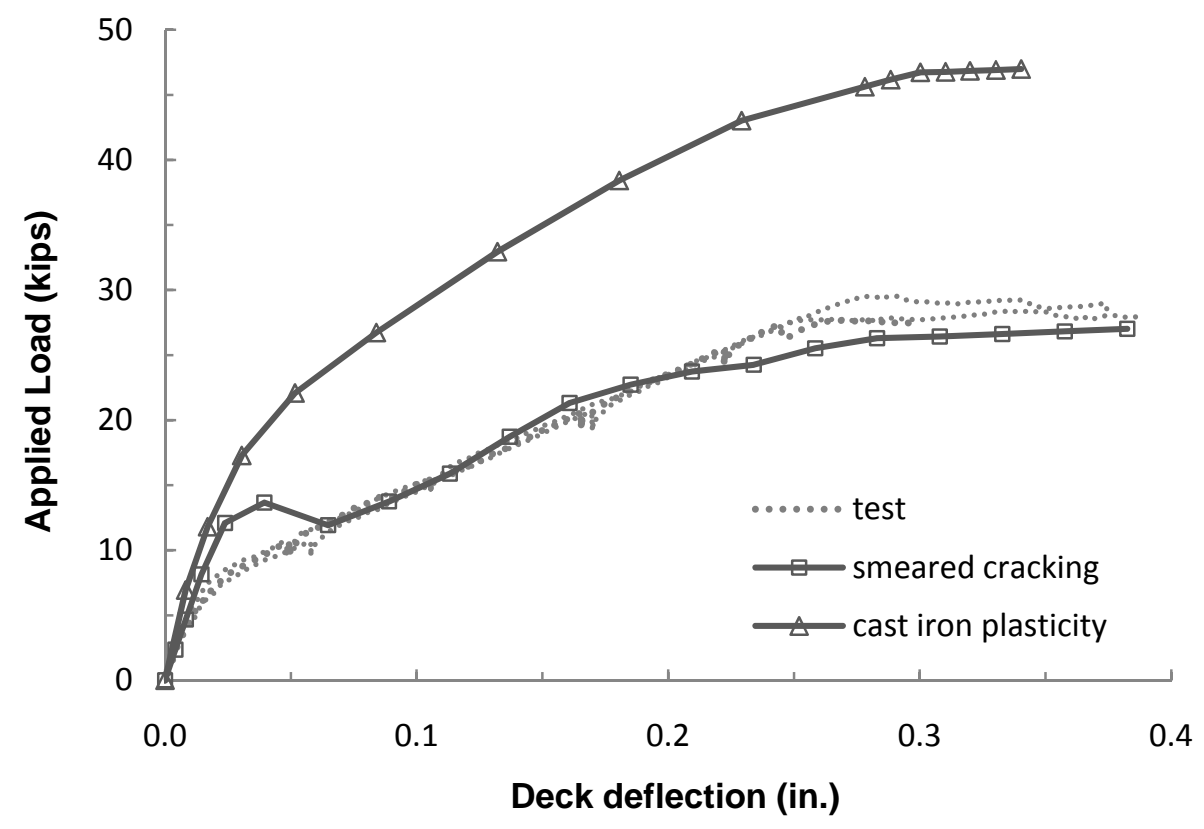

Figure 3.10 Deflection behavior of small deck (cast iron plasticity)

As mentioned previously in Section 3.3.2.2, the material parameters and the mesh density are important factors that can affect the computed finite element analysis results. With the cast iron plasticity model, the primary material parameters that define the yield surface are the compressive strength and the tensile strength. The assumed post-yielding behavior in both tension and compression is perfectly plastic, which is a less severe condition numerically than the strain softening of the concrete smeared cracking model. To determine an appropriate value for the tensile strength of this inelastic material model, finite element simulations of the small deck tests were conducted, and the deflection response of the simulations was compared with the test results. Figure 3.10 shows the simulated load-deflection behavior of the small deck models along with measured test data. The number of elements used in the simulation was 10 along the deck width and five across the deck thickness, and cracking was assumed to occur at $10 \%$ of the 
compressive strength for both concrete material models. As expected, because of the post-yielding stress-strain behavior, the deck model utilizing the cast iron plasticity model was stiffer than that of the concrete smeared cracking model.

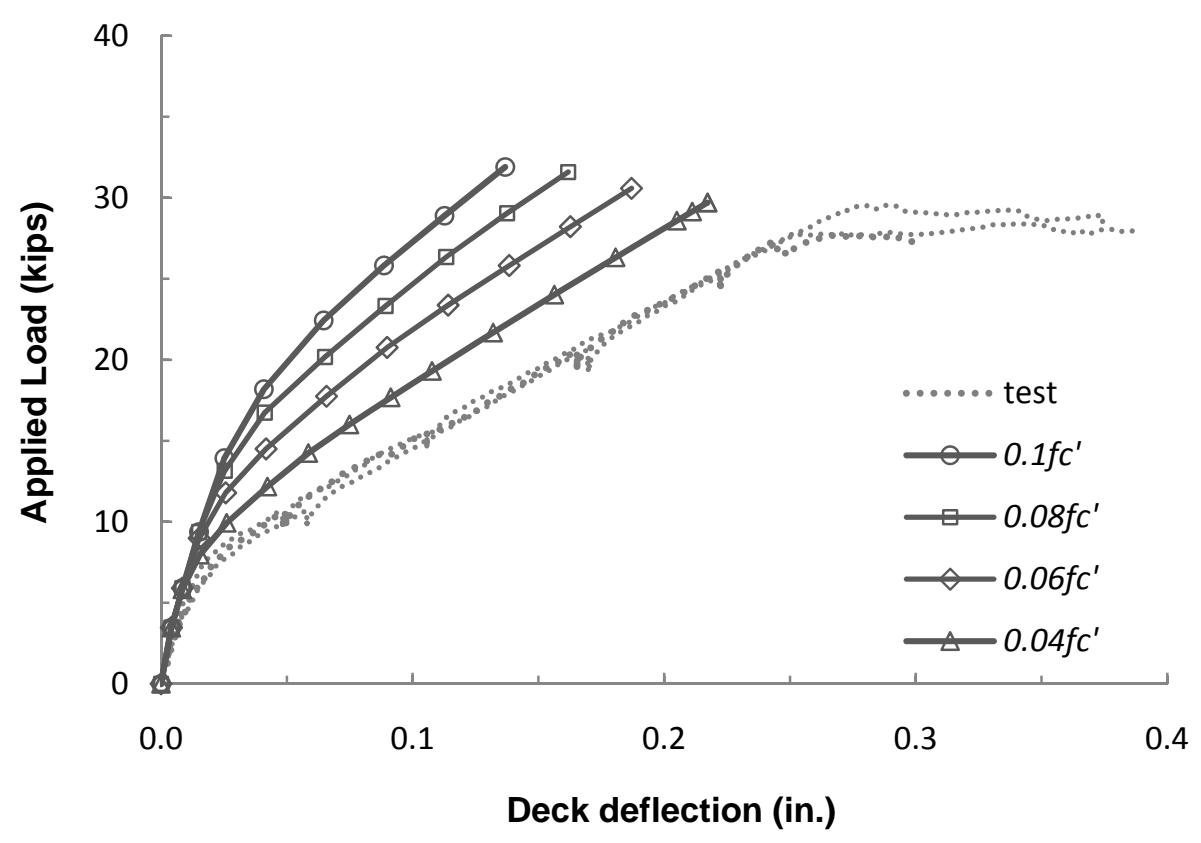

Figure 3.11 Tensile strength effect on deck deflection response

In order to match the measured deflection behavior of the small deck model using cast iron plasticity, the tensile strength and the number of elements through the thickness were varied. Figure 3.11 shows the analysis results of a parametric evaluation that considers various concrete tensile strengths for models utilizing five elements through the thickness of the concrete deck. The investigated range of tensile strengths was $4 \%$ to $10 \%$ of the compressive strength: $0.04 f_{c}^{\prime}, 0.06 f_{c}^{\prime}, 0.08 f_{c}^{\prime}$, and $0.1 f_{c}^{\prime}$. Even with the tensile strength reduced to $4 \%$ of the compressive strength, the small deck finite element model showed a stiffer deflection response than the measured test results. Reducing the tensile 
strength further caused numerical instability during the analysis. Therefore, it was decided to decrease the number of elements through the thickness of the small deck model from five to three because the bending stiffness of the deck model tended to decrease as the number of elements through the thickness diminished, as discussed in the small deck simulations with the concrete smeared cracking model.

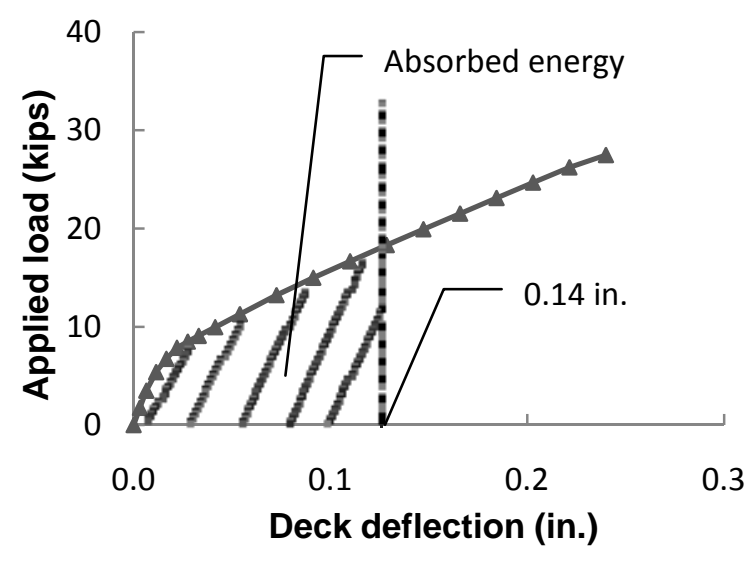

(a) Deck model with cast iron plasticity

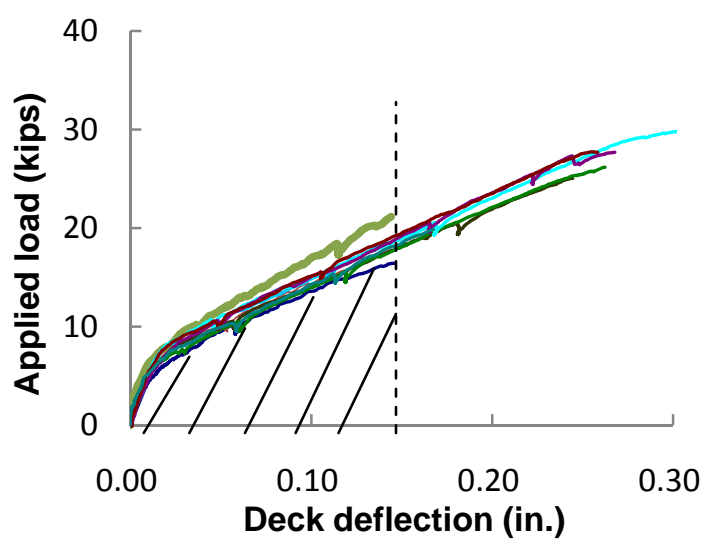

(b) Small deck test results

Figure 3.12 Deck top deflection vs. tension force

Using three elements through the thickness of the small deck finite element model, four different tensile strengths were considered for investigating the sensitivity of the computed results to this parameter. Rather than focusing entirely on the loaddeflection response at individual points, absorbed energy (defined as the area under the load-deflection curve) was used to compare the computed results with the measured results as depicted in Figure 3.12. With this approach, while there may be slight variations in the localized behavior computed in the small deck model response, overall behavior would be considered to be in good agreement if the absorbed energy compared 
well between the tests and the simulations. For this particular study, a limiting deflection of 0.14 in. was used when computing the absorbed energy. This value was selected based on an analysis of the simulation results and the collected test data; thus, it was felt that 0.14 in. of displacement was large enough to capture significant nonlinear behavior in the deflection response over a wide range of possible tensile strengths as shown in Figure 3.11. This figure shows that the initial large change in slope of the load-deflection curve occurs when the stresses in the elements at the bottom of the deck reach their tensile capacity as a result of bending in the specimen. Another slope change occurs when the loading is approximately equal to $30 \mathrm{kips}$, which is due to the breakout failure of concrete surrounding a shear stud. This phenomenon, however, was taken into account by the mechanical behavior of the connector elements that were incorporated into the model to represent a shear stud embedded into the deck through a haunch. Thus, for the purposes of evaluating the concrete model, a limiting deflection of 0.14 -in. was selected so that the computed response, at least for the cases of tensile strength considered, would remain less than the tensile capacity of the shear stud connections in the model. A detailed discussion of the connector element behavior is presented in Section 3.3.3.

Figure 3.13 shows the differences in the absorbed energy between the finite element simulations and the experimental results. The differences in absorbed energy were normalized by the average absorbed energy obtained from the test data. When the tensile strength of the cast iron plasticity model was lowered to $4 \%$ of the compressive strength, the normalized energy difference between the simulation results and the test data became only $0.29 \%$. 


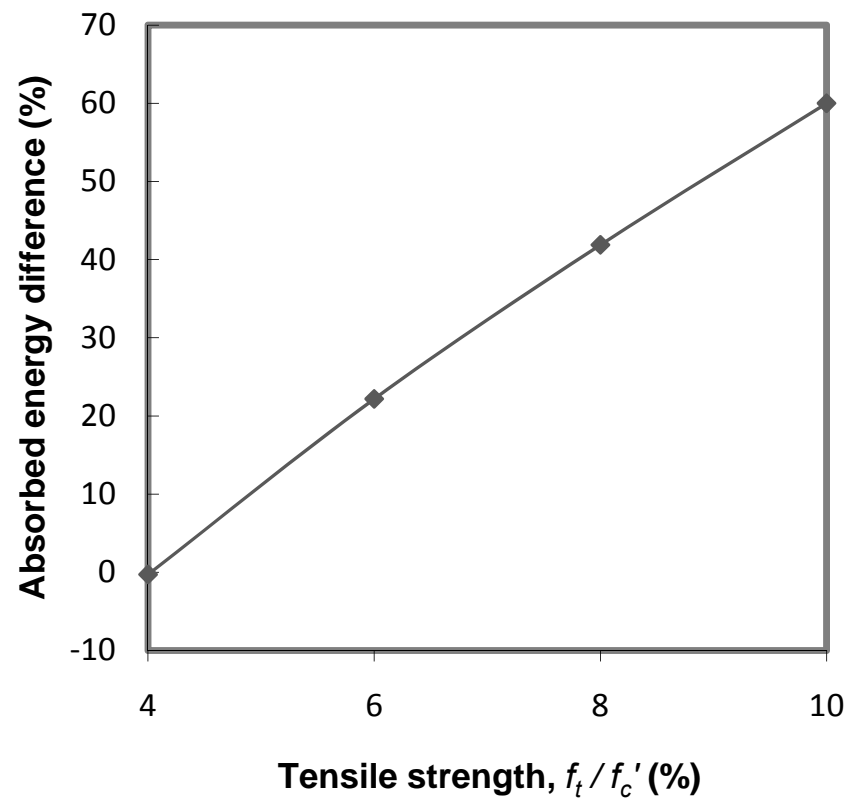

Figure 3.13 Normalized energy difference between tests and FE analysis

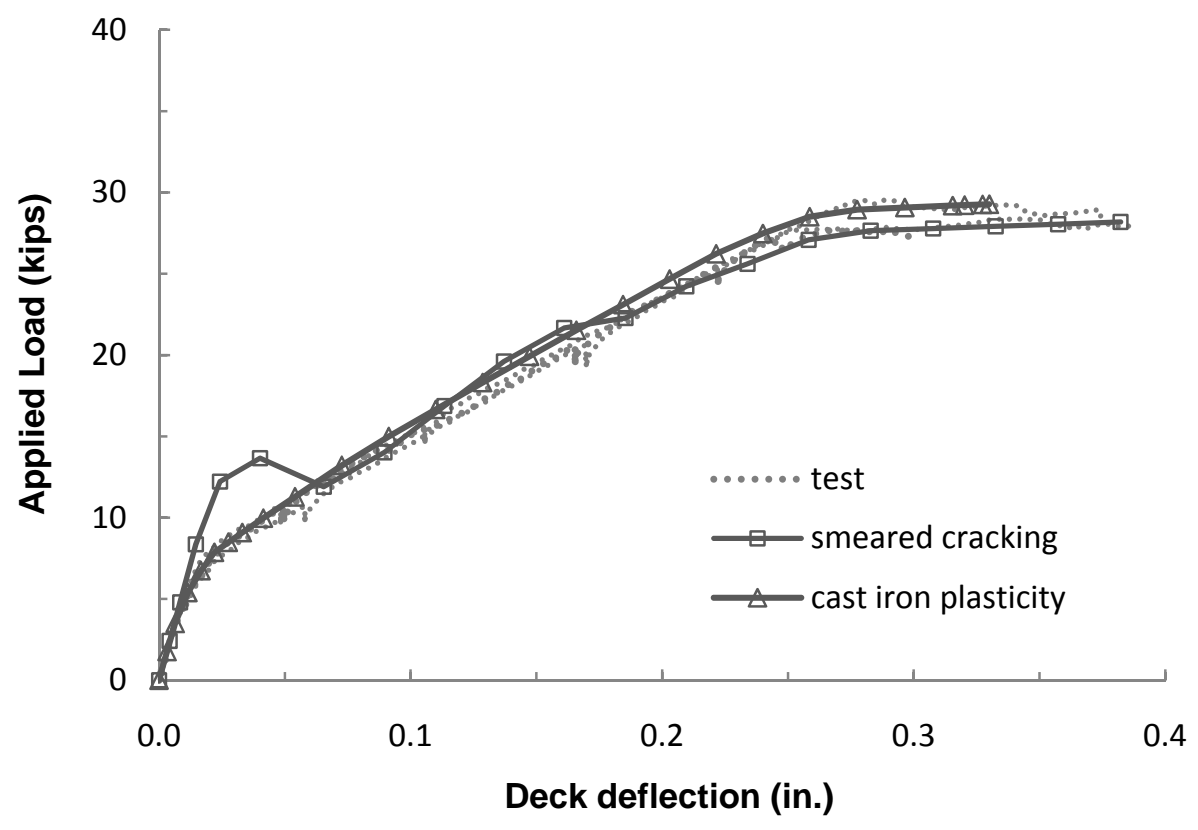

Figure 3.14 Deflection behavior of calibrated cast iron plasticity deck model 
Figure 3.14 shows the deck deflection response of the small deck model using this tensile strength and the mesh density described above (i.e., three elements through the thickness). Its general deflection response shows excellent agreement with the test results. Therefore, the tensile strength was assumed to be $4 \%$ of the compressive strength for the concrete material used in the finite element simulations, and this tensile strength was also used to construct full-scale bridge models. As stated previously, the small deck simulation results were affected not only by material parameters such as the tensile strength but also by the mesh density of the model. Furthermore, the tensile strength and mesh density for the full-scale bridge model were selected based on the particular bending behavior observed in the damaged twin box-girder bridge tested during this research project. Therefore, the tensile strength and the mesh density selected for this research may not be suitable for other types of bridge slabs or concrete structures.

\subsubsection{Shear stud and haunch}

A haunch as shown in Figure 3.2(b) is typically used in bridge construction to help maintain a uniform thickness of the concrete deck. One potential drawback with the

use of a haunch, particularly as it relates to the current study, is that it can reduce the penetration length of a shear stud into the deck. Such reduced penetration of the stud could limit the available shear and tensile capacity of the connection between the concrete deck and the steel girders. For this reason, the AASHTO LRFD Specification (2007) requires that shear connectors penetrate at least 2 in. into the deck, and the TxDOT Bridge Detailing Manual (2001) limits the maximum haunch height to 3 in. when there is no reinforcement in the haunch region.

Shear studs installed on the top flange of a steel box girder provide a mechanical connection between the girders and the concrete deck for the primary benefit of 
transferring horizontal shear forces. The transfer of these shear forces leads to the development of composite action between the steel girders and the concrete deck. Chemical bonding and friction between the top flange of a girder and the deck might also provide limited load-transferring capability, but they were not considered in this study due to their limited strength and the uncertainty in computing their contributions. Therefore, only mechanical interaction between the shear studs and the concrete deck were considered in the finite element bridge models developed for this research.

In the redundancy evaluation of a twin steel box-girder bridge, the assumed damage level was the full-depth fracture of one of the girders (i.e., fracture of the bottom flange and webs of one girder). Once the assumed damage was induced to the bridge finite element model, the shear studs could be required to carry significant tension forces due to the self-weight of the steel girder and the transverse bending of the concrete deck resulted from the fracture. If the tension force in the studs becomes too large, it could cause a tensile failure to occur between the concrete deck and the steel box girders. Such a failure might be attributed to yielding of the stud or breakout of the concrete. Therefore, bridge models were constructed in such a way that connector elements imitating the stud connections could capture the tension failure behavior. Mechanical properties and failure mechanisms of the connector elements are detailed in the following paragraphs.

\subsubsection{Shear strength and load-slip behavior}

Topkaya (2002) investigated the ultimate shear strength and load-slip behavior of shear studs experimentally. Based on push-out tests, he proposed the ultimate shear strength $Q_{u}$ and the load-slip relationship $Q$ as follows: 


$$
Q_{u}=2.5 A_{s c}\left(f_{c}^{\prime} E_{c}\right)^{0.3}
$$

Equation 3.3

$$
\begin{aligned}
& \text { where } \begin{aligned}
& A_{s c}\left.=\text { cross-sectional area of shear stud (in. }{ }^{2}\right) \\
& f_{c} \quad=\text { concrete compressive strength }(\mathrm{ksi}) \\
& E_{c} \quad=\text { elastic modulus of concrete }(\mathrm{ksi}) \\
& Q=Q_{d} \frac{3\left(\frac{\Delta}{0.03}\right)}{1+2\left(\frac{\Delta}{0.03}\right)}
\end{aligned}
\end{aligned}
$$

$$
\text { where } \begin{aligned}
\Delta & =\text { slip of shear stud (in.) } \\
Q_{d} & =\text { shear load at } 0.03 \text { in. displacement (kip) }
\end{aligned}
$$

$Q_{d}$ is defined as the shear load where the shear displacement becomes $0.03 \mathrm{in}$., and the suggested empirical equation is as follows:

$$
Q_{d}=1.75 A_{s c}\left(f_{c}^{\prime} E_{c}\right)^{0.3}
$$

In the full-scale test bridge, three 5-in. long and 7/8-in. diameter shear studs were installed in a row transversely on the girder top flanges. For simplicity, the three studs were modeled with a single connector element to represent the group. For example, the compressive strength of concrete used in the second and third bridge test simulations was $6.23 \mathrm{ksi}$; thus, the modulus of elasticity of concrete for this case is 4,500 ksi from Equation 3.6, which is based on the guidelines in ACI Section 8.5.1 (ACI 318-08). 


$$
E_{c}=57000 \sqrt{f_{c}^{\prime}}
$$

Equation 3.6

Equation 3.6 is empirically based, and the values of $E_{c}$ and $f_{c}^{\prime}$ must be expressed in psi.

Because the shear stud diameter was $7 / 8$ in. and three studs were grouped as one connector element, the total area of shear studs is 1.325 in. $^{2}$, and the ultimate strength is 97.38 kips according to Equation 3.3. $Q_{d}$ is 68.16 kips according to Equation 3.5. Inserting this value into Equation 3.4, the shear load-slip relationship can be obtained, and it is plotted in Figure 3.15. Beyond 0.3-in. displacement, where the maximum shear strength is reached, perfectly plastic behavior was assumed in this study. This shear loadslip relationship was utilized to define the horizontal response of connector elements used to represent shear studs at the interface between the steel flanges and the concrete deck.

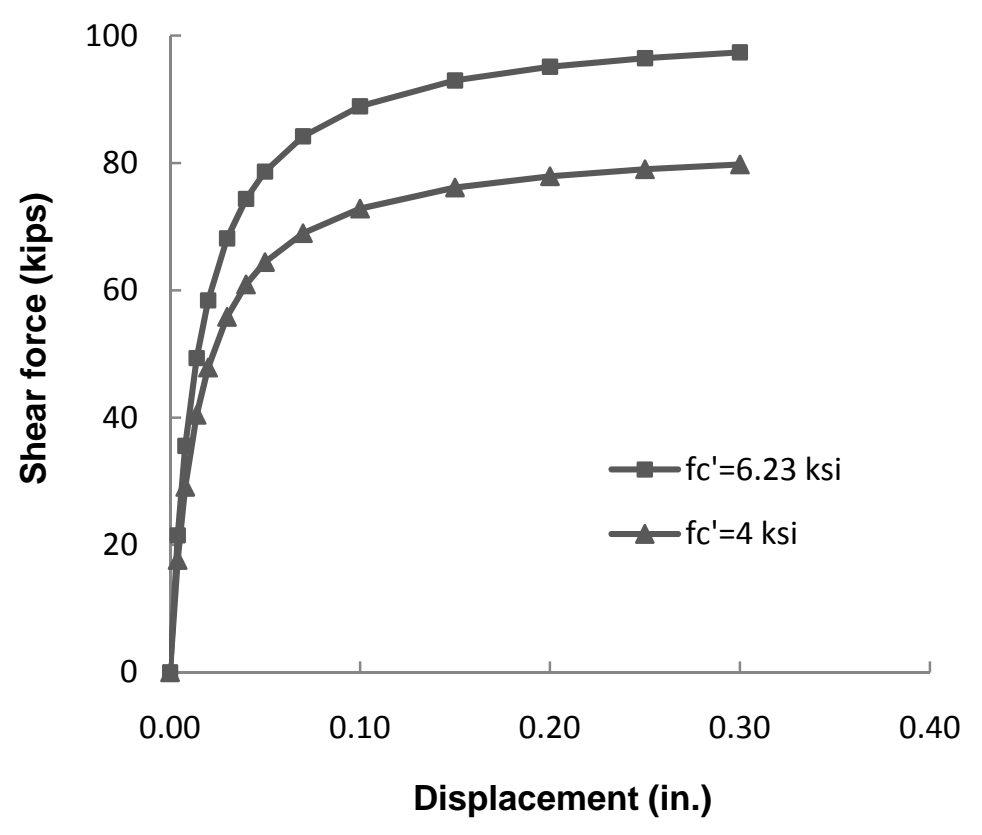

Figure 3.15 Shear force vs. stud slip 


\subsubsection{Tensile strength and load-deflection behavior}

Sutton (2007) and Mouras (2008) studied the tensile strength of shear studs embedded in concrete decks under tension forces. As described in the previous section (Section 3.3.2.2), they used small deck specimens that were capable of representing transverse bending of a concrete bridge deck between points of inflection. According to their test results, all specimens failed through concrete breakout (i.e., yielding of shear studs was not observed). The tensile strength varied depending on the presence of a haunch, the length of shear studs, the number of shear studs, and the arrangement of shear studs (i.e., longitudinally or transversely oriented). To quantify the tensile strength of shear studs embedded in a reinforced concrete deck, they used an ACI equation (ACI 318-08 Appendix D) developed for anchor strength under tension force. In the case of specimens with a haunch, tensile strengths calculated using the ACI equation did not agree well with the measured test data. The variation in measured and calculated values was attributed to the presence of a haunch in some specimens, which is not considered in the ACI equation. To account for the haunch effect on the tensile strength of shear stud connections, Mouras (2008) proposed the following modifications to the ACI equation:

$$
\begin{gathered}
N_{c b g}=\frac{A_{N c}}{A_{N c o}} \psi_{g, N} \psi_{e c, N} \psi_{e d, N} \psi_{c, N} N_{b} \\
N_{b}=k_{c} \sqrt{f_{c}^{\prime}}\left(h_{e f}{ }^{\prime}\right)^{1.5} \\
h_{e f}{ }^{\prime}=h_{e f}-h_{h} \geq \frac{w_{h}}{3}
\end{gathered}
$$

Equation 3.9 


$$
\begin{gathered}
\psi_{e d, N}=0.7+0.3 \frac{c_{a, \min }}{1.5 h_{e f}^{\prime}} \leq 1.0 \\
\psi_{e c, N}=\frac{1}{\left(1+\frac{2 e_{N}^{\prime}}{3 h_{e f}^{\prime}}\right)}
\end{gathered}
$$

where $N_{c b g} \quad=$ design concrete breakout strength of a stud or group of studs (lb)

$A_{N c} \quad=$ projected concrete failure cone area of a stud group $\left(=3 h_{e f} w_{h}\right.$ for $\left.w_{h} \leq 3 h_{e f}\right)\left(\right.$ in. $\left.^{2}\right)$

$A_{N c o}=$ projected concrete failure cone area of a single stud $\left(=9 h_{e f}{ }^{2}\right)\left(\right.$ in. $\left.^{2}\right)$

$\psi_{g, N} \quad=$ group effect modification factor

1 stud $\quad: 1.00$

2 studs spaced transversely $: 0.95$

3 studs spaced transversely $: 0.90$

Stud spaced longitudinally $\quad: 0.80$

$\psi_{e c, N}=$ eccentric load modification factor

$\psi_{e d, N}=$ edge distance modification factor

$\left(=1.0\right.$ for $\left.c_{a, \min } \geq 1.5 h_{e f}^{\prime}\right)$

$\psi_{c, N}=$ cracked concrete modification factor

Cracked concrete where a stud installed $\quad: 1.00$

Uncracked concrete

$N_{b} \quad=$ concrete breakout strength of a single isolated stud (lb)

$k_{c} \quad=24$ (cast-in-place shear studs) 


$$
\begin{aligned}
& h_{e f} \quad=\text { effective length of a shear stud in concrete - stud length } \\
& \text { excluding the stud head in concrete (in.) } \\
& h_{h} \quad=\text { haunch height (in.) } \\
& h_{e f}{ }^{\prime}=\text { effective stud length embedded into concrete } \operatorname{slab}\left(=h_{e f}\right. \text { - } \\
& \left.h_{h}\right) \text { (in.) } \\
& w_{h} \quad=\text { width of haunch in the cross-section of a bridge span (in.) } \\
& c_{a, \min }=\text { smallest edge distance measured from center of stud to } \\
& \text { the edge of concrete (in.) } \\
& e_{N}^{\prime} \quad=\text { eccentricity of resultant stud tensile load }
\end{aligned}
$$

To utilize Equation 3.7 for evaluating the tensile strength of a stud connection with a haunch, careful attention is needed in specifying the problem parameters because many components in the equation — such as projected failure cone areas $\left(A_{N C}\right.$ and $\left.A_{N c o}\right)$, concrete breakout strength of a single isolated stud $\left(N_{b}\right)$, and edge distance modification factor $\left(\psi_{e d, N}\right)$ - are affected by haunch geometries. In addition to those components, two more modification factors should be considered for the strength evaluation: cracked concrete modification factor $\left(\psi_{c, N}\right)$ and the group effect factor $\left(\psi_{g, N}\right)$. The tensile strength evaluation procedure proposed by Mouras can become computationally intensive due to the many factors required to be considered in the equation. Alternatively, a simplified modification of the ACI anchor strength equation developed by author can be used, which is available in APPENDIX A. In the proposed simplified modification method, only a haunch modification factor is required to be computed using Equation A.6 for evaluating the tensile strength of a stud connection with a haunch. This modification factor is then multiplied by the value computed using the original ACI equation. One example for a stud connection with three 5-in. studs is available in APPENDIX B. 


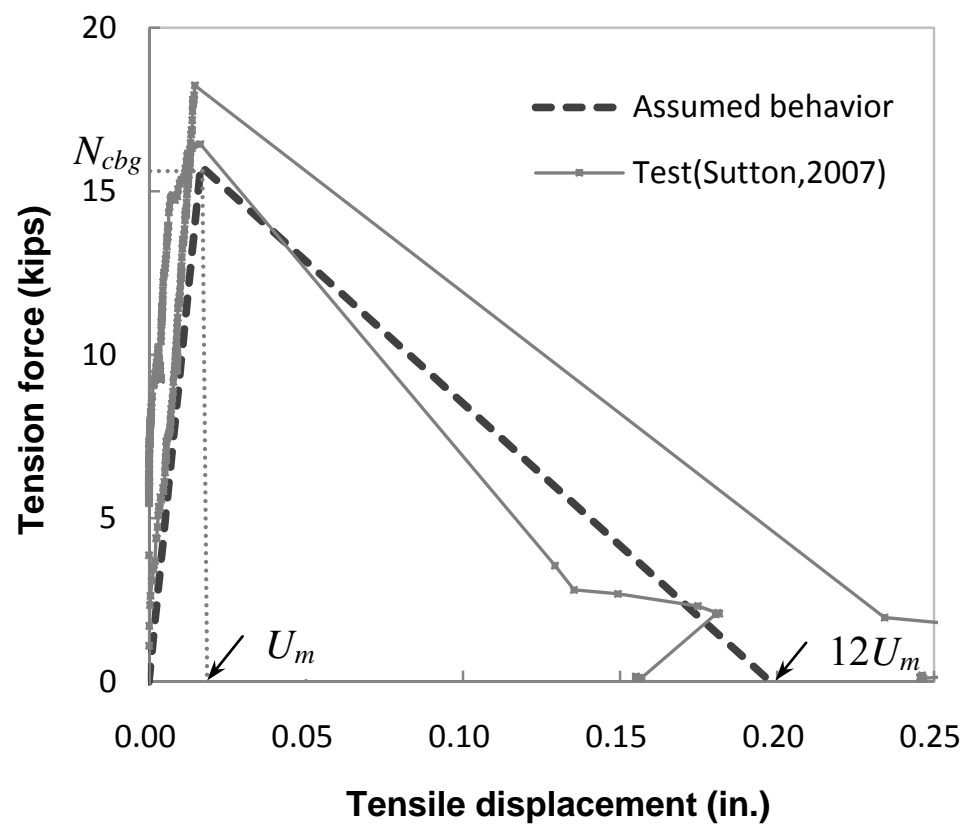

Figure 3.16 Tensile load-displacement behavior of stud connection

In addition to the maximum tensile strength of shear stud connections, loaddeformation data are needed to define the vertical behavior of connector elements under tension forces. Figure 3.16 shows a typical load-displacement response of shear studs in tension. The applied load in the load-displacement response is linearly proportional to the displacement until it reaches the tensile strength. Beyond the tensile strength, the load quickly drops because of a brittle concrete breakout failure. For simplicity, two lines were used to simulate the load-displacement response for the vertical behavior of the connector elements. The two lines were constructed using the displacement $U_{m}$ corresponding to the tensile strength and the maximum displacement corresponding to failure. The maximum displacement was selected to be 12 times $U_{m}$ to match the 
measured test data and to ensure a smooth change of the deflection curve so as to avoid a numerical convergence failure in the finite element analyses.

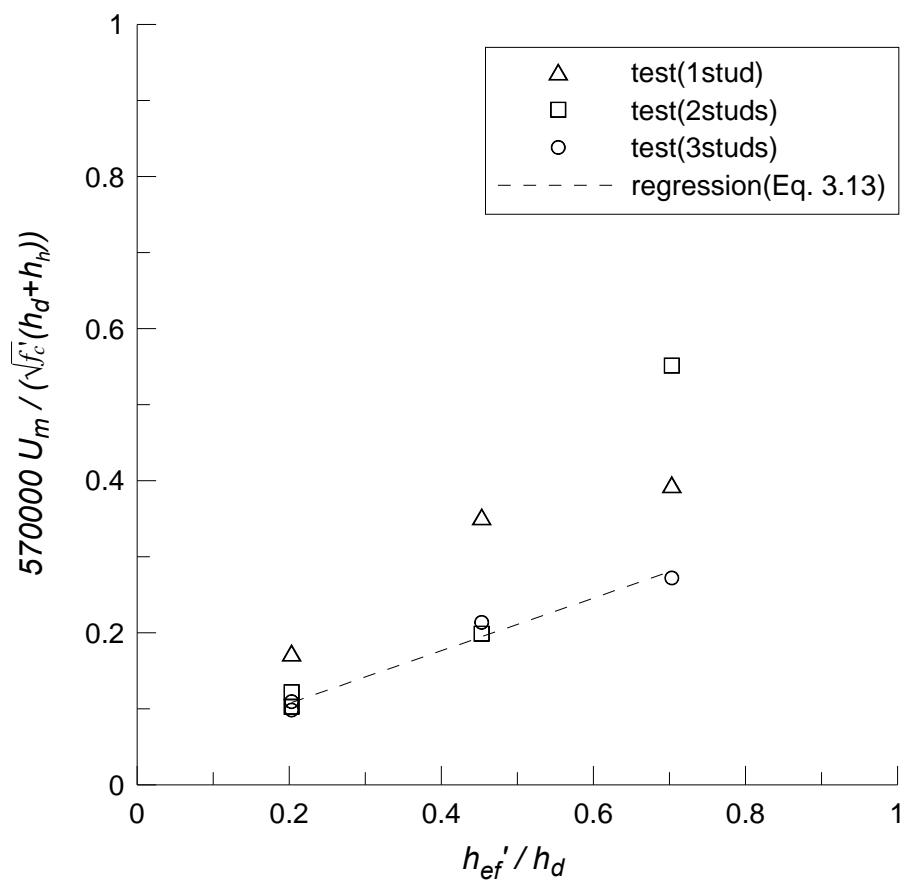

Figure 3.17 Displacement at tensile strength

To determine the value of $U_{m}$, a regression analysis of the data was conducted using the test results of Sutton (2007) and Mouras (2008). As shown in Figure 3.17, the displacement $U_{m}$ tends to increase as the effective stud length excluding the haunch height $\left(h_{e f}\right)$, normalized by the bridge deck thickness $\left(h_{d}\right)$, increases. The figure also shows some scatter depending on the number of studs installed in a row. Although the dependency of $U_{m}$ on the number studs in a row is not clear because of the limited amount of data available, specimens containing two studs in a row or one stud show higher deformation at the tensile strength than specimens with three studs. In this study, 
all bridges investigated - including the full-scale test bridge- had three studs in a row. Therefore, to reduce the uncertainty in the selection of $U_{m}$, the cases with two studs in a row or one stud were excluded from the regression analysis, and only cases with three studs were used to construct the haunch effect modification factor in Equation 3.13.

$$
\begin{gathered}
U_{m}=\frac{\sqrt{f_{c}^{\prime}}\left(h_{d}+h_{h}\right)}{570000} \psi_{h, U} \\
\psi_{h, U}=3.8+34.6 \frac{h_{e f}{ }^{\prime}}{h_{d}}
\end{gathered}
$$

$$
\begin{aligned}
& \text { where } U_{m} \quad=\text { relative displacement at tensile strength (in.) } \\
& \psi_{h, U}=\text { haunch effect modification factor } \\
& h_{d} \quad=\text { deck height (in.) } \\
& h_{h} \quad=\text { haunch height (in.) } \\
& h_{e f}{ }^{\prime}=\text { effective stud length embedded into concrete slab } \\
& \text { excluding haunch height }\left(=h_{e f}-h_{h}\right) \text { (in.) }
\end{aligned}
$$

In APPENDIX D, a detailed explanation of the procedure used to construct Equation 3.12 is provided. Additionally, APPENDIX D contains a discussion regarding the applicability of the haunch effect modification factor (Equation 3.13) to other stud connections having different numbers of studs in a row. 


\subsubsection{Shear strength degradation by tensile failure of stud connection}

Based on results from stud pull-out tests, embedded shear studs in a reinforced concrete deck fail in tension due to the formation of a concrete breakout cone in a zone surrounding the studs. In cases where a haunch is present and the studs are not deeply embedded, which is consistent with the full-scale bridge tested at FSEL, failure is associated with the haunch breaking off from the deck. This mode of failure governs the tensile strength of the stud connection. After tensile failure of a stud connection occurs, there is clearly no longer any shear resistance mechanism because the studs are completely embedded in the haunch that is no longer connected to the deck. This observation suggests that the shear resistance should be interrelated with the tensile failure of a stud connection. To achieve this relationship, a linear damage model was applied to the shear resistance of the connector elements. According to the applied linear damage model, a reduction in the shear resistance of the connector elements is initiated when the vertical tension force exceeds the tensile strength of the connector elements. After damage initiation, damage is assumed to evolve linearly, which reduces the shear resistance of the studs as deformation increases. Eventually, there is a complete loss of resistance as shown schematically in Figure 3.18.

To investigate the behavior of a single connector element with the assumed linear damage model under combined shear and tensile loading, the same displacement magnitudes were applied transversely (for shear) and vertically (for tension), both acting on one end node of a connector element. Although a linear damage evolution was assumed for the shear resistance, Figure 3.19 shows a nonlinear load-deflection response in the shear load-slip behavior. This response is due to the nonlinear plasticity hardening rule of the shear studs, which was presented in the previous section. 


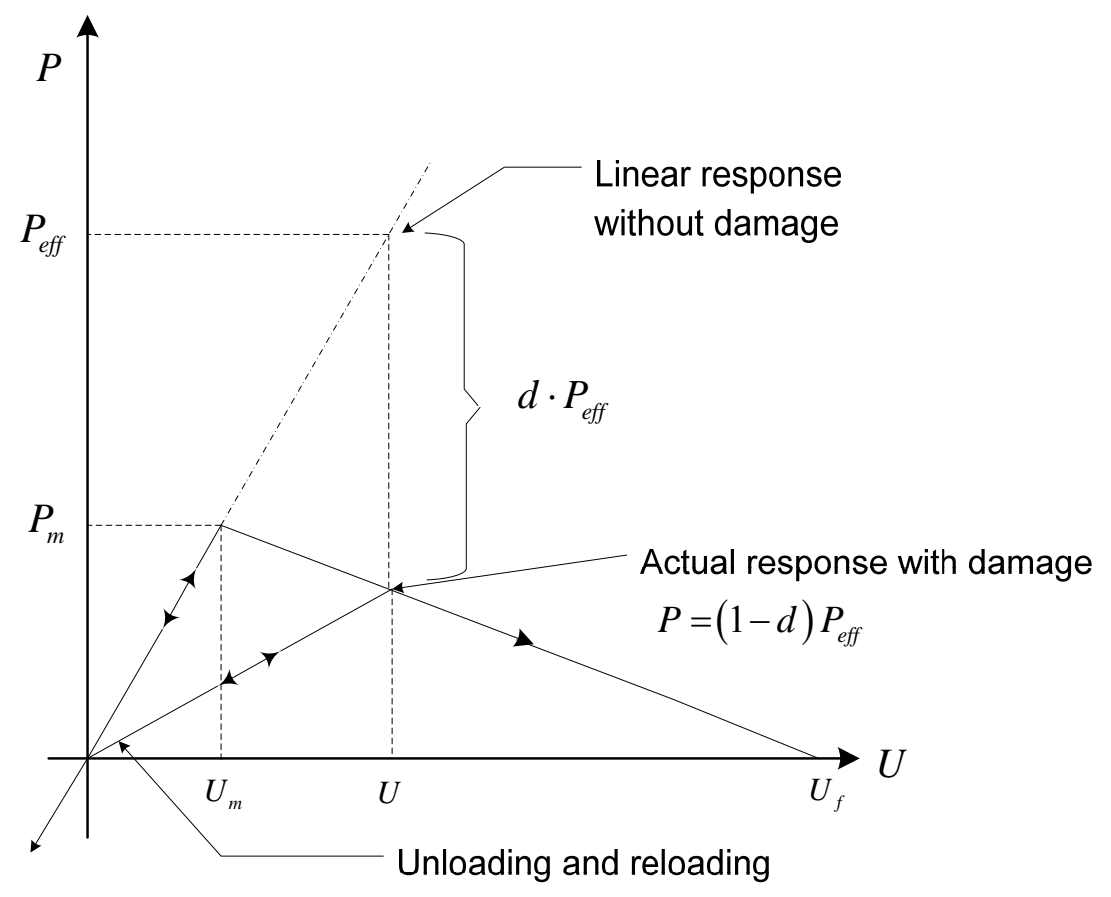

Figure 3.18 Damage initiation and evolution mechanism (Dassault Systemes, 2007a)

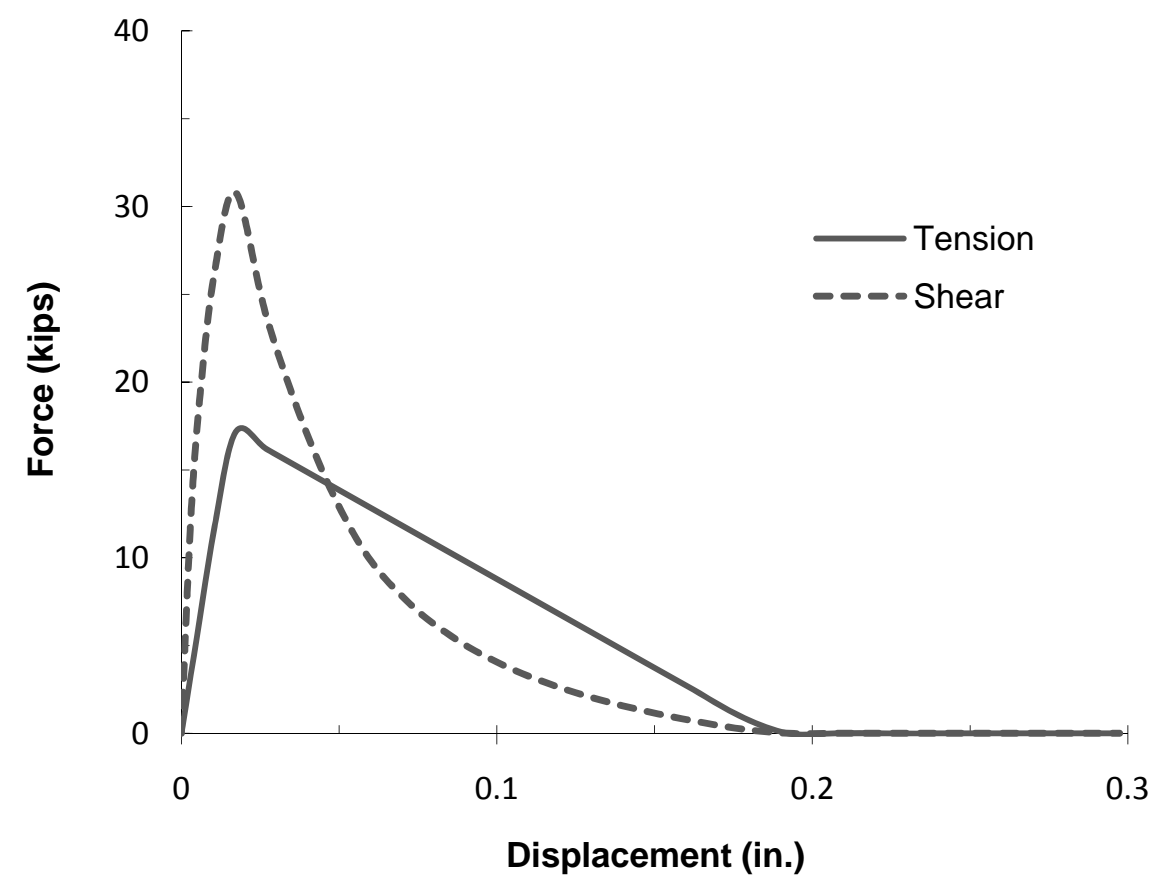

Figure 3.19 Single connector element behavior under tension and shear forces 


\subsubsection{Railing interaction}

Under normal loading conditions, the contribution of a reinforced concrete bridge rail is ignored and not considered to be a structural component for resisting gravity loads because it has gaps for expansion joints. The primary function of a railing is to provide safety for vehicles on a bridge. When a bridge is subjected to large vertical and rotational deformations due to severe damage, however, railing gaps may close. Once such gaps close, the railing may be able to carry significant forces in the longitudinal direction of a bridge. This situation is similar to having a deep beam at the edges of the bridge.

In this study, a simplified modeling approach was used to account for the possibility of the engagement of rail sections. Rather than performing a direct contact analysis, nonlinear springs in expansion joint gaps were used. For a direct contact analysis, a refined mesh density is needed at contact surfaces in order to obtain suitably accurate results, and convergence problems frequently arise when the analysis includes nonlinear material properties (Dassault Systemes, 2007a). In modeling a full-scale bridge, significant effort and computational resources are needed to create a finite element model with appropriate mesh refinement in regions where contact can occur. Furthermore, convergence problems associated with small contact regions can lead to excessively long run times and potentially prevent an analysis from running to completion due to convergence issues. For these reasons, spring elements inserted between rails were used to simulate the potential railing engagement through expansion joints. Once the rails engage, it is possible that limited shear forces may be transferred due to friction, but this effect was ignored in the finite element models developed for this research. It was assumed that spring elements in expansion joint gaps transferred only normal forces.

Before the gaps in the railings become completely closed, no normal forces should develop in the spring elements. This behavior is captured in the spring load- 
deflection behavior shown in Figure 3.20. This figure shows that the spring elements resist only compression forces once the deflection exceeds $3 / 4$ in., which was the initial gap distance of the rails in the test bridge and the value specified by TxDOT. Beyond the 3/4-in. deflection, a stiffness corresponding to the initial concrete stiffness was assumed for the spring element to simulate railing contact. The specific stiffness value is not very important, but it must be large enough to cause a large increase in force; however, it must not be so large as to lead to numerical inaccuracies in the conditioning of the structural stiffness matrix. The value selected provided reasonable results, and the computed response was not very sensitive to variations in the selected stiffness value.

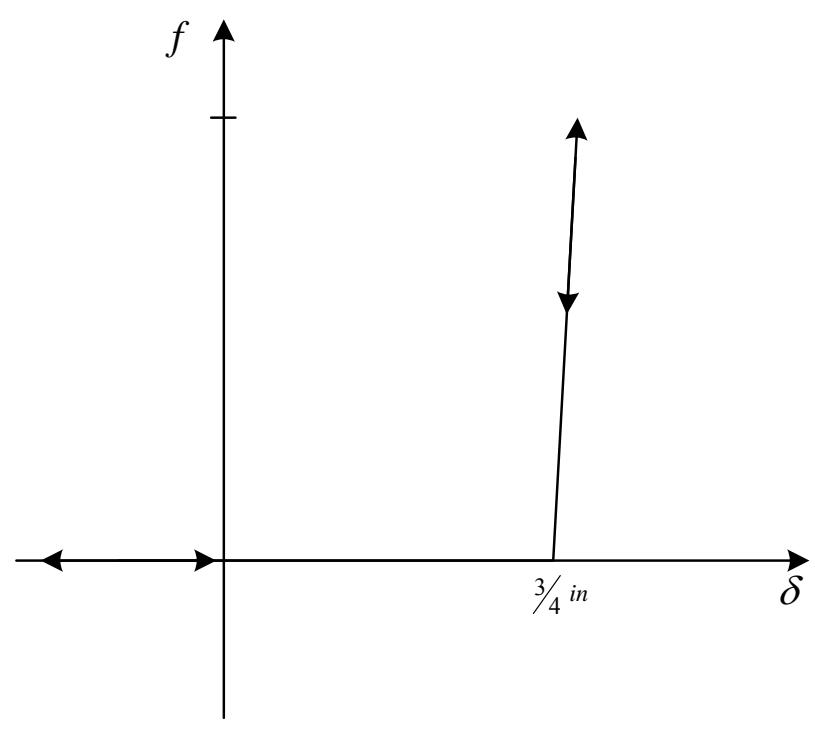

Figure 3.20 Spring element behavior between rails

In the following chapter, modeling procedures for simulating the assumed damage and loading scenarios for redundancy evaluations and for estimating the remaining load- 
carrying capacity of a twin box-girder bridge are introduced. The full-scale bridge fracture tests were conducted according to these damage and loading scenarios. The computed results are compared with measured test data to verify the validity of the modeling approach developed for this study. 


\section{CHAPTER 4: $\quad$ BRIDGE FRACTURE TEST AND SIMULATION}

\subsection{INTRODUCTION}

The full-scale bridge that was used in the experimental testing program (Figure 4.1) had been in service as an HOV lane near the intersection of Interstate I-10 and Loop 610 in Houston, Texas. Because of a highway expansion project, this bridge was removed from service, and TxDOT made the steel box girders to the research project in 2005 . The steel box girders were transferred to the Ferguson Structural Engineering Laboratory at the University of Texas at Austin, and the deck and bridge rails were reconstructed. Detailed reconstruction procedures and geometries of the test bridge are available in Barnard (2006). After the reconstruction of the test bridge, three separate tests were performed on the full-scale bridge. The experimental testing program was extensive and required the development of several unique testing procedures. Below, a brief overview of the testing program is given. Detailed information describing each of the tests and the measured data that were collected are available in Neuman (2009).

The purpose of the first bridge fracture test was to investigate how the sudden loss of the bottom flange of one girder in the bridge affected bridge performance. A rapid failure of the bottom flange of the exterior girder, which simulates what is expected to occur during a fracture event, was achieved using a linear-shape-charge explosive to cut through the complete width of the bottom flange at the midspan. The second test was conducted to determine whether the bridge could sustain the sudden potential energy release of a specified live load and the bridge self-weight in a damaged condition (bottom flange and $83 \%$ web removal of exterior girder). For the rapid release of the loads, a temporary truss support was placed in a prearranged location beneath the bridge's bottom flange, and then the web was cut with a torch from the bottom flange to a point 
approximately $10 \mathrm{in}$. below the top flange. The temporary truss support was designed to rapidly release the load it was carrying by severing a tension tie using an explosive in a similar fashion as the first test. The third test was performed to investigate the reserve load-carrying capacity of the damaged bridge and the contributions made by individual bridge components to the overall capacity of the system. To apply loads incrementally in the experiment, road base was placed on the deck along with concrete blocks. Loading continued until the bridge collapsed.

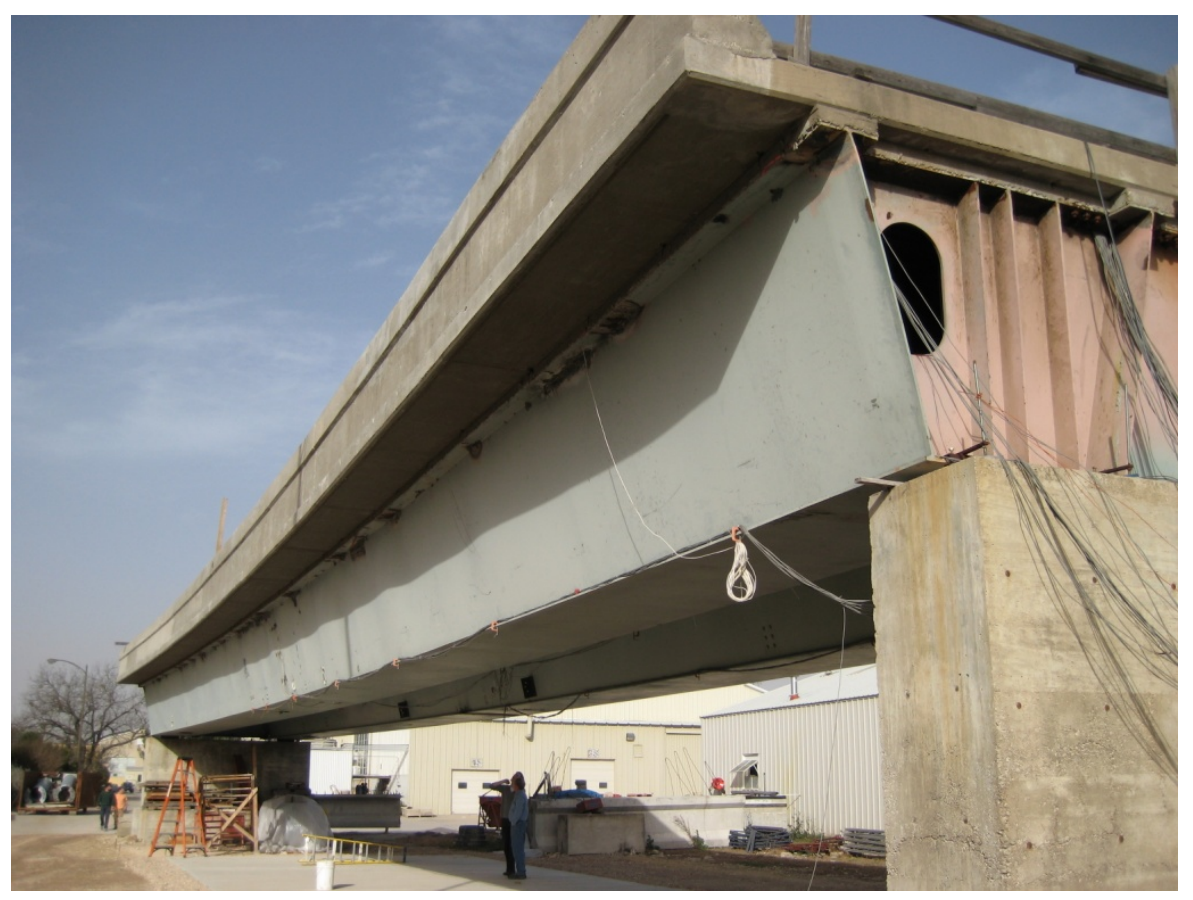

Figure 4.1 Full-scale test bridge 


\subsection{FIRST BRIDGE TEST (BOTTOM FLANGE REMOVAL)}

\subsubsection{Test procedure}

The first bridge test was performed to investigate how the bridge responds when the bottom flange of one girder suddenly fails as might be expected if a fracture were to occur. The bottom flange is currently classified as a fracture-critical member in the twogirder bridge system. An explosive was used to cut the bottom flange extremely rapidly to imitate the sudden loss of the whole bottom flange of one girder (east side girder) at the midspan as shown in Figure 4.2. For safety purposes, the explosive was encased in a blast shield, which was attached underneath the bottom flange of the east girder and tethered to a concrete block placed under the bridge. Other concrete blocks (in the form of prestressed concrete girders) intended to simulate the AASHTO standard HS-20 design truck load were placed on the deck so as to cause the maximum positive bending moment at the damaged location. Detailed descriptions of the bridge test setup and the results that were collected have been reported by Neuman (2009).
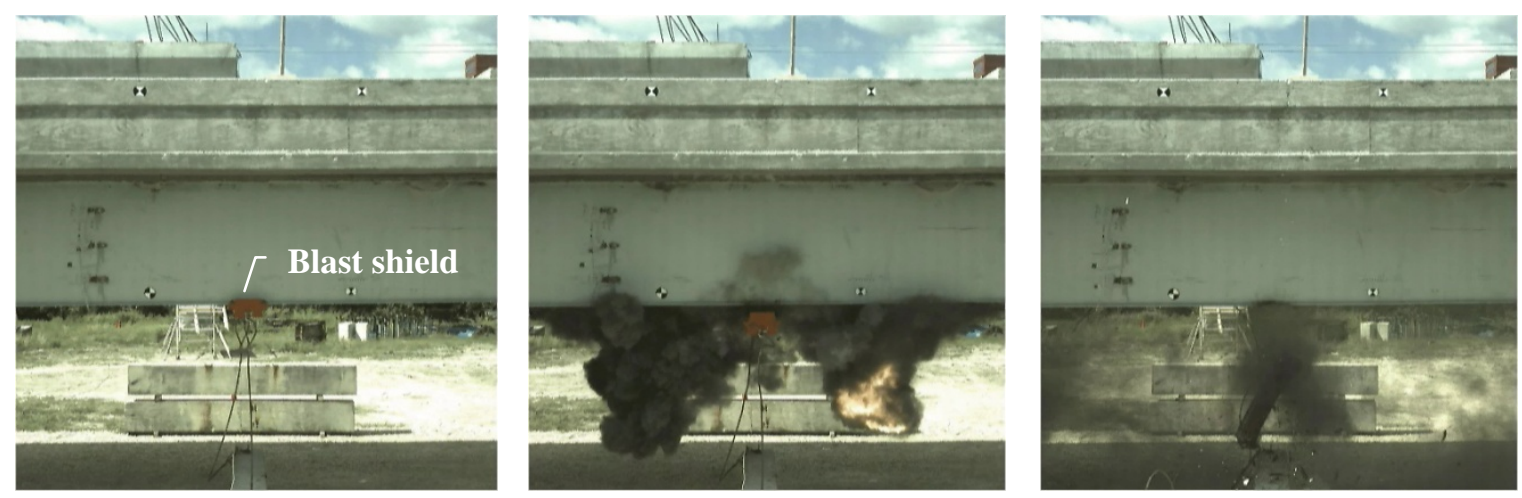

Figure 4.2 First bridge fracture test (bottom flange removal by explosion) 


\subsubsection{Simulation procedure}

The finite element simulation procedure for modeling the response of this bridge fracture test can be divided into three main analysis categories: bridge construction, load application, and simulation of bottom flange fracture, as shown in Table 4.1. The analysis steps in the bridge construction category are intended to incorporate load histories through the erection and construction process in which the deck acts non-compositely with the girders. For the first analysis step, all of the deck, railing, and rebar elementsexcept girder elements - were deactivated to simulate the non-composite section behavior of the bridge. During bridge construction, only the steel box girders resisted the deck and railing weight before the concrete deck hardened. Therefore, deck and railing elements were removed using the element deactivation technique in ABAQUS/Standard v6.7 to simulate non-composite section response because the deactivated elements have no effect on the mass and the stiffness of the system. After deactivating these elements, equivalent pressure loads for the self-weight of the deck and railing were evenly applied on the girder top flanges. As a result, the applied loads on the girder top flanges were resisted only by the steel girders.

The deactivated elements maintain their initial node locations when they are deactivated. The node locations of deck and railing elements need to be shifted, however, so that they deform consistently with the girders because uncured concrete flows freely before it is hardened. For this reason, dummy elements for the deck and railing were used to follow such node location shifts. The dummy elements shared the same nodes with the original deck and railing elements, but they had very low stiffness $\left(10^{-4} \times\right.$ concrete stiffness $)$ and were almost without mass $\left(10^{-9} \times\right.$ concrete density) so as not to affect the bridge stiffness and weight. As a result, because the original deck and railing elements were deactivated and an equivalent pressure load was applied to the top flanges of the 
girders, the deck and railing nodes deformed freely, following the girder deflection due to the dummy elements. After this procedure, the deck and railing elements were reactivated, without strain changes, in the deformed position to simulate the hardened concrete, and the equivalent pressure load was removed.

Table 4.1 Simulation procedures for first bridge fracture test

\section{Bridge construction}

1. Deactivating deck, railing, rebar elements and applying gravity to girder

2. Applying deck, railing, and rebar weight on the top flange

3. Activating deck, railing, and rebar elements with gravity and removing the weight on the top flange

4. Deactivating external cross frame elements and dummy elements

\section{Applying truck live load}

1. Applying truck load (concrete blocks)

\section{Dynamic loading}

1. Deactivating elements connecting the girder fracture

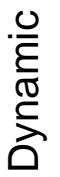

The truck live load, simulated using concrete blocks in the bridge test, was applied to the top nodes of the deck using concentrated loads in the finite element model. These concentrated loads had the same axle spacing as the concrete blocks used during the test. For the bottom flange cutting, the fracture path was predefined on the bottom flange of the east girder, as shown in Figure 4.3. The selected damage location was at the midspan because this location is where the maximum positive bending moment is caused by a moving vehicle in a simply supported bridge. Shell elements adjoining the predefined fracture path shared duplicate nodes. These independent nodes were initially 
joined by connector elements (CONN3D2) with weld properties to mimic the intact condition of the bottom flange. The cutting of the bottom flange was simulated, therefore, by removing the connector elements using the element deactivation technique. The removal of the connector elements was sudden, as was the explosive damage inflicted during the first bridge fracture test. Computationally, this step was carried out using a transient dynamic analysis with a "step-amplitude" loading in ABAQUS/Standard v6.7.

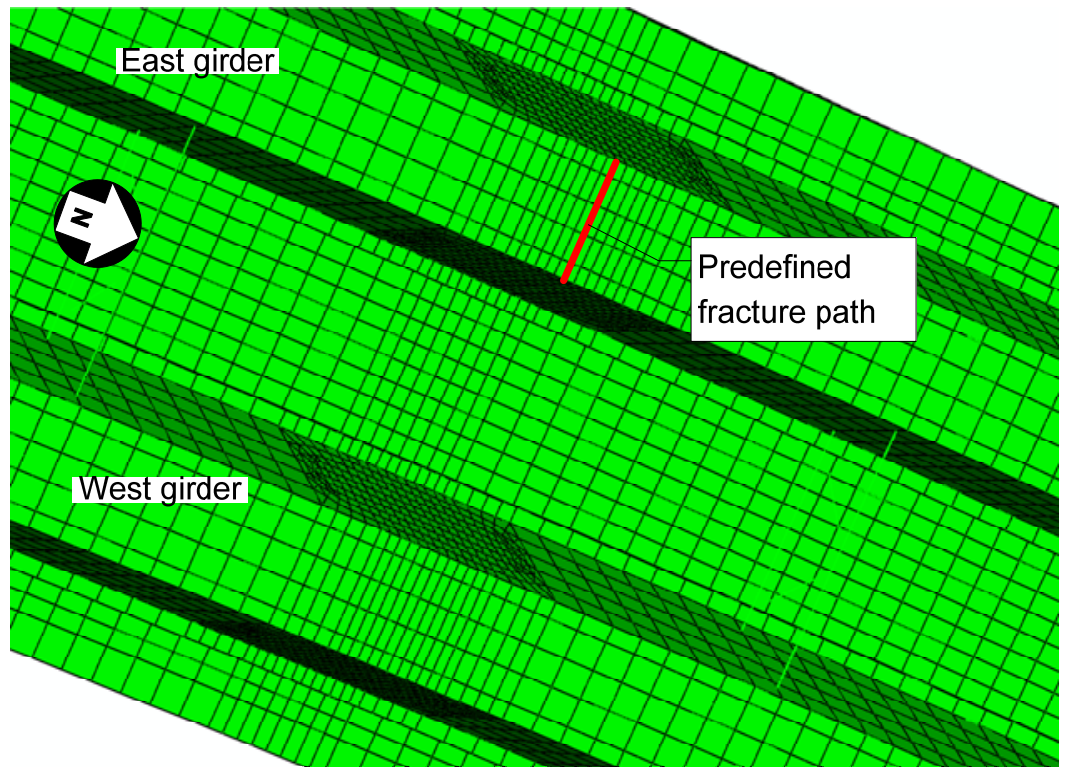

Figure 4.3 Predefined bottom flange fracture path

\subsubsection{Bridge test and simulation results}

After the first bridge fracture test, it was observed that the bottom flange was severed completely along its width and through its depth. The fracture, however, did not propagate into the webs as shown in Figure 4.4. Despite the bottom flange fracture of one 
girder, the test bridge did not show any significant damage, and the resultant girder deflections were very small.

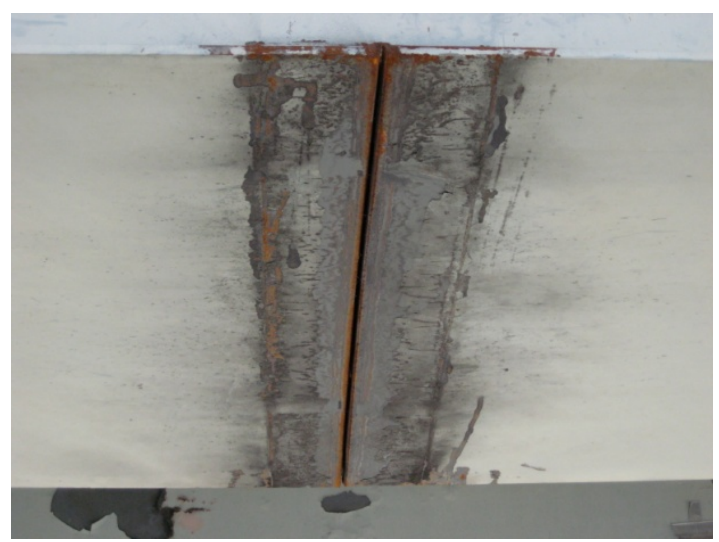

(a) Full cut of the bottom flange

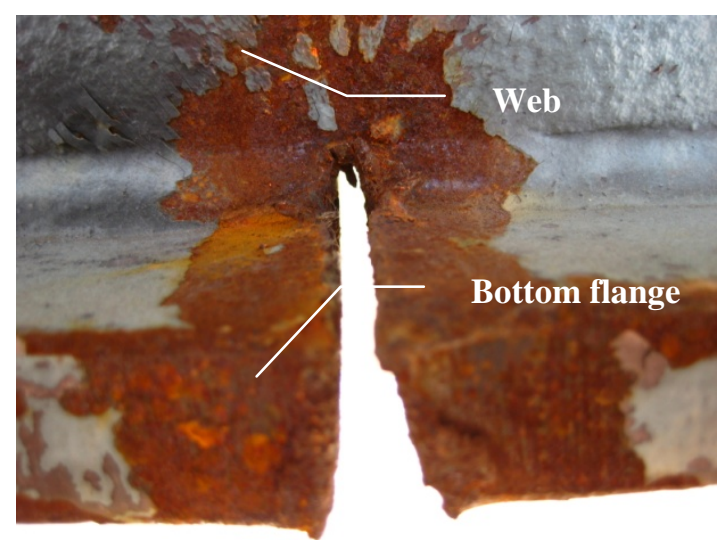

(b) Detained fracture at web

Figure 4.4 Bottom flange cut of fractured girder

Figure 4.5 shows the measured relative girder deflection changes of the west girder (WG) and the east girder (EG) before and after the bottom flange was severed with the explosive. Data shown in this figure are based on the static deflection that resulted after the girder came to rest. Thus, the values do not show the peak dynamic deflection that occurred shortly after the fracture was induced. The girder deflections were measured using a laser level having $\pm 1 / 16$ in. accuracy. The baseline of the deflection measurements was the deformed position of the steel box girders before the concrete deck cured. Therefore, the deflection due to the self-weight of the steel box girders was not included in the relative deflection measurement. In Figure 4.5, the deflection of the east girder is larger than that of the west girder because the applied concrete block loads 
(used to simulate an HS-20 truck) were biased transversely toward the east girder to create the worst-case loading scenario on the fractured girder (Neuman, 2009).

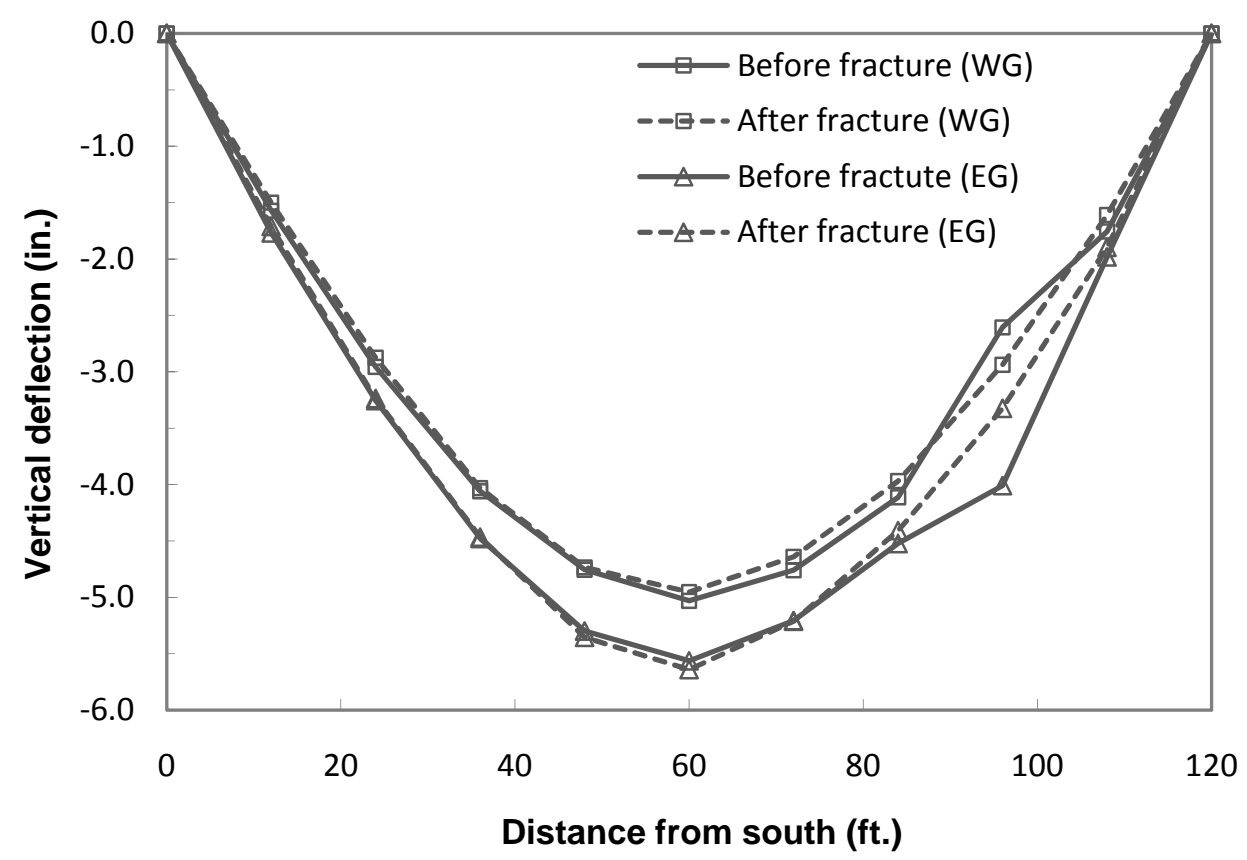

Figure 4.5 Girder deflection of intact and fractured girder

According to the surveyed data, the east girder deflected downward 5.56 in. at its midspan (relative to the baseline) when the concrete blocks were loaded and before the bottom flange fracture occurred. The resulting additional deflection of the east girder was only 0.08 in. after its bottom flange was fractured. This result is inconclusive, however, as it is within the specified accuracy of the laser level. Moreover, the deflection surveys were conducted on different days and at different times, which could mean that different environmental conditions affected the bridge deflection (i.e., temperature gradient change could affect the bridge deflection measurements). Therefore, the measured additional 
deflection might not be caused solely by the bottom flange fracture of the east girder. Nonetheless, the measured deflections and post-test observations of the bridge indicate that the fracture of the bottom flange of the exterior girder caused limited damage to the overall load-carrying capacity of the bridge.

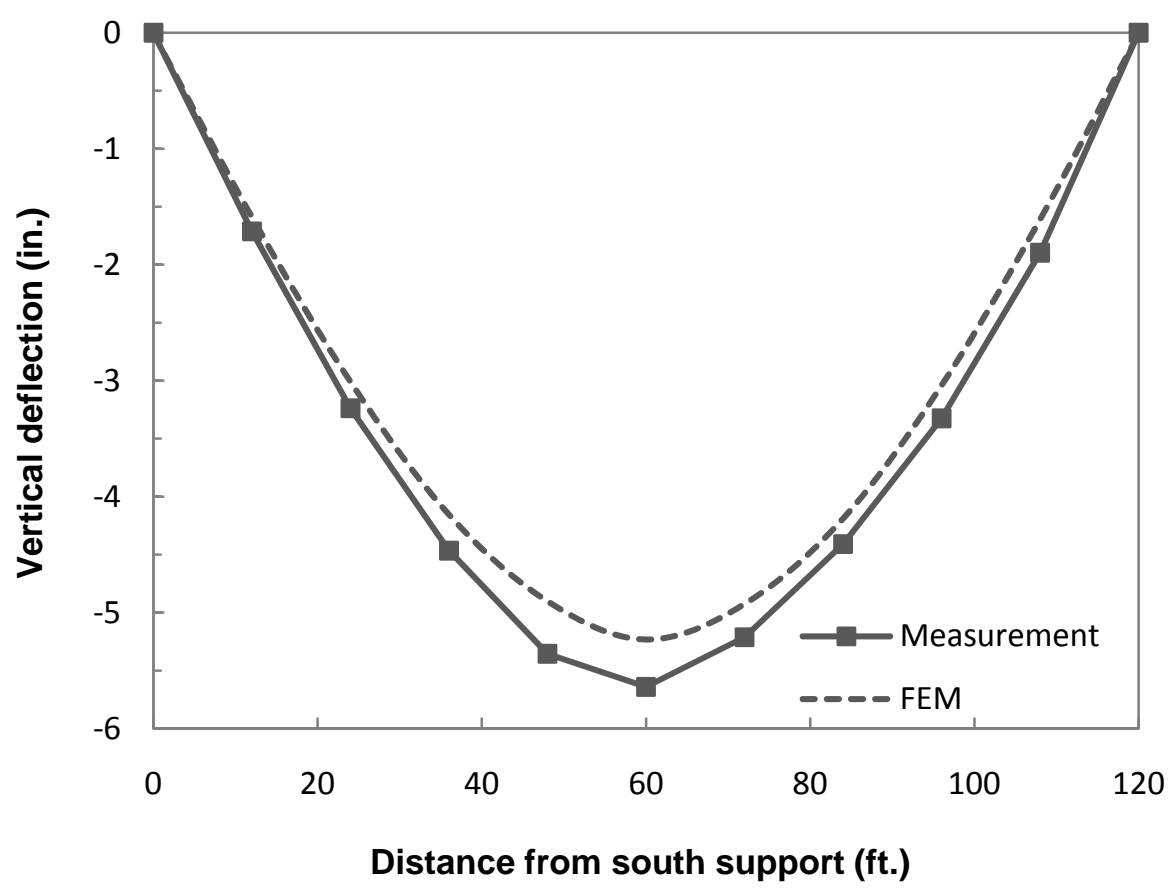

Figure 4.6 Fractured girder deflection after bottom flange removal

The finite element simulations gave girder deflections that were similar to those obtained from the surveyed data. Figure 4.6 compares the measured deflections of the fractured girder with those predicted by the finite element model following the fracture of the bottom flange. The predicted deflection at the midspan by the finite element model was 5.23 in., which was slightly less than the measured deflection of 5.64 in. Considering the accuracy of the laser level and the possibility for environmental conditions to affect 
the measured deflections, however, the prediction by the finite element model was considered to be acceptable.

\subsection{SECOND BRIDGE TEST (BOTTOM FLANGE AND WEB REMOVAL)}

\subsubsection{Test procedure}

The purpose of the second bridge test was to investigate whether or not the FSEL bridge could sustain a simulated dynamic loading following a nearly full-depth fracture of the exterior girder (the east side girder). The applied damage and loading conditions were similar to those described in Chapter 2 for the redundancy evaluation of a twin steel box-girder bridge. The only difference was the level of damage that existed prior to the test. In the experiment, $83 \%$ of the east girder's web was cut, rather than the total web, because of safety issues. For the bridge test, in order to apply the additional web damage without the loss of the gravitational potential energy of the bridge, a temporary truss support was installed under the fractured girder. Then, the bottom flange fracture made in the first bridge fracture test was manually extended to the inside and outside webs of the east girder using an acetylene torch. Figure 4.7 shows the condition of the bridge after the webs had been cut.

After inducing the additional web damage, concrete blocks were placed on the top of wooden blocks on the deck to represent truck axles. The concrete blocks were intended to simulate the AASHTO HS-20 truck load, but it had a slightly different total weight- 4 kips higher than the HS-20 truck. Figure 4.8 shows a schematic of the concrete block loading configuration used in the second bridge fracture test. The assumed spacing of axles was $14 \mathrm{ft}$., and the middle axle was positioned at the midspan to cause the maximum vertical bending moment at the fracture location. The transverse location of the 
concrete blocks was biased toward the east girder side so that the axle (wooden block) corners were placed $2 \mathrm{ft}$. away from the east railing. This configuration was intended to simulate the worst-case loading condition that could be achieved by a single truck on the test bridge.

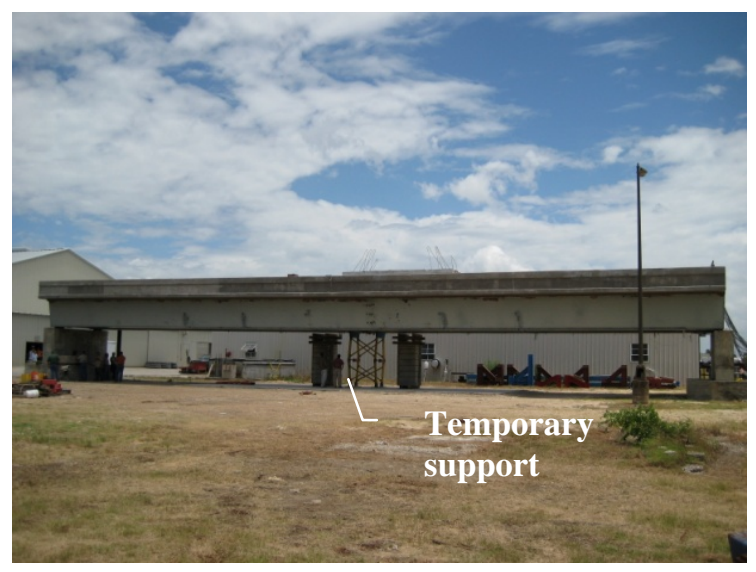

(a) Second bridge test setup

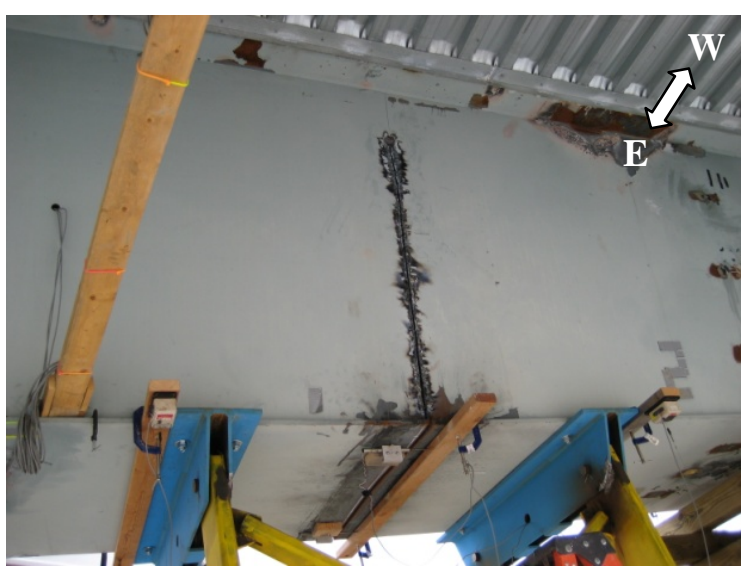

(b) Manually extended cut to webs

Figure 4.7 Temporary support and web cutting
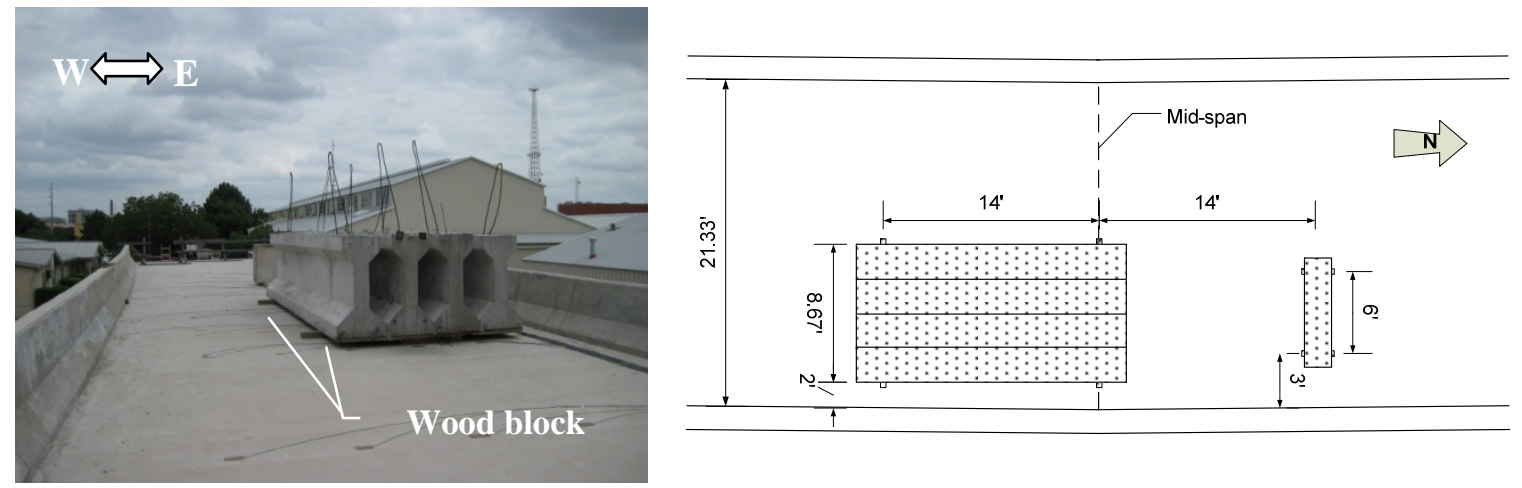

Figure 4.8 Simulated truck live load configuration (AASHTO HS-20) 

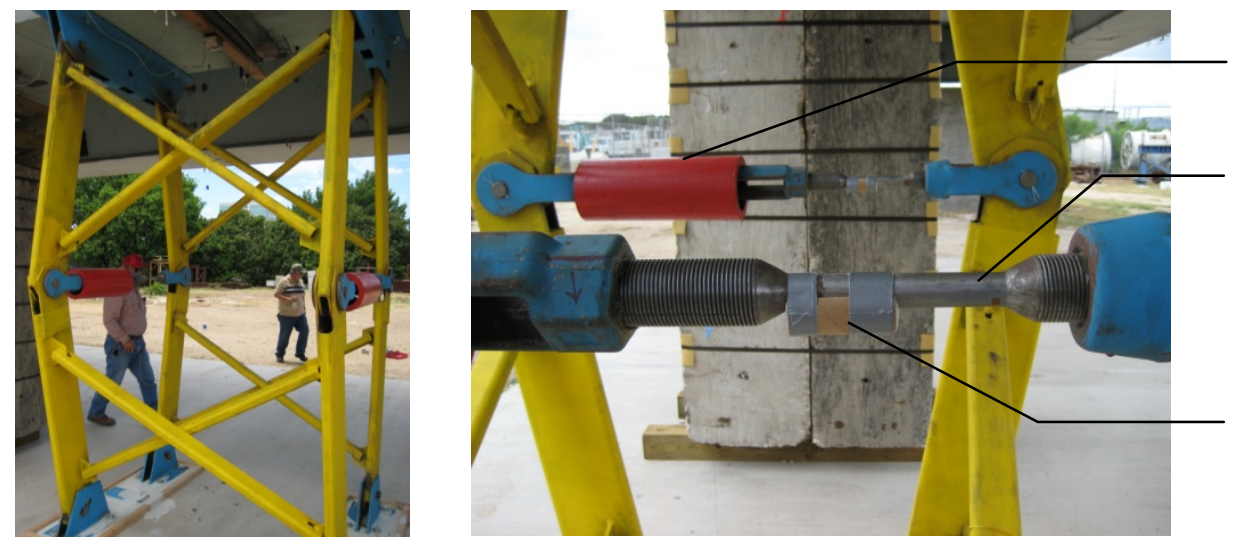

Blast shield

Horizontal truss member

Figure 4.9 Temporary truss support and explosive setup
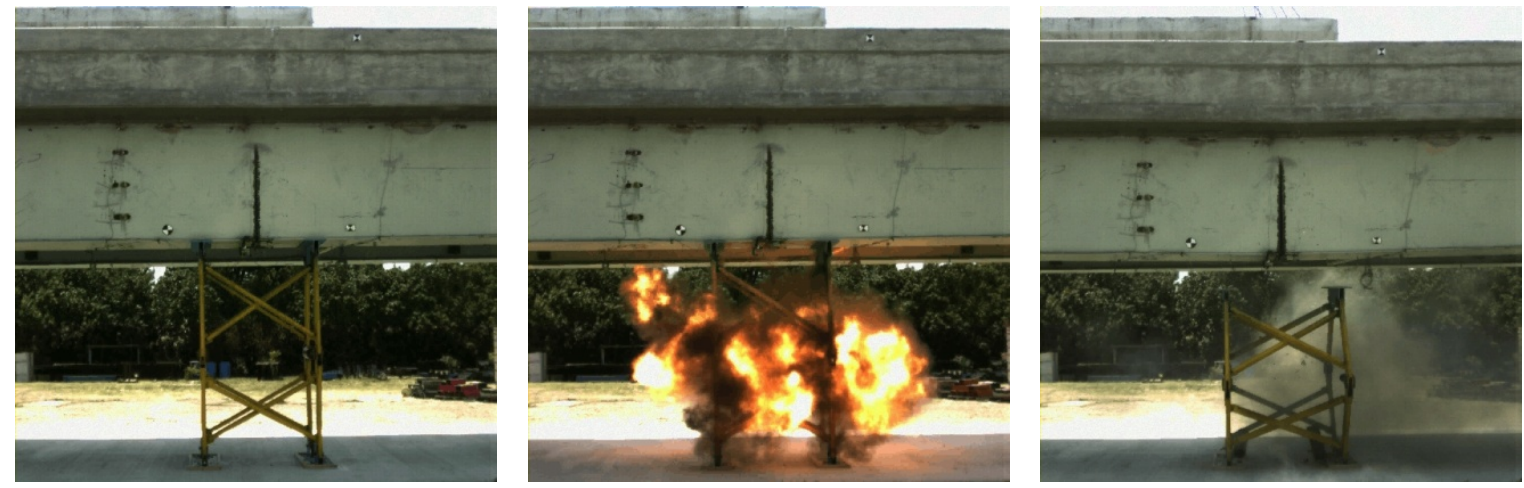

Figure 4.10 Second bridge fracture test (bottom flange and $83 \%$ web removal)

For the second bridge fracture test, the temporary truss support was designed so that it could collapse nearly instantaneously without interfering with the response of the bridge as it deflected downward. The temporary truss support designed by Neuman (2009) satisfied these requirements successfully. It became structurally unstable once horizontal ties, as shown in Figure 4.9, were severed by explosive contact charges, and it quickly dropped down before the bridge girder deflected. This behavior was clearly observed in the high-speed video recording of the test; captured still images from the high-speed video are shown in Figure 4.10. 


\subsubsection{Simulation procedure}

To simulate the damage and loading scenario used in the second full-scale bridge fracture test, the finite element analysis followed procedures similar to those in the first bridge test. The finite element simulation of the second bridge test was composed of three major analysis steps, as described in Table 4.2: bridge construction, applying temporary boundary conditions and girder damage, and removing the temporary boundary conditions.

Table 4.2 Simulation procedures for second bridge fracture test

\section{Bridge construction}

1. Deactivating deck, railing, rebar elements and applying gravity to girder

2. Applying deck, railing, and rebar weight on the top flange

3. Activating deck, railing, and rebar elements with gravity and removing the weight on the top flange

4. Deactivating external cross frame elements and dummy elements

Applying B.C. and girder fracture

1. Applying temporary boundary condition

2. Deactivating elements connecting the girder fracture

3. Applying truck load (concrete blocks)

\section{Dynamic loading}

1. Removing temporary boundary condition suddenly

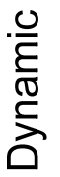

The bridge construction step was used to incorporate loading histories associated with non-composite behavior before casting the concrete deck, as discussed in the first bridge fracture test simulation procedure. For the next step, temporary boundary conditions were applied to the bottom flange, spanning $5 \mathrm{ft}$. and centered on the midspan of the east girder where the temporary truss supports were placed. The temporary 
boundaries constrained the vertical translation of the east girder while the bottom flange damage, the web damage, and the simulated truck live load were applied to the simulation model. To incorporate damage on the east girder, connector elements initially binding separated nodes along a predefined fracture path were deactivated. The predefined fracture path and temporary boundaries under the bottom flange are shown in Figure 4.11. The truck live load represented by the concrete blocks in the bridge test was simulated with concentrated forces acting on the bridge deck.

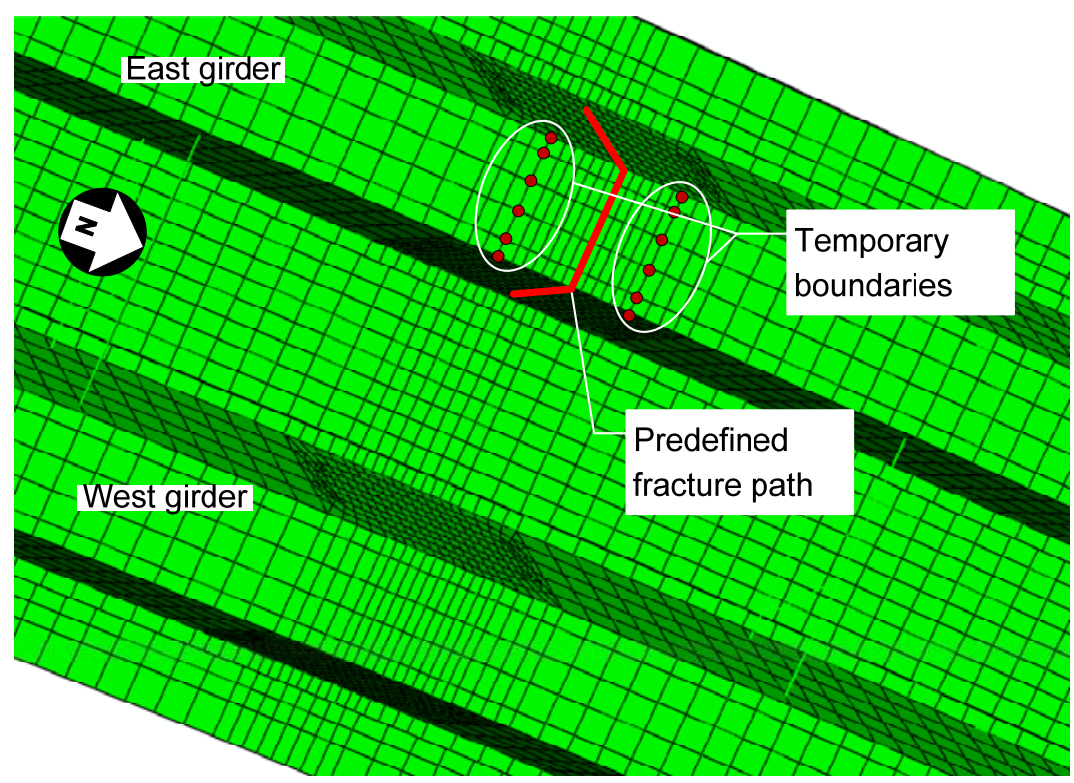

Figure 4.11 predefined fracture path in east girder

After the loading step of the truck live load, the temporary boundaries were eliminated to simulate the sudden removal of the temporary truss supports in the bridge fracture test. To computationally achieve dynamic loading effects caused by the abrupt removal of the temporary supports, a transient dynamic analysis was conducted with a "step-amplitude" loading condition. 


\subsubsection{Bridge test and simulation results}

After the second bridge fracture test, visual inspections were conducted to investigate the overall condition of the bridge. During the initial inspections, the only damage observed included tensile cracks on the deck and crushed cover concrete on the top of the east railing at the midspan. Analytical models of the deck response (Samaras, 2009) and finite element simulations, however, predicted that extensive stud tensile failures would occur along the inside of the fractured girder. For this reason, the corrugated metal deck spanning between the girders and used as formwork during the construction of the deck was removed to inspect the stud connections closely, and it revealed that a large amount of haunch separation along the inside of the fractured girder had in fact occurred (Figure 4.12 (a)). Along the outside of the fractured girder, both longitudinal and diagonal cracks were observed where the studs connected with the concrete deck, as shown in Figure 4.12 (b). These cracks developed near the midspan. As indicated by the figure, haunch separation on the inside of the girder was more severe than on the outside.

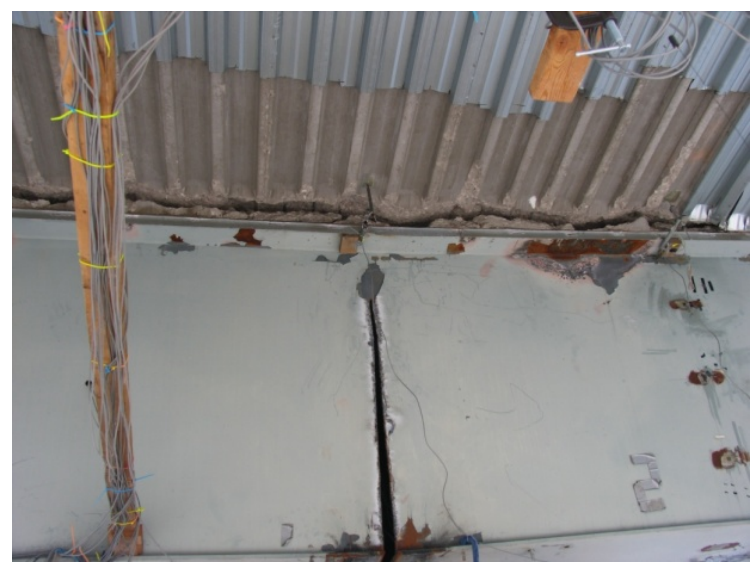

(a) Fractured girder: inside

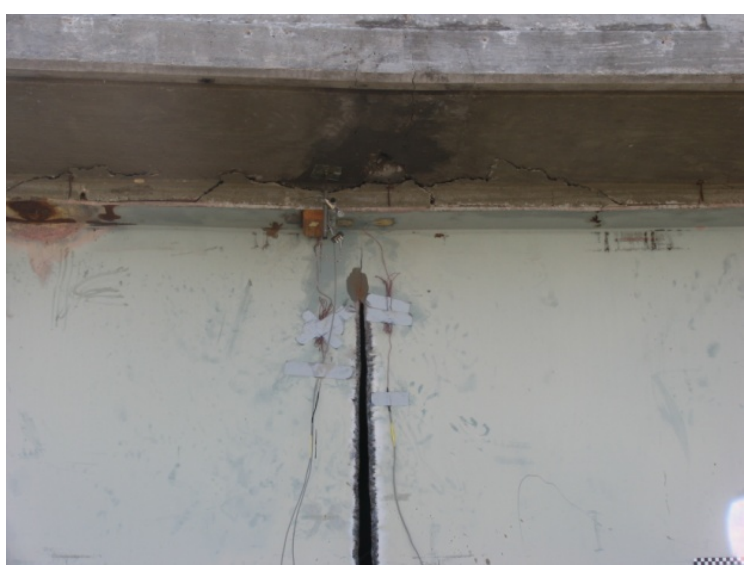

(b) Fractured girder: outside

Figure 4.12 Haunch separation of fractured girder 


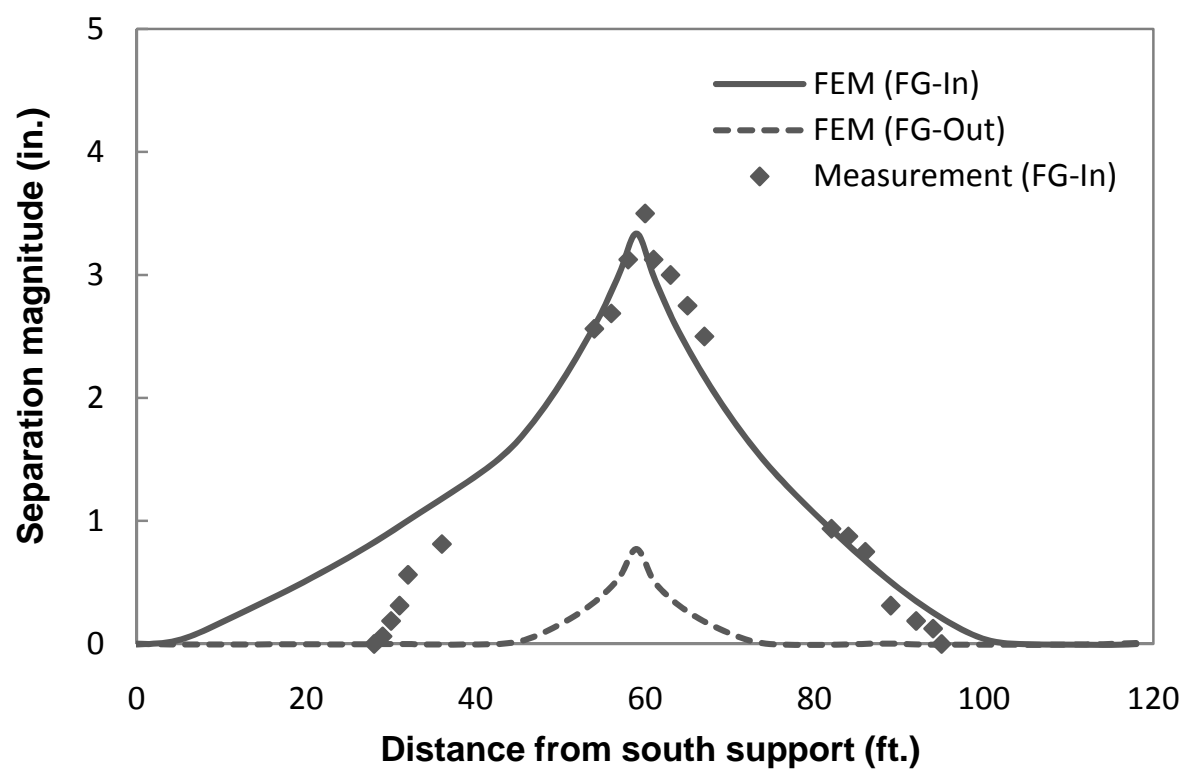

Figure 4.13 Haunch separation along bridge span

In the test bridge, haunch separation was initiated by stud tensile failure near the midspan of the bridge. As the tensile failures propagated along the bridge span, the haunch started to separate from the concrete deck of the fractured girder. Figure 4.13 shows the predicted length of haunch separation along the inside of the fractured girder (FG-In) and along the outside (FG-Out); the figure also shows the measured haunch separation along the inside of the fractured girder. A comparison of the results indicates that the finite element model over-predicted the separation length along the inside of the fractured girder- $96 \mathrm{ft}$. predicted compared to $67 \mathrm{ft}$. measured. Along the outside of the fractured girder near the midspan, cracking in the haunch spanned $14 \mathrm{ft}$., but the cracking pattern was irregular, as shown in Figure 4.12(b) (i.e., diagonal and longitudinal cracks were both observed). This cracking pattern suggests that the outside haunch failed due to a combination of tension and shear. Because the degree to which haunch separation occurred along the outside of the fractured girder could not be accurately measured, only 
the simulation model prediction is included in Figure 4.13; the predicted separation length was $32 \mathrm{ft}$.

Concerning the over-prediction of the haunch separation length, there are various possible reasons: haunch slope, participation of the metal deck, dynamic effects on material strength, and potentially others. In the test bridge, the edge of the haunch was sloped transversely due to the corrugated metal stay-in-place forms used to construct the deck (Figure 4.14). The presence of such a haunch slope could change the tensile strength of a stud connection because it reduces the concrete breakout cone size less than does a haunch with right angles. The strain rate of the dynamic loading could also affect the tensile strength of a stud connection because material strength is affected by the loading rate. Figure 4.15 shows the variation in the tensile strength of stud connections as a function of the loading rate based on tests conducted by Mouras (2008). According to the test results, when the strain rate reached 30.67 in./in./msec.- the maximum obtained during the testing program - the tensile strength increased by about $40 \%$ over the static test results. The finite element simulation model, however, did not consider such an increase in tensile strength caused by the high strain rate; for simplicity and due to a lack of data, constitutive models used in the finite element simulations were not strain-rate dependent.

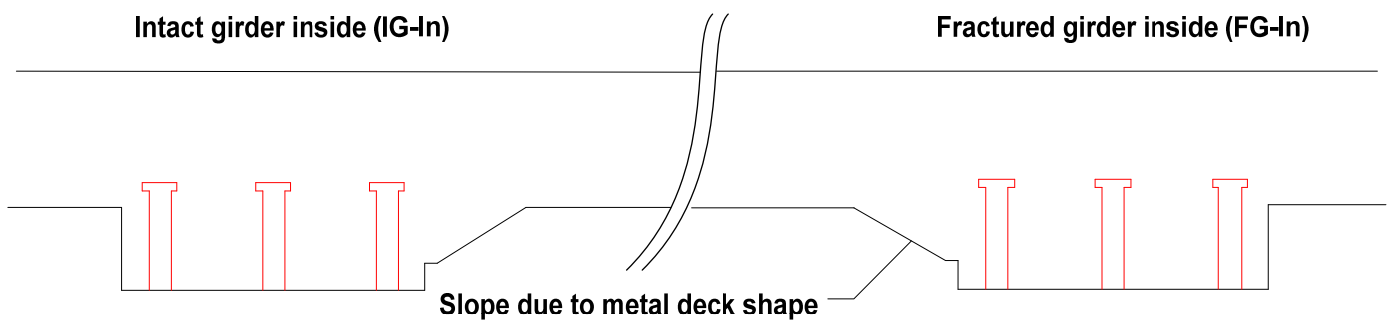

Figure 4.14 Haunch slope in cross-sectional plane 


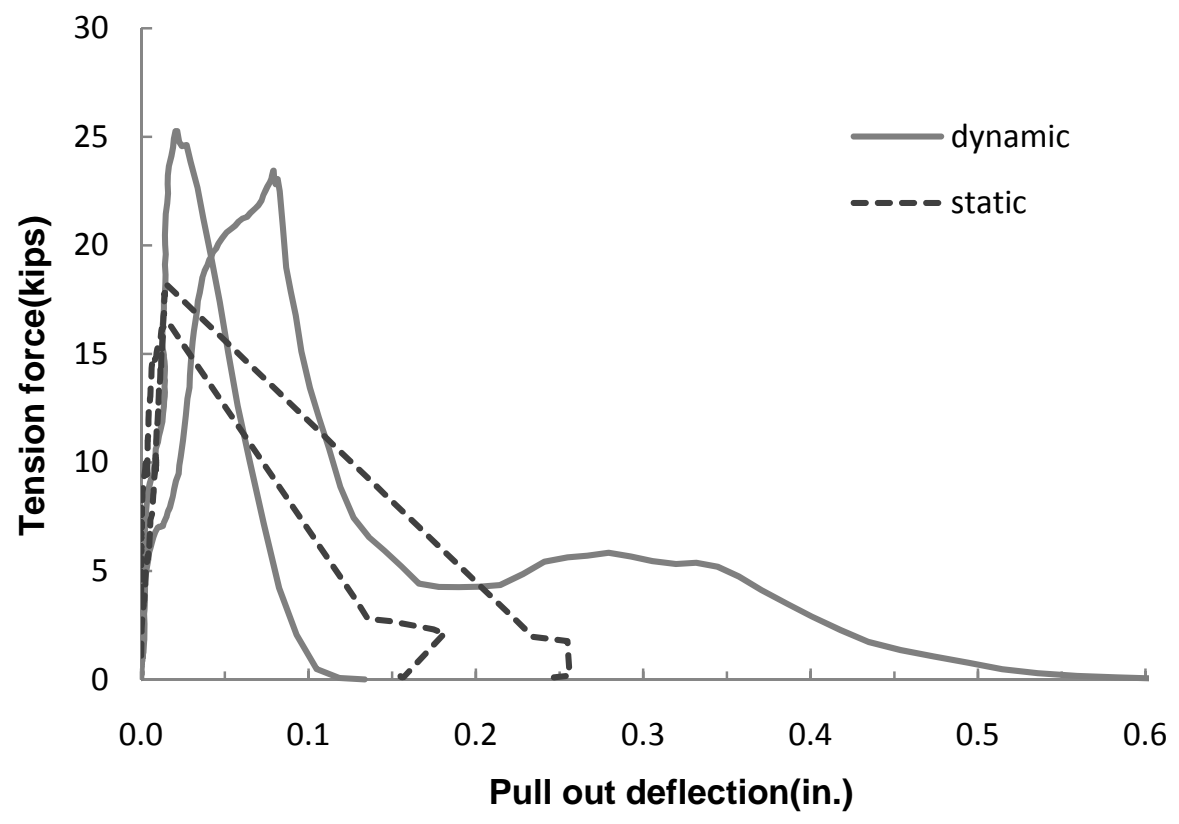

Figure 4.15 Dynamic and static stud pullout test (Mouras, 2008)

Figure 4.16 shows the girder midspan deflections as a function of time obtained from the finite element simulation. The dashed line indicates the vertical deflection of the intact girder (IG-CL), and the solid line represents the vertical deflection of the fractured girder (FG-CL); both quantities were obtained from the centerline position of the bottom flange. To obtain the centerline deflections at the midspan of the bridge, edge deflections of the bottom flange of each girder were averaged. Because of the simulated girder fracture and the transversely biased loading position of the live load, the vertical displacement of the fractured girder was significantly larger than that of the intact girder (Figure 4.16). It is important to note that haunch separations are included in the vertical displacements that are plotted because the girder displacements were computed from the response of the bottom flanges. 


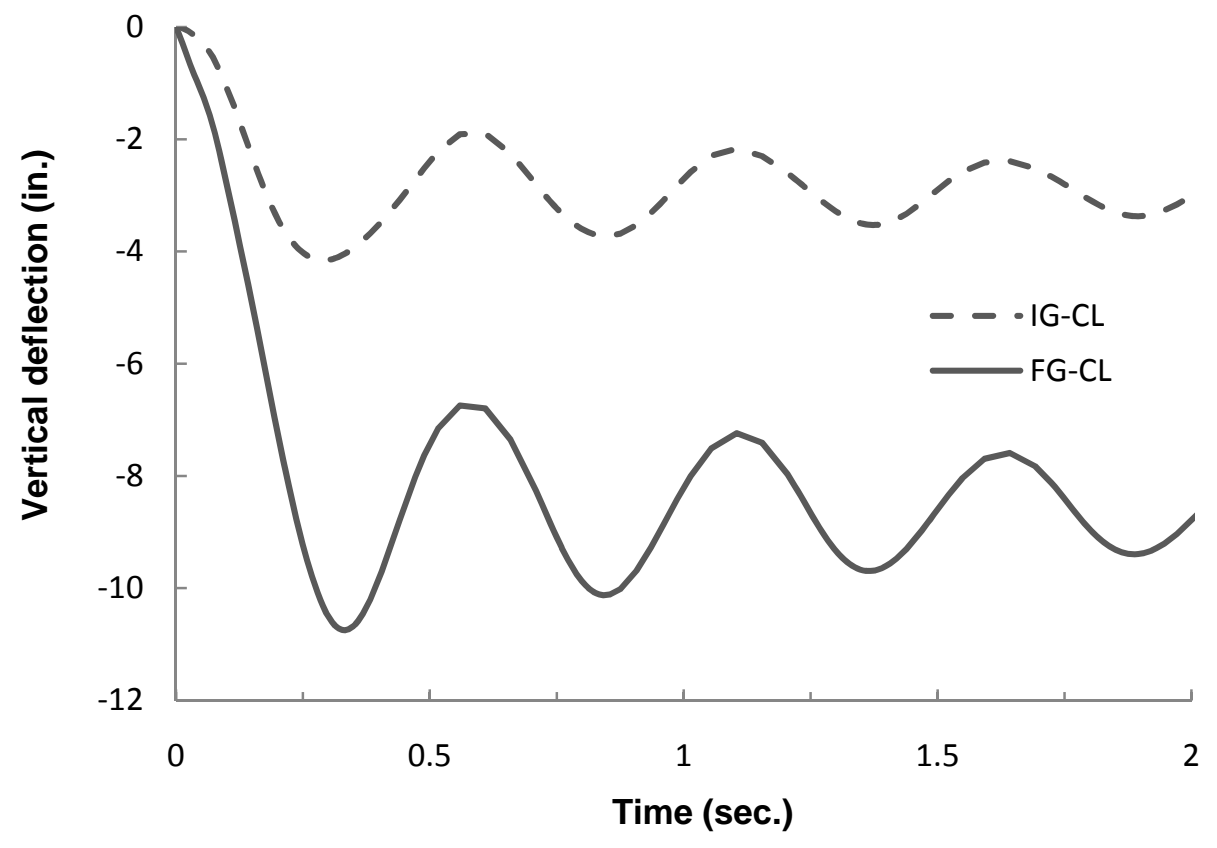

Figure 4.16 Dynamic girder deflection

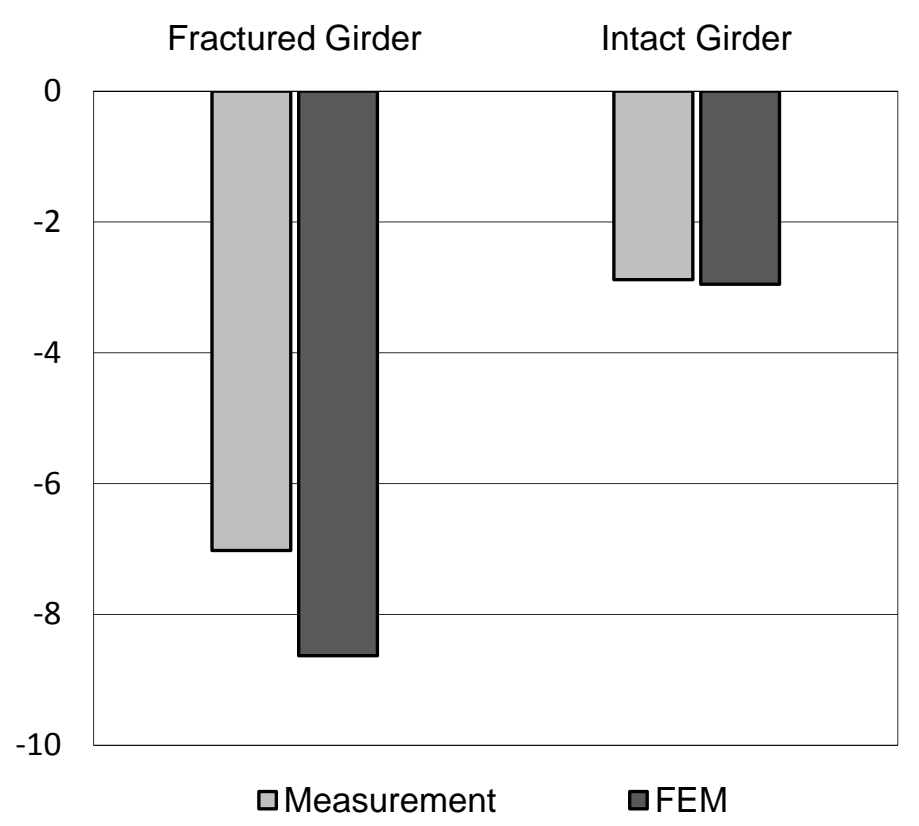

Figure 4.17 Static displacements of test and simulation 
During the bridge test, an attempt was made to measure the dynamic displacement of the fractured girder at its midspan using a string potentiometer attached to the center of the bottom flange, but the string potentiometer was damaged from the explosion used to collapse the temporary truss supports. Consequently, displacements of the bottom flanges were measured after the test bridge came to rest; these static displacements were compared with those obtained from the finite element simulation. Displacement values from the finite element model were obtained by averaging the peak dynamic displacements after three periods of oscillation (Figure 4.16). This approach was taken because it was too computationally demanding to carry the dynamic analyses further in time, and the results showed significant damping. As a result, taking the average value after three periods of oscillation was reasonable. Figure 4.17 shows the static displacement results of the intact and the fractured girders, comparing the measured test data with the computed values. In the bridge fracture test, the vertical displacement at the midspan of the intact girder was 4.16 in., and the finite element model predicted a value that was only $2 \%$ higher than the test result. Conversely, for the vertical displacement of the fractured girder, the measured data and predicted value did not compare closely. The measured deflection of the fractured girder following the test was 7.02 in., but the girder deflection in the simulation model was 8.63 in. (23\% higher). One reason for such a large difference between the measured and predicted displacement of the fractured girder can be attributed to the over-predicted separation length of the haunch in the simulation model compared with that in the bridge fracture test as discussed previously.

The deflected shape of the reinforced concrete deck transitioned from double curvature to single curvature during the bridge fracture test and the simulation. Figure 4.18 shows the displacement at the top of the deck across the width of the bridge following the removal of the temporary supports in the bridge fracture test simulation. 
Early in time $(t=0.06 \mathrm{sec}$.$) , the graph shows that the deck bends in double curvature; as$ time progresses, however, the shape transitions to single curvature.

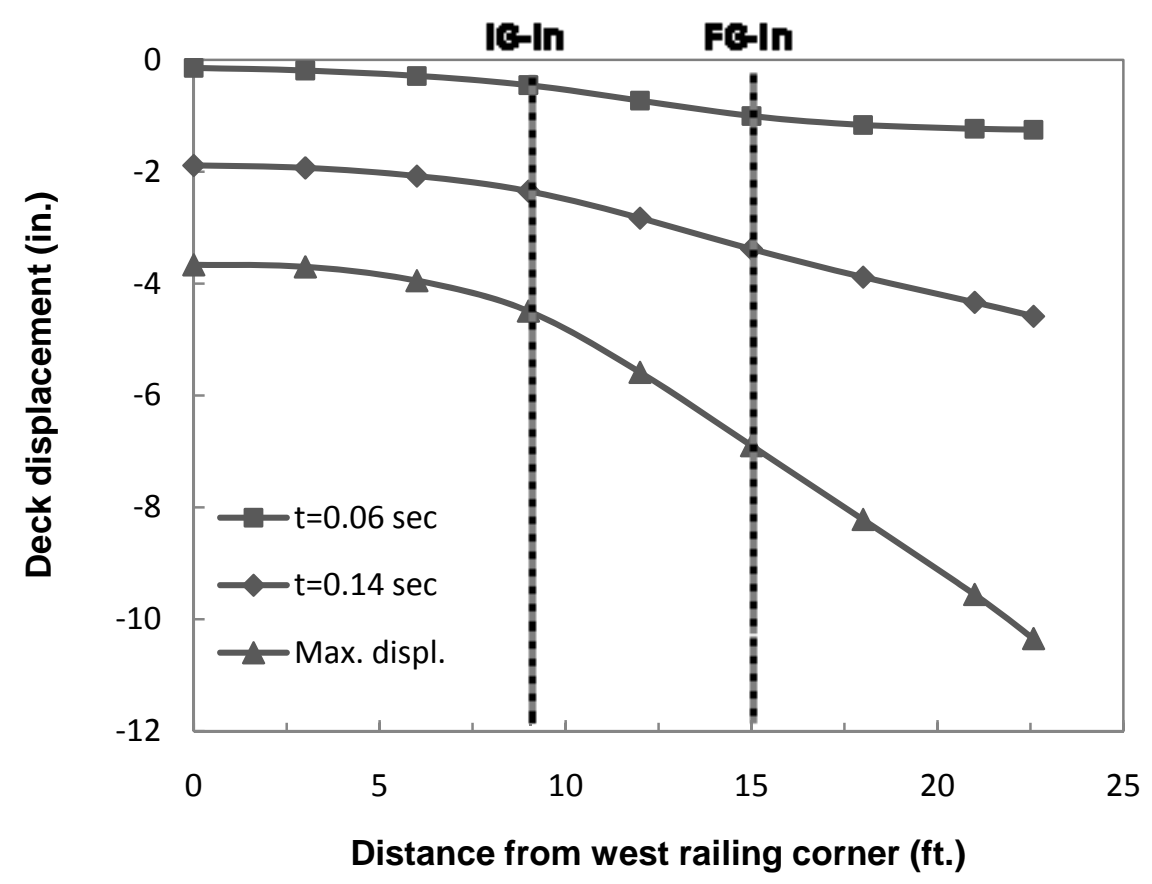

Figure 4.18 Deck displacement at midspan

This transition in the deformed shape was initiated by the tensile failure of the stud connection on the inside of the fractured girder. As the pullout failure propagated along the length of the bridge, the bridge haunch separated from the concrete deck, leading to single curvature bending of the deck. Haunch separation in the bridge crosssection is schematically depicted in Figure 4.19. Once the haunch of the fractured girder separated from the deck, the transverse bending stiffness of the deck diminished. Subsequently, the tensile loading attributed to the fractured girder self-weight had to be carried by the studs on the outside of the fractured girder, which increased the bending 
moment arm for transverse bending of the deck. Therefore, with a wider separation of the haunch on the inside of the fractured girder, a larger deflection could be expected in the fractured girder than what was observed in the test.

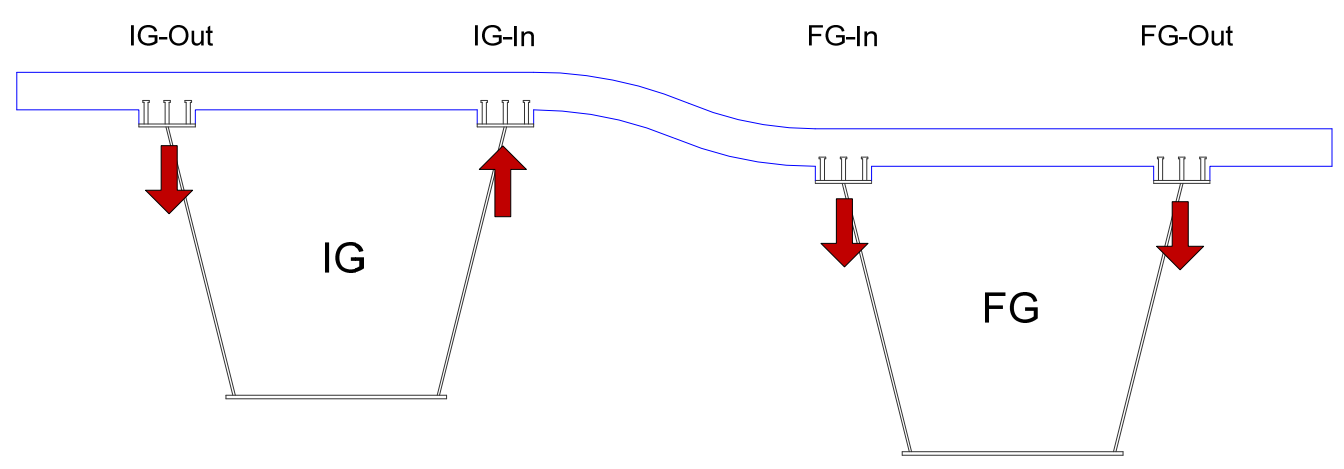

(a) Deck deflection before haunch separation

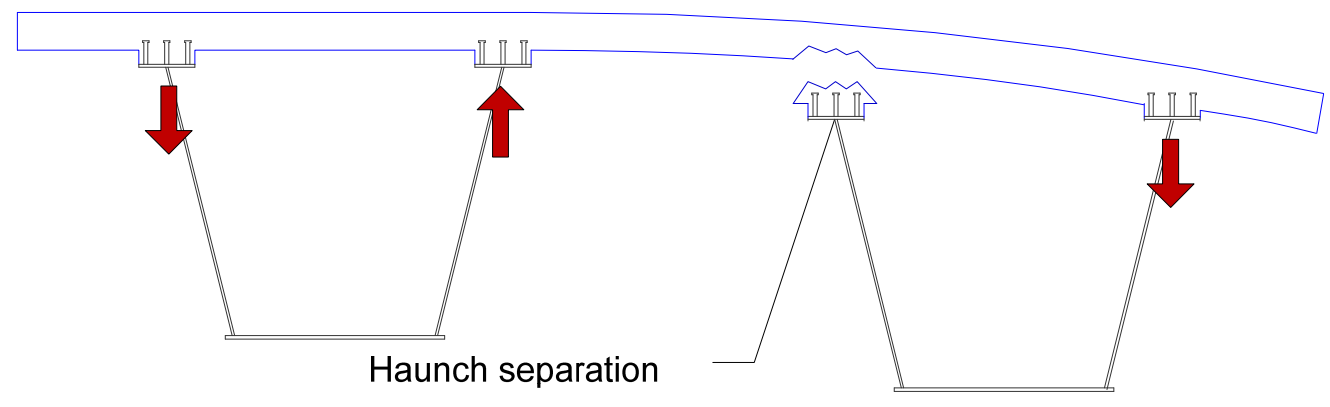

(b) Deck deflection after haunch separation

Figure 4.19 deck deflection shape change caused by haunch separation 


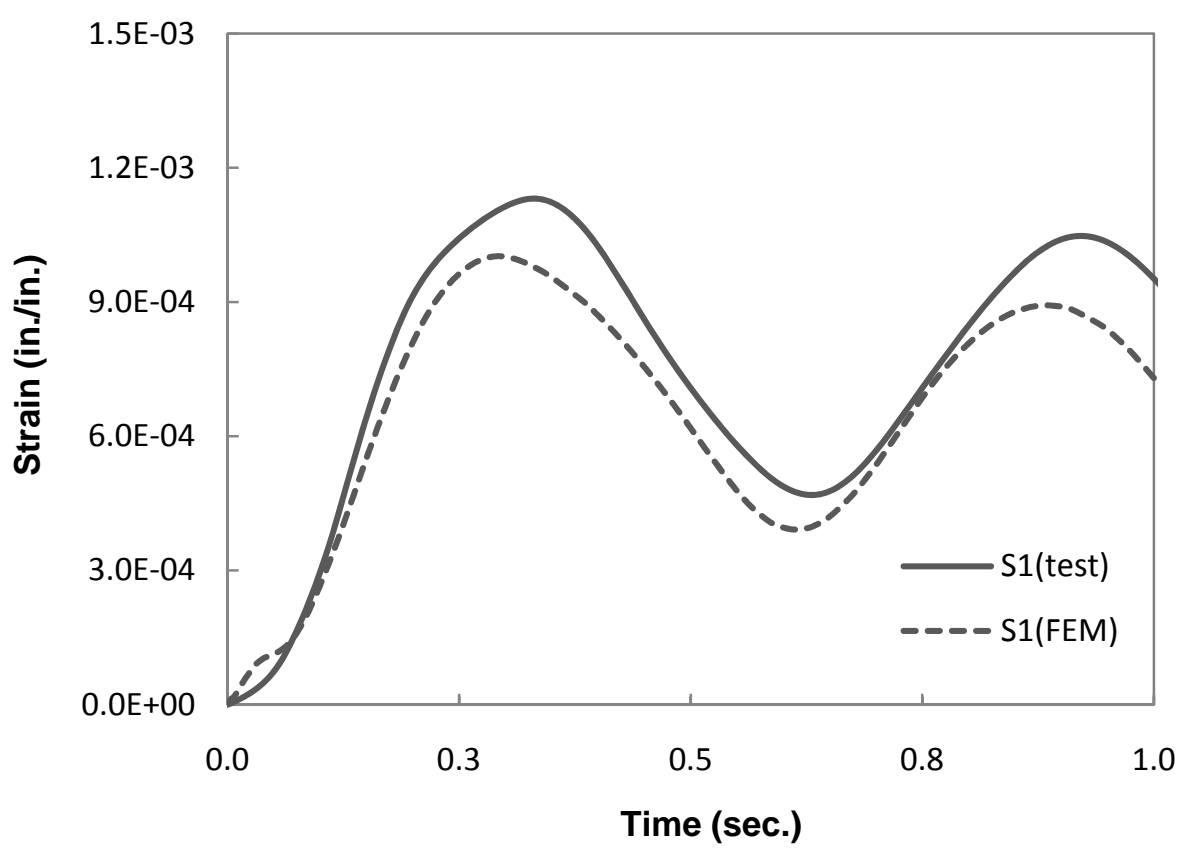

Figure 4.20 Longitudinal strain response by dynamic loading

Figure 4.20 shows the longitudinal strain as a function of time at the centerline of the bottom flange of the intact girder at a location $6 \mathrm{ft}$. away from the midspan. The strains from the simulation and the bridge test show good correspondence, though the peak measured strain from the test was 13\% higher than the simulation result. During the second bridge fracture test, it is important to note that the crack induced from the acetylene torch propagated 1 in. upward on the outside of the fractured girder, but this crack extension was not accounted for in the finite element simulation. Therefore, in the test bridge, more energy could be released than in the simulation, which may be one of the reasons why there is a slight discrepancy between the measured and computed results. Regarding the period of oscillation, there is a slight difference between the measured and computed values. This difference is most likely attributed to the differences between the actual damped response of the bridge and the assumptions made about damping in the 
finite element model. In the simulation, 5\% damping was assumed-which is a common assumption for cracked reinforced concrete (Newmark and Hall, 1982) - and the natural frequency of the first mode of the bridge model was utilized to determine a damping factor. Because no forced vibration testing of the bridge was carried out, the actual damped response was not precisely known. Nonetheless, the computed and measured results show good agreement.

\subsection{THIRD BRIDGE TEST (REMAINING CAPACITY EVALUATION)}

\subsubsection{Test procedure}

The third bridge test was performed to determine the ultimate load-carrying capacity of the FSEL bridge in its damaged state. It should be noted that no attempts were made to repair the bridge following either of the first two tests. The concrete blocks used to simulate the truck live load in the second bridge fracture test were rearranged for the third test, and one additional concrete block was utilized to create a bin that could accommodate the road base that was used to incrementally load the bridge (Figure 4.21). Accordingly, the total weight of the concrete blocks in the third bridge fracture test was 82.1 kips. Figure 4.21 shows a schematic of the concrete block configuration on the bridge deck. The concrete blocks were symmetrically arranged about the bridge midspan, and they were transversely biased toward the fractured girder. Wooden planks used to support the concrete blocks were located $2 \mathrm{ft}$. away from the east railing. 


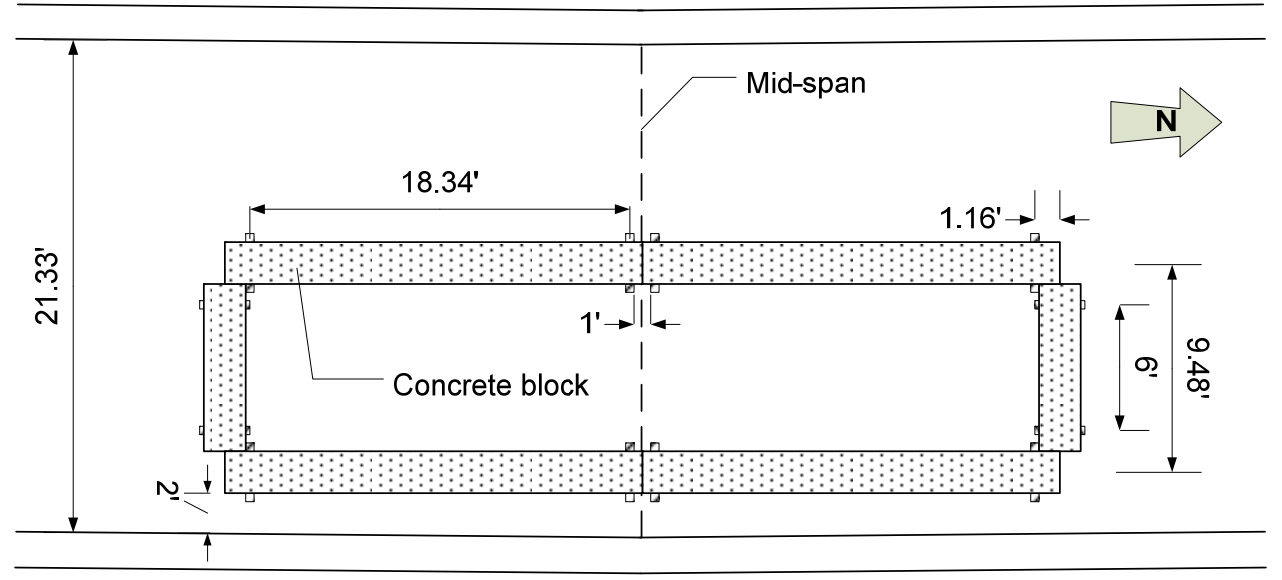

Figure 4.21 Concrete block configuration on bridge deck

While positioning the concrete blocks on the deck, the crack in the outside web of the fractured girder propagated toward the top flange, as shown in Figure 4.22. Prior to this crack propagation, the crack was sharpened by the 1-in. crack extension upward from the point where the torch cut terminated during the second bridge fracture test. The total loaded weight of the concrete blocks was 40.9 kips when the crack propagation occurred. This sudden crack propagation caused the bridge to vibrate, but the small oscillations quickly subsided. The crack on the inside web did not propagate when the concrete blocks were placed on the bridge. Though the weight and positioning of the blocks represented a less severe load case than the bridge withstood during the second test, it is believed that the cold weather present while the blocks were being placed during the third bridge test contributed to the crack extension (Neuman, 2009). 


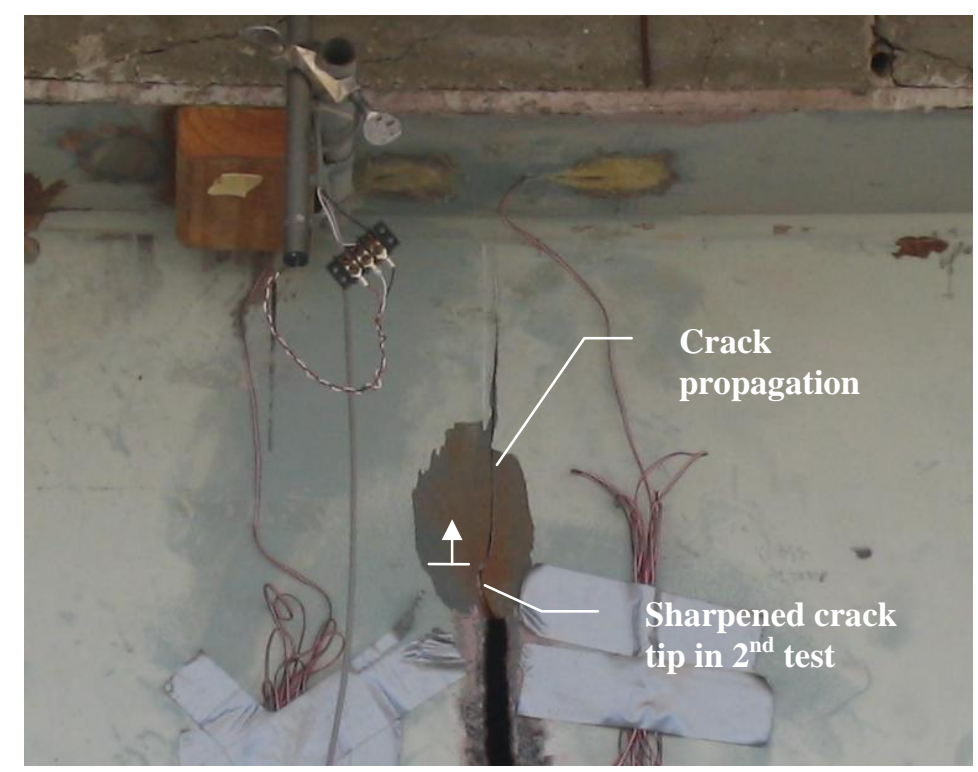

Figure 4.22 Crack propagation in fractured girder outside web

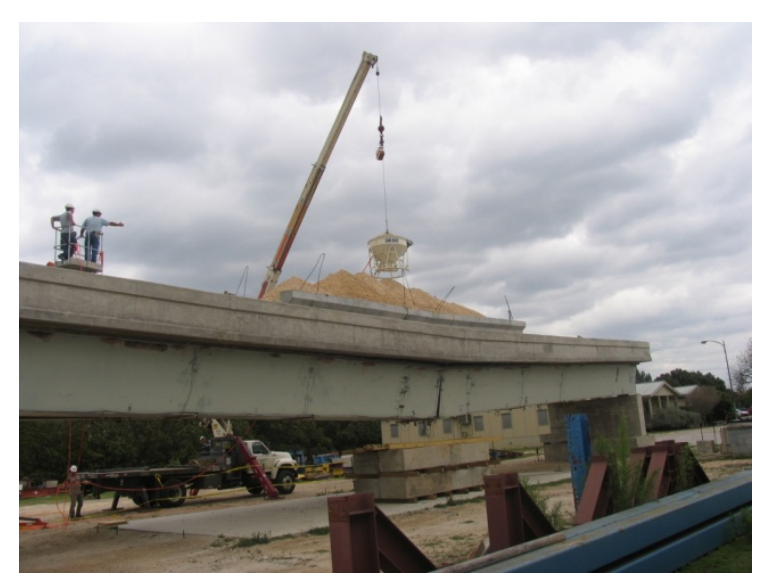

(a) Incremental loading

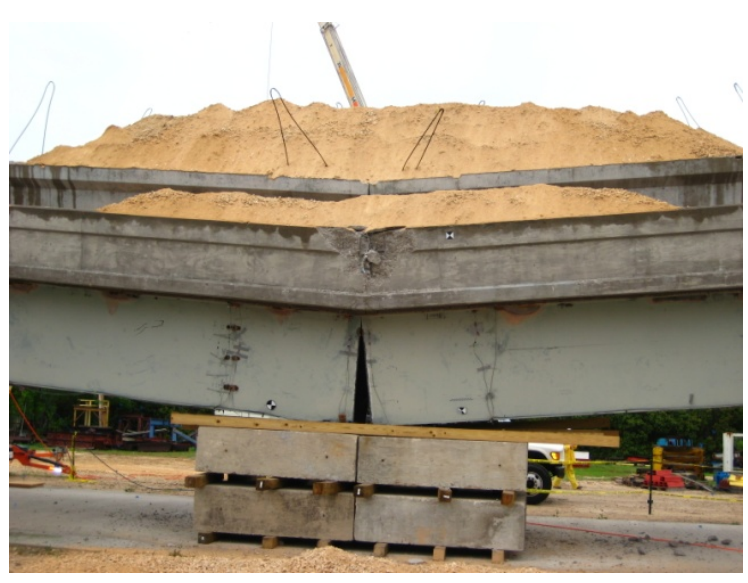

(b) Collapsed bridge

Figure 4.23 Loading process and bridge collapse in third bridge fracture test 
Figure 4.23(a) shows the loading process used during the third test on the FSEL bridge. Road base, consisting primarily of gravel and dirt, was placed in an air-operated lift bucket using a small backhoe. The lift bucket was attached to the lifting hook of a crane. Once the bucket was filled, the weight of the road base was measured using a load cell attached to the end of the crane hook. After the crane lifted the bucket and the weight was recorded, the lift bucket was positioned above the bridge, and the road base was placed inside the concrete bin located on the bridge deck (Figure 4.21). When 258.3 kips of road base was loaded onto the bridge, there was no more space available inside the bin. Therefore, it was decided to apply additional road base between the concrete blocks and the east railing. The bridge finally collapsed when the total applied load of the concrete blocks and road base reached 363 kips - more than five times the legal truck load-as shown in Figure 4.23(b).

\subsubsection{Simulation procedure}

The third bridge test simulation consisted of three main steps similar to those in the previous bridge test simulations, as presented in Table 4.3. Recall that for the second bridge fracture test, approximately $83 \%$ of the full height of the web was cut using an acetylene torch. During the second test, a fracture initiated from the top of the cut on the outside web of the fractured girder and extended approximately $1 \mathrm{in.}$ upward toward the top flange. While applying the concrete blocks for the third bridge test, this web crack extended to the top flange. The inside web crack also propagated up from the crack manually induced prior to the second test, and this cut extended through the entire depth of the web during the third bridge test. For these reasons, it was assumed that the entire web depth of the fractured girder was fractured. Accordingly, the web connector elements along the predefined fracture path were removed through the entire web height for the 
third bridge test simulation. Because the loading was incremental, the connector elements binding separated nodes along the predefined crack path were statically deactivated from the bottom flange to the top flange.

Table 4.3 Simulation procedures for third bridge fracture test

\section{Bridge construction}

1. Deactivating deck, railing, rebar elements and applying gravity to girder

2. Applying deck, railing, and rebar weight on the top flange

3. Activating deck, railing, and rebar elements with gravity and removing the weight on the top flange

4. Deactivating external cross frame elements and dummy elements

Applying girder fracture and truck live load

1. Deactivating elements connecting cracks in girder

2. Applying truck load (concrete blocks)

\section{Applying additional Load}

1. Applying additional load (road base)

After removing the web connections, the weight of the concrete blocks and the road base were applied to the bridge using pressure forces placed consistently with the bridge test as shown in Figure 4.24. When 258.3 kips of road base was placed inside the concrete bin during the third bridge test, there was no more space available to accommodate any additional material inside the bin. Consequently, additional road base was placed outside the bin between the east railing and the concrete block forming the eastern edge of the bin as shown in Figure 4.24(c). To match the loading location of this 
additional road base, the pressure load for the additional road base was applied between the east railing and the concrete block as shown in Figure 4.24(d).

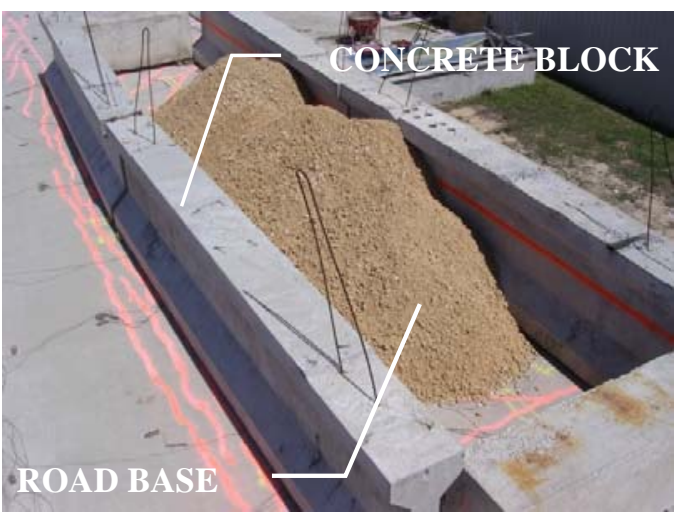

(a) Concrete block and load base

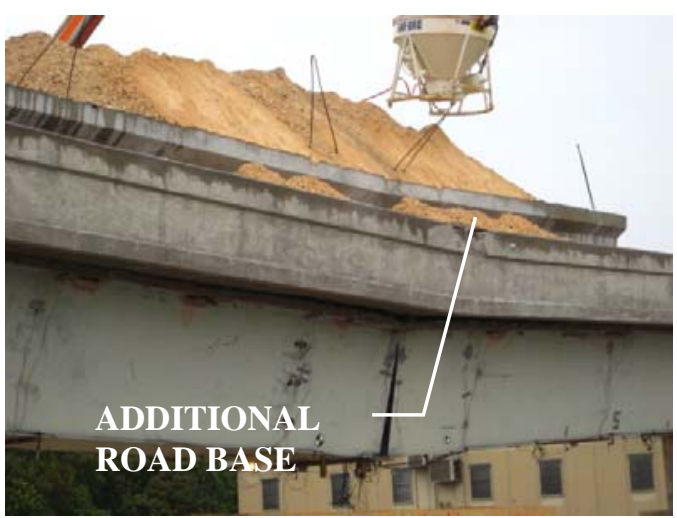

(c) Additional road base

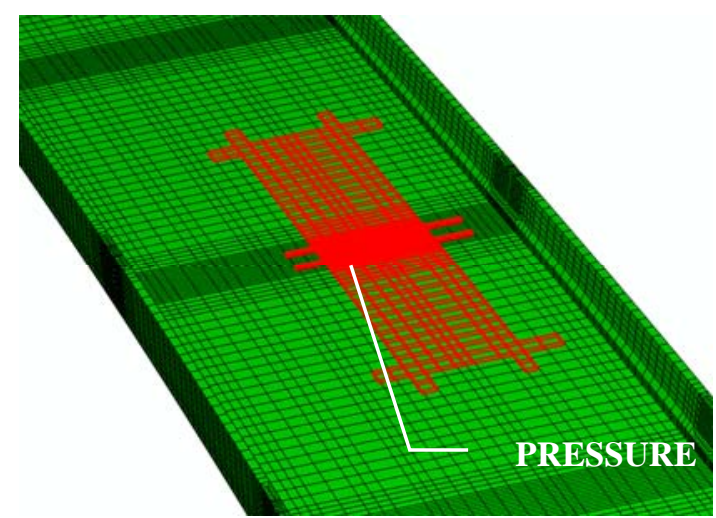

(b) Simulated pressure load

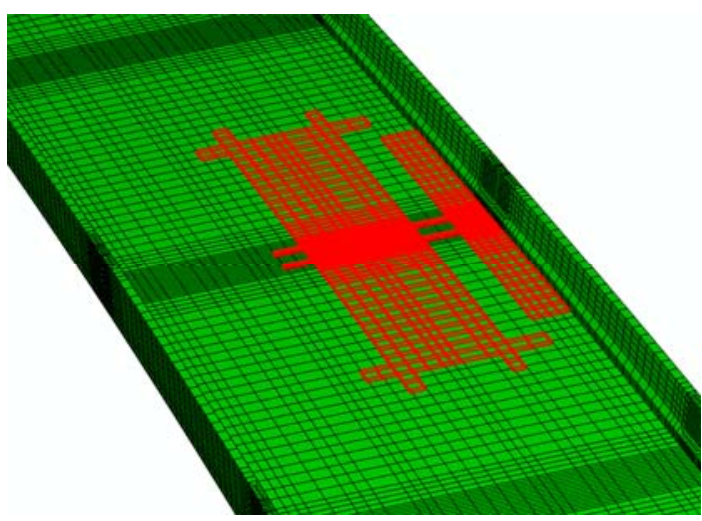

(d) Simulated additional load

Figure 4.24 Applying concrete block and road base load

For simulating the last step of applying the road base, a dynamic analysis was conducted using a ramped-loading condition; this approach was not intended to account for any dynamic loading effects associated with placing the road base. During the last 
analysis step, various local component failures were expected to occur, such as concrete cracking or crushing, haunch separation, and so on. Although those component failures might not necessarily mean collapse of the test bridge, they could cause computational problems with the static analysis procedure, potentially resulting in an analysis failure due to numerical convergence problems. Therefore, a dynamic analysis with a rampedloading condition was used to avoid such numerical problems.

\subsubsection{Bridge test and simulation results}

Data collected from the third bridge test were used to determine the ultimate strength of the bridge and the contribution made by each bridge component in resisting the applied loads. It was observed that the shear studs and the concrete deck had important roles in redistributing the applied loads to undamaged regions of the bridge. The rails also redistributed loads and initially reduced the deflection of the fractured girder before stud pull-out failures occurred. The finite element model developed for this research successfully captured the progressive bridge component failures that were found in the bridge fracture test and closely predicted the measured collapse load.

\subsubsection{Failure sequence of the bridge}

With the exception of the haunch separation along the outside of the intact girder near midspan, the simulation model predicted failure modes consistent with those observed in the bridge test. In Figure 4.25, the failure sequences predicted by the simulation and those observed during the bridge test are compared at each prominent component failure event. The failure sequence leading to the collapse of the bridge initiated with the concrete deck cracking due to transverse bending. As the loading 
continued, extensive tensile cracking started to form on the top of the concrete deck above the inside top flange of the intact girder and propagated along the bridge span. While the bridge continued to deform under the applied loads and transverse bending increased across the width of the deck, the demand on the shear studs along the inside of the fractured girder exceeded the tensile strength, leading to extensive tensile failures of stud connections on both top flanges of the fractured girder. As the tensile failures propagated along the bridge span, the inside haunch of the fractured girder began to separate from the bottom of the deck near the midspan of the bridge. While the separated haunch length along the inside of the fractured girder kept extending over the bridge span, the bridge deck experienced large deformations near the midspan, and the expansion joint at the top of the east railing closed over most of its height. Because of the contact forces acting over the depth of the expansion joint of the east rail at the midspan location, crushing of cover concrete became pronounced. As the east railing began to pick up loading and started to crush, the haunch separation along the inside of the fractured girder continued to extend as did the haunch separation along the outside of the fractured girder near the midspan. Separation of the haunch along the outside of the fractured girder was arrested when the separation had propagated to the next expansion joints (the expansion joint $30 \mathrm{ft}$. south and the expansion joint $30 \mathrm{ft}$. north away from the midspan expansion joint) along the length of the bridge. As the damage in the haunches of the fractured girder and the east railing progressed, the bottom of the reinforced concrete deck next to the interior top flange of the intact girder began to crush as a result of the transverse bending of the deck. Crushing at this location started at the midspan and propagated in both the north and south directions along the bridge span. This crushing of the deck was not readily detectable during the test because the permanent metal deck forms between the girders did not allow the concrete to be observed directly, but the 
extensive cracking on the top of the deck along a line corresponding to the position of the interior top flange of the intact girder and deck rotation about this line provided evidence that the bottom of the deck was crushed. As the applied load approached the maximum load, shear stresses along the haunch on the outside of the fractured girder increased, and bridge collapse eventually occurred when a shear failure took place over the entire length of the outside haunch of the fractured girder.
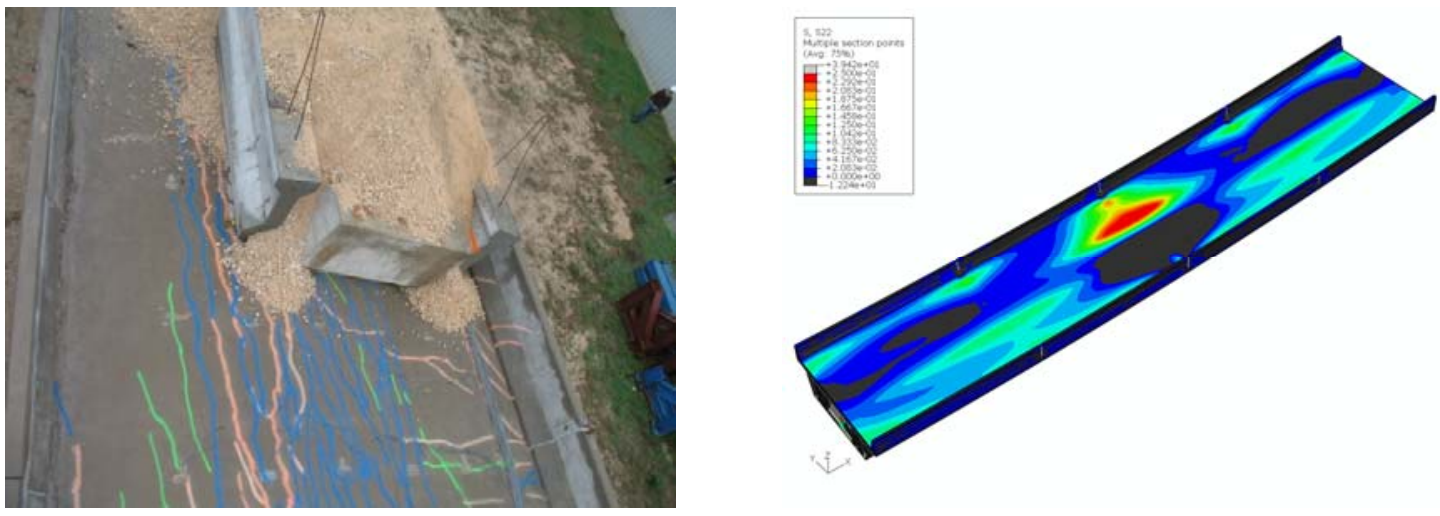

(a) Tensile cracking on top of the deck above IG-In top flange
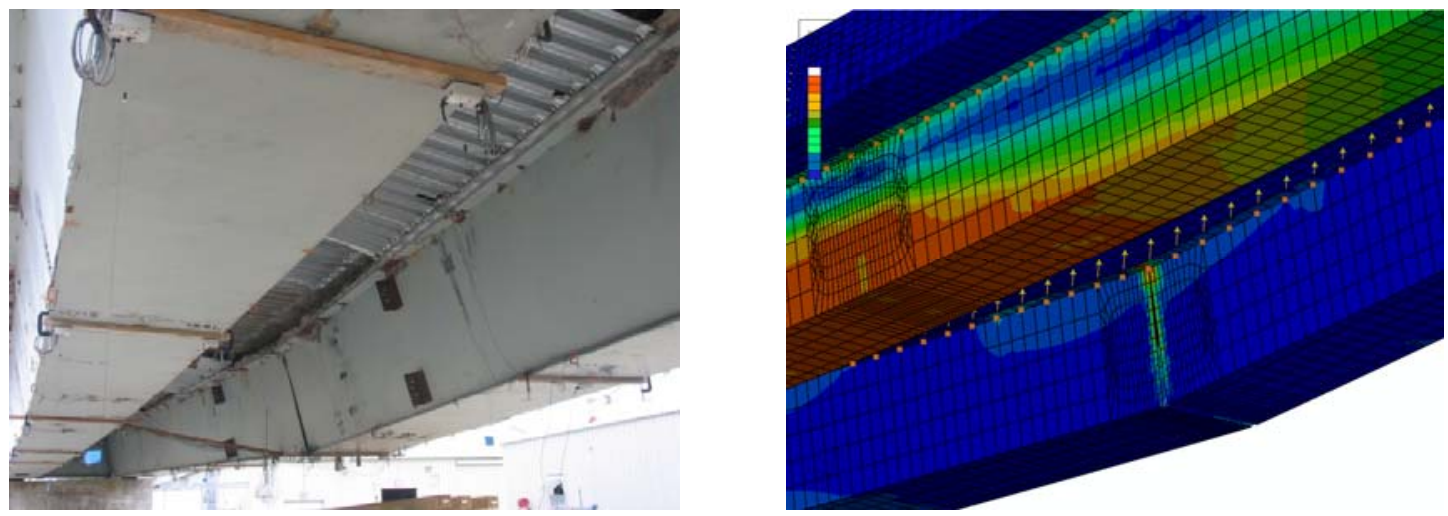

(b) Haunch separation along FG-In haunch 

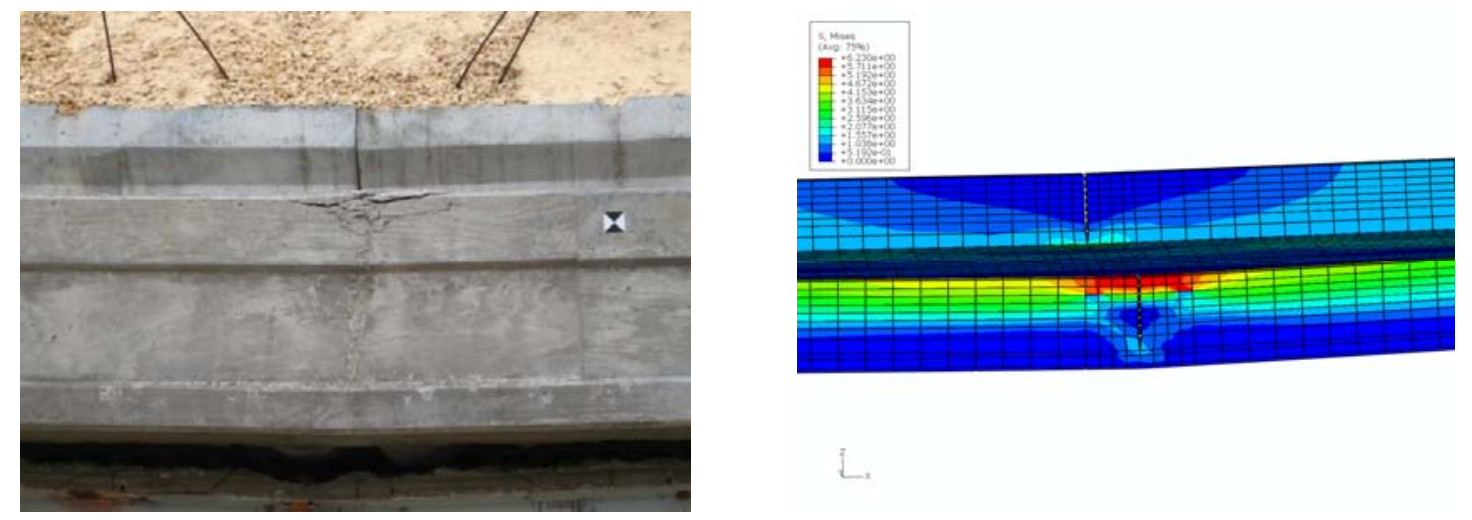

(c) Railing crushing from top
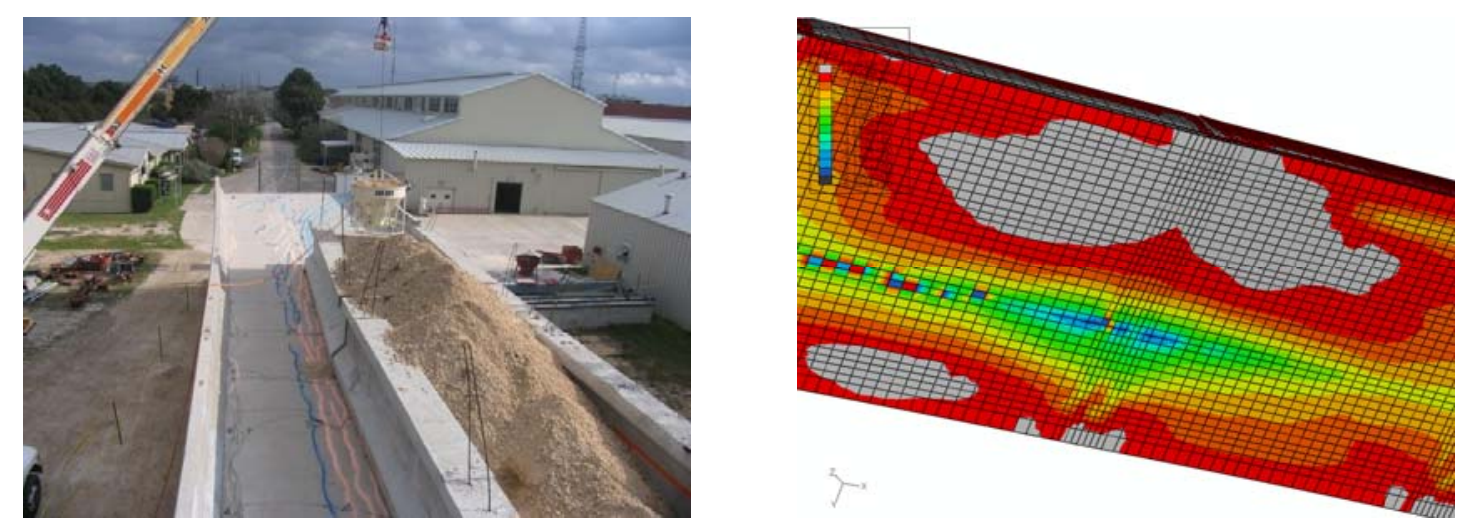

(d) Deck hinge formation along IG-In top flange
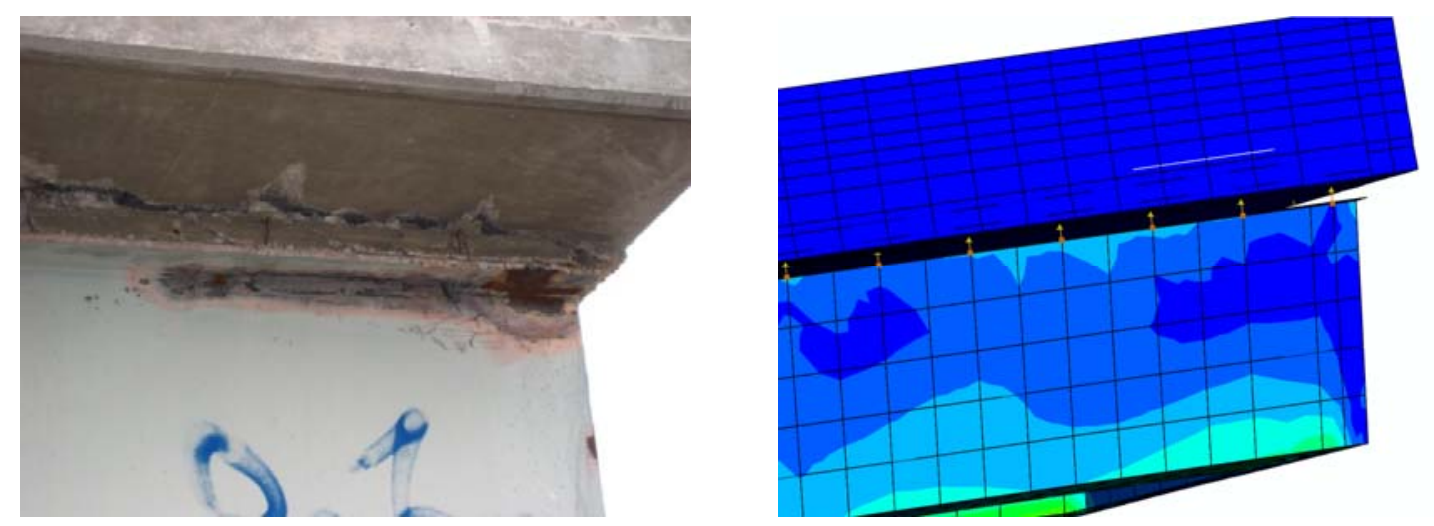

(e) Shear and tension failure of shear studs along FG-Out haunch 

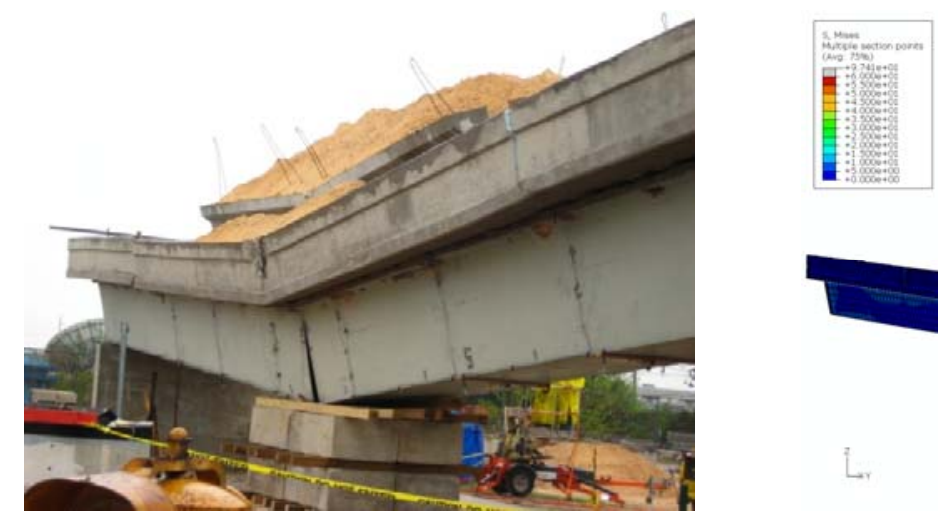

(f) Bridge collapse

Figure 4.25 Bridge component failure sequence

\subsubsection{Girder deflection response}

The girder vertical deflections measured in the third test are compared with the simulation results in Figure 4.26. The solid lines show the measured test data, and the dashed lines show the simulation results. During the bridge test, there was a sudden vertical deflection in the fractured girder when the applied load reached 160 kips, which is indicated with the first plateau in Figure 4.26. This sudden increase of the deflection was caused by the haunch separating from the outside of the fractured girder. The haunch separation initiated near the midspan and suddenly extended approximately $20 \mathrm{ft}$. to both the north and the south (i.e., a total separation of approximately $40 \mathrm{ft}$.), which is shown in Figure 4.27. Further separation of the haunch on the outside of the fractured girder did not occur until the applied load reached approximately $363 \mathrm{kips}$, which was the maximum load applied to the test bridge. Unlike the actual test, in the finite element simulation, the haunch separated gradually along the outside of the fractured girder until the applied loading reached 308 kips; no further haunch separation occurred until the applied load reached 413 kips, which was the maximum load the bridge could carry in the 
simulation. Although the gradual haunch separation in the simulation was not consistent with the sudden jump observed during the test, the simulation predicted $36 \mathrm{ft}$. of haunch separation along the outside of the fractured girder, which is similar to the actual haunch separation length of approximately $40 \mathrm{ft}$. observed during the test.

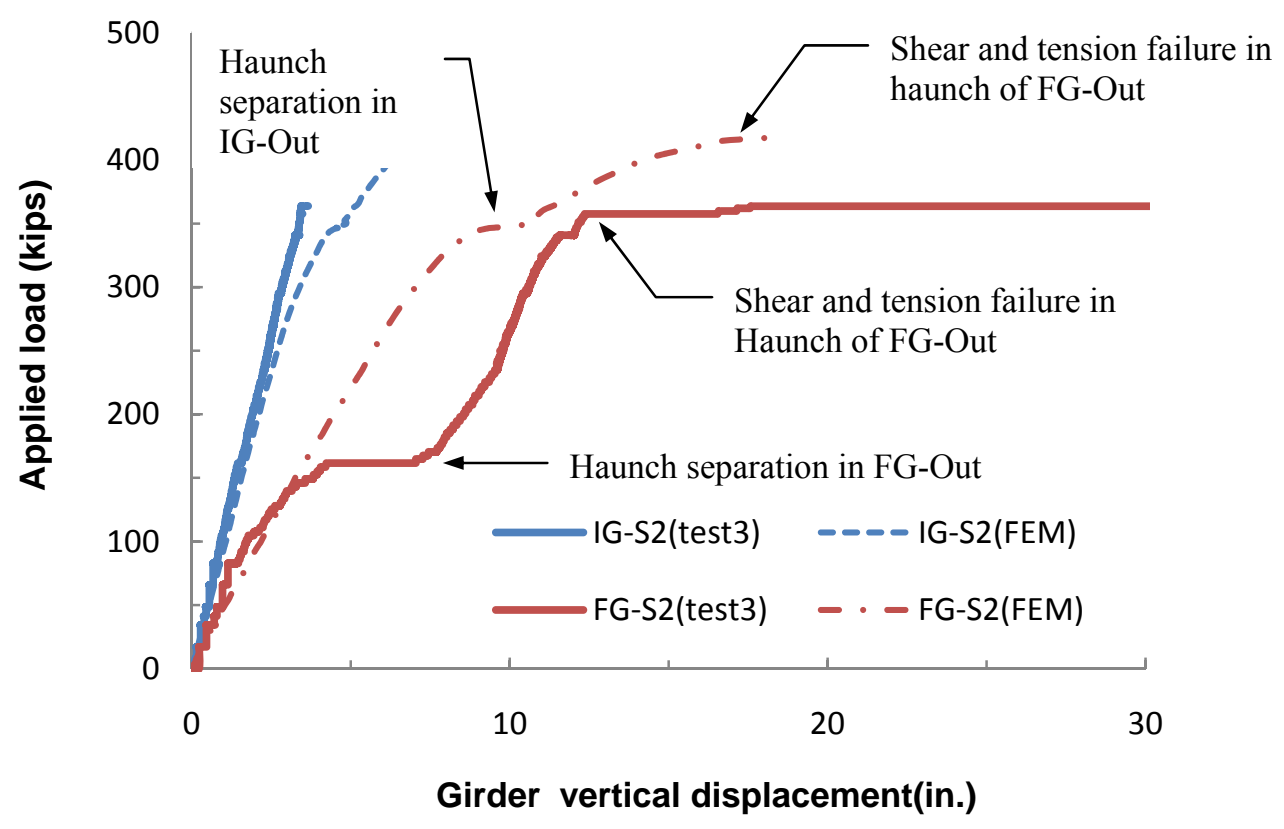

Figure 4.26 Girder deflection response (18 ft. away from midspan) 


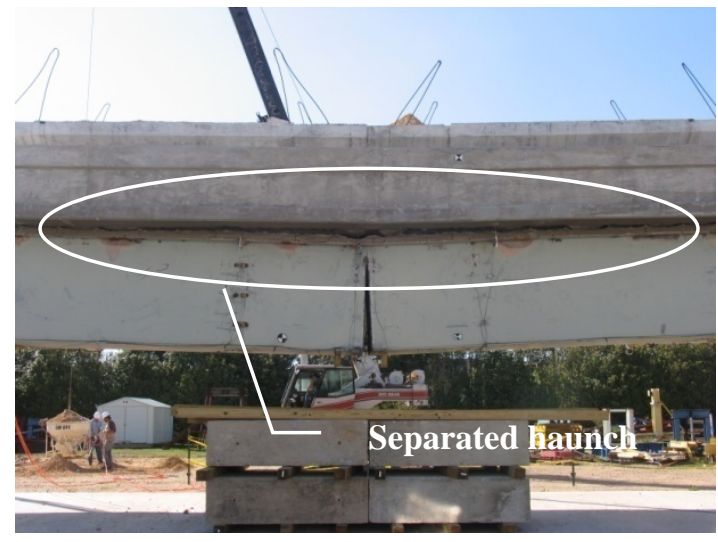

(a) Third bridge test

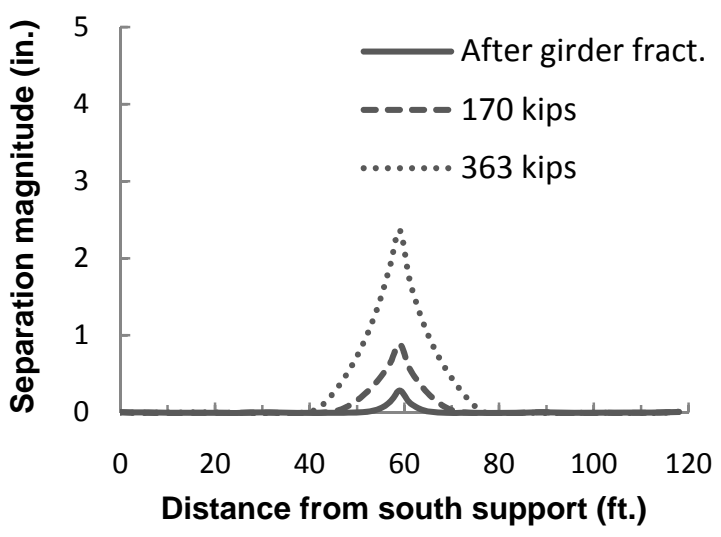

(b) Simulation model

Figure 4.27 Haunch separation in FG-Out
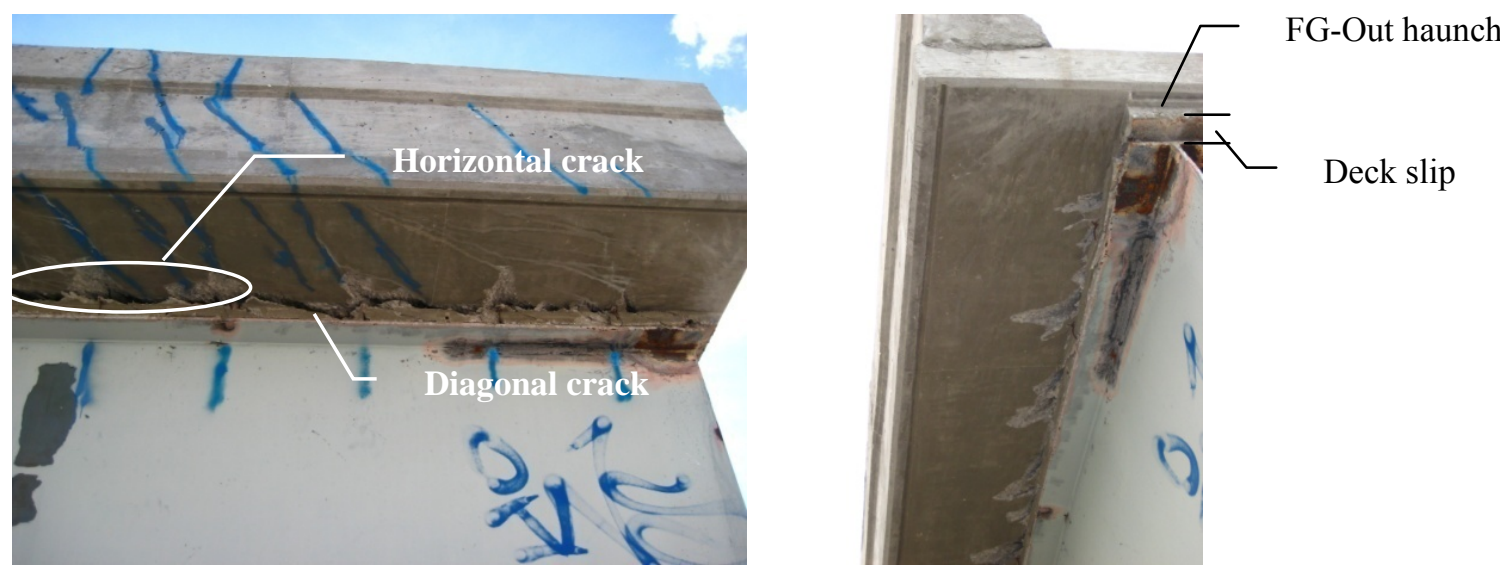

Figure 4.28 Slip between the deck and girder top flange along FG-Out

Another prominent feature in the girder deflection response of the test bridge occurred at the maximum load. When the applied load reached 363 kips, the fractured girder deflected significantly, and the bridge collapsed. This large deflection was initiated by the slip between the outside top flange of the fractured girder and the concrete deck, as 
shown in Figure 4.28. Along the outside haunch of the fractured girder, horizontal cracks and diagonal cracks were observed, which suggests that failure of the stud connection was due to the interaction of tension and shear forces. In the simulation model, shear forces in the connector elements became large along the outside of the fractured girder when the applied load approached its maximum value of 413 kips. Although the simulation showed a failure mode that was similar to that of the test bridge, the maximum load of the simulation model was $14 \%$ higher than that of the test bridge.

A notable point for this discrepancy is the shear strength equation (Equation 3.3) for the connector elements used to simulate the response of the shear studs in the bridge. As discussed in Chapter 3, Topkaya's (2002) experimental equations (Equation 3.3 and 3.4) for shear strength and shear load-slip behavior were based on stud push-out tests, and these equations were utilized in the simulation model for the shear response of the connector elements. In his tests, Topkaya (2002) used direct shear forces to investigate the shear load-slip behavior of shear studs embedded in a concrete block. Therefore, his equation might overestimate the shear strength of stud connections when a tension force is present. In the simulation model, the shear and tension responses of the connector elements were dealt with independently, and it was assumed that they did not affect each other's strength (i.e., they were uncoupled). The only exception was the shear strength degradation due to stud tensile failure, as discussed in Chapter 3. This degradation model, where the tensile failure of a stud connection can lead to shear failure, does not account for the possibility of the shear strength or the tensile strength being affected by the interaction of the combined shear-tension force acting on the shear studs. Thus, the shear strength of a stud connection might be affected if a high tension force-one that is less than the tensile strength-exists on that connection. Likewise, the tensile strength may be influenced by the presence of shear forces acting on a stud connection. 
Besides the possibility of the combined force effect (shear-tension force interaction) influencing the shear or the tensile strength of a stud connection, the geometry of the haunch might also affect the shear strength. In the bridge test, deck-slip failure started at a location about $20 \mathrm{ft}$. away from the midspan and extended both northward and southward. It was observed that cracks causing the deck slip were formed horizontally along the junction where the haunch was connected to the bottom of the deck and diagonally through the haunch height, as shown in the Figure 4.28. This observation suggests that the shear failure strength of stud connections could be affected by the haunch geometry. In the test setup utilized by Topkaya (2002), studs were embedded in a flat concrete block without a haunch; thus, equations used to predict shear response do not account for the potential influence of a haunch. In his tests, shear failure of the stud connection was initiated by concrete crushing around the stud. In the case where a haunch is present, extensive cracking in the haunch could influence the failure mechanism — an ultimately the shear capacity_ of stud connections.

To investigate the effects of stud shear strength on the ultimate load-carrying capacity of the bridge, a test simulation with a lower shear strength than the strength computed from the shear strength equation (Equation 3.3) was conducted. Figure 4.29 shows the simulation results using a reduced shear strength for the connector elements. A reduction in shear strength of approximately $23 \%$ was utilized in the simulation, which corresponds to the shear strength of a 3/4-in. diameter shear stud (the real shear stud diameter was $7 / 8$ in.). The simulation with the reduced shear strength predicted a maximum load capacity that was only $9 \%$ higher than the value measured during the bridge test, which demonstrates the significant impact that a small change in the specified capacity of the shear studs can have on the prediction of overall bridge capacity. Although the simulation with the reduced shear strength showed better agreement with 
the measured results, additional research is needed to develop expressions that can accurately account for the interaction of shear and tension forces acting on a stud embedded in a haunch.

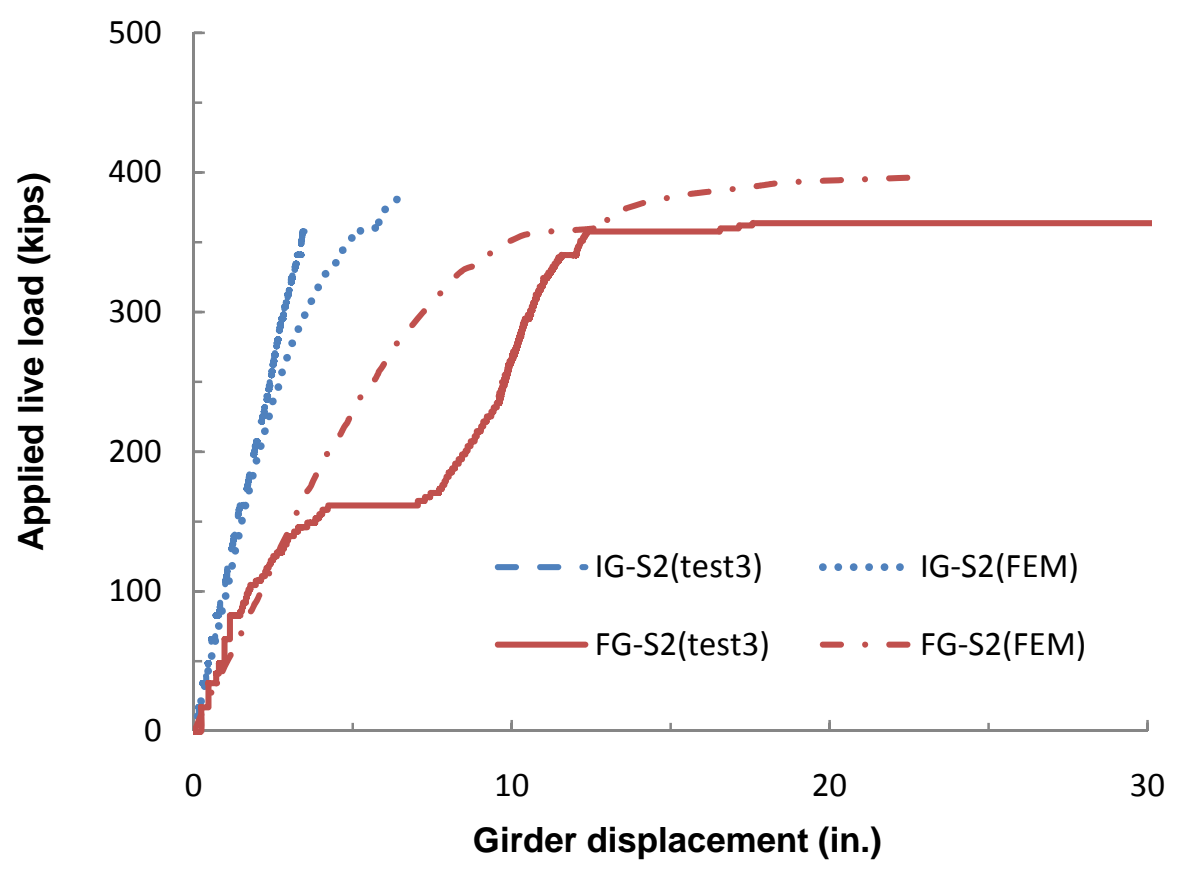

Figure 4.29 Girder displacement response with reduced shear strength

The simulation model indicated a failure mode that was not observed during the test. Unlike the experiment, the simulation showed separation of the haunch and deck along the outside of the intact girder, leading to an abrupt increase of the fractured girder deflection as the applied load approached 350 kips. This haunch separation initiated near the midspan. Once the haunch separated along the outside of the intact girder, the bridge lost transverse bending resistance, and the concrete deck rotated about the bridge's longitudinal axis because the outside and the inside haunches of the fractured girder had already separated near the midspan prior to the outside haunch separation of the intact 
girder. This difference in response between the simulation and test is believed to be attributed to the underestimated tensile strength of the stud connection computed from the modified pull-out strength equation (Equation 3.7) as discussed in the previous section.

\subsubsection{Railing engagement}

In the test bridge, the concrete cover on top of the east railing at the midspan location spalled off during the second bridge test, and the railing remained closed (i.e., in contact) at the top following the test. As the applied load was increased during the third bridge test, the concrete at the top of the railing began to crush, and the crushing propagated downward along the height of the rail. When the applied load reached approximately 360 kips, a large amount of concrete spalled off, as shown in Figure 4.30. The depth of spall was approximately $2 / 3$ the height of the railing.

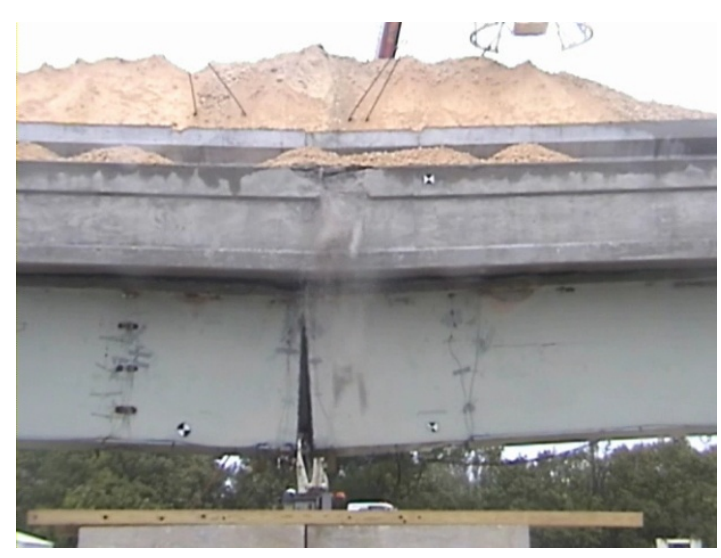

(a) Railing crush during test

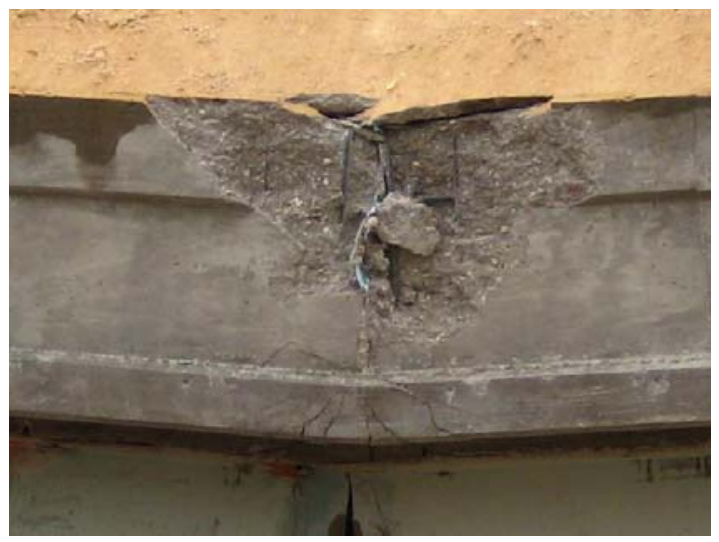

(b) Railing crush after collapse

Figure 4.30 East railing crush at midspan 
To account for the engagement of the rails at the midspan expansion joint, nonlinear spring elements were used rather than conducting a direct contact analysis. As discussed in the previous chapter, this choice was made based on computational efficiency. Figure 4.31(a) shows strain gauges installed on the inside of the east rail, and Figure 4.31(b) compares the longitudinal strains obtained from the bridge test with those computed from the finite element simulation. Railing contact occurred progressively from the top to the bottom of the east rail, which was confirmed by the strain gauge readings. Figure 4.31 (b) indicates that the simulation successfully captures the progressive contact of the rails along the railing height; however, the computed strains start to deviate from the test results after railing contact initiated. It is uncertain why such discrepancies exist, but they could be attributed to such factors as spalling of concrete cover, crushing and cracking of the rail concrete, and the presence of non-uniform contact forces through the width of the railing. The simplified modeling approach used in this study is not capable of representing these localized effects. After the bridge test, a large amount of spalled concrete cover was observed on the inside of the east rail at midspan. This observation suggests that the concrete strain gage readings may not accurately represent the strain variation in the rails during the test. In addition, it is likely that the contact forces that existed through the width of the railing were not uniform because the large deck deflection above the fractured girder caused the rails to rotate about a longitudinal axis parallel to the bridge span. The simulation model could not account for these effects because of limitations in the material model that was used to represent concrete and due to a limited mesh density through the width of the rails. 


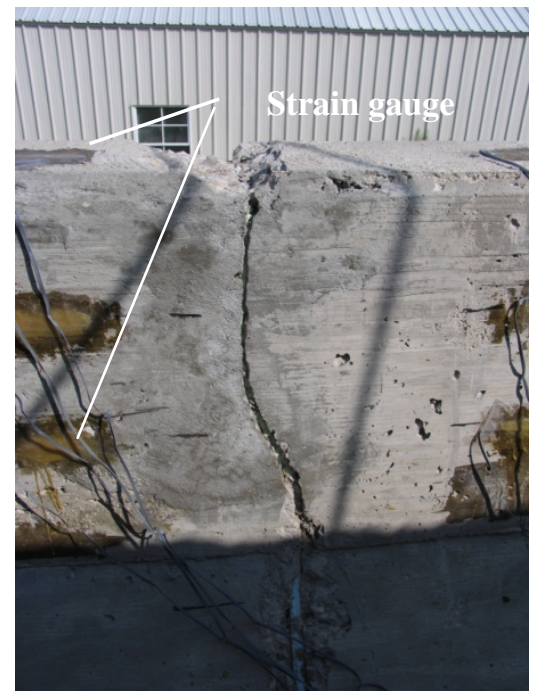

(a) Strain gauge setup

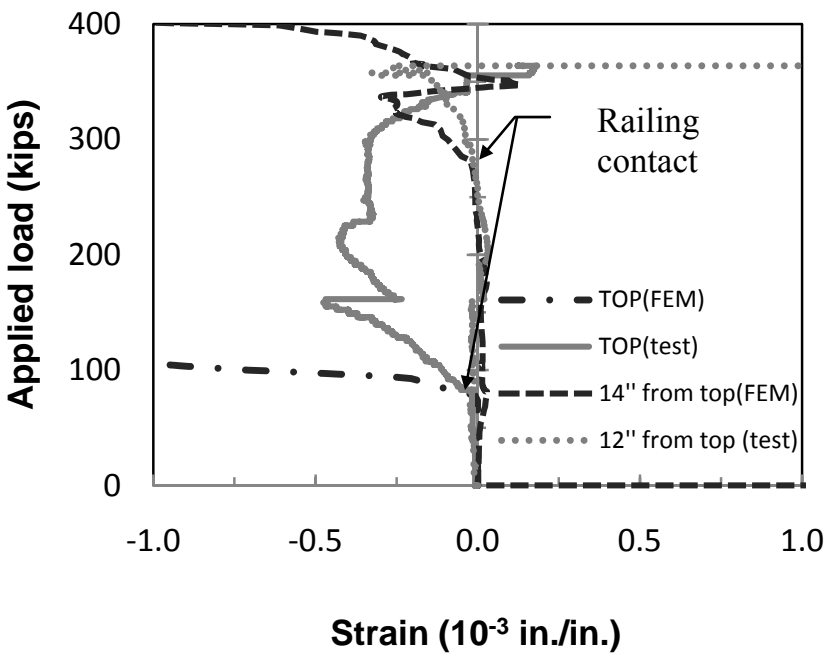

(b) Strain response through railing height

Figure 4.31 Longitudinal strain response along railing height

\subsection{SUMMARY}

Three sets of tests on a full-scale box-girder bridge were performed at the Ferguson Structural Engineering Laboratory at the University of Texas at Austin. The first bridge test involved rapidly severing the bottom flange of the exterior girder using explosives. The bridge demonstrated excellent performance despite the loss of the bottom flange. At the midspan position of the fractured girder, the bridge experienced a residual deflection of less than 1 in., and there was no damage evident to any components of the bridge. In the second bridge test, the webs of the east (exterior) girder were cut using an acetylene torch while the bridge was supported by a temporary truss system. The cut extended from the bottom flange fracture that existed following the first test up towards the top flanges, with $83 \%$ of the web height in a "pre-fractured" condition. With a simulated HS-20 truck positioned so as to generate the most severe loading, explosives were used to cause the sudden failure of the temporary truss system supporting the 
bridge. The failure of the temporary truss supports allowed the sudden release of the gravitational potential energy of the truck live load and the bridge self-weight. The bridge successfully sustained the induced damage and sudden release of the loads, though some of the components were damaged. The last bridge test was conducted to investigate the remaining load-carrying capacity of the damaged bridge. It sustained approximately 363 kips - more than five times the HS-20 truck load.

The finite element models developed to simulate the bridge tests compared well with the collected data and post-test observations. Furthermore, the finite element models successfully captured prominent bridge component failures that were observed during the second and the third bridge tests. A comparison of the test data with the simulation models suggested the possibility that equations used to define the behavior of connector elements used to represent shear studs in the bridge could overestimate the shear strength of stud connections and could underestimate the pullout strength. According to the bridge tests and the simulations, prominent failures of the bridge components were the haunch separation, initiated by tensile failures of stud connections, and crushing of the concrete rail. Therefore, including such component contributions is crucial for modeling a bridge to evaluate redundancy. In the next chapter, various factors that can affect the loadcarrying capacity of a fracture critical twin steel box-girder bridge are presented. 


\section{CHAPTER 5: PARAMETERS AFFECTING BRIDGE LOAD- CARRYING CAPACITY}

\subsection{INTRODUCTION}

Twin steel box-girder bridges have various load-transferring mechanisms that allow them to sustain traffic loads even if they suffer a full-depth fracture of one of their main girders, as demonstrated by the full-scale bridge tests and the corresponding simulations presented in Chapter 4. To better identify the sensitivity of the research findings to variations in some of the key performance parameters, finite element simulations were performed. Investigated parameters included changes in shear stud length, railing details, variations in horizontal curvature, variations in bridge span length, and degree of structural indeterminacy (i.e., a bridge with simple spans compared to a bridge with continuous spans).

To investigate how variations in these parameters affect the load-carrying capability of these types of fracture critical bridges, incremental load-displacement analyses were conducted for bridge models that were subjected to initial fractures of the bottom flange and webs of one girder, which is the same approach previously utilized to model the response of the FSEL test bridge during the third test (loading scenario B). The applied external loading consisted of an HS-20 truck positioned at the most critical location, but each axle load was increased proportionally until collapse was detected or the load reached five times one HS-20 truck load, whichever came first.

\subsection{CONCRETE STRENGTH AND TRUCK LIVE LOAD}

The HS-20 standard design truck utilized in this parameter study has a slightly different configuration than the simulated loading that was used in the third bridge test 
simulation. An HS-20 truck has three axles spaced $14 \mathrm{ft}$. apart longitudinally and two axles spaced $6 \mathrm{ft}$. apart transversely; the total truck weight is $72 \mathrm{kips}$. To apply a live load beyond one truck load, each axle load was increased proportionally relative to its original axle load. Although the simulated truck live load for the third bridge test (Chapter 4) was intended to represent an HS-20 truck loading configuration, it did not have distinct loading axles because of the manner in which the road base was applied to the test bridge. The road base was distributed through the inside of the concrete bin and the outside of the bin between the concrete block and the east railing of the test bridge.

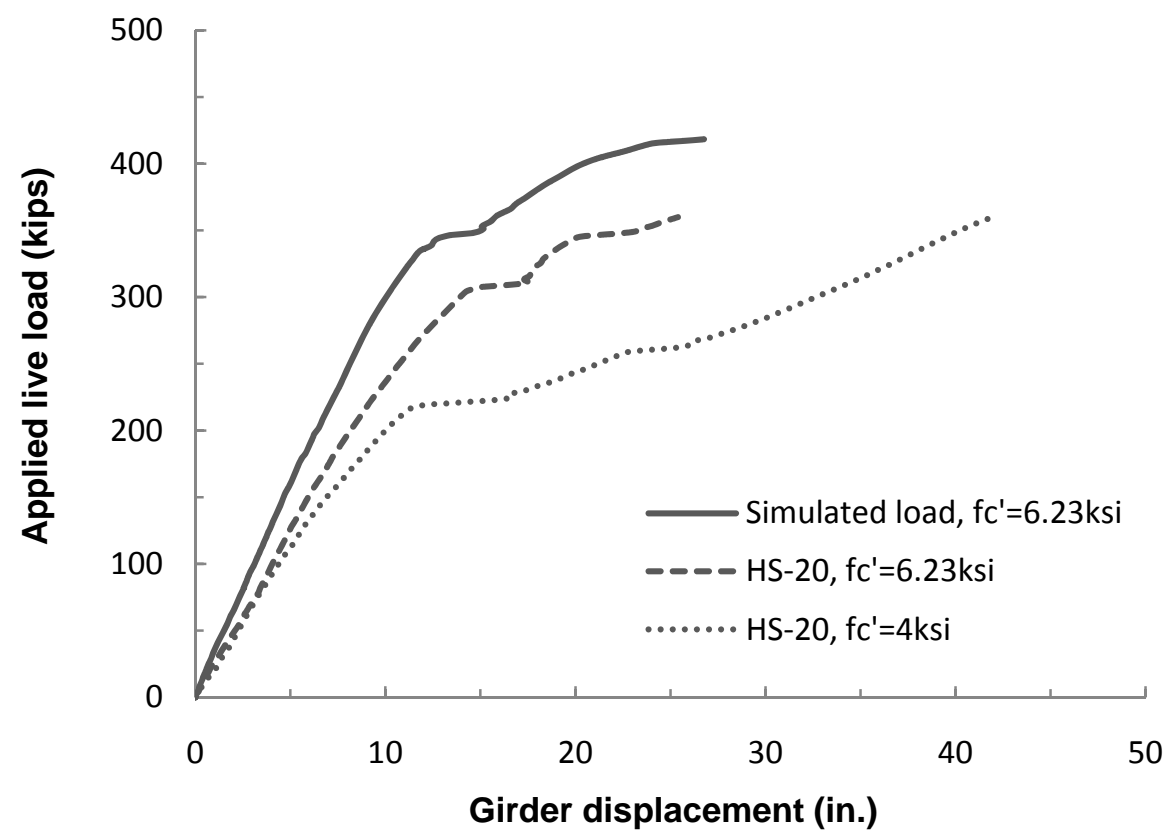

Figure 5.1 Fractured girder deflection at midspan (loading type and concrete strength effect)

To quantify the effects of changes in loading configuration and concrete material strength on the overall capacity of the test bridge, fractured girder displacements were 
computed for three different cases as shown in Figure 5.1. The displacements shown are those that occurred due to the applied live load following the girder fracture (i.e., no displacements due to construction loads or the girder fracture are included). All displacements shown in subsequent figures consider only the post-fracture displacements. The solid line in Figure 5.1 shows the result of the simulated live load from the third bridge fracture test, while the dashed line shows the results for the case when the live load is changed to an HS-20 truck. As mentioned above, the axle loads for the HS-20 truck load were increased proportionally relative to the original axle loads of one truck. Therefore, in the figure, a 144 kip load means placing one HS-20 truck on top of another. Comparing the results of the HS-20 load case and the simulated loading, the HS-20 load case has a more severe loading effect than the simulated loading used during the third bridge test. One reason for these results is that the HS-20 loading configuration has a longer lever arm for transverse bending than the simulated loading because the road base of the simulated load was distributed over a wider region of the deck than the more concentrated loading of the HS-20 truck.

In addition to the issue of loading configuration differences, it is important to consider variations in concrete compressive strengths because of the wide range that has been used in the bridge industry. According to Russell's report (2003), specified concrete strengths used for bridge deck construction varied predominantly from 4,000 psi to 8,000 psi. In order to have consistent evaluations on bridge load-carrying capacities for the current parameter study, a concrete compressive strength of 4,000 psi was used; when representing the actual bridge tests described in Chapter 4, measured material strengths from concrete cylinder tests were specified in the finite element models. The concrete compressive strength not only affects the bending stiffness of a bridge deck, but according to Equations 3.3 and 3.8, it also influences the shear strength and the tensile 
strength of a stud connection (i.e., decreased concrete strength reduces the shear and the tensile strength of a stud connection). The dotted line in Figure 5.1 is the computed girder deflection for a bridge model that has a concrete deck with a specified compressive strength of 4,000 psi. As expected, the results show a lower stiffness and a load-carrying capacity than the other cases. Consequently, in order to develop conservative estimates of the remaining capacity of fracture critical twin steel box-girder bridges subjected to the full-depth fracture of one girder, loads are assumed to be positioned and proportioned according to the axle loads of an HS-20 truck, and concrete material strengths are conservatively estimated to be 4,000 psi.

\subsection{BACKGROUND INFORMATION ON BRIDGES INVESTIGATED DURING PARAMETER STUDIES}

Four bridge models that differed in span length were utilized to investigate various parameters affecting bridge load-carrying capacity. Box-girder dimensions and geometries of these models are presented in Figure 5.2 and Table 5.1. The values in Table 5.1 are representative dimensions at girder fracture locations. These dimensions were collected from shop drawings provided by TxDOT. Among the four prototype bridges shown in Table 5.1, three bridges (S200, S170, and C130) are currently in service as the WOODWAY exit ramp near the intersection of Interstate I-10 and Loop 610 in Houston, and another one (S120) is the test bridge reconstructed at the Ferguson Structural Engineering Laboratory at the University of Texas at Austin. In Table 5.1, three models are simply supported bridges that are labeled with an "S" in the front of the model name, and the model with the label " $\mathrm{C}$ " is a continuous bridge having two equal spans. 


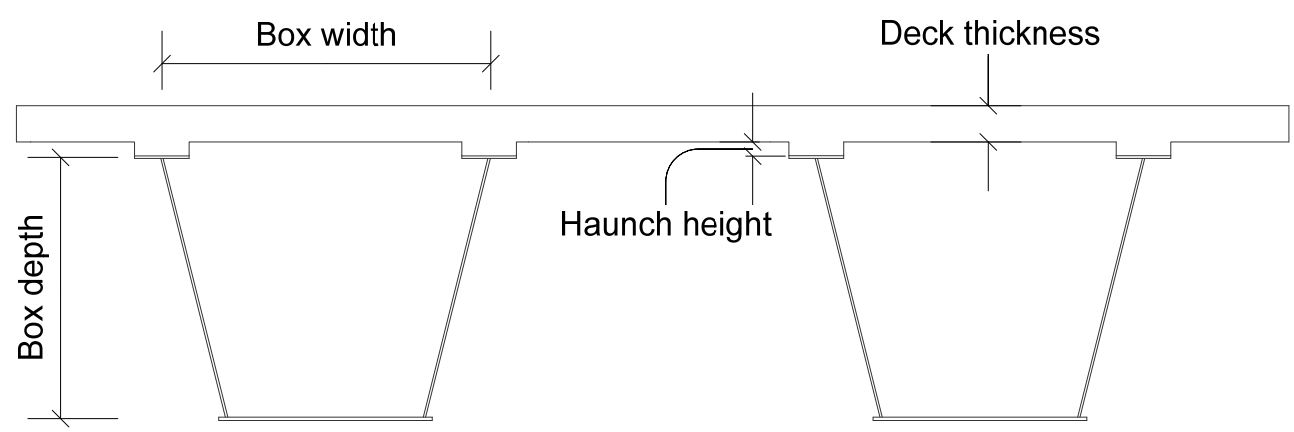

Figure 5.2 Cross-section view of twin steel box-girder bridge

Table 5.1 Box girder dimensions at fracture location

\begin{tabular}{|c|c|c|c|c|c|c|c|}
\hline \multirow{2}{*}{ Model } & \multirow{2}{*}{$\begin{array}{c}\text { Span } \\
\text { length (ft.) }\end{array}$} & \multicolumn{5}{|c|}{ Box girder dimension } \\
\cline { 3 - 6 } & & Thickness (in.) & \multirow{2}{*}{ Width (in.) } & \multirow{2}{*}{ Depth (in.) } & Span/Depth \\
\cline { 3 - 8 } & & Bot. flange & Web & Top flange & & & \\
\hline S200 & 200 & 2.00 & 0.75 & 1.75 & 84.0 & 86.0 & 27.9 \\
\hline S170 & 170 & 1.50 & 0.75 & 1.50 & 84.0 & 86.0 & 23.7 \\
\hline C130 & 130 & 0.88 & 0.50 & 0.75 & 84.0 & 53.2 & 29.1 \\
\hline S120 & 120 & 0.75 & 0.50 & 0.64 & 72.0 & 57.7 & 25.0 \\
\hline
\end{tabular}

\subsection{BRIDGE COMPONENT CONTRIBUTIONS ON BRIDGE CAPACITY}

\subsubsection{Stud length and deck haunch}

The robustness of stud connections plays an important role in the overall loadcarrying capacity of a bridge because they enable the bridge to maintain composite action between the steel girders and the concrete deck. Under normal conditions when both girders are fully intact, the stud connections resist mainly shear forces. In the event that a girder fracture occurs, however, high tension forces will act on the stud connections of the fractured girder. During the bridge tests carried out under this research project, such 
tension forces initiated tensile failures of the stud connections along the fractured girder, leading to a significant reduction in the transverse bending stiffness of the bridge.

Based on the stud pull-out test results reported by Mouras (2008), the tensile strength of a stud connection is proportional to the embedded length of a stud into the deck because a longer length increases the concrete failure cone size surrounding a stud. The presence of a haunch between the bottom of the deck and the top flanges of the steel girders, however, reduces the effective embedded length of a stud. In addition to the embedded length reduction, the haunch also confines the failure cone shape and thereby reduces the concrete surface area available to resist the applied tension force. Because of these two factors, the tensile strength of a stud embedded in a haunch is less than it would be in the case no haunch is present. In spite of these drawbacks, a haunch is frequently used in bridge construction because it is needed to maintain a uniform concrete deck thickness. For this reason, the effect of a haunch on the tensile strength of a stud connection was considered in the bridge parameter studies, and the height of the haunch was consistently assumed to be $3 \mathrm{in}$, which is the maximum haunch height allowed by the TxDOT Bridge Detailing Manual (2001) unless reinforcing in the haunch is provided.

Figure 5.3 shows the tensile strengths of stud connections for different stud configurations obtained from laboratory tests (Mouras, 2008) along with the predicted results from Equation 3.7. The tensile strength is plotted against the effective stud length, $h_{e f}$, normalized by the haunch width, $w_{h}$. The variable $h_{e f}$ is defined as the length a stud is embedded into the concrete deck, excluding the haunch height and the stud head. As shown in Figure 5.3, tensile strength goes up as the effective stud length becomes longer and the concrete strength increases. 


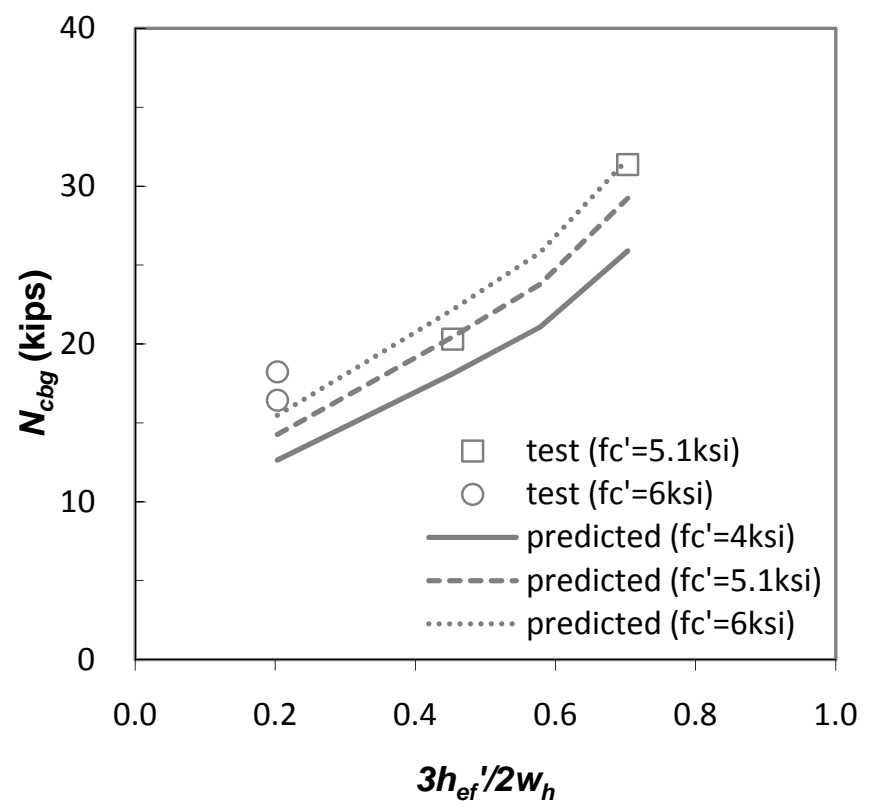

Figure 5.3 Tensile strength variation along stud length

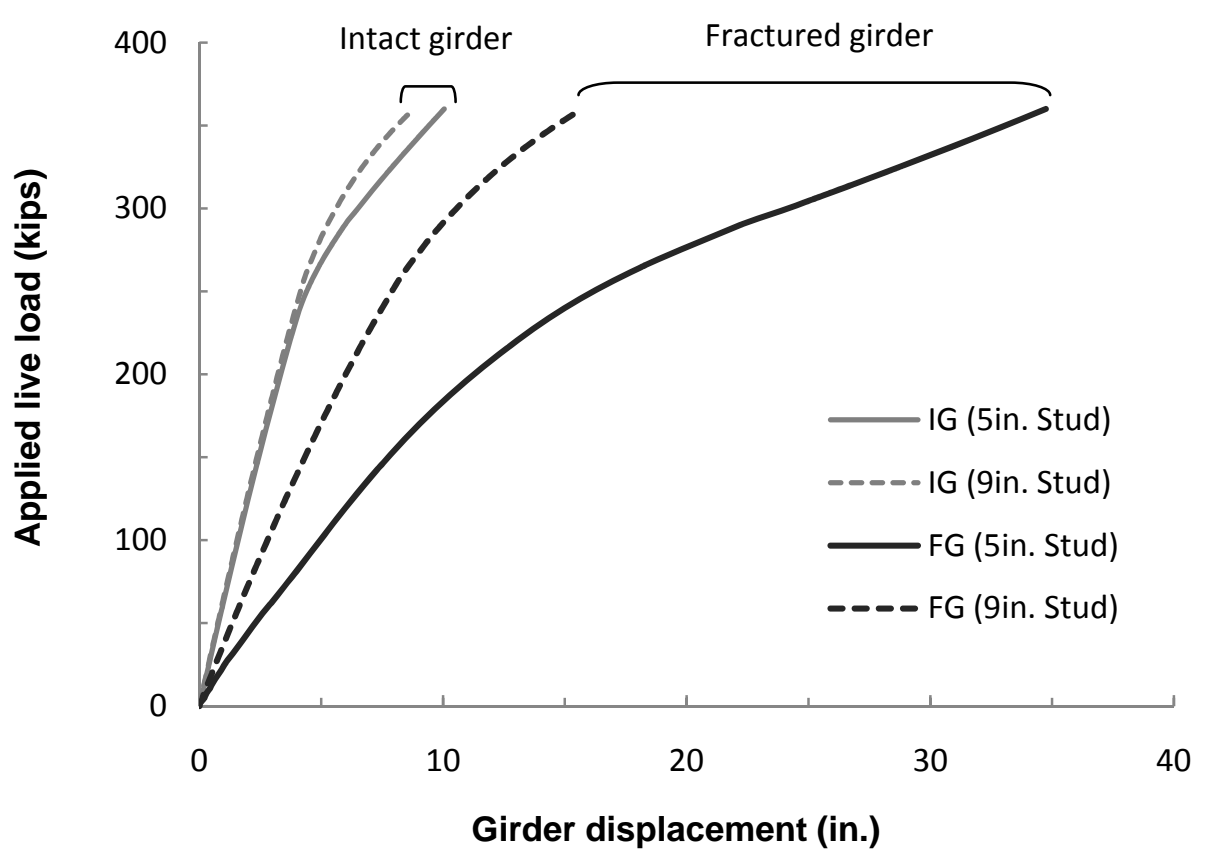

Figure 5.4 Girder deflection at midspan (stud length effect) 
To investigate the tensile strength effects of a stud connection on bridge loadcarrying capacity, finite element bridge models excluding rails were studied. Rails were excluded from these models in an attempt to isolate the effects of the shear stud strength on overall performance. For these analyses, the assumed concrete strength was 4,000 psi, and the HS-20 loading configuration was used. Figure 5.4 shows the girder displacements for bridge models with a span of $120 \mathrm{ft}$. In this figure, girder displacements of a bridge model with 5-in. stud connections are plotted with solid lines, and displacements of a bridge model with 9-in. studs are plotted with dashed lines. This figure shows that the displacements of both girders are reduced when the stud length is increased, and such displacement reductions are significant in the fractured girder. This tendency was consistently observed through simulations of bridge models with other span lengths (C130, S170, and S200).

A detailed study of the simulation results indicated that such displacement reductions were related to differences in haunch separation behavior. In all models studied, prominent haunch separations occurred along the insides of fractured girders, which resulted in transverse bending stiffness reductions across bridge decks and led to large increases in the displacements of the fractured girders. The outside haunches of fractured girders also separated near the fracture locations in the bridge simulation models. In addition to the transverse bending stiffness reductions, these haunch separations also reduced the vertical bending stiffness of bridges by removing composite behavior between the concrete decks and the steel girders. Computed results suggest that as the haunch separation length increases, bridges will demonstrate reduced stiffness and larger deflections. Figure 5.5 shows the separated haunch length along the inside of the fractured girder for a model with 5-in. studs. When a separation magnitude representing the vertical displacement of a stud connector element exceeded its tensile displacement, 
$U_{m}$, computed from Equation 3.12, it was assumed that the stud connection was separated from the deck. To investigate the separated length of a haunch as a function of the embedded stud length, haunch separation lengths were plotted against applied live loads following a girder fracture event. These results are shown in Figure 5.6, where the separation lengths are normalized by the bridge span length and the applied loads are normalized by one HS-20 truck load. The 9-in. stud model did not show any haunch separation along the outside of the fractured girder; thus only the separated length of the fractured girder inside haunch (FG-in) is plotted in Figure 5.6. The separated haunch length of the 9-in. stud model is much less than that of the 5-in. stud model which led to a stiffer response and smaller deflections for the fractured girder in the 9-in. stud model compared to the model with 5 -in. studs.

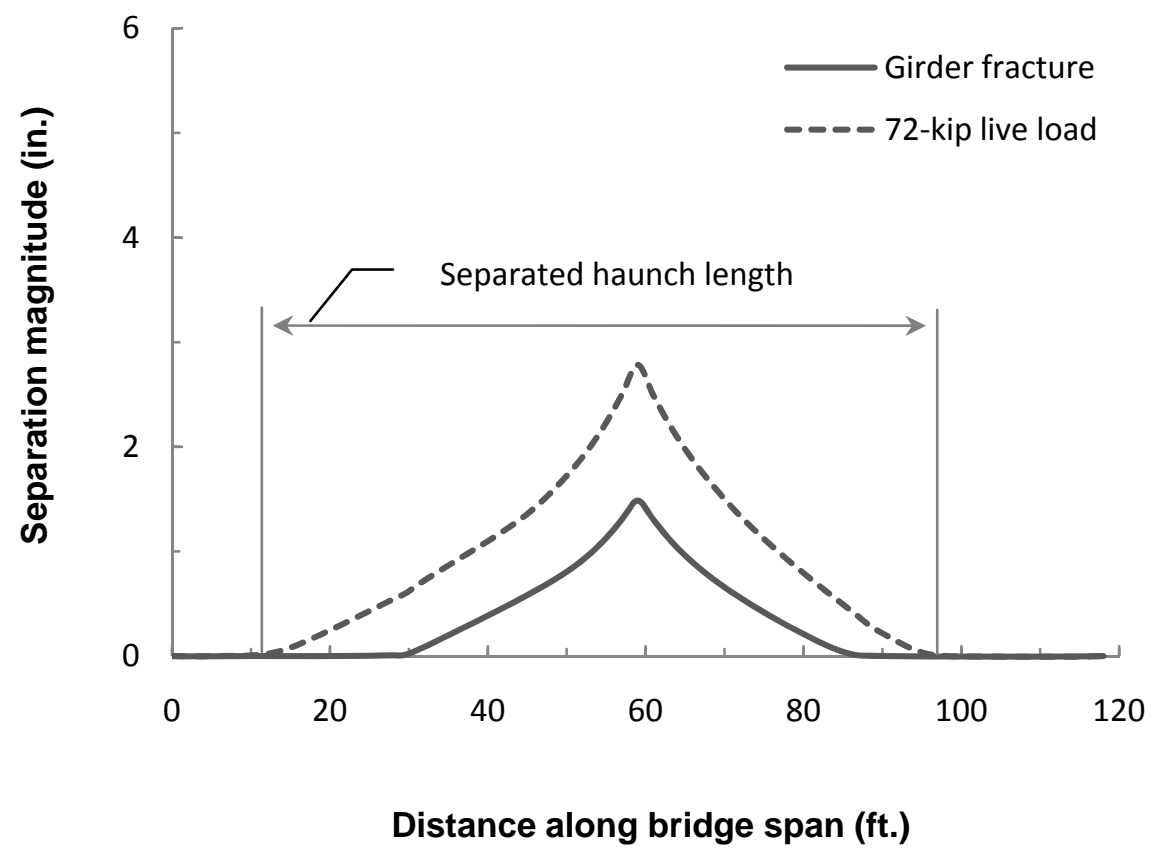

Figure 5.5 Haunch separation in FG-In (5in. stud model) 


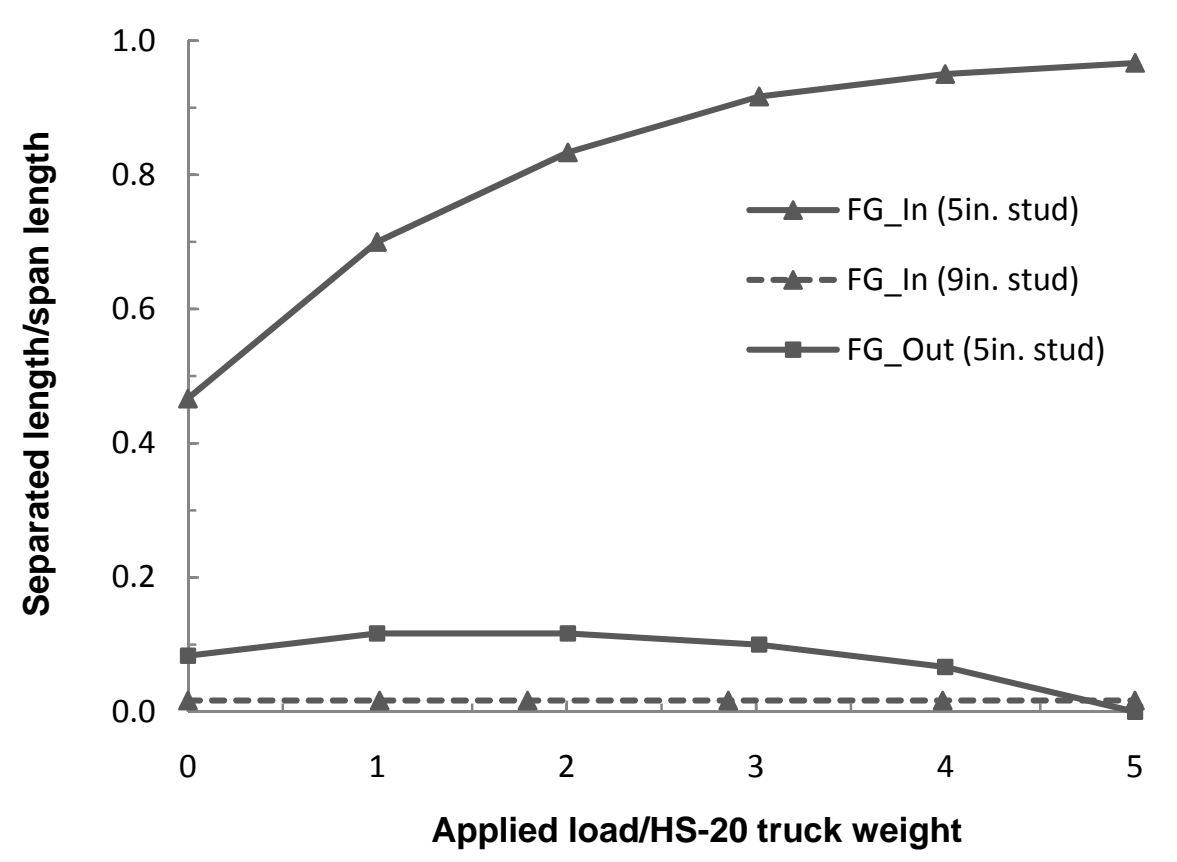

Figure 5.6 Separated haunch length variation along applied load

\subsubsection{Railing}

Bridge deflections with and without the presence of a railing were investigated using a TxDOT standard T501 rail as shown in Figure 5.7; this rail was selected because it is widely used in practice. For models that include rails, expansion joints were placed above the fracture location to minimize the potential increase in bending stiffness rails may offer at that location. For consistency with the full-scale test bridge, all finite element models with rails assumed that expansion joints were spaced every $30 \mathrm{ft}$. along the bridge span, and gap openings between rail sections were assumed to be 3/4-in. As with the models used to represent the FSEL test bridge, spring elements were placed in the expansion joints to account for potential contact of railing sections in the event that large deflections caused the expansion joints to close. 


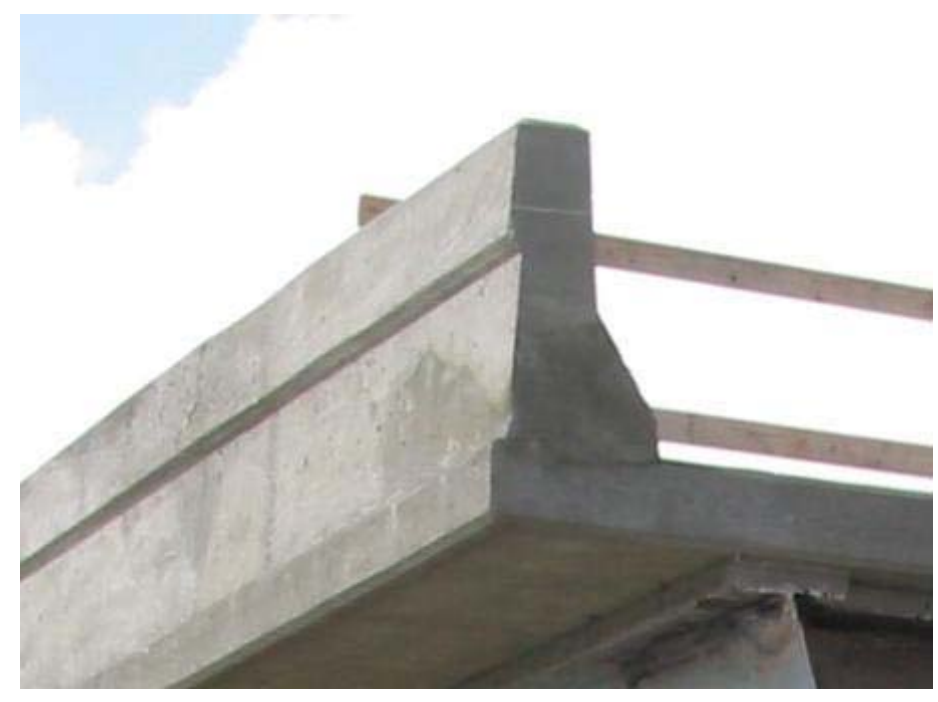

Figure 5.7 T501 rail of FSEL bridge

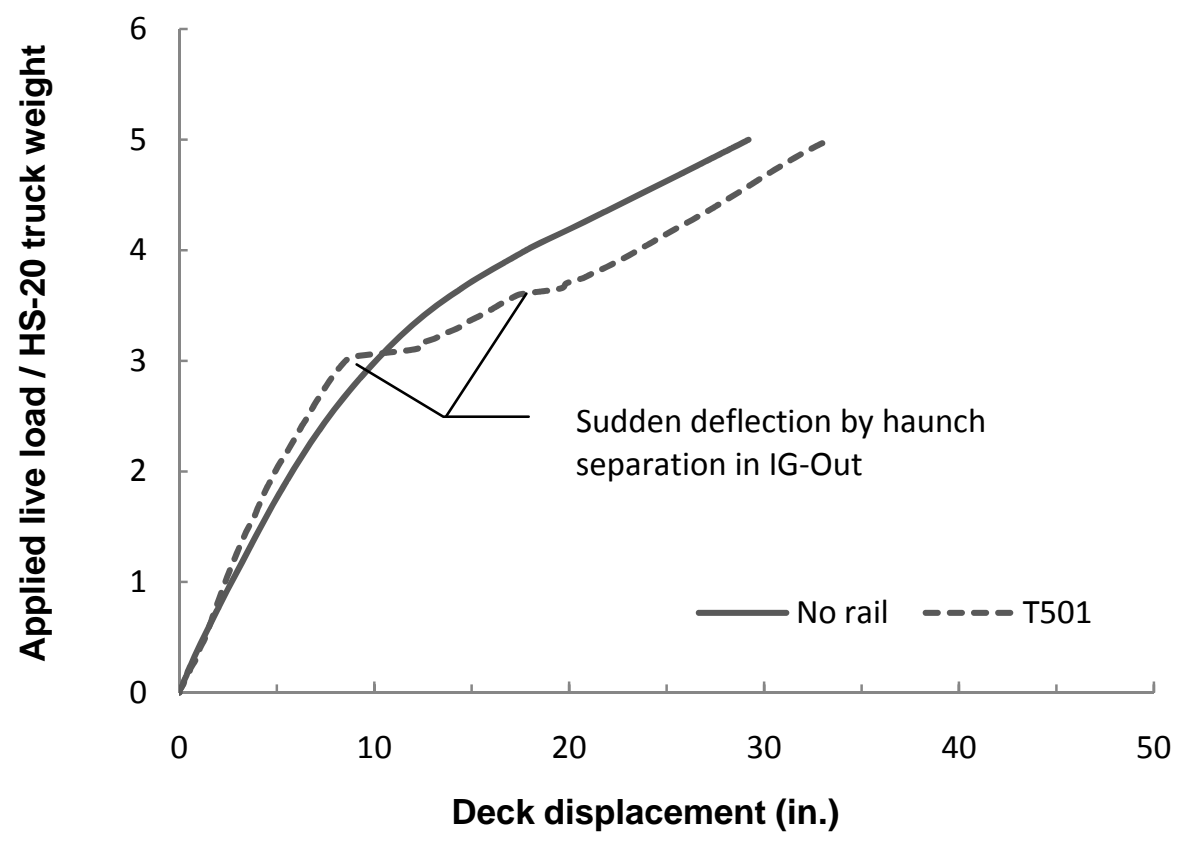

Figure 5.8 Deck deflection of fractured girder centerline at midspan 
Figure 5.8 shows deck displacements of bridge models with 120-ft. spans after the fracture of one girder plotted against the applied live load normalized by HS-20 truck weight. The deck displacements correspond to the top of the deck at the centerline of the fractured girder. Initially, as expected, the bridge model with rails deflects less than the model without rails; however, the deflection at the maximum applied live load (e.g., live load equivalent to five HS-20 truck weight) is greater for the model with rails than the one that does not include rails. A prominent feature shown in the figure is the sudden increase in the deck displacement for the model that included rails as the applied live load approached 216 kips. This load is equivalent to three HS-20 trucks. Conversely, a sudden increase in the deck displacement was not observed in the model without rails.

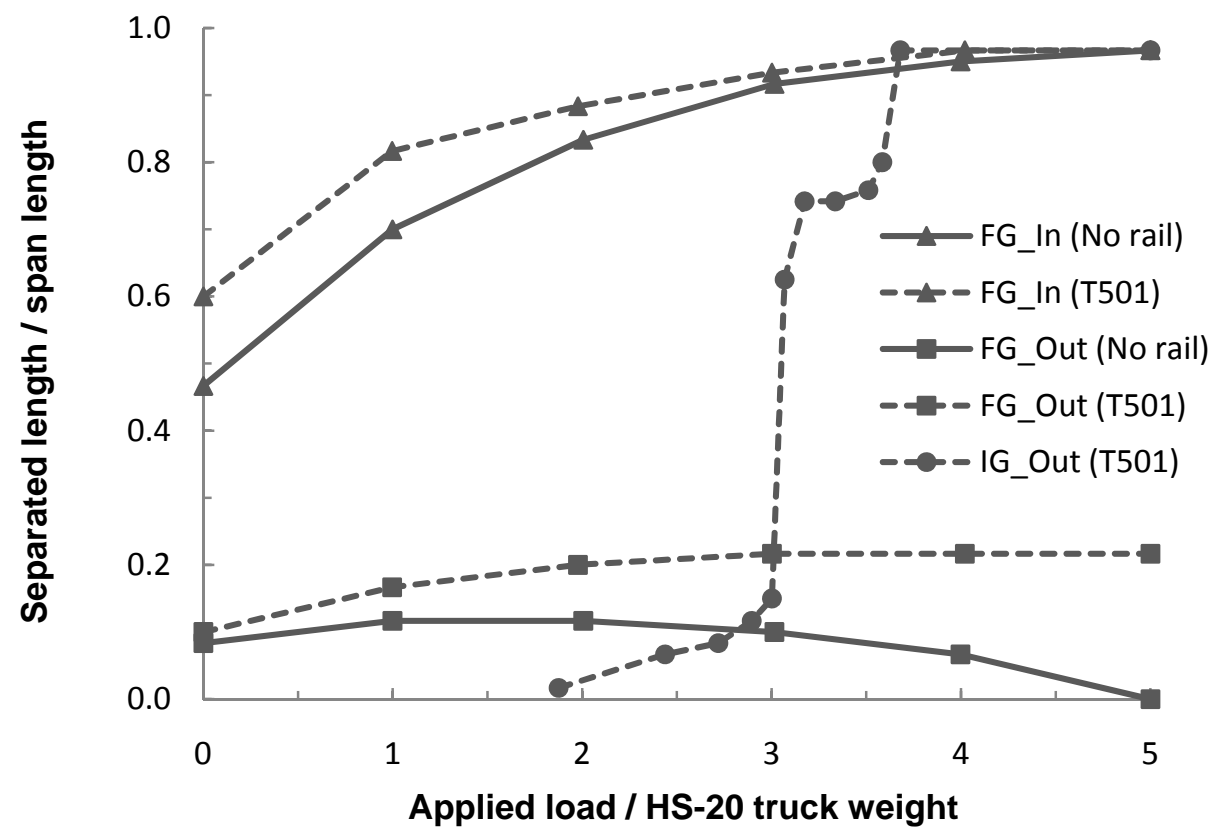

Figure 5.9 Separated haunch length difference depending on railing presence 
According to the finite element analyses of these two models, the main notable difference in bridge component failures was the haunch separation along the outside flange of the intact girder. Such haunch separation was observed only in the bridge model with rails. Figure 5.9 shows variations in the separated haunch length as a function of the applied live load. The dashed line with circle markers indicates the haunch separation length along the outside flange of the intact girder for the bridge model that included rails. As shown in this figure, the haunch separation increased abruptly when the normalized load level reached approximately three, which is equivalent to three HS-20 trucks. This haunch separation led to a reduction in the transverse bending resistance of the bridge deck, allowing a rigid rotation of the deck to take place. Therefore, the deck above the fractured girder could deflect downward abruptly, as shown in Figure 5.8. In addition, the difference in the haunch separation length shown in Figure 5.9 indicates that the separated length is longer on the finite element model with rails than the one without rails. As discussed in the previous section, bridges are expected to exhibit softer behavior as separated haunch length increases due to a reduction in the transverse bending stiffness and the vertical bending stiffness of the bridge. Results presented in Figure 5.9 support this observation.

A detailed investigation of the response helps explain the results shown above in which, near the onset of failure (i.e., haunch separation along the outside of the intact girder), bridge models with rails deflect more than models that do not include rails. Under low levels of applied load, the bridge model with rails showed a slightly stiffer behavior in the deck displacement response than the model without rails. When the sudden haunch separation occurred along the outside flange of the intact girder, the deflection of the bridge model with rails became larger than the one without rails, and this trend continued up until the applied live load reached to the equivalent weight of five HS-20 design 
trucks. To explain this behavior, there is a need to focus on the variations in the haunch separation length along the outside of the fractured girder; Figure 5.9 shows a noticeable difference between the T501-rail model and the no-rail model. In Figure 5.9, the length over which the haunch separates in the no-rail bridge model - plotted with solid lines and squares - initially increases as the applied load increases, but it starts to decrease once the loading exceeds a single HS-20 truck (i.e., 72 kips). This behavior was caused by the localized large deflection of the deck above the fractured girder. Because of the position of the applied live load, the deck deflection increased at a faster rate than that of the girder. As a result, the deck and girder move closer to each other, with the deck eventually supported by the girder. When the girder and concrete deck come together, the haunch separation distance becomes zero. Conversely, for the case of the finite element model that included the T501 bridge rail, this reduction and eventual closure of the haunch separation distance was not observed (Figure 5.9). It is believed that this result is caused by the engagement of the railing above the fractured girder. Once bridge rail sections are engaged, rails increase the bending stiffness of the deck because they act like deep beams at the edge of the deck. The increased bending stiffness reduces the deck deflection and prevents the deck from coming to rest on top of the fractured girder as was observed in the bridge model that neglected the presence of the rails. Eventually, however, haunch separation along the outside flange of the intact girder causes the displacements in the model with rails to exceed those of the model without rails.

\subsection{CURVATURE EFFECT ON BRIDGE CAPACITY}

Steel box-girder bridges are frequently used in curved regions of highway interchanges because of their high torsional resistance. As the radius of curvature of a bridge decreases, torsional stresses increase due to the eccentricity of gravity loads 
relative to the line of support. In cases where a bridge is damaged, such as the fracture of one girder assumed for a redundancy evaluation, bridge curvature may negatively affect a bridge's load-carrying capacity because the bridge would lose a significant level of torsional resistance due to the girder fracture. For this reason, curvature effects were investigated for bridge models with 120 -ft. spans.

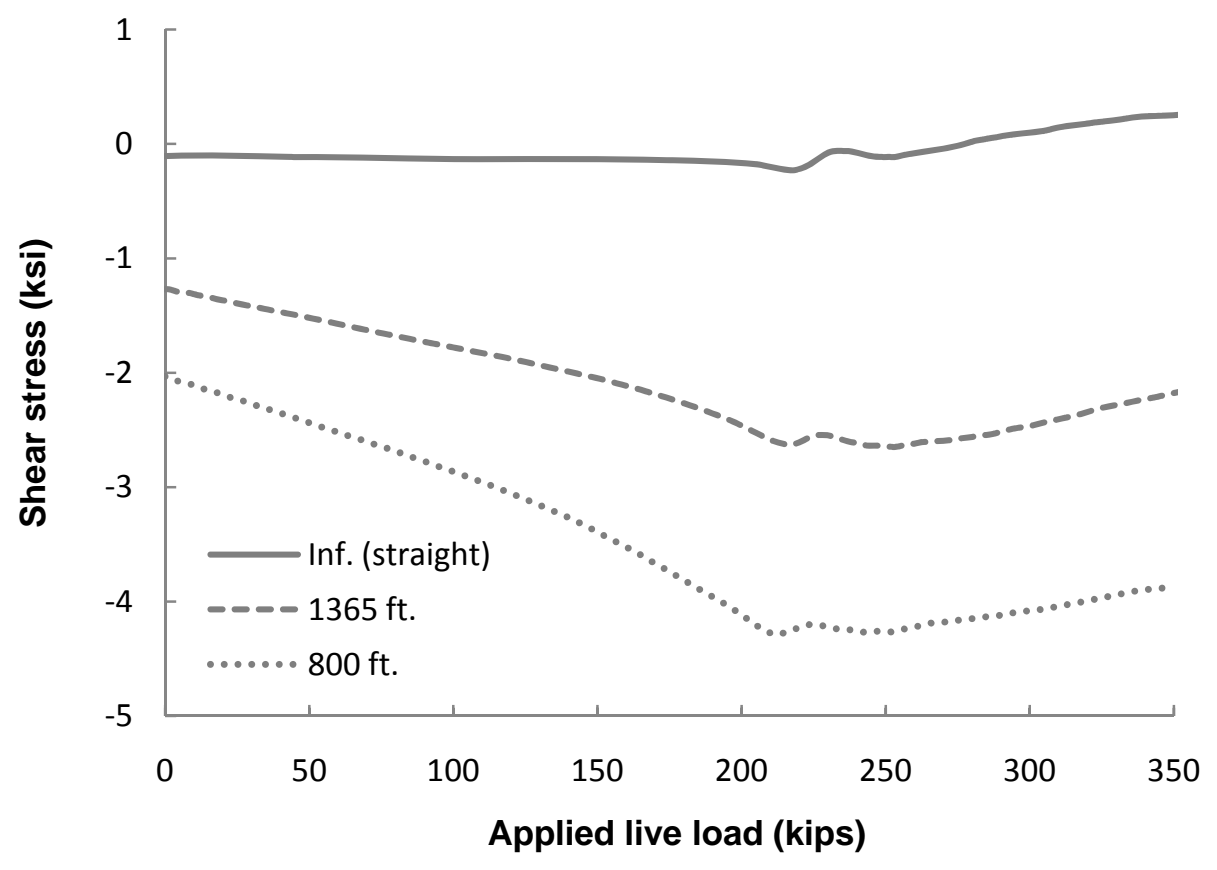

Figure 5.10 Shear stress of bottom flange at midspan

Figure 5.10 shows shear stresses (i.e., those associated with torsion) in the bottom flanges at the midspan location of three bridge models having different radii of curvature: 1.) an infinite radius (i.e., a straight bridge), 2.) a radius of curvature equal to $1365 \mathrm{ft}$., which is equivalent to the full-scale test bridge, and 3.) a radius of curvature equal to 800 ft., which is near the lower limit seen in typical field applications. As expected, higher shear stresses were observed in curved bridges with smaller radii of curvature than those 
in bridges with larger radii of curvature; for all cases considered, the actual magnitude of these stresses was small. As indicated in Figure 5.11, the vertical displacements of the fractured girders showed behavior consistent with that of the shear stresses. Although the bridge curvature does not affect the vertical deflection notably in these cases, the effect might be significant in cases where the span length is much longer than these models. Therefore, additional research is needed to clarify the curvature effects on this type of bridge.

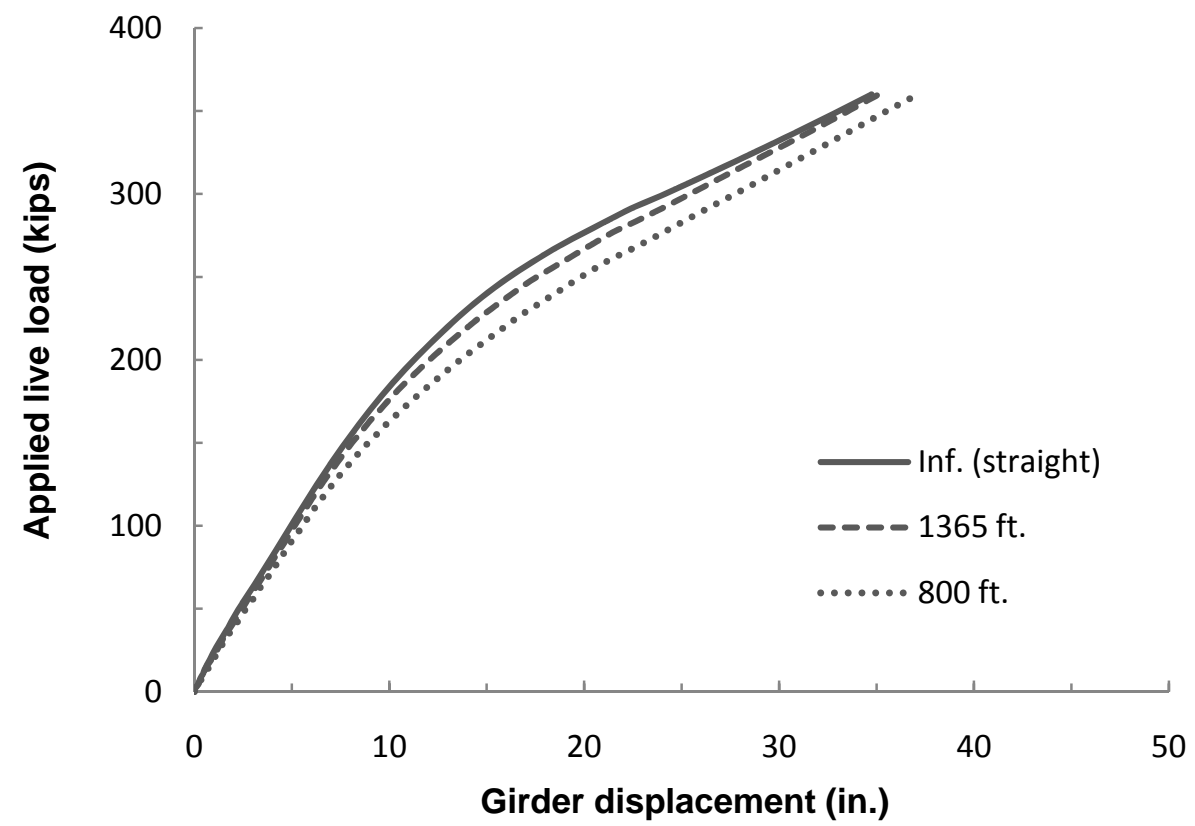

Figure 5.11 Fractured girder deflection at midspan (curvature effect)

\subsection{STRUCTURAL INDETERMINACY}

Unlike a simply supported bridge, bridges with continuous spans are statically indeterminate and therefore inherently possess some degree of system redundancy. Thus, 
if a twin steel box-girder bridge is constructed continuously over multiple supports, its response following the fracture of one girder can be redistributed to a neighboring girder as well as neighboring spans - potentially improving its chances to survive a fracture event more effectively than a simply supported bridge. To investigate the possible beneficial effects of structural indeterminacy, the post-fracture behavior of the two-span continuous bridge model (C130), as described in Table 5.1, was analyzed in this study.

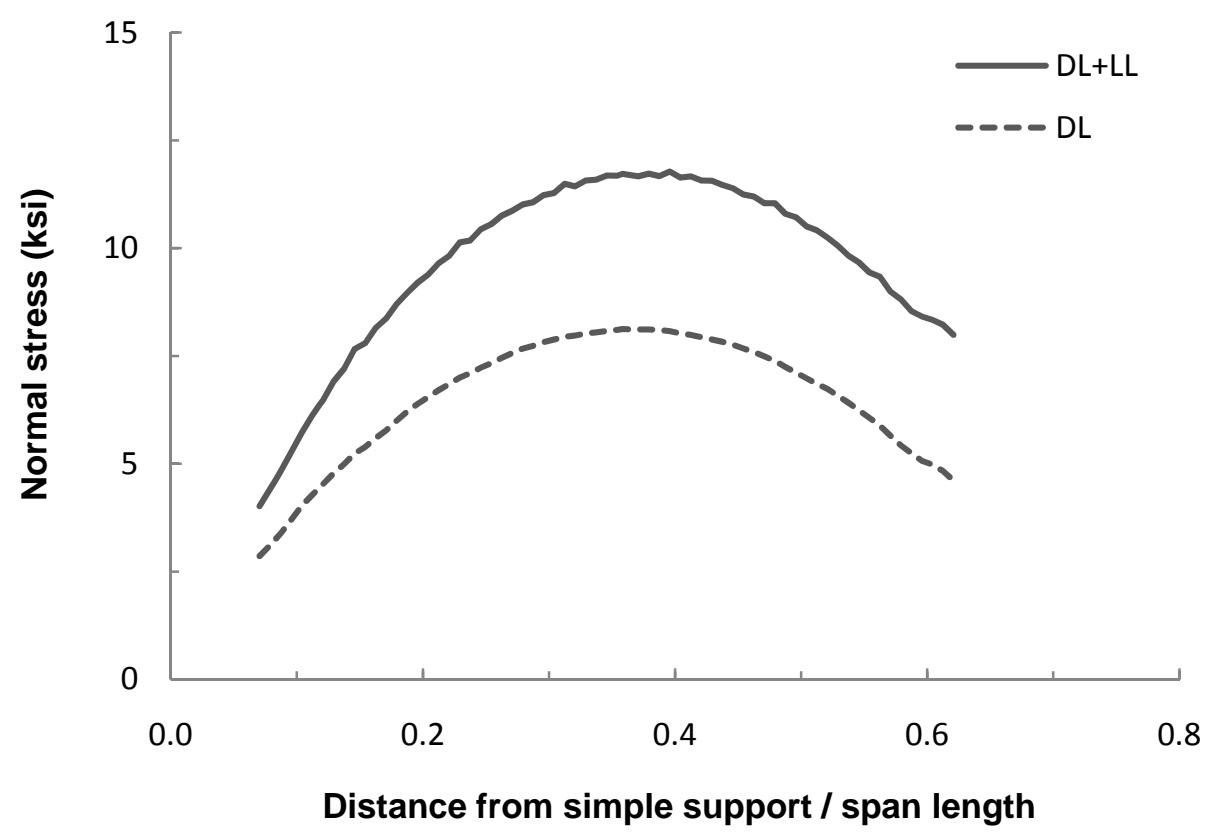

Figure 5.12 Normal stress envelop curve along bridge span

In the analysis of the simply supported bridge models described previously, the girder fracture location was selected to be at the midspan because the maximum positive bending moment caused by the bridge self-weight and a truck live load occurred at this location. To determine the location where positive bending moment was maximized by bridge self-weight and a live load for the continuous span bridge model, a moving load 
analysis was conducted. Before applying the moving load to the bridge, deck self-weight was applied on the top flanges of the bridge girders with gravity loading for girder selfweight (to account for non-composite section behavior), and then the moving load representing a truck live load was applied by changing its location by increments of $2 \mathrm{ft}$. along the bridge span. Figure 5.12 shows the results of the moving load analysis for the C130 model. The solid line shows the normal stress envelope induced by the bridge selfweight (dead load, DL) and the moving load (live load, LL). The normal stress was measured in the bottom flange of the girder for which the simulated fracture was to be specified. As shown in Figure 5.12, it was found that the maximum normal stress occurred at $51 \mathrm{ft}$. away from the simple support, which corresponded to a relative position of $40 \%$ of one span length. Therefore, this location was specified as the fracture location of the continuous span bridge model.

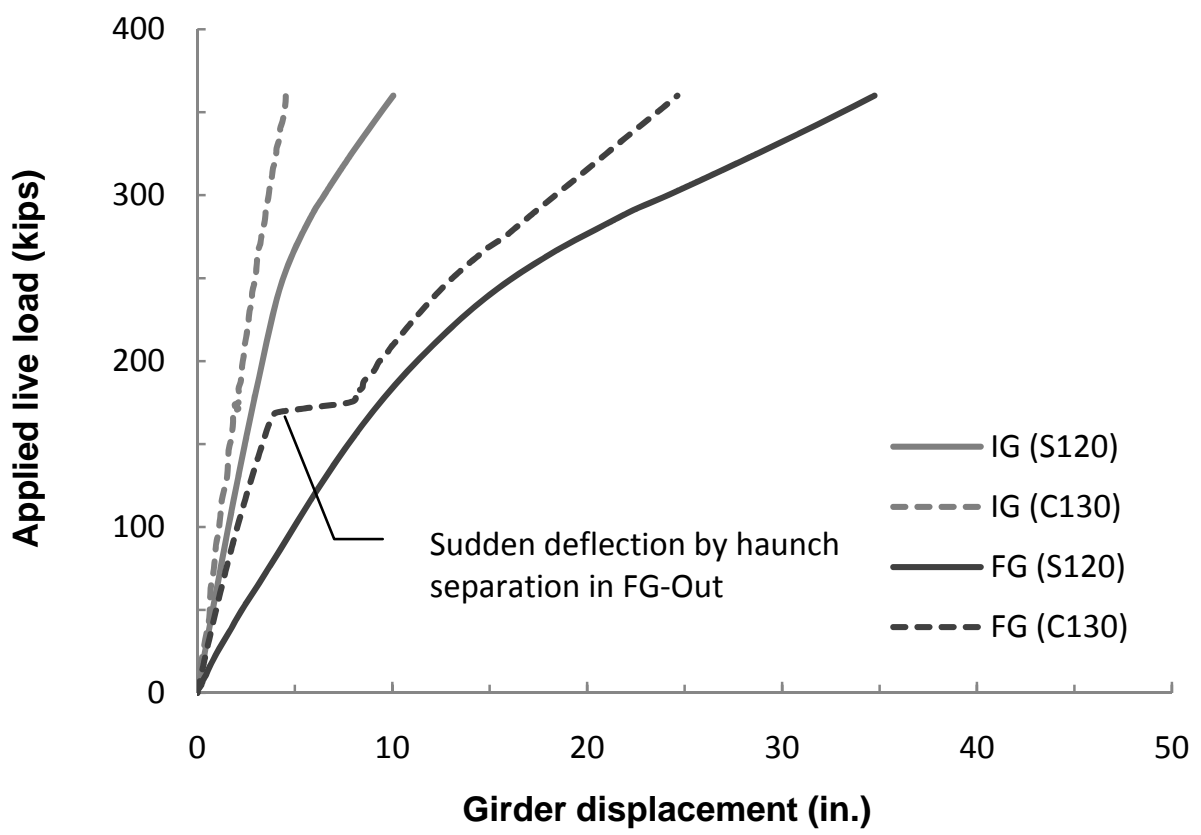

Figure 5.13 Girder deflection at midspan (continuous span) 
Figure 5.13 compares girder deflection behavior at midspan of the simply supported bridge model (S120) and the two-span continuous bridge model (C130). Due to the differences in cross-section size and other dimensions (Table 5.1), it is not appropriate to compare the computed results directly. Nonetheless, it is important to identify differences in the response behavior of these models and to recognize that the continuous span model had a longer span and a smaller cross-section than the simplespan model.

Notably different responses were observed between these two models for the fractured girder deflection behavior, as shown in Figure 5.13. As the applied load reached approximately 160 kips, sudden haunch separation along the outside of the fractured girder was observed near the fracture location of the continuous span bridge model. It was caused by the cantilever action emanating from the interior support side of the bridge. Because of the position of the assumed fracture location relative to the layout of this two-span continuous bridge, the far end rested on a simple support that could not provide such cantilever action. Thus, the interior side that could develop cantilever action restrained the far side resting on the simple support. This restraint caused the tension force on the stud connection near the girder fracture location to increase, eventually causing haunch separation to occur locally near the fracture location along the outside of the fractured girder.

An interesting observation is that the continuous span bridge model showed fairly stiff deflection behavior in the fractured girder although it showed the sudden displacement increase in the fractured girder. T501 rails were added to these two models because the rails increased tensile forces on the stud connections in the simple-span model (S120) and led to haunch separation along the outside of the intact girder causing 
the unstable deflection in the fractured girder under the loading range considered (i.e., 5 times an HS-20 truck load).

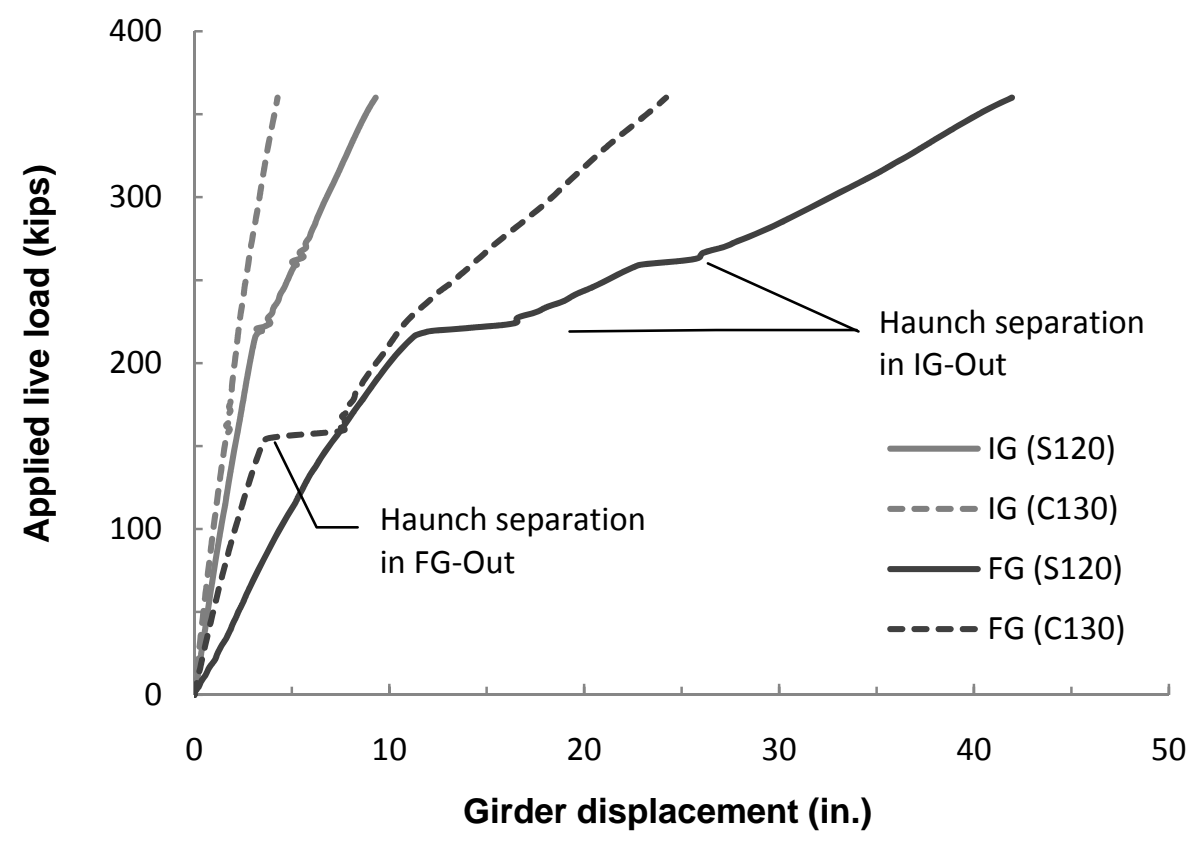

Figure 5.14 Girder deflection at midspan (continuous span with T501 rail)

Figure 5.14 shows the analysis results for these two bridge models with the T501 railing. Although the haunch separation along the outside of the fractured girder in the continuous span bridge model occurred and caused sudden deflections in the fractured girder, the continuous bridge showed stiffer deflection behavior, particularly for the fractured girder, than the simple-span bridge. The girder displacement differences became large after the haunch separation along the outside of the intact girder was initiated in the simple-span model. Interestingly, such haunch separation along the outside of the intact girder did not occur for the continuous bridge model. This behavior 
may be attributable to the fact that vertical bending resistance could be developed for the continuous bridge due to the cantilever action even after the fracture of one girder, and the applied load could be transferred longitudinally along the bridge interior span. Conversely, in the simple-span model, the applied load was transferred through the transverse bending behavior of the deck, which caused the increase of the tensile force on the stud connection along the outside of the intact girder. These results imply that the continuous bridge has higher post-fracture load-carrying capacity than the simply supported bridge even though it has a longer span and a smaller cross-section.

\subsection{BRIDGE SPAN LENGTH AND DYNAMIC AMPLIFICATION FACTOR}

Three simple-span bridges that differed in their span lengths were analyzed to investigate post-fracture load-carrying capacity as a function of span length. Figure 5.15 shows girder deflection behavior for these bridge models, and it is interesting to note that the results do not show any significant span length dependency. However, considering the ratio of span length to steel box-girder depth — values are indicated on top of each fractured girder deflection plot - the fractured girder deflections increase as this ratio increases. Intact girder deflections also tended to behave similarly with the fractured girder until yielding in the bottom flange of the 120-ft span bridge model (S120) was initiated. 


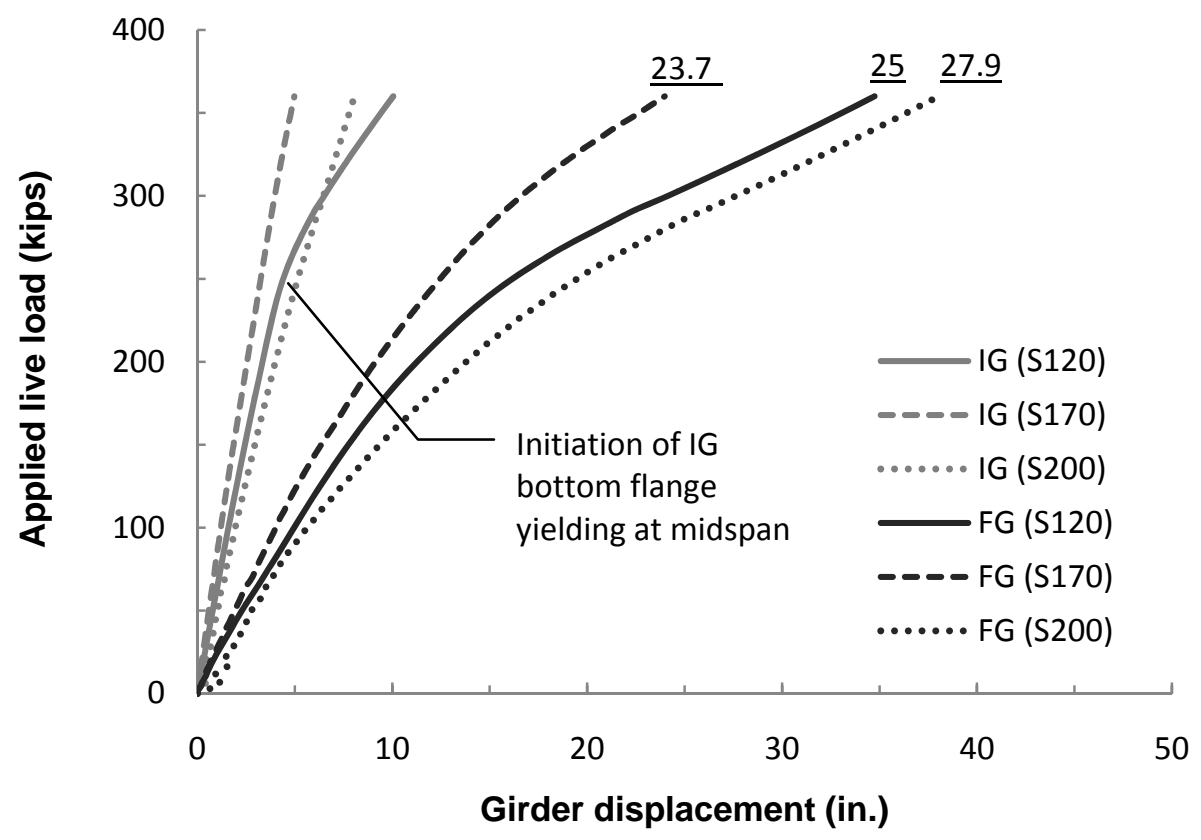

Figure 5.15 Girder deflection at midspan (span length effect)

\subsection{SUMMARY}

In this chapter, the following parameters were investigated to determine their influence on the load-carrying capacity of a twin steel-box girder bridge: stud length, railings, bridge curvature, structural indeterminacy, and span length. It was found that the tensile strength of stud connections played a major role in the post-fracture behavior of these types of bridges. Results from this research program indicate that the tensile strength of a stud connection is negatively influenced by the presence of a haunch and limits the maximum load a twin steel box-girder bridge can carry following the fracture of one of its girders. T501 bridge railings act as deep beams at the edges of the concrete deck and can carry substantial loads after their expansion joints close. In the models studied, their presence initially reduced the deck deflection compared to the models that 
did not include rails; however, models with rails showed an increase in the tensile forces acting on stud connections, which resulted in the haunch separating along the outside of the intact girder near the fracture location. This haunch separation caused the deflection in the fractured girder to increase abruptly. Another parameter that was varied in the finite element models developed for this research was the radius of curvature, and the results showed sensitivity to changes in this value. As the radius of curvature decreased, deflections in the fractured girder increased. Structural redundancy achieved through a continuous span bridge positively affected the overall load-carrying capacity of the twin steel box-girder bridges analyzed for this research. The continuity of the bridge helped it sustain the applied load without causing haunch separation along the outside of the intact girder. Finally, post-fracture girder deflections showed a stronger dependence on the span length-to-depth ratio than the span length itself. As the ratio of span to depth increased, the fractured girder deflections also increased.

In the next chapter, application of the redundancy evaluation methods described in Chapter 2 is presented. For the redundancy evaluations, four bridge models were utilized. Because the finite element results presented in this chapter showed that bridge rails could negatively affect the load-carrying capacity of a bridge, rails were included in the investigated bridge models. 


\section{CHAPTER 6: $\quad$ REDUNDANCY EVALUATION (APPLICATION)}

\subsection{INTRODUCTION}

In Chapter 2, loading scenario A, which entails the sudden full-depth fracture of one girder in a twin box-girder bridge, was introduced as a basis for evaluating bridge redundancy. Using this methodology, four bridge models were analyzed to evaluate the role played by different system parameters in affecting overall performance, and the results of these analyses are included in this chapter. To numerically achieve the damage and loading conditions assumed for the redundancy evaluation of these bridges, the same analysis procedure utilized in the simulation of the second full-scale bridge fracture test in Chapter 4 was followed.

\subsection{BRIDGE MODELING AND ASSUMPTIONS}

For the redundancy evaluation of twin steel box-girder bridges described herein, the same bridge models used in the parametric study presented in Chapter 5 were utilized. The primary dimensions of these bridge cross-sections are given in Table 5.1. These models were constructed according to the modeling guidelines (such as element types, inelastic material behavior, mechanical behavior of a stud connection, and railing interaction using spring elements) described in Chapter 3. For the deck and the rail concrete of these bridge models, a compressive strength of 4,000 psi was conservatively assumed, and a TxDOT standard T501 rail was utilized similarly to the full-scale test bridge. All of the investigated bridge models utilized stud connections comprised of three studs in a row as schematically shown in Figure 6.1, and the studs had a diameter of 7/8in; however, the stud length and the haunch width differed as listed in Table 6.1. The haunch height of the prototype bridges varied from 2 in. to 3 in., but a 3 -in haunch height 
was conservatively assumed for all bridge models. Table 6.1 shows resultant shear and tension strengths of stud connections utilized for the models. For the expansion joints between rail sections, a 3/4-in. gap distance was assumed, and spring elements were inserted in the gap to account for railing engagement in all bridge models.

Table 6.1 Primary dimensions and strength of stud connection

\begin{tabular}{|c|c|c|c|c|c|}
\hline \multirow{2}{*}{ Model } & \multicolumn{2}{|c|}{ Stud } & \multirow{2}{*}{$\begin{array}{c}\text { Haunch } \\
\text { width }\end{array}$} & \multicolumn{2}{|c|}{ Shear and tension strength (kips) } \\
\cline { 2 - 3 } \cline { 6 - 6 } & $\begin{array}{c}\text { length } \\
\text { (in.) }\end{array}$ & $\begin{array}{c}\text { Spacing } \\
\text { (in.) }\end{array}$ & (in.) & Shear (Eq. 3.3) & Tension (Eq. 3.7) \\
\hline S200 & 6 & 6 & 18 & & 18.82 \\
\hline S170 & 6 & 4 & 18 & \multirow{2}{*}{79.77} & 18.82 \\
\hline C130 & 6 & 4 & 14 & & 17.19 \\
\hline S120 & 5 & 4 & 12 & & 12.64 \\
\hline
\end{tabular}

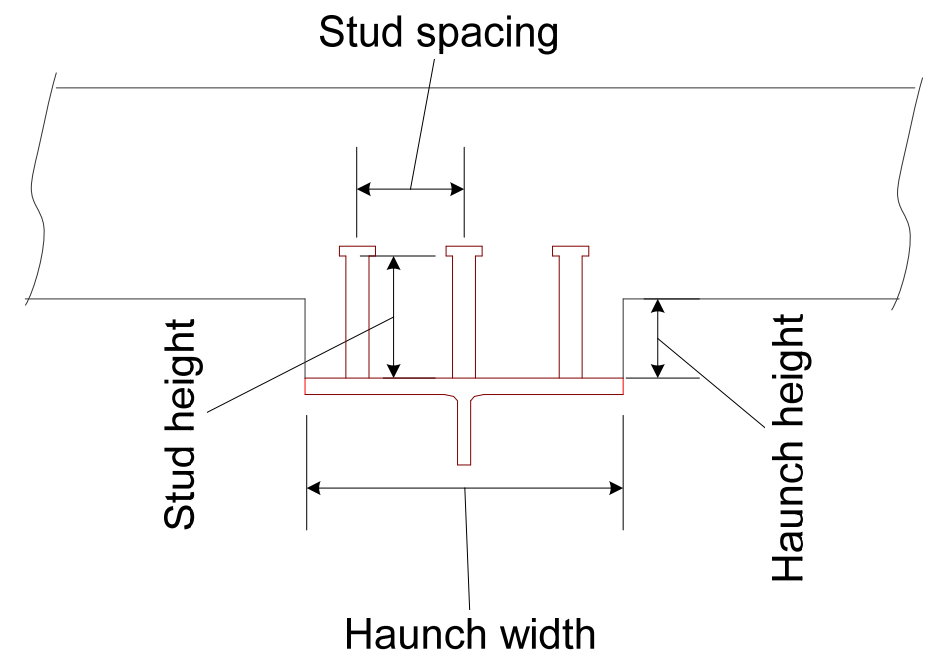

Figure 6.1 Schematic of stud connection with haunch 


\subsection{DETERMINATION OF FRACTURE LOCATION AND ANALYSIS PROCEDURE}

The applied damage and loading scenario for the redundancy evaluation of the prototype bridges was the sudden full-depth fracture of one girder with an HS-20 standard design truck positioned to cause the maximum positive bending moment at the fracture location. The investigated bridges contained one physical traffic lane; thus one truck live load was considered. The truck live load (i.e., the HS-20 standard design truck load) was placed on the deck of each bridge such that the middle axle was positioned at the fracture location while the axle spacing was assumed to be fixed at $14 \mathrm{ft}$. The transverse location of the truck live load was biased toward the fractured girder so that the axle corners were placed $2 \mathrm{ft}$. away from the bridge railing.

To numerically simulate the sudden full-depth fracture of one girder, duplicate nodes were included along the predefined fracture path. Thus, elements of the girder along the fracture path shared coincident nodes, but these duplicate nodes were not connected. Instead, the duplicate nodes were initially joined using connector elements with welding properties to simulate the pre-fracture condition of the girder; later, they were deactivated to simulate girder fracture along the predefined path. Initially, to simulate sudden fracture along the predefined fracture path, the connector elements were deactivated instantaneously. However, this technique resulted in numerical convergence problems, and analyses failed to run to completion. As a result, the same procedure used in the simulation of the second full-scale bridge fracture test was used for these analyses. The detailed analysis procedure is available in Table 4.2. 


\subsection{EVALUATION RESULTS}

\subsubsection{Dynamic displacement response}

The investigated bridges successfully sustained the considered damage and loading level simulating the full-depth fracture of one girder in a two-girder bridge. Figure 6.2 shows post-fracture dynamic displacement responses at the girder fracture locations of these bridge models. As shown in this figure, the maximum girder displacement induced by the sudden fracture tended to increase as the span length increased for the simple span bridge models. When the displacements were normalized by each bridge span length, however, the increasing tendency of the displacement was dependant on the span-length-to-box-depth ratio rather than the span length itself (Figure 6.3). The continuous bridge model (C130) showed much smaller girder displacements than any of the simple span models due to the benefit of structural indeterminacy in addition to the load path redundancy that the bridge possessed. Table 6.2 lists detailed values of maximum girder displacement results obtained from the finite element simulations. The listed maximum girder displacements do not include bridge self-weight (i.e., the displacements by bridge self-weight prior to the girder fracture were not included).

Although a bridge may possess sufficient strength to sustain a specified level of damage and loading, excessive displacements that could be a potential hazard to bridge users could be caused if the level of damage and loading is so large as to induce material inelasticity or local failures of bridge components. Therefore, the displacement of a bridge should be checked to determine whether or not a bridge is redundant. The current AASHTO LRFD bridge design specifications (2007), however, do not provide any provisions or guidance regarding the displacement limit (based on the ultimate load capacity of a bridge) that can be utilized for a redundancy evaluation. Ghosn et al. (1998) 
proposed a displacement limit caused by live load as one percent of the span length based on engineering judgment, and they defined the displacement limit as a "functionality limit state". If the functionality limit state is utilized as the displacement limit for the redundancy evaluation of a twin steel box-girder bridge, some of the investigated bridges would not satisfy this requirement. For the judgment of the displacement limit, however, Ghosn et al. (1998) used a somewhat ambiguous definition based on "the maximum visible displacement that a bridge user or an observer can tolerate". The assumed damage and loading level in this study was intended to simulate the worst-case loading with very severe damage; thus, the possibility of occurrence would be rare. For such a rare event, it is questionable as to whether or not an allowable displacement criterion should be based on maintaining a tolerable appearance. Instead it might be preferable to ensure a level of protection that allows for the safe evacuation of bridge users. To establish such a displacement limit, however, additional research is needed.

Table 6.2 Maximum dynamic displacement of intact (IG) and fractured girder (FG)

\begin{tabular}{|c|c|c|c|c|c|c|}
\hline \multirow{2}{*}{ Model } & \multirow{2}{*}{$\begin{array}{c}\text { Span } \\
\text { length } \\
\text { (in.) }\end{array}$} & \multirow{2}{*}{$\begin{array}{c}\text { Span / } \\
\text { Depth }\end{array}$} & \multicolumn{2}{|c|}{$\begin{array}{c}\text { Max. displacement } \\
\text { (in.) }\end{array}$} & \multicolumn{2}{c|}{$\begin{array}{c}\text { Displacement ratio } \\
\text { (Max. displ./Span length, \%) }\end{array}$} \\
\cline { 4 - 7 } & & IG & FG & IG & FG \\
\hline S200 & 2382 & 27.9 & 10.92 & 38.14 & 0.46 & 1.60 \\
\hline S170 & 2040 & 23.7 & 5.79 & 19.63 & 0.28 & 0.96 \\
\hline C130 & 1536 & 29.1 & 2.76 & 6.24 & 0.18 & 0.41 \\
\hline S120 & 1440 & 25.0 & 5.05 & 15.37 & 0.35 & 1.07 \\
\hline
\end{tabular}




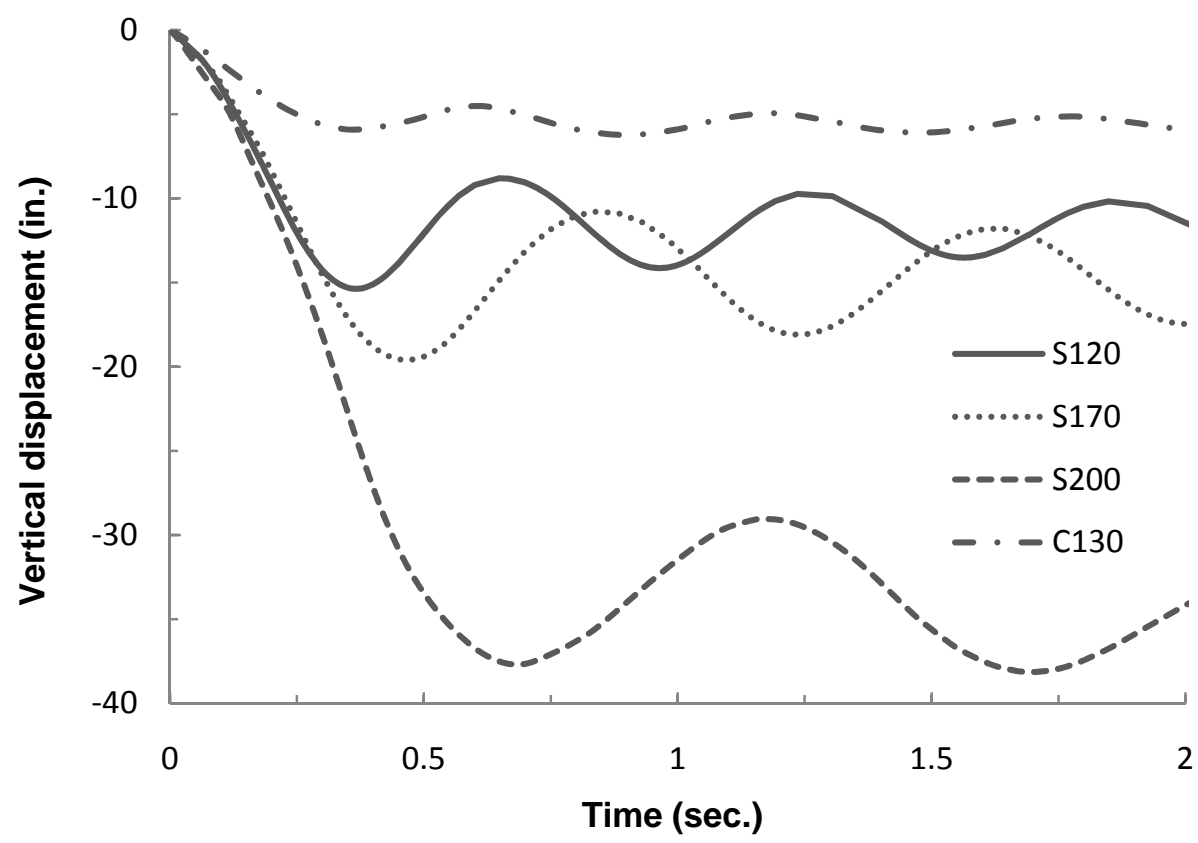

Figure 6.2 Dynamic displacement behavior of fractured girder (FG)

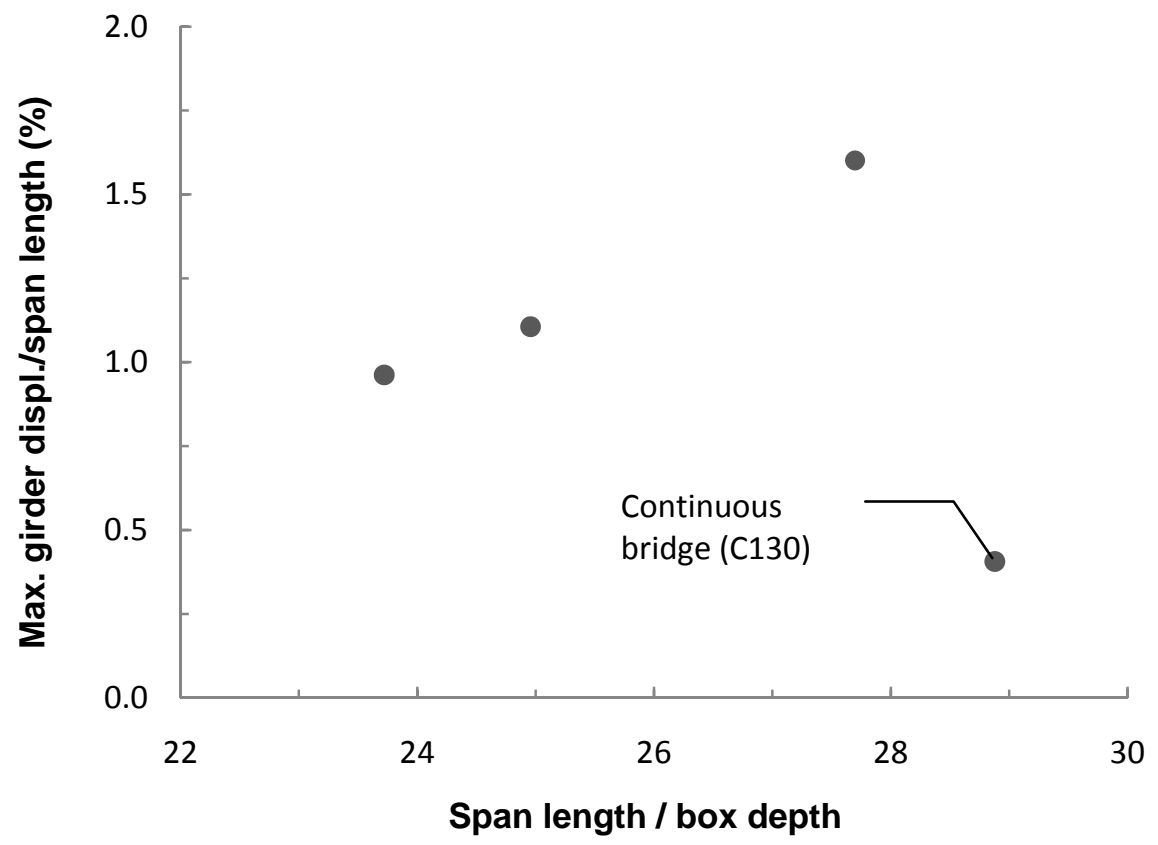

Figure 6.3 Normalized maximum displacement of fractured girder along span to depth ratio 


\subsubsection{Dynamic amplification factor}

In addition to the investigation of bridge displacement responses, the dynamic amplification factor attributed to suddenly released loads was studied using the bridge models: three simple-span bridge models (S120, S170, and S200) and the continuous span bridge model (C130). The dynamic amplification factor was obtained by dividing the maximum dynamic deflection of the intact girder by the static deflection of the girder.

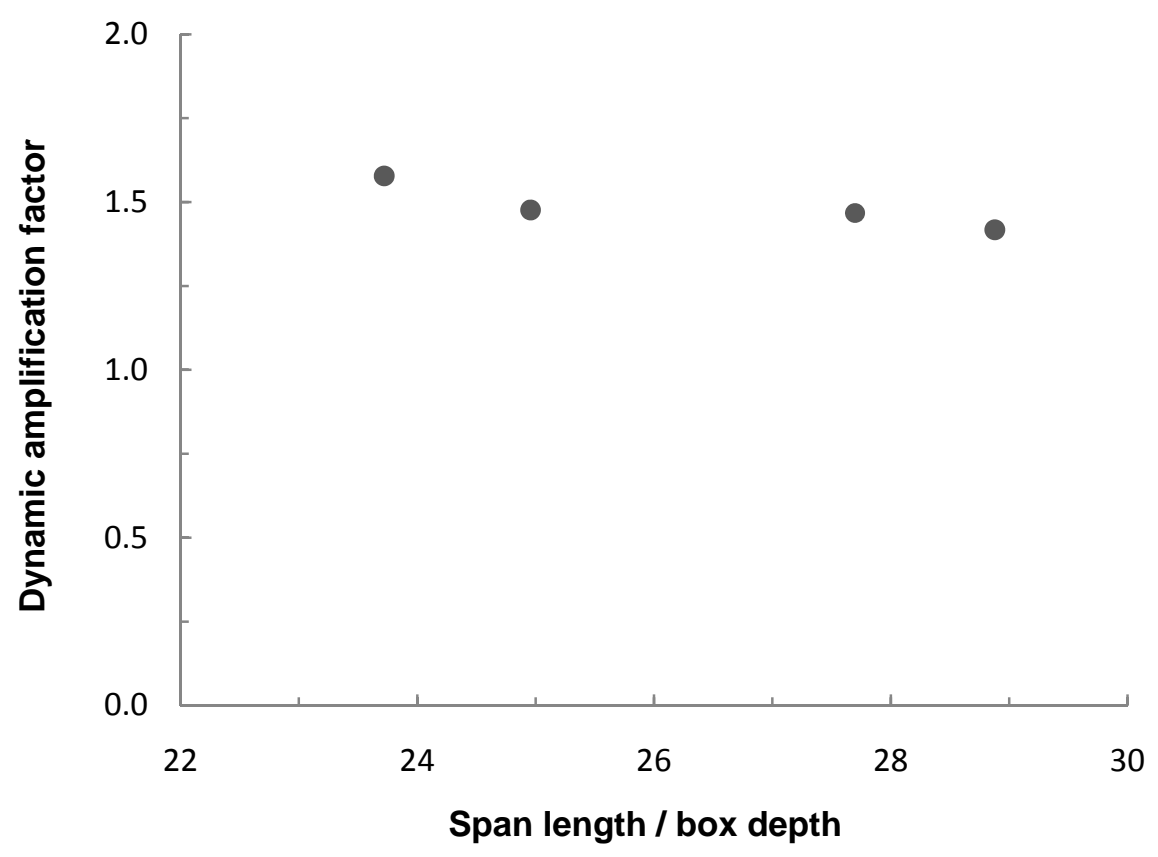

Figure 6.4 Dynamic amplification factor

In Figure 6.4, the computed dynamic amplification factors are plotted against bridge span normalized by the depth of the steel girders. Although the plot shows that the dynamic amplification factor slightly decreases as the ratio of the span to the box depth increases, the dynamic amplification factor varied in a narrow range between 1.47 and 1.58. This observation is important, as other specifications for redundancy evaluation of 
cable stay bridges require a load amplification factor of 2 (PTI Cable Stayed Bridge Committee, 2007), which is much greater than what was observed in these analyses or in the full-scale bridge fracture test (i.e., according to the second full-scale bridge fracture test, the dynamic amplification factor was 1.35 based on the longitudinal strain response in the bottom flange of the intact girder) reported by Neuman (2009).

\subsection{SUMMARY}

The redundancy of four bridges was evaluated using the damage and loading scenario suggested for a twin steel box-girder bridge. The evaluation results showed that these bridges had enough strength to sustain the suggested damage and loading level. In

addition to the strength, the maximum girder displacements of these bridges were investigated; according to the analyses, the displacements varied from $0.4 \%$ to $1.6 \%$ of each bridge span length. Although an excessive displacement could raise safety issues for bridge users, a proper displacement limit criterion to evaluate the redundancy of a bridge is not currently available.

In the following chapter, conclusions about the modeling of twin steel box-girder bridges for redundancy evaluations are provided, and recommendations for future research are given. The conclusions are based on the findings obtained from the detailed testing program executed during this study and from detailed finite element analyses conducted for this project. 


\section{CHAPTER 7: $\quad$ CONCLUSIONS AND RECOMMENDATIONS}

\subsection{SUMMARY OF RESEARCH}

The AASHTO LRFD Bridge Design Specifications (AASHTO, 2007) currently classify twin steel box-girder bridges as fracture critical. According to this designation, such a bridge "contains one or more fracture critical members whose failure is expected to result in the collapse of the bridge or the inability of the bridge to perform its

function." The purpose of this research program was to investigate and quantify the inherent redundancy that this type of bridge may possess contrary to the current fracture critical bridge classification. To meet this goal, a comprehensive research program was carried out that included three tests on a full-scale fracture critical bridge (Neuman, 2009), laboratory tests to quantify the tensile capacity of stud connections (Sutton, 2007 and Mouras, 2008), and development of a simplified modeling method to evaluate the redundancy of twin steel box-girder bridges (Samaras, 2009). In this dissertation, finite element modeling techniques were studied to evaluate redundancy of these types of bridges in cases where the simplified modeling approach does not provide sufficient information or in cases where the results obtained from the simple analysis approach require refinement.

For the detailed finite element models developed for this research, various simulation techniques were utilized to capture important response mechanisms that were expected to occur in a severely damaged bridge, as described in Chapter 3. These techniques were also utilized to construct bridge models simulating the full-scale bridge fracture tests, and these bridge models successfully captured prominent bridge behavior and subsequent component failures that were observed during the experimental program. Various bridge models constructed in the same way as the bridge test simulation models 
were then used to investigate contributions of various bridge components and changes in bridge geometry on remaining load-carrying capacity of twin steel box-girder bridges following the full-depth fracture of one girder.

Based on the literature review of past bridge fractures, results collected from the full-scale bridge fracture tests, and detailed finite element simulations, several important conclusions about the performance of twin steel box-girder bridges can be drawn. The conclusions are presented in the next section.

\subsection{CONCLUSIONS AND RECOMMENDATIONS}

\subsubsection{Damage level and loading method}

Because there are no fracture incidents involving twin steel box-girder bridges reported in the research literature, a full-depth fracture of one girder was assumed for redundancy evaluations based on past experiences with damage in plate girder bridges. Some notable cases in which a brittle fracture occurred in a steel girder bridge include the I-79 Glenfield Bridge at Neville Island, PA (Fisher et al., 1985), the US-422 Bridge in Pottstown, PA, and the I-794 Hoan Bridge in Milwaukee, WI (Connor et al., 2007). Based on these events, the sudden fracture of one girder was selected as the damage level for evaluating redundancy in a twin steel box-girder bridge.

An HS-20 standard design truck was used as the primary live load for this research project. In this study, two different types of loading schemes were utilized to apply the truck live load for evaluating bridge redundancy and remaining load-carrying capacity. First, for the purposes of carrying out a redundancy evaluation, the truck load was positioned statically above the girder where the fracture would occur so as to induce the maximum positive bending moment on the fracture location of the bridge under 
investigation. To simulate worst-case loading conditions, it was assumed that the girder fracture occurred suddenly right after the live load was placed above the fracture location. Second, for the purposes of computing overall post-fracture load-carrying capacity, the truck live load was positioned after applying the fracture of a girder in the same location as used for the redundancy evaluation, but the live load was incrementally increased in proportion to the axle loads until failure occurred or a predetermined load level was met.

\subsubsection{Bridge modeling}

\subsubsection{Concrete deck}

In this study, the concrete deck was modeled using solid elements with embedded truss elements to simulate reinforcing steel. Considering the importance of the concrete deck as a load transferring component in twin steel box-girder bridges, it is critical to simulate its behavior accurately. As shown in the second and third full-scale bridge tests, extensive material failures, including extensive cracking and crushing, are inevitably expected for redundancy evaluations due to the expected damage level near the onset of collapse. To account for these material failures, a cast iron plasticity model was utilized for the concrete deck modeling rather than a concrete smeared cracking model. Though the cast iron plasticity model does not allow for the softening behavior that a smeared cracking model permits, it does have the essential feature of being able to specify different strengths for tension and compression. The cast iron plasticity model was found to be an excellent compromise between accuracy and efficiency. It produced simulation results that agreed well with benchmark tests, yet it did not cause the same types of convergence problems that were experienced when the smeared cracking model was used. 
Using the cast iron plasticity model, the deflection of the concrete deck was found to be sensitive to both the specified tensile strength and the mesh density. Based on parametric studies of finite element models developed to represent laboratory tests on the tensile behavior of studs embedded in a concrete deck with a haunch, it was found that the model properly simulated deck bending behavior when the tensile strength of the model was specified to be $4 \%$ of the compressive strength with the specific mesh density of three elements through the deck thickness and ten elements along the deck width. It is important to recognize, however, that this specific tensile strength and mesh density do not apply to all cases because they were validated against a limited set of test data.

\subsubsection{Stud connection}

Under normal conditions, shear studs installed on girder top flanges are subjected to shear forces induced by the composite action between the girders and the concrete deck. Results from this research have shown, however, that significant tensile forces develop in shear studs of twin steel box-girder bridges as deformations increase following the fracture of a girder. Such tensile forces induce concrete breakout failures on stud connections, which leads to extensive haunch separation. This behavior was observed during the full-scale tests that took place under this research program and was detected in the finite element simulations. Tensile failures of stud connections reduce both the transverse and the vertical bending stiffness of a bridge, thereby inducing large deflections following the fracture of a girder. Because predictions of bridge redundancy are sensitive to the specified load-deformation response of shear stud connections, and because observations from full-scale tests indicated possible damage mechanisms initiated through both shear and tension, it is important that models used for redundancy evaluations account for these components of response. The experimental equations 
proposed by Topkaya (2002) and Mouras (2008) were used in this research and allowed for a determination of stud connection response for shear and tension independently, but no information is currently available on the coupled interaction of shear and tension in stud connections.

Even when the shear and tension response of the stud connections are defined independently, it is essential that accurate values for capacity be specified. Because of the sensitivity that the tensile strength of a stud connection has on the predicted load-carrying capacity of twin steel box-girder bridges following the fracture of one of its girders, care must be taken to properly account for such factors as the presence of a haunch, stud embedment length, stud spacing, and stud positioning when computing the tension capacity of different shear stud arrangements. The equation used to determine shear strength, however, does not consider these factors. Thus, aside from research needed on how shear and tension interact in stud connections near the onset of collapse, additional research is needed to accurately evaluate the shear strength of stud connections when a haunch is present.

\subsubsection{Railing}

The presence of a railing (TxDOT standard T501 rail) significantly affected girder deflections by increasing the haunch separation length in both the fractured and the intact girders. Although it reduced the deck deflection during the initial stages of response before haunch separation was initiated along the outside of the intact girder, it eventually increased the haunch separation length in both girders by locally raising tensile forces on the stud connections. Therefore, a bridge analysis that ignores the effects of railings when carrying out a redundancy evaluation may not be conservative. 


\subsubsection{Bridge curvature}

In this study, the response of a bridge with a span of $120 \mathrm{ft}$. was evaluated considering three different bridge radii of curvature. The range considered included a bridge with an infinite radius of curvature (i.e., a straight bridge), one with a curvature of $1365 \mathrm{ft}$., and another one with a curvature of $800 \mathrm{ft}$., which is near the limit of what is found in practice. For the redundancy evaluations, girder fracture was assumed to occur in the exterior girders of the curved bridges to achieve larger torsional forces than would be obtained by fracturing the inside girders. According to the finite element analyses of these bridge models, a decrease in the radius of curvature led to an increase in the vertical displacement of the fractured girder. Thus, it was concluded that bridge curvature can play an important role in controlling the post-fracture behavior of twin steel box-girder bridges. Because of the limited number of cases that were evaluated, however, it is recommended that additional analyses be carried out to identify the dependency of bridge redundancy on radius of curvature.

\subsubsection{Structural redundancy}

To investigate differences in bridge behavior between a simple-span bridge and a multiple-span bridge following the fracture of one girder, a two-span continuous bridge was analyzed using a finite element model that was developed in the same way as for the bridge fracture test simulation models. Due to different cross-sectional dimensions and component sizes (i.e., thickness and width of bottom flange, top flange, and web), it was not reasonable to compare directly the computed response of the two-span continuous bridge model with the simply supported bridge models developed for this project. Nonetheless, the analyses indicated that the two-span bridge could carry load without significantly increasing tensile forces on the stud connection along the outside of the 
intact girder. The simple-span bridge model, conversely, showed an increase in the tensile forces on the stud connections along the outside of the intact girder; the simplespan model with a railing showed haunch separation in that stud connection. The good performance achieved by the continuous two-span bridge was a result of redundancy achieved through structural indeterminacy.

\subsection{SUGGESTIONS FOR FUTURE STUDY}

\subsubsection{Strength of stud connection}

In the third bridge fracture test, collapse was initiated by slipping between the outside top flange of the fractured girder and the concrete deck. After the test, it was observed that extensive horizontal cracks and diagonal cracks developed along the outside haunch of the fractured girder. This observed damage suggests that the shear strength of a stud connection may be affected by the presence of a haunch and sheartension interaction. Past research has not considered these factors, and equations that are currently available may over-estimate the shear strength of a stud connection. Because of the sensitivity of the computed results to changes in stud connection behavior, additional testing is needed to accurately capture the response of shear studs in a haunch under combined states of tension and shear.

\subsubsection{Bridge curvature}

Results obtained from finite element models developed for this research indicate that as the radius of curvature decreases, the exterior girder deflections increase due to the eccentricity between the loading position and the bridge supports. Because of this eccentricity, curved bridges must resist higher torsional forces than straight bridges. For 
the cases studied, however, the shear stresses associated with such increased torsional forces were small compared to those developed in a straight bridge. For the bridge model that was analyzed, which was a simply supported bridge with a span of $120 \mathrm{ft}$., the shear stresses associated with torsion increased by only $4 \mathrm{ksi}$ as the radius of curvature changed from infinity (i.e., a straight bridge) down to $800 \mathrm{ft}$. Because the eccentricity between the loading position and the supports is a function of bridge span, and because torsional moment increases with this eccentricity, the effects of curvature require further investigation than what was carried out during this study.

\subsubsection{Bridge railings}

Results from this research showed that railing performance strongly influences the overall load-carrying capacity of twin steel box-girder bridges following the fracture of one girder. In this study, only the influence of T501 rails, using standard construction details, was investigated. In contrast, many other fracture critical bridges utilize bridge rails that have an intermittent base or have less depth than the T501. Consequently, it is not certain how these other rail systems influence system capacity following the failure of a critical component. As such, research is needed to assess the performance of various rail systems used on fracture critical bridges to determine how they contribute to bridge redundancy. While rails can act like deep beams on the edges of the deck and can carry significant loads, they also lead to increased tensile forces acting on stud connections. Such increased tensile forces hasten stud connection failures, and thus can cause unstable deflection behavior in a bridge. Accordingly, additional research is needed to investigate how these components may be used to improve overall redundancy. While attempts should not be made to drastically change design details that can detract from the primary purpose of a railing as a crash barrier, such factors as the number, size, and placement of 
expansion joints should be studied to determine how such details affect performance. For bridge rails that do not meet desired performance measures, retrofit methods should be investigated. 


\section{APPENDIX A}

\section{MODIFIED ACI ANCHOR STRENGTH EQUATION USING HAUNCH MODIFICATION FACTOR FOR DECK HAUNCH}

\section{A.1 ANCHOR STRENGTH IN CONCRETE UNDER TENSION FORCE}

ACI 318-08 Appendix D provides an empirical equation for the strength of anchors loaded in tension under a broad range of configurations. It considers various failure modes such as stud yielding, concrete breakout, stud pull-out, and concrete sideface blowout. In the construction of steel box-girder bridges, shear studs are used to develop composite behavior between the steel girders and the concrete deck using headed studs. Such shear studs are installed on the top flanges of steel girders and cast with concrete to form a bridge deck. Typically, construction joints are used between girder top flanges and a bridge deck, making what is called a deck haunch and is used to maintain the uniform deck thickness of a bridge. Sutton (2007) and Mouras (2008) recognized from their laboratory stud pull-out tests that the tensile strength of an embedded stud into a concrete deck through a haunch was governed by a concrete breakout failure mode. For the tensile strength of anchors showing a concrete breakout type failure, the ACI 318-08 anchor strength equation utilizes the concrete capacity design (CCD) method. The assumed shape of broken concrete in the CCD method is a prism, as shown in Figure A.1. 


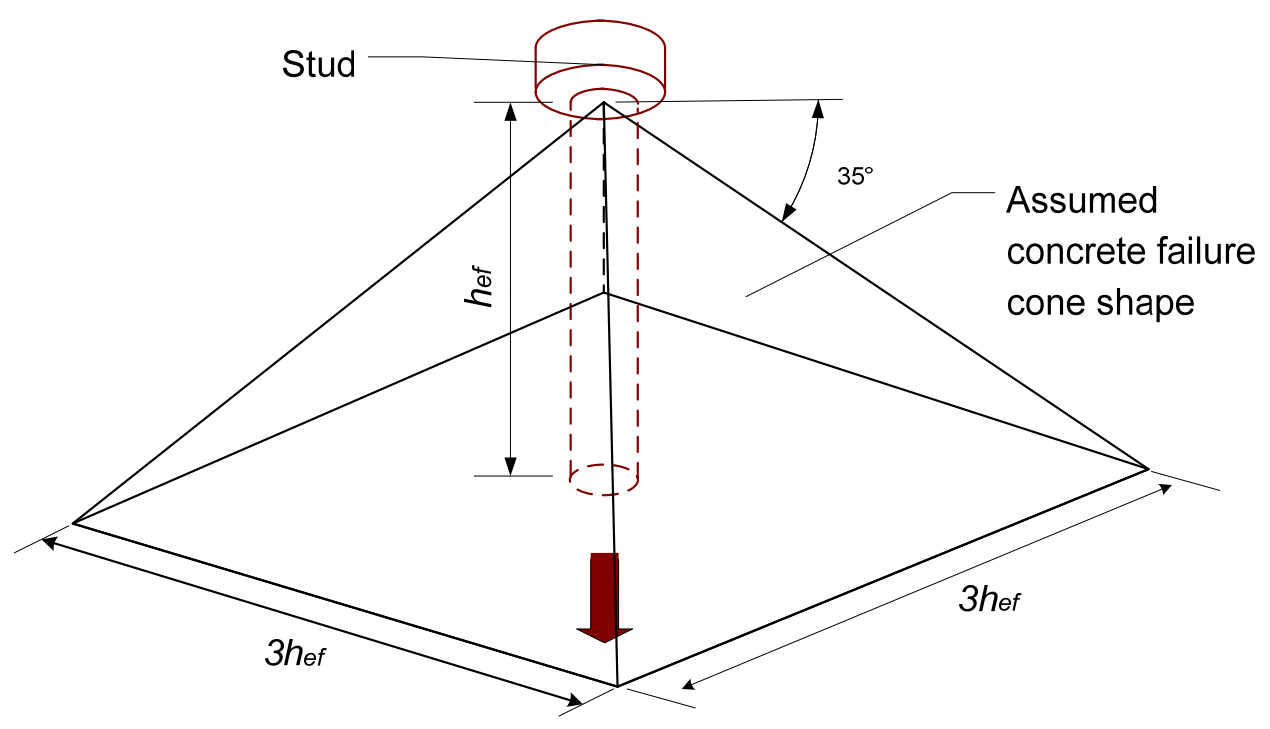

Figure A.1 Concrete breakout shape under tension force (CCD method)

The anchor strength equation (Equation A.1) for the concrete breakout failure consists of three main parts: (1) projected concrete failure area ratio for group of anchors, (2) modification factors depending on loading and geometric conditions, and (3) nominal concrete breakout strength. The equations below are used to compute the nominal concrete breakout strength in tension of a group of studs.

$$
\begin{gathered}
N_{c b g}=\frac{A_{N c}}{A_{N c o}} \psi_{e c, N} \psi_{e d, N} \psi_{c, N} \psi_{c p, N} N_{b} \\
N_{b}=k_{c} \sqrt{f_{c}^{\prime}} h_{e f}^{1.5} \\
\psi_{e d, N}=0.7+0.3 \frac{c_{a, \min }}{1.5 h_{e f}} \leq 1.0 \\
\psi_{e c, N}=\frac{1}{\left(1+\frac{2 e_{N}^{\prime}}{3 h_{e f}}\right)}
\end{gathered}
$$


where $N_{c b g} \quad=$ design concrete breakout strength of a stud or group of studs (lb)

$A_{N c} \quad=$ projected concrete failure cone area of a stud group $\left(\right.$ in. $^{2}$ )

$A_{N c o}=$ projected concrete failure cone area of a single stud $\left(=9 h_{e f}{ }^{2}\right)\left(\right.$ in. $\left.^{2}\right)$

$\psi_{e c, N}=$ eccentric load modification factor

$\psi_{e d, N}=$ edge distance modification factor $\left(=1.0\right.$ for $\left.c_{a, \min } \geq 1.5 h_{e f}\right)$

$\psi_{c, N}=$ cracked concrete modification factor Cracked concrete where a stud installed $\quad: 1.00$ Uncracked concrete $: 1.25$

$\psi_{c p, N}=$ modification factor for post-installed anchors ( $=1.0$ for cast-in-place anchors)

$N_{b} \quad=$ concrete breakout strength of a single isolated stud (lb)

$k_{c} \quad=24$ for cast-in-place shear studs

$f_{c}^{\prime} \quad=$ specified concrete compressive strength (psi)

$h_{e f} \quad=$ effective length of a shear stud in concrete—stud length excluding the stud head in concrete (in.)

$N_{c b g}=$ nominal concrete breakout strength in tension of a stud or group of studs (lb)

\section{A.2 MODIFIED ANCHOR STRENGTH EQUATION FOR HAUNCH CONFIGURATION}

Sutton (2007) and Mouras (2008) applied the ACI anchor strength equation (Equation A.1) to estimate the tensile strength of shear studs embedded in a concrete 
deck. They found that the equation did not agree well with their test results when shear studs were embedded through a deck haunch.

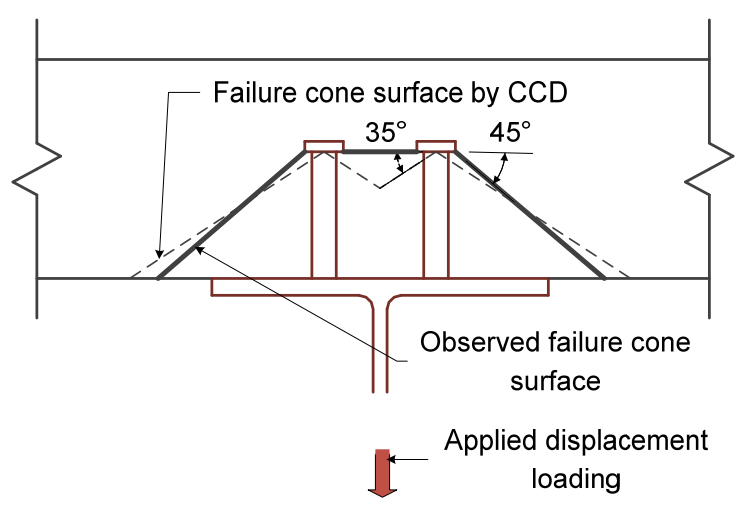

(a) Stud connection without haunch

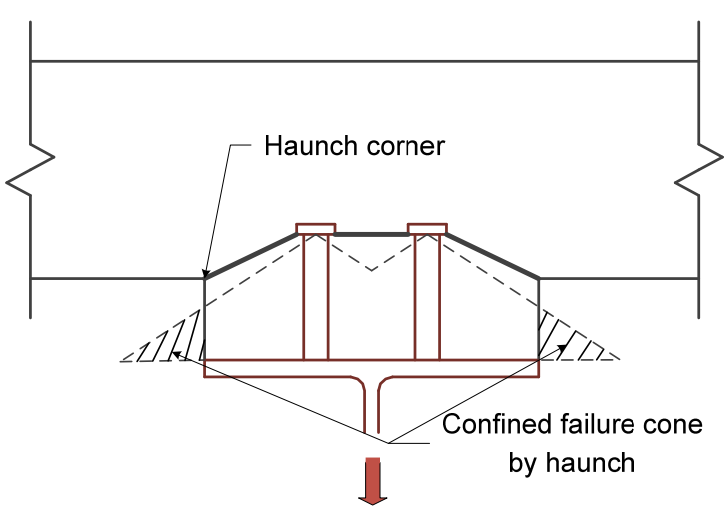

(b) Stud connection with haunch

Figure A.2 CCD (dashed) and observed (solid) failure cone shapes (Mouras, 2008)

Mouras (2008) observed that the breakout concrete cone shapes of stud connections following the $\mathrm{CCD}$ approach were confined by the haunch geometry, as shown in Figure A.2(b). To apply the ACI equation for a shear stud connection with a haunch configuration, Mouras (2008) modified the projected concrete failure cone area of a single stud $\left(A_{N c o}\right)$ with an effective stud length embedded into a concrete slab excluding haunch height $\left(h_{e f}\right)$, and used the haunch width $\left(w_{h}\right)$ for computing the projected failure cone area of a group $\left(A_{N c}\right)$ to account for the confined failure area by the presence of the haunch, as described in Chapter 3. In addition to the modification of the projected failure cone areas, modification factors such as the edge distance modification factor $\left(\psi_{e d, N}\right)$, the cracked concrete modification factor $\left(\psi_{c, N}\right)$, and the group effect factor $\left(\psi_{g, N}\right)$ should be properly evaluated. Though the proposed approach provides estimates of capacity that agree well with test data, such a detailed procedure is a disadvantage of Mouras' 
approach because it is potentially inconvenient for designers to use the equation and to perform parameter studies. For this reason, the stud pull-out test results conducted by Sutton (2007) and Mouras (2008) were reinvestigated by the author to simplify the procedure for computing the tensile strength of a stud connection with a haunch.

Figure A.2 compares concrete failure cone surfaces of the CCD method and those observed by Mouras (2008) in his stud pull-out tests. In this figure, the assumed failure cone surface with the CCD method is indicated with the dashed line, and the observed failure surface is indicated with the solid line for stud connections comprised of two 5-in. studs with and without a haunch. Various failure cone surfaces of stud connections varying in stud length or number of studs in a row are available in APPENDIX C. As shown in Figure A.2(a), the failure cone surface of the CCD method agrees well with the observed surface in the case of a stud connection without a haunch, although the failure surface angles measured from a horizontal line differed from each other (i.e., $35^{\circ}$ for the CCD failure cone and $45^{\circ}$ for the observed failure cone). In this case, Mouras (2008) found that the ACI anchor strength equation (Equation A.1) estimated well the tensile strength of the stud connection, which was obtained from the test. Conversely, the failure cone of the stud connection with the haunch could not fully develop because the haunch constrained the failure cone size, as indicated by the shaded lines in Figure A.2(b). Furthermore, the haunch corner cracking that developed in the early stage of loading process changed the failure cone shape (i.e., the observed failure cone shape), forming the failure cone along the line connecting the haunch corner and the stud head instead of at the $45^{\circ}$ angle that was observed in the case without a haunch. As shown in APPENDIX $\mathrm{C}$, these haunch effects on the failure cone development of stud connections, such as constraining failure cone size and changing failure cone angles (i.e., changing failure cone shape), were consistently observed until the stud length became so long that the 
perimeter of a projected cone area moved apart from a haunch corner, such as when using 9-in. stud connections with two or three studs. For these cases, haunch corner cracking did not govern the failure cone shapes. Instead, they showed failure cone shapes similar to those with stud connections without haunches.

Concrete failure cone size and shape are important factors in evaluating the tensile strength of a stud connection because they are involved in determining concrete breakout strength. Therefore, if the failure cone size and shape of a stud connection are similar to the prism failure cone assumed in the CCD method, then the ACI anchor strength equation (Equation A.1) should give a good estimation for the tensile strength, as in the case of the stud connection without a haunch described in the above paragraph. However, the ACI equation could not be directly applied to estimate the tensile strength of a stud connection with a haunch because the haunch reduces the concrete failure cone size and changes the failure cone shape from the assumed prism shape in the CCD method. For this reason, a modification to the $\mathrm{ACI}$ anchor strength equation was conducted to extend the ACI equation to apply to a stud connection with a haunch. The considered modification approach in this study involved developing a simple modification factor similar to other modification factors (e.g., eccentric loading modification, edge distance modification, and so on). This approach would be beneficial because the original ACI equation form and meanings of equation variables could be maintained, which might reduce confusion for users.

To find a haunch modification factor, dimensional parameters of a stud connection affecting a failure cone shape and size were investigated. Figure A.3 shows primary dimensions in a typical stud connection with a haunch configuration. As shown in Figure A.3, only a symmetrical arrangement of studs was considered for stud connections having two or three studs in a row. Among the dimensions of the stud 
connection in Figure A.3, effective stud length embedded into a concrete slab excluding haunch height $\left(h_{e f}\right)$, and the haunch edge distance $\left(c_{a h}\right)$ between the haunch corner and the exterior stud were selected as main dimensional parameters to determine the haunch modification factor because they are related to the failure cone's size and shape. Most of all, haunch corner cracking could change the failure cone shape of a stud connection by creating a concrete cracking failure surface between a haunch corner and a stud head, as shown in Figure A.2(b). To account for this concrete failure cone shape change, the haunch edge distance was selected as one of the primary variables because the distance is proportional to the failure surface area connecting the haunch corner and the stud head. In addition, increasing the effective stud length enlarges the failure cone size, and it could also mitigate haunch corner cracking that affects a failure cone shape (i.e., failure cone shape change by haunch corner cracking), as observed in 9-in. stud connections. For these reasons, the effective stud length was also chosen as the other variable.
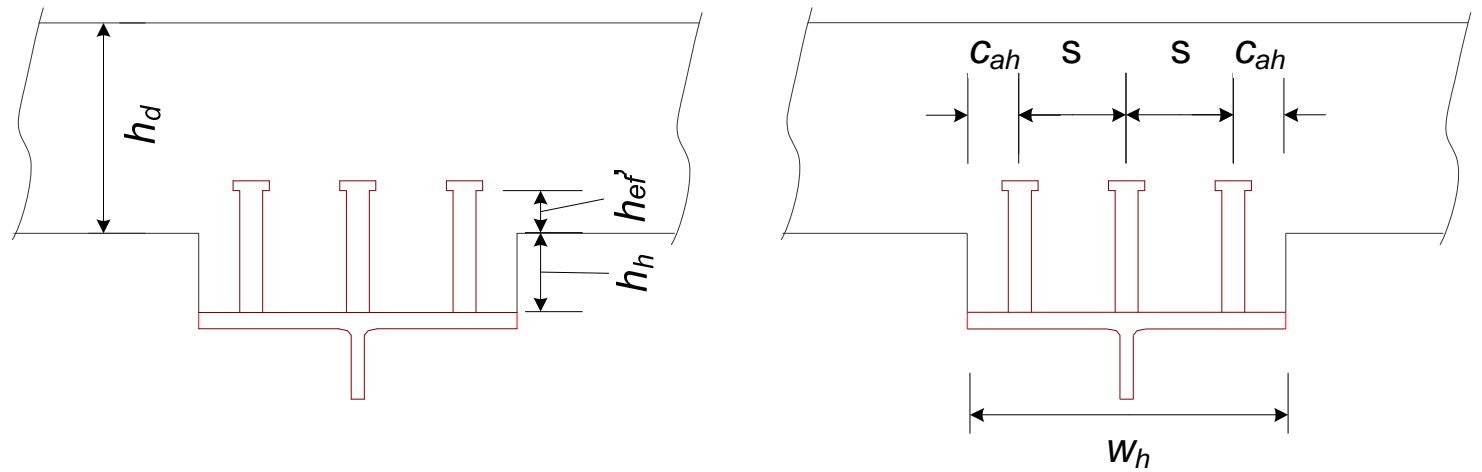

Figure A.3 Dimensions for stud connection with haunch 


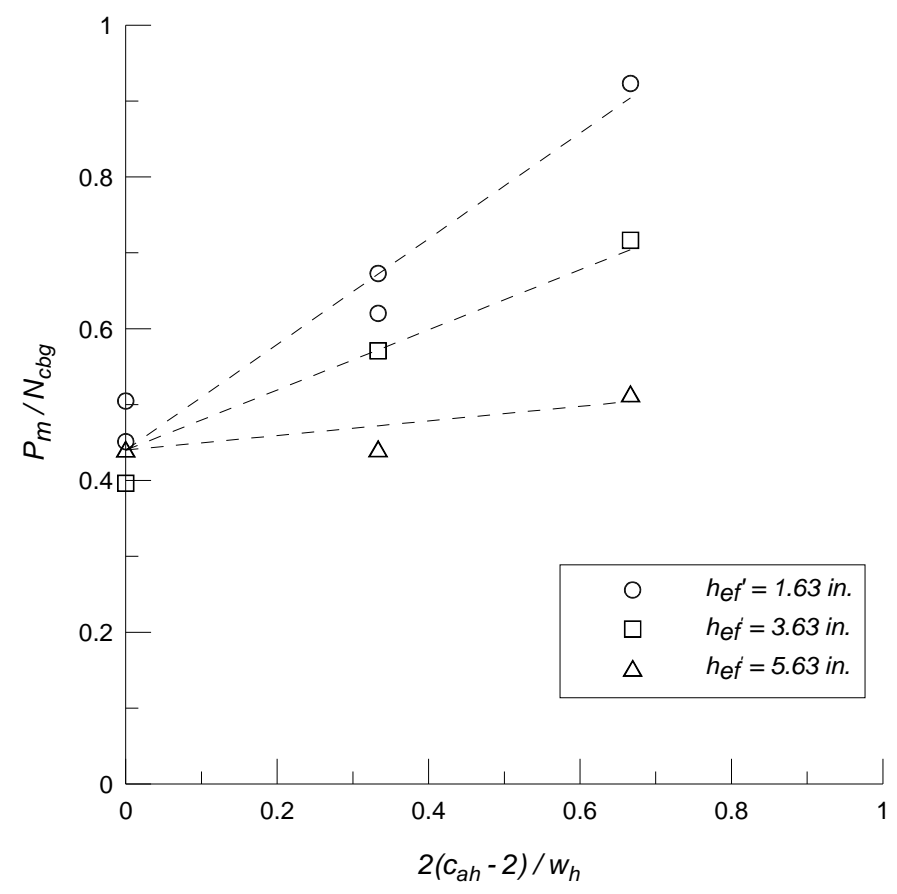

Figure A.4 Normalized tensile strength variation along haunch edge distance

Figure A.4 shows measured tensile strength results of stud connections with a haunch as a function of haunch edge distance. The measured tensile strength $\left(P_{m}\right)$ and the haunch edge distance $\left(c_{a h}\right)$ are normalized with the predicted strength using the ACI anchor strength equation (Equation A.1) and a haunch width ( $\left.w_{h}\right)$, respectively. As shown in Figure A.4, the normalized tensile strength increases as the normalized haunch edge distance increases, which means that the divergence (between the measured and the predicted strength) diminishes. The increasing rate of the normalized strength is approximately linear, but the rate differs depending on effective stud length embedded into a concrete slab excluding haunch height $\left(h_{e f}\right)$ : as $h_{e f}$ increases, the tensile strength dependency on the haunch edge distance diminishes. 


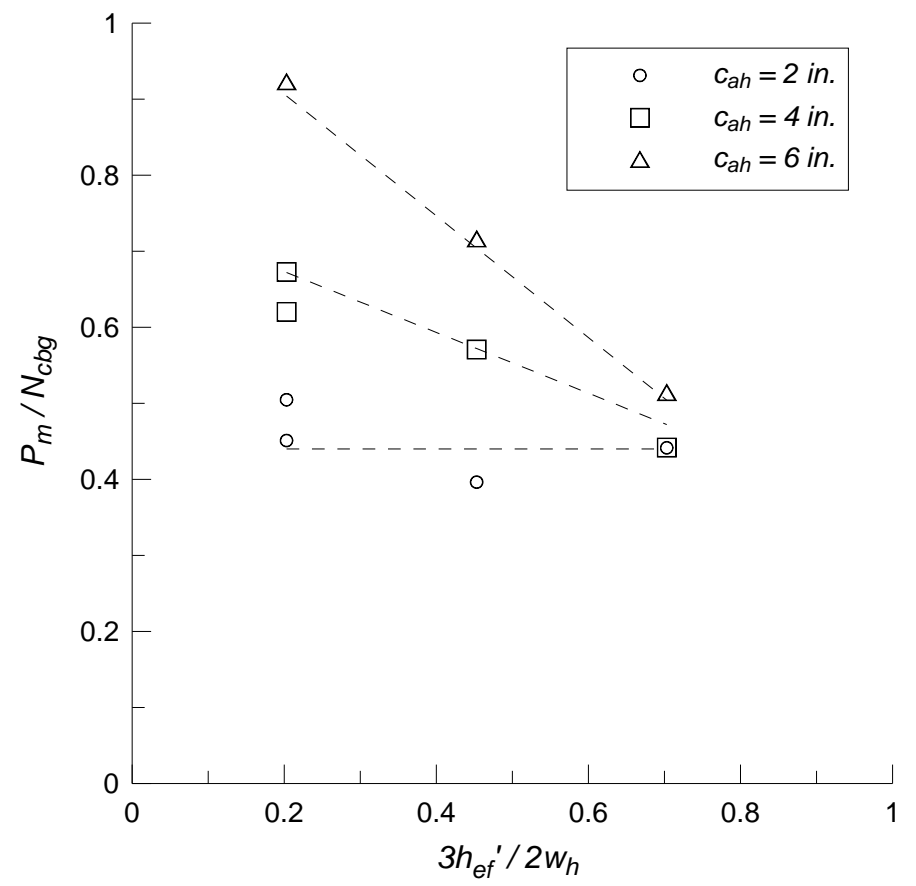

Figure A.5 Normalized tensile strength variation along effective stud length excluding haunch height

The fact that the tensile strength is dependent on the effective stud length excluding haunch height can be observed in Figure A.5. In this figure, the normalized tensile strength of a stud connection is plotted along the effective stud length excluding haunch height normalized by the haunch width. It shows that the normalized tensile strength tends to decrease as the effective stud length excluding haunch height increases, which implies that the ACI equation (Equation A.1) overpredicts the tensile strength of a stud connection, and the rate of such overprediction of the tensile strength increases along with the increase of the effective stud length excluding haunch height. The decreasing rate of the normalized stud tensile strength varies with the haunch edge distance. As the edge distance diminishes, the decreasing rate of the normalized stud tensile strength is also reduced, and the decreasing tendency eventually seems to disappear. 
As shown in Figure A.4 and Figure A.5, the tensile strength of a stud connection with a haunch is dependent on both the haunch edge distance and the effective stud length excluding haunch height. To factor these parameters into the ACI anchor strength equation, multivariable regressions based on the test results of Sutton (2007) and Mouras (2008) were attempted in order to obtain a haunch modification factor, which has the following form:

$\psi_{h, N}=0.44+\left(0.94-1.2 \frac{3 h_{e f}^{\prime}}{2 w_{h}}\right)\left(\frac{2\left(c_{a h}-2\right)}{w_{h}}\right) \leq 1.0$

Equation A.5

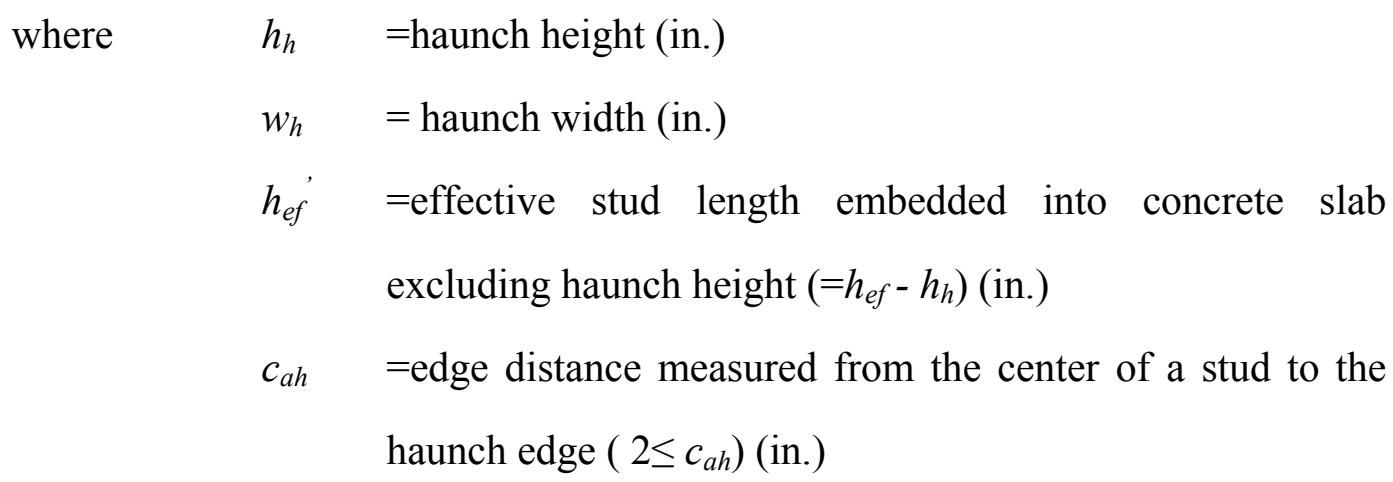

Regression results are plotted in Figure A.4 and Figure A.5, with dashed lines using Equation A.5. A modified ACI anchor strength equation that incorporates haunch effects can be obtained by simply multiplying Equation A.5 and Equation A.1 as follows:

$$
N_{c b g}=\frac{A_{N c}}{A_{N c o}} \psi_{e c, N} \psi_{e d, N} \psi_{c, N} \psi_{c p, N} \psi_{h, N} N_{b}
$$

Although the terms and modification factors in Equation A.6 have the same meanings as those of the original ACI anchor strength equation (Equation A.1), the edge 
distance modification factor $\left(\psi_{e d, N}\right)$ and the cracked concrete modification factor $\left(\psi_{c, N}\right)$ are notable because they can cause confusion with the haunch modification factor. The edge distance effects are evaluated in the haunch modification factor in terms of the haunch edge distance; thus, the edge distance modification factor $\left(\psi_{e d, N}\right)$ should not be incorporated in the strength evaluation of a stud connection with a haunch. Another notable feature is the cracked concrete modification factor. In the original ACI anchor strength equation, the anchor strength is permitted to be increased up to $25 \%$ using the cracked concrete modification factor (i.e., $\psi_{c, N}=1.25$ for uncracked concrete) once no concrete cracking occurs around the anchors. Mouras (2008) observed that no cracking occurred within the haunch of his stud connection specimens until at or after failure cone formation. If concrete cracking does not occur within a haunch, as in the cases that Mouras observed, the cracked concrete modification factor should be incorporated in the strength evaluation because the haunch modification factor does not account for an uncracked concrete condition.

Figure A.6, Figure A.7, and Figure A.8 compare the tensile strengths of stud connections between the test results and the modified ACI anchor strength equation using the haunch modification factor (Equation A.6): stud connections with three studs arranged transversely in Figure A.6, with two studs in Figure A.7, and with one stud in Figure A.8. They show that the modified ACI equation for haunch effects agrees well with test results for all cases, varying in the number of studs, stud lengths, and concrete strength. Table A.1 lists test results of stud connections, the estimated results using Equation 3.7 proposed by Mouras (2008), and the estimated results using Equation A.6. In Table A.1, the specimen type label represents stud length, haunch height, number of studs and identification for duplicates in order. 


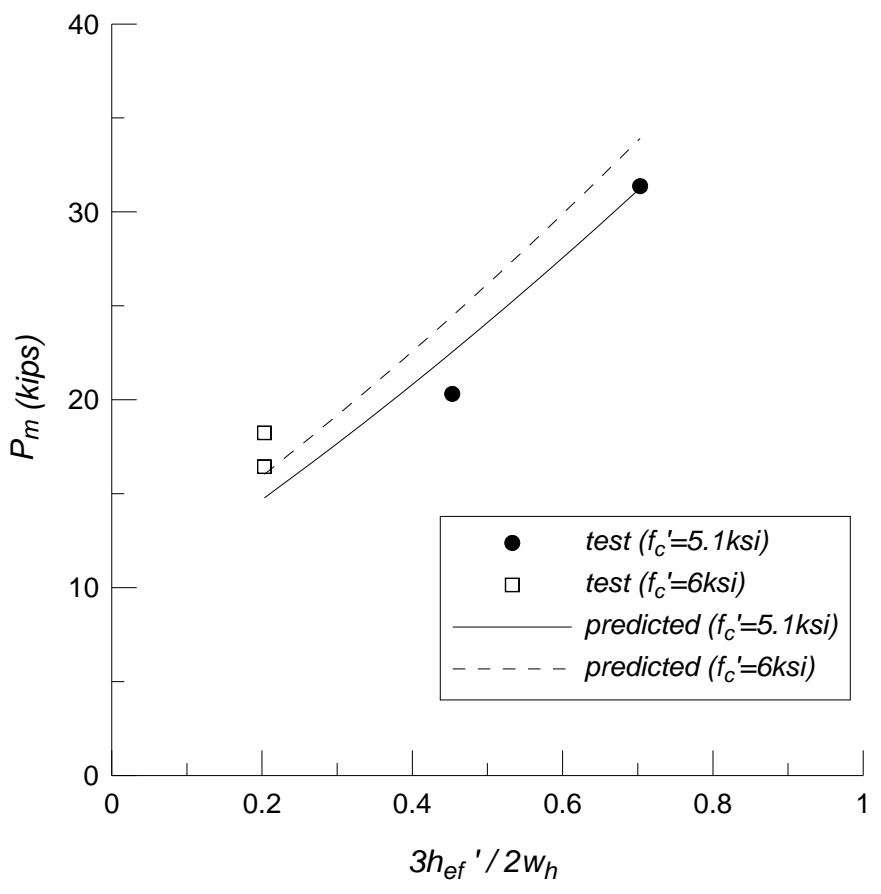

Figure A.6 Tensile strength estimation for three studs in a row

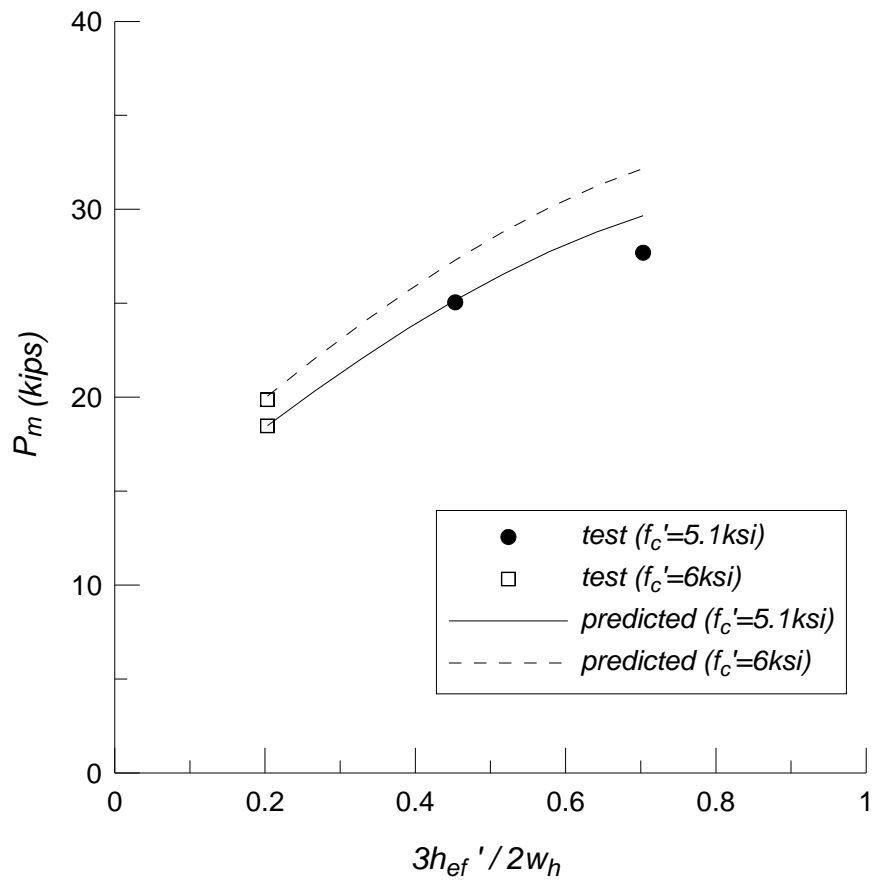

Figure A.7 Tensile strength estimation for two studs in a row 


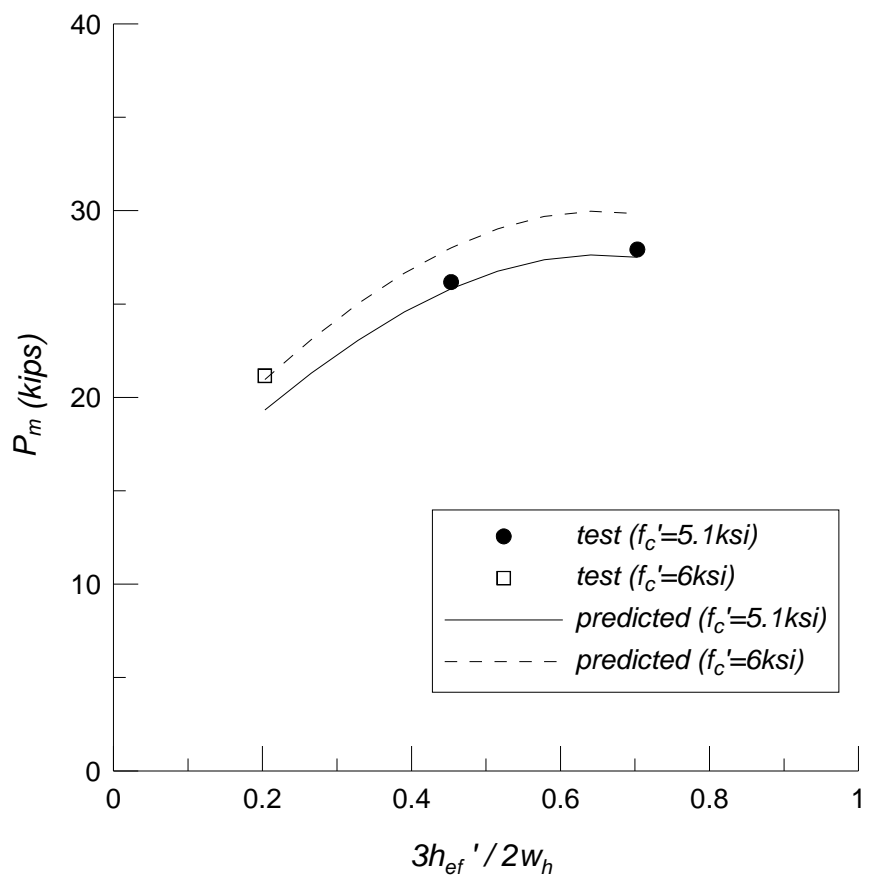

Figure A.8 Tensile strength estimation for one stud

Table A.1 Comparison of test results and estimations using modified equations

\begin{tabular}{|c|c|c|c|c|c|c|}
\hline $\begin{array}{l}\text { Specimen } \\
\text { type }\end{array}$ & $\begin{array}{l}f_{c}^{\prime}, \\
\mathrm{ksi}\end{array}$ & $\begin{array}{l}P_{m} \\
\text { kips }\end{array}$ & $\begin{array}{c}N_{c b g}, \text { kips } \\
\text { (Eq. 3.7, Mouras) }\end{array}$ & $\begin{array}{c}\left(P_{m}-N_{c b g}\right) / P_{m} \\
\text { (Eq. 3.7, Mouras) }\end{array}$ & $\begin{array}{l}N_{c b g}, \text { kips } \\
\text { (Eq. A.6) }\end{array}$ & $\begin{array}{c}\left(P_{m}-N_{c b g}\right) / P_{m} \\
\quad(\text { Eq. A.6) }\end{array}$ \\
\hline 5:3-3Ta & 6.00 & 16.44 & 15.48 & 0.06 & 16.03 & 0.02 \\
\hline 5:3-3Tb & 5.90 & 18.24 & 15.35 & 0.16 & 15.90 & 0.13 \\
\hline 5:3-2Тa & 6.00 & 18.47 & 18.35 & 0.01 & 20.01 & -0.08 \\
\hline $5: 3-2 T b$ & 5.90 & 19.87 & 18.20 & 0.08 & 19.84 & 0.00 \\
\hline $5: 3-1 b$ & 5.90 & 21.16 & 21.32 & -0.01 & 20.71 & 0.02 \\
\hline 7:3-3T & 5.10 & 20.31 & 21.20 & -0.04 & 22.54 & -0.11 \\
\hline $7: 3-2 T$ & 5.10 & 25.05 & 25.20 & -0.01 & 25.15 & 0.00 \\
\hline 7:3-1 & 5.10 & 26.18 & 29.50 & -0.13 & 25.80 & 0.01 \\
\hline 9:3-3T & 5.10 & 31.37 & 30.70 & 0.02 & 31.26 & 0.00 \\
\hline 9:3-2T & 5.10 & 27.69 & 29.70 & -0.07 & 29.73 & -0.07 \\
\hline 9:3-1 & 5.10 & 27.92 & 27.60 & 0.01 & 27.62 & 0.01 \\
\hline & & & Average & 0.01 & & -0.01 \\
\hline & & & Std. Dev. & 0.08 & & 0.06 \\
\hline
\end{tabular}




\section{APPENDIX B}

\section{EXAMPLE CALCULATIONS OF STUD CONNECTION TENSILE STRENGTH}

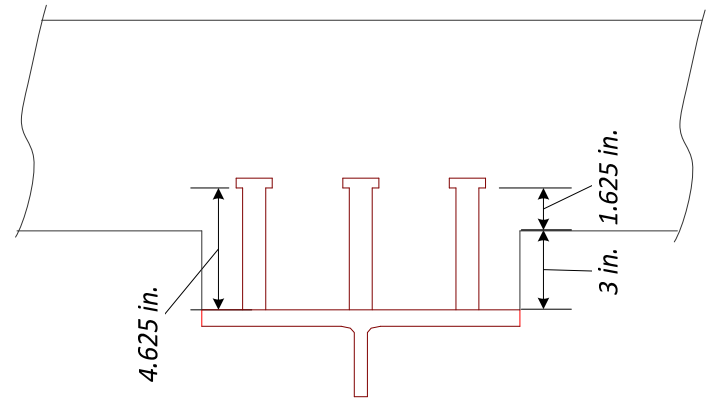

(a) Cross-section view

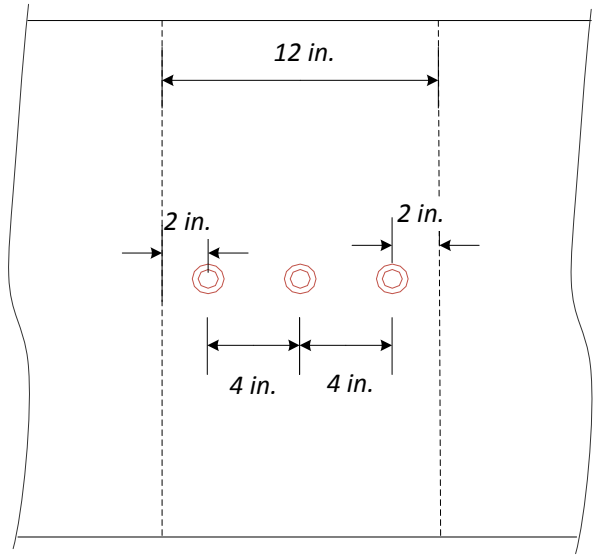

(b) Top view

Figure B.1 Stud connection with haunch (three 5-in. studs)

\section{B.1 ACI ANCHOR STRENGTH EQUATION}

Graphical interpretations of variables used for the ACI anchor strength equation corresponding to the example stud connection (Figure B.1) are presented in Figure B.2

$$
\begin{aligned}
& f_{c}{ }^{\prime}=5900 \mathrm{psi} \\
& h_{e f}=5-0.375=4.625 \mathrm{in} . \\
& k_{c}=24 \text { for cast-in-place anchor } \\
& N_{b}=k_{c} \sqrt{f_{c}^{\prime}} h_{e f}^{1.5}=24 \sqrt{5900} \times 4.625^{1.5}=18,336 \mathrm{lbs} \text { from Equation A.2 } \\
& A_{N c o}=9 h_{e f}^{2}=9 \times 4.625^{2}=192.5 \text { in. }^{2} \\
& A_{N c}=3 h_{e f}\left(2 S+3 h_{e f}\right)=3 \times 4.625 \times(2 \times 4+3 \times 4.625)=303.5 \text { in. }^{2}
\end{aligned}
$$




$$
N_{c b g}=\frac{A_{N c}}{A_{N c o}} N_{b}=\frac{303.5}{192.5} \times \frac{18,336}{1000}=28.9 \mathrm{kips}, \text { for } \psi_{e c, N}=\psi_{e d, N}=\psi_{c, N}=\psi_{c p, N}=1.0
$$

from Equation A.1
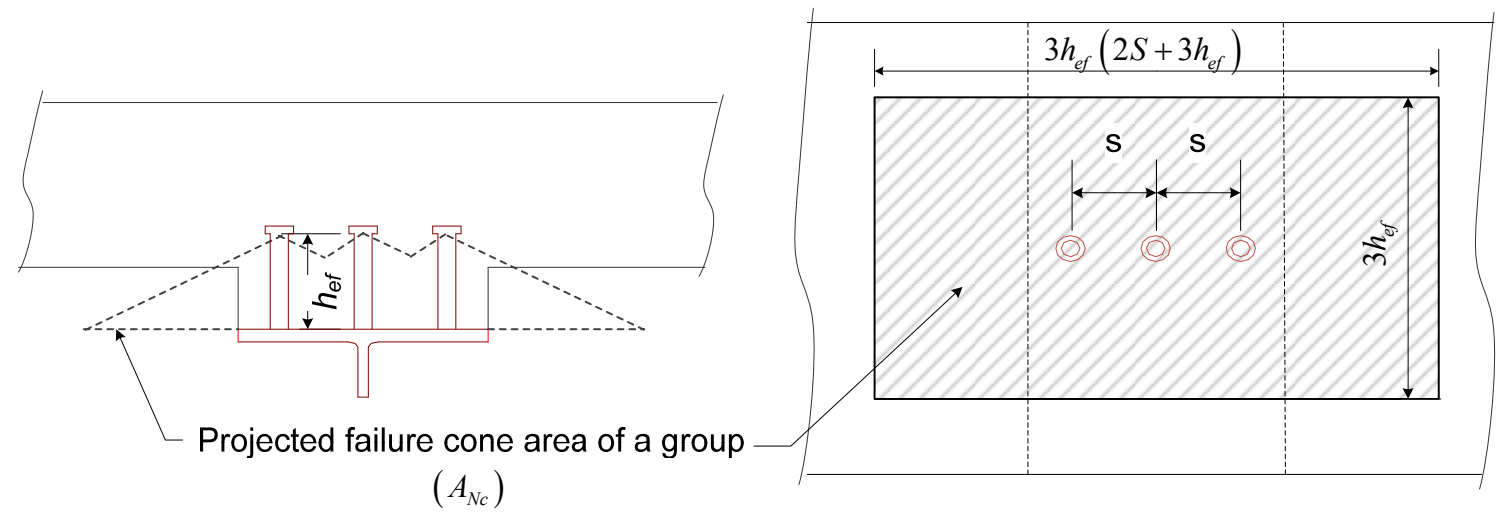

Figure B.2 Dimensions of stud connection with haunch and projected failure cone area in $\mathrm{ACI}$ anchor strength equation

\section{B.2 METHOD 1 (MODIFIED EQUATION PROPOSED BY MOURAS)}

Graphical interpretations of variables used for the modified ACI anchor strength equation corresponding to the example stud connection (Figure B.1) are presented in Figure B.3.

$$
\begin{aligned}
& f_{c}^{\prime}=5900 \mathrm{psi} \\
& h_{e f}=5-0.375=4.625 \mathrm{in} . \\
& h_{h}=3 \mathrm{in} . \\
& w_{h}=12 \mathrm{in.} \\
& c_{a, \min }=2 \mathrm{in} .
\end{aligned}
$$


$k_{c}=24$ for cast-in-place anchor

$h_{e f}{ }^{\prime}=h_{e f}-h_{h} \geq \frac{w_{h}}{3}=4.625-3 \geq \frac{12}{3}=1.625<4 ; h_{e f}{ }^{\prime}=4.0$ in. from Equation 3.9

$N_{b}=k_{c} \sqrt{f_{c}^{\prime}}\left(h_{e f}\right)^{1.5}=24 \sqrt{5900} \times 4.0^{1.5}=14,748 \mathrm{lbs}$ from Equation 3.8

$A_{\text {Nco }}=9\left(h_{e f}{ }^{\prime}\right)^{2}=9 \times 4.0^{2}=144 \mathrm{in}^{2}, h_{e f}$ is used instead of $h_{e f}$.

$A_{N c}=3 h_{e f} w_{h}=3 \times 4.625 \times 12=166.5$ in. $^{2}, w_{h}$ is used in the calculation.

$\psi_{e d, N}=0.7+0.3 \frac{c_{a, \min }}{1.5 h_{e f}{ }^{\prime}}=0.7+0.3 \frac{2}{1.5 \times 4.0}=0.80$ from Equation 3.10

$\psi_{c, N}=1.25$, uncracked concrete within haunch

$\psi_{g, N}=0.90$, three studs spaced transversely

$$
\begin{aligned}
N_{c b g} & =\frac{A_{N c}}{A_{N c o}} \psi_{g, N} \psi_{e d, N} \psi_{c, N} N_{b} \\
& =\frac{166.5}{144} \times 0.90 \times 0.8 \times 1.25 \times \frac{14,748}{1000}=15.3 \mathrm{kips}
\end{aligned}
$$
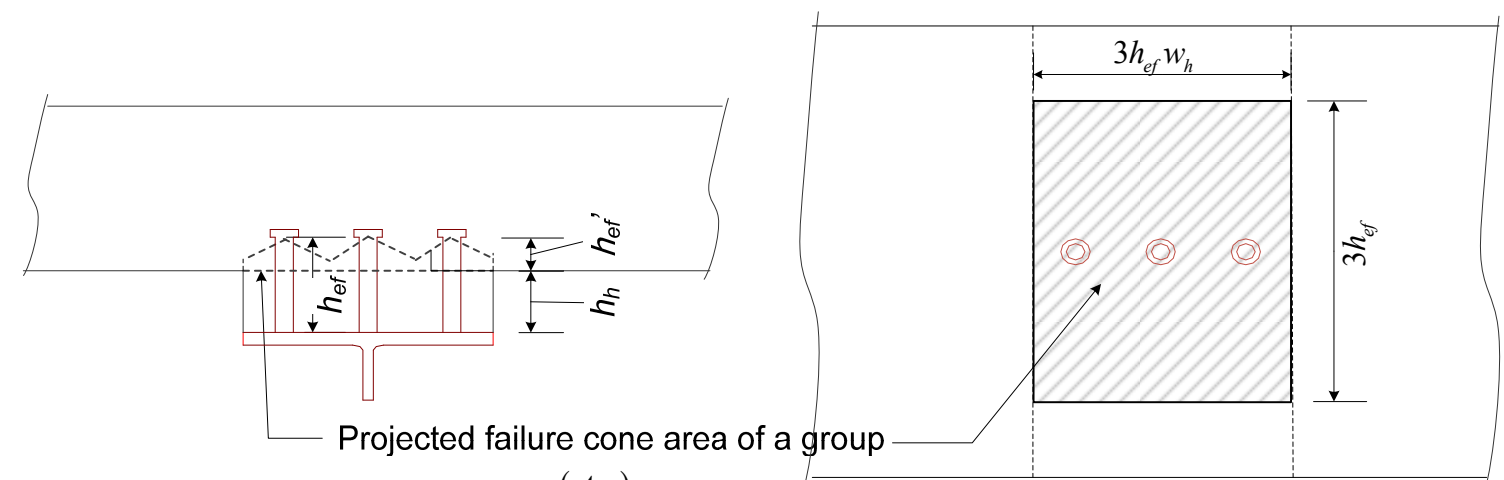

$\left(A_{N c}\right)$

Figure B.3 Dimensions of stud connection with haunch and projected failure cone area in modified ACI anchor strength equation by Mouras (2008) 


\section{B.3 METHOD 2 (MODIFIED EQUATION USING A HAUNCH MODIFICATION FACTOR)}

Graphical interpretations of variables used for the ACI anchor strength equation modified by the haunch modification factor corresponding to the example stud connection (Figure B.1) are presented in Figure B.4.

$$
\begin{aligned}
& f_{c}^{\prime}=5900 \mathrm{psi} \\
& h_{e f}=5-0.375=4.625 \mathrm{in} . \\
& h_{h}=3 \mathrm{in} . \\
& w_{h}=12 \mathrm{in} . \\
& c_{a h}=2 \mathrm{in} . \\
& k_{c}=24 \text { for cast-in-place anchor } \\
& h_{e f}=h_{e f}-h_{h}=4.625-3=1.625 \mathrm{in},, \text { no limitation such as } h_{e f}{ }^{\prime} \geq \frac{w_{h}}{3}
\end{aligned}
$$

$N_{b}, A_{N c o}$ and $A_{N c}$ have same meanings and values as in Section B.1.

$$
\psi_{h, N}=0.44+\left(0.94-1.2 \frac{3 h_{e f}{ }^{\prime}}{2 w_{h}}\right)\left(\frac{2\left(c_{a h}-2\right)}{w_{h}}\right)=0.44 \leq 1.0 ; \psi_{h, N}=0.44
$$

$\psi_{c, N}=1.25$, uncracked concrete within haunch

$$
N_{c b g}=\frac{A_{N c}}{A_{N c o}} \psi_{c, N} \psi_{h, N} N_{b}=\frac{303.5}{192.5} \times 1.25 \times 0.44 \times \frac{18,336}{1000}=15.9 \mathrm{kips}
$$
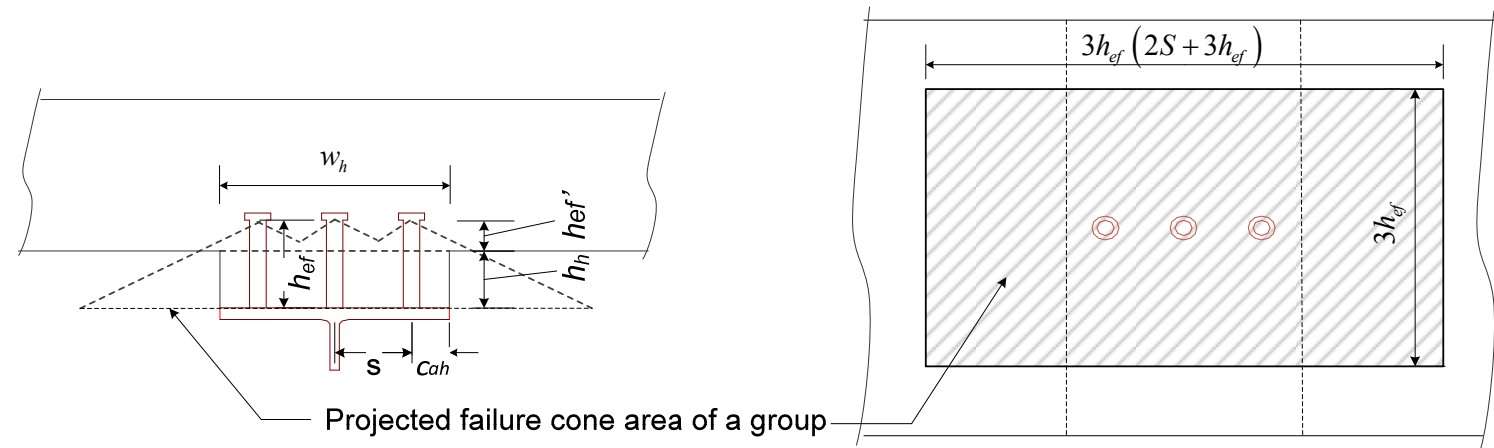

$\left(A_{N c}\right)$

Figure B.4 Dimensions of stud connection with haunch and projected failure cone area in $\mathrm{ACI}$ anchor strength equation modified by haunch modification factor 


\section{APPENDIX C}

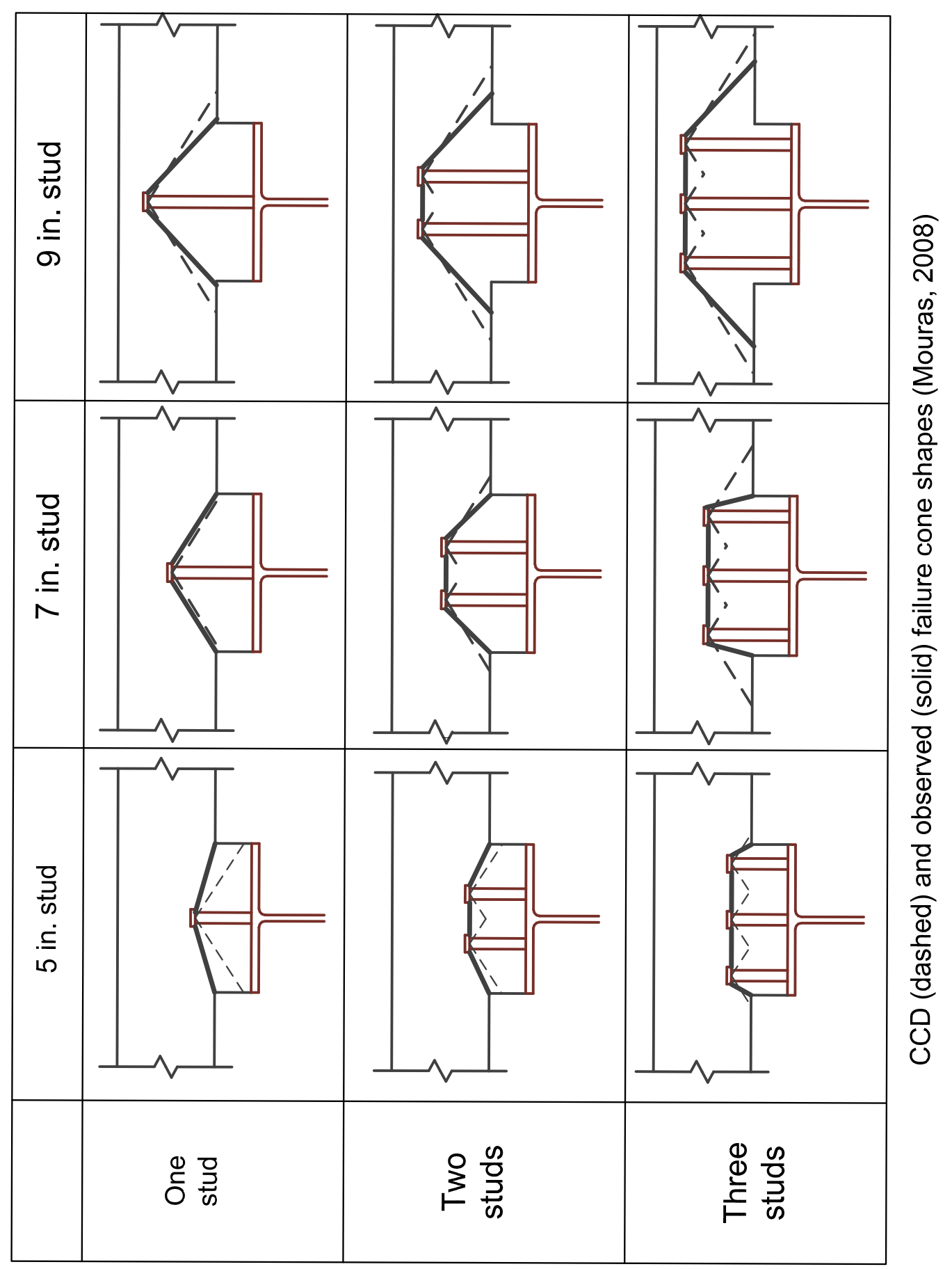




\section{APPENDIX D}

\section{TENSILE DISPLACEMENT EQUATION OF STUD CONNECTION WITH HAUNCH}

As discussed in Chapter 3, the displacement $U_{m}$ corresponding to the tensile strength of a stud connection is required to define the failure initiation of a connection element under tension force. For this reason, tensile displacement data of stud connections - based on the results of stud pull-out tests conducted by Sutton (2007) and Mouras (2008) — were collected and analyzed to obtain a displacement equation of a stud connection at tensile strength. Figure D.1 shows the collected displacement data at tensile strengths of stud connections, and they are plotted along with effective stud length embedded into a concrete slab excluding haunch height.

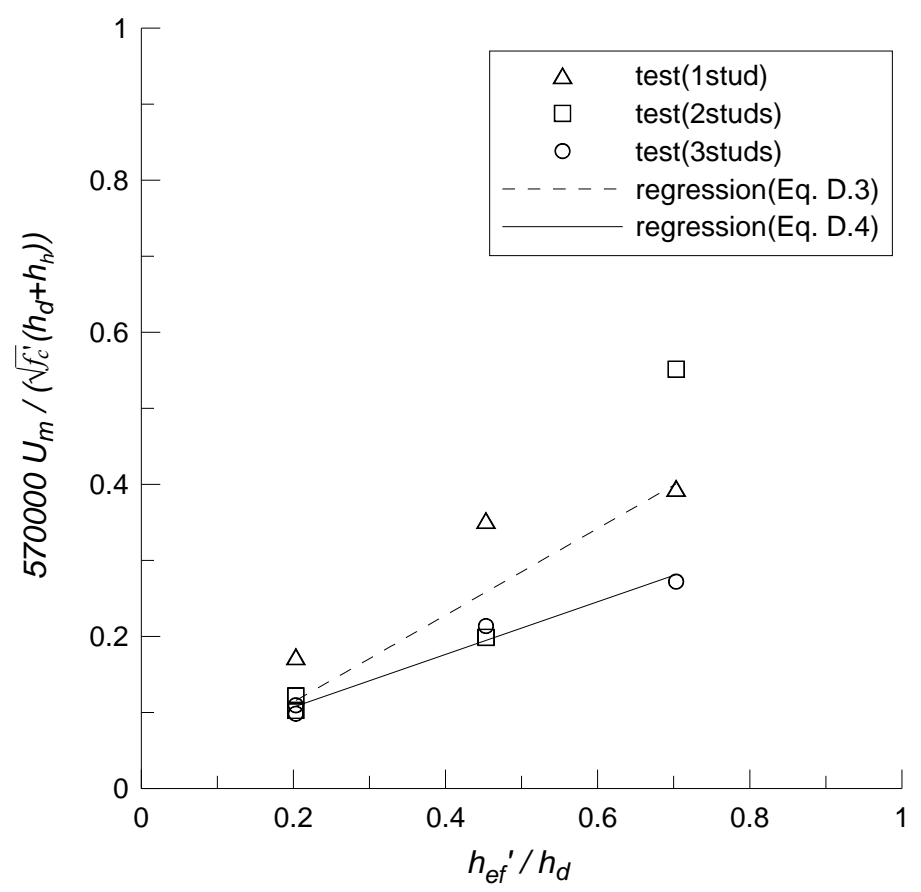

Figure D.1 Displacement at tensile strength of stud connection 
As shown in Figure D.1, the displacement $U_{m}$ was normalized by a scaling factor as follows:

$$
\bar{U}=\frac{\sqrt{f_{c}^{\prime}}\left(h_{d}+h_{h}\right)}{570000}
$$

Equation D.1

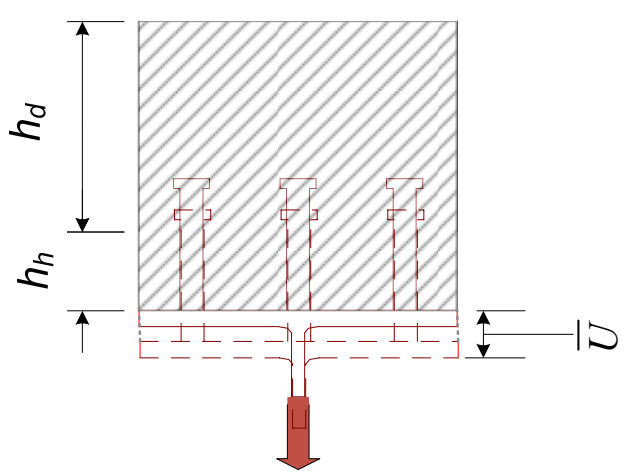

(a) Assumed tension region

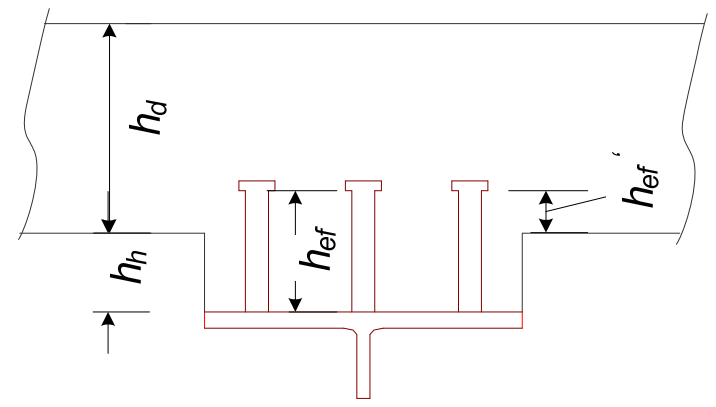

(b) Dimensions for tensile deformation

Figure D.2 Schematic of assumed tension region and dimensions for computing haunch effect modification factor

The scaling factor (Equation D.1) represents the tensile displacement of a concrete block by the tensile force applied to the embedded studs as shown in Figure D.2(a). For the scaling factor calculation, it was assumed that the total concrete block bounded by the haunch width, indicated by the shaded area in Figure D.2(a), was subjected to uniform tension stress. In this case, the tensile deformation $U$ of the concrete block can be obtained by multiplying the tensile strain $\left(\varepsilon_{t}\right)$ and the block height $(h)$; the tensile strain can be replaced by the tensile stress $\left(f_{t}\right)$ divided by the modulus of elasticity of concrete $\left(E_{c}\right)$. If it is assumed that the tensile strength of the concrete is $10 \%$ of the 
compressive strength and the elastic modulus is replaced with the concrete compressive strength using Equation 3.6, then the tensile deformation is given as follows:

$$
\bar{U}=\varepsilon_{t} h=\frac{f_{t}}{E_{c}} h=\frac{0.1 f_{c}^{\prime} h}{57000 \sqrt{f_{c}^{\prime}}}=\frac{\sqrt{f_{c}^{\prime}} h}{570000}
$$

In the above calculation, Equation D.1 is derived by replacing the block height $(h)$ with the summation of the haunch height $\left(h_{h}\right)$ and the deck height $\left(h_{d}\right)$, which are indicated in Figure D.2(b). As shown in Figure D.1, the displacement $U_{m}$ normalized by the scaling factor $\bar{U}$ (Equation D.1) tends to be proportional to the effective stud length excluding haunch height normalized by the deck height $\left(h_{d}\right)$. To account for this tendency, a displacement equation to estimate the displacement of a stud connection at its tensile strength was proposed in the following form:

$$
\begin{gathered}
U_{m}=\frac{\sqrt{f_{c}^{\prime}}\left(h_{d}+h_{h}\right)}{570000} \psi_{h, U} \\
\psi_{h, U}=57 \frac{h_{e f}^{\prime}}{h_{d}} \\
\psi_{h, U}=3.8+34.6 \frac{h_{e f}^{\prime}}{h_{d}}
\end{gathered}
$$$$
\text { Three studs in a row }
$$

where $U_{m} \quad=$ deformation where tensile strength is reached (in.)

$\psi_{h, U}=$ haunch effect modification factor

$f_{c}^{\prime} \quad=$ concrete compressive strength (psi) 


$$
\begin{array}{ll}
h_{d} & =\text { deck height (in.) } \\
h_{h} \quad=\text { haunch height (in.) } \\
h_{e f}^{\prime} \quad=\text { effective stud length embedded into concrete slab } \\
\quad \text { excluding haunch height }\left(=h_{e f}-h_{h}\right) \text { (in.) }
\end{array}
$$

In Equation D.2, $\psi_{h, U}$ represents a haunch effect modification factor accounting for the effect of the effective stud length excluding haunch height on the displacement $U_{m}$. It was obtained from data regression based on the displacements at the tensile strengths of stud connection specimens that were collected from the stud pull-out test results of Sutton (2007) and Mouras (2008). Equation D.3 is the data regression result utilizing all available data (i.e., 11 total cases). As shown in Figure D.1, the displacement $U_{m}$ shows some scatter depending on the number of studs in a row; specimens containing two studs in a row or one stud show higher displacement than those containing three studs. However, the tendency of displacement variation is not clear because of the limited amount of data available. In this study, all investigated bridges had stud connections comprised of three studs in a row. To reduce the uncertainty in the determination of $U_{m}$ for the analyses of these bridges, the four cases with three studs in a row were utilized to determine the haunch effect modification factor, which resulted in Equation D.4 (equivalent with Equation 3.13).

For other bridges utilizing stud connections comprised of more or fewer than three studs in a row, it is questionable how much the responses of the bridges could be affected by the selection of $U_{m}$. Figure D.3 shows how the tensile load-displacement behavior of a stud connection is affected by the proposed haunch modification factor equations. Equation D.3 shows a little softer behavior than using Equation D.4 does. If bridge responses are sensitive to the displacement $U_{m}$, this implies that it would be 
necessary to refine the haunch effect modification factor to account for the displacement variation depending on the number of studs. For this reason, sensitivity of bridge responses was investigated by comparing girder deflections and haunch separations of bridge models utilizing Equation D.3 and Equation D.4, respectively.

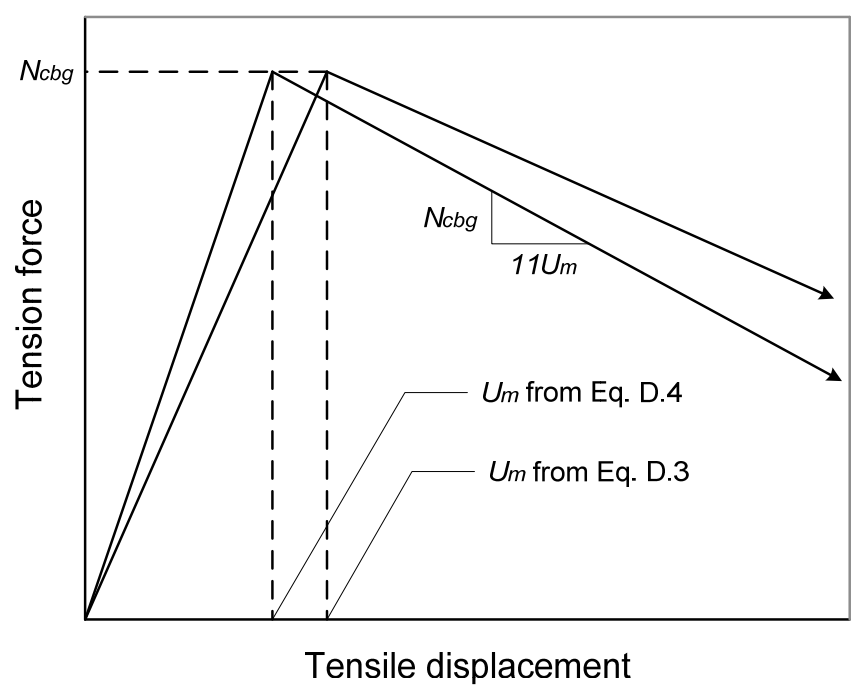

Figure D.3 Schematic of tensile load-displacement behavior of stud connection depending on haunch effect modification factor

All bridge models used for the sensitivity analysis of the selection of the haunch effect modification factor had the same 120-feet straight span but different lengths of studs in their stud connections: 5-in., 7-in., and 9-in. studs. The sensitivity investigation was focused on the bridge responses following one girder fracture, and the same loading scheme used for the parametric study described in Chapter 5 was applied. Figure D.4 compares the separated haunch length along the inside of the fractured girder between bridge models utilizing Equation D.3 and Equation D.4 respectively. For the 9-in. stud model, only the haunch separation result obtained from the model utilizing Equation D.4 
was plotted because there was no difference between the two bridge models utilizing Equation D.3 and Equation D.4. As shown in Figure D.4, other bridge models also do not show any significant difference in the separation length of the haunch, although models utilizing Equation D.4 show slightly less haunch separation than those utilizing Equation D.3. Figure D.5 shows the fractured girder deflection behavior of the bridge model with 7-in. studs. It shows that the girder deflection is not very sensitive to the selection of the haunch modification factor between Equation D.3 and Equation D.4. This tendency was consistent for other models with different stud lengths. Therefore, Equation D.4 can be used for evaluating responses of bridges following one girder fracture regardless of the number of studs.

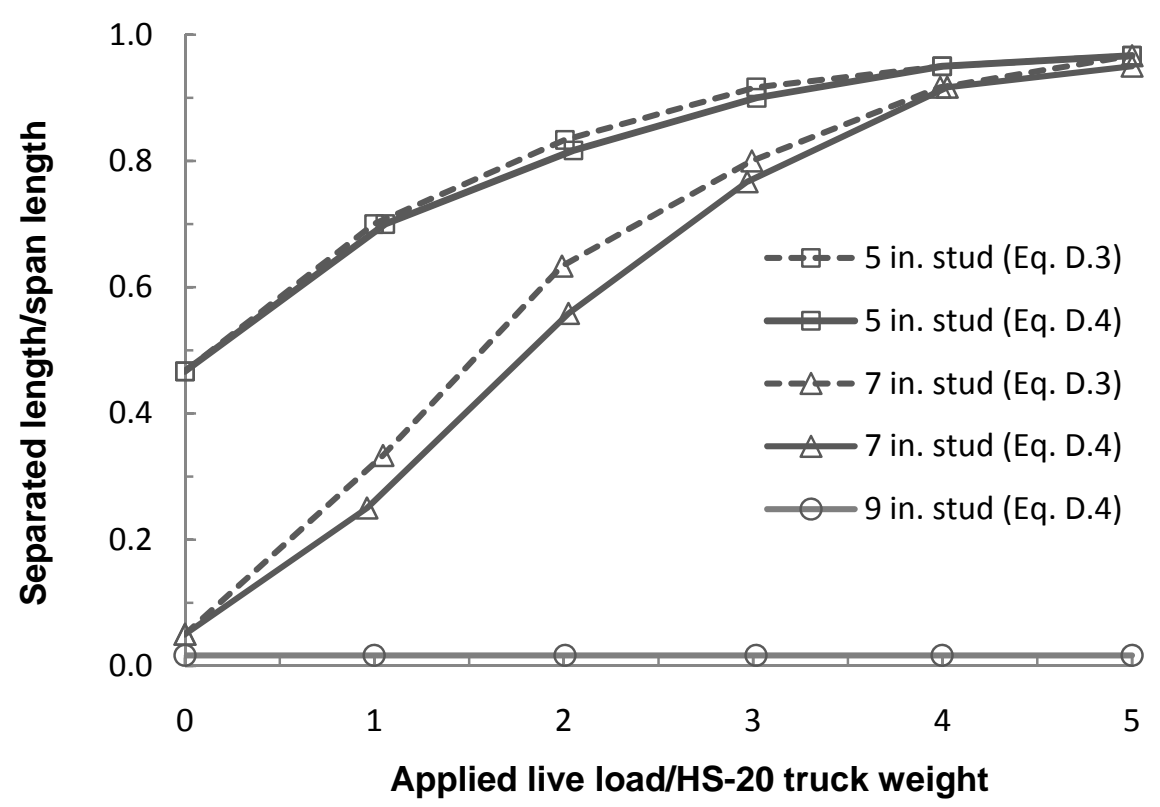

Figure D.4 Separated haunch length of fractured girder inside along applied live load 


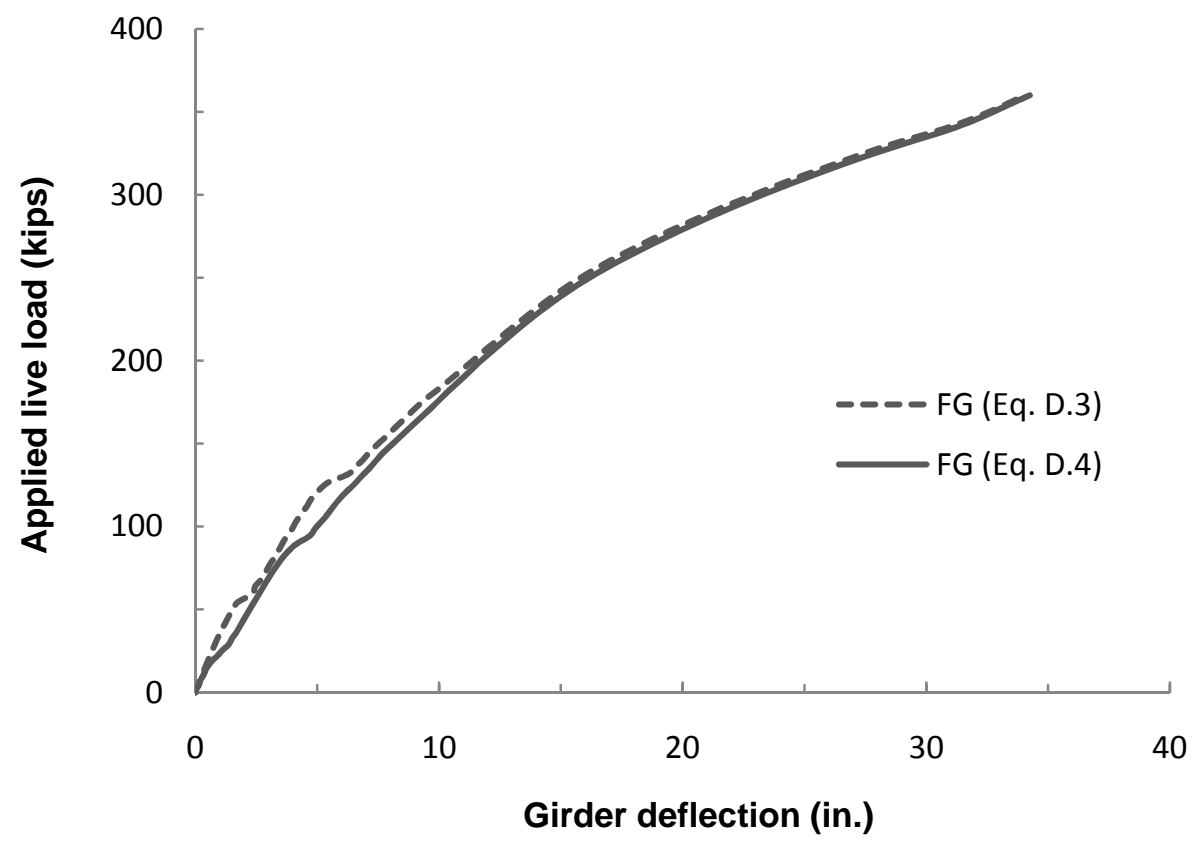

Figure D.5 Vertical deflection behavior of fractured girder 


\section{REFERENCES}

ACI Committee 209. (1982). "Prediction of Creep, Shrinkage and Temperature Effects in Concrete Structures." Designing for Creep and Shrinkage in Concrete Structures, ACI Publication SP-76. Detroit, pp.193-300.

ACI Committee 318. (2008). Building Code Requirements for Structural Concrete (ACI 318-08) and Commentary (ACI 318R-08). ACI, Farmington Hills, MI.

American Association of State Highway Transportation Officials. (1977). AASHTO Standard Specification for Highway Bridges. 12th edition. Washington, D.C.

American Association of State Highway Transportation Officials/American Welding Society. (2002). AASHTO/AWS D1.5M/D1.5:2002 Bridge Welding Code. AASHTO/AWS, Washington D.C./Miami, FL.

American Association of State Highway Transportation Officials. (2007). AASHTO LRFD Bridge Design Specifications. Washington, D.C.

Barnard, Timothy J. (2006). "Constructing a Full-Scale Horizontally-Curved Twin Steel Trapezoidal Box Girder Bridge Segment to Determine Redundancies in Fracture Critical Bridges.” M.S. Departmental Report. The University of Texas at Austin, Austin, TX.

Barsom, John M., and Rolfe, Stanley T. (1999). Fracture and Fatigue Control in Structures: Applications of Fracture Mechanics. Third Edition. ButterworthHeinemann: Woburn, MA. pp. 414-424. 
Connor, Robert J., Dexter, Robert, and Mahmoud, Hussam. (2005). "Inspection and Management of Bridges with Fracture-Critical Details." National Cooperative Highway Research Program Synthesis 354. Transportation Research Board, National Academy Press, Washington, D.C.

Connor, Robert J., Kaufmann, Eric J., Fisher, John W., and Wright, William J. (2007). "Prevention and Mitigation Strategies to Address Recent Brittle Fractures in Steel Bridges." Journal of Bridge Engineering, ASCE, Vol. 12, No. 2, pp. 164-173.

Dassault Systemes. (2007). ABAQUS Analysis User's Manual, Version 6.7. Rising Sun Mills, RI: ABAQUS, Inc.

Dassault Systemes. (2007). ABAQUS Theory Manual, Version 6.7, Rising Sun Mills, RI: ABAQUS, Inc.

Dexter, Robert J., Connor, Robert J., and Mahmoud, Hussam. (2005). "Review of Steel Bridges with Fracture-Critical Elements." Transportation Research Record, Design of Structures 2005, No. 1928, pp. 75-82.

Fisher, John W., Pense, Alan W., and Roberts, Richard. (1977). "Evaluation of Fracture of Lafayette Street Bridge.” Journal of the Structural Division, ASCE, Vol. 103, No. ST7, pp.1339-1357.

Fisher, John. W. (1984). "Fatigue and Fracture in Steel Bridges.” Wiley, NY.

Fisher, John W., Pense, Alan W., and Hausammann, Hans. (1985). “Analysis of Cracking of I-79 Bridge at Neville Island." Fracture Problems in the Transportation Industry. ASCE: New York, pp. 1-19. 
Ghosn, Michel, and Moses, Fred. (1998). "Redundancy in Highway Bridge Superstructures." NCHRP Report 406, TRB, National Research Council, Washington, D.C.

Hartle, R. A., Amrhein, W. J., Wilson III, K. E., Baughman, D. R., and Tkacs, J. J. (1991). Bridge Inspector's Training Manual/90. FHWA-PD-91-015. FHWA: McLean, VA.

Hognestad, E. (1951). "A Study of Combined Bending and Axial Load in Reinforced Concrete Members." University of Illinois Engineering Experimental Station, Bulletin Series, No. 399, pp. 128

Hovell, Catherine. (2007). "Evaluation of Redundancy in Trapezoidal Box-Girder Bridges Using Finite Element Analysis.” M.S. Thesis. The University of Texas at Austin, Austin, TX.

Idriss, R. L., White, K. R., Woodward, C. B., and Jauregui, D. V. (1995). "Evaluation and Testing of a Fracture Critical Bridge.” NDT\&E International, Vol. 28, No. 6, pp. 339-347.

Kupfer, Helmut B., and Gerstle, Kurt H. (1973). "Behavior of Concrete Under Biaxial Stresses." Journal of the Engineering Mechanics Division, ASCE, Vol. 99, No. EM4, pp. 853-866.

Mouras, Joshua M. (2008). "Evaluating the Redundancy of Steel Bridges: Improving the Strength and Behavior of Shear Stud Connections under Tensile Loading." M.S. Thesis. The University of Texas at Austin, Austin, TX. 
Neuman, Bryce J. (2009). "Evaluating the Redundancy of Steel Bridges: Full-Scale Destructive Testing of a Fracture Critical Twin Box-Girder Steel Bridge.” M.S. Thesis. The University of Texas at Austin, Austin, TX.

Newmark, N. M., and Hall, W. J. (1982). "Earthquake Spectra and Design.” Earthquake Engineering Research Institute: Berkeley, CA.

Post-Tensioning Institute Cable-Stayed Bridge Committee. (2007). Recommendations for Stay Cable Design, Testing and Installation, 5th edition. Phoenix, AZ.

Russell, H. G., Miller, R. A., Ozyildirim, H. C., and Tadros, M. K. (2003). "Compilation and Evaluation of Results from High Performance Concrete Bridge ProjectsFinal Report." (CD-ROM), Proceedings, 3rd International Symposium on High Performance Concrete and PCI National Bridge Conference, Orlando, FL. pp. 1922.

Samaras, V. (2009). "Simplified Methods of Evaluating the Redundancy of Twin Trapezoidal Box Girder Bridges.” M.S. Thesis. The University of Texas at Austin, Austin, TX.

Scheffey, C. F. (1971). "Pt. Pleasant Bridge Collapse: Conclusions of the Federal Study." Civil Engineering, Vol. 41, No. 7.

Sutton, James P. (2007). "Evaluating the Redundancy of Steel Bridges: Effect of a Bridge Haunch on the Strength and Behavior of Shear Studs under Tensile Loading." M.S. Thesis. The University of Texas at Austin, Austin, TX.

Texas Department of Transportation. (2001). Bridge Detailing Manual. 
Texas Department of Transportation. (2006). Bridge Railing Manual.

Texas Department of Transportation. (2003). Traffic Rail: Type T501. Retrieved from ftp://ftp.dot.state.tx.us/pub/txdot-info/cmd/cserve/standard/bridge/rlstde16.pdf on July 2, 2007.

Ugural, A. C., and Fenster, S. K. (1995). Advanced Strength and Applied Elasticity, Third Edition. Upper Saddle River, NJ: Prentice-Hall PTR, pp. 155-162.

Wikipedia (2010), "Silver Bridge." Retrieved from http://en.wikipedia.org/wiki/Silver Bridge (bridge) on March 8, 2010. Wikimedia Foundation, Inc. 


\section{VITA}

Janghwan Kim was born on February 20, 1977, in Seoul, Korea, to Myeongja Hwang and Youngin Kim. After graduating from Baemun High School in Seoul in 1995, he enrolled at the University of Seoul, where he earned a bachelor's degree in Civil Engineering in 2002. In the same year, he began his graduate education in the university's graduate school. He earned his Master of Science degree in Civil Engineering in 2004. In September 2004, he entered the graduate school of the University of Texas at Austin to begin his doctoral studies. He also participated in research at the Ferguson Structural Engineering Laboratory under the supervision of Dr. Eric B. Williamson and Dr. Karl H. Frank.

Permanent address: Janghwan Kim

206-17 Hongeun

Seodaemun, Seoul, Korea

This dissertation was typed by the author. 